\title{
Documentation of the Oil and Gas Supply MOtরiछle (OGSM)
}

Prepared by:

Oil and Gas Analysis Branch

Energy Supply and Conversion Division Office of Integrated Analysis and Forecasting

Energy Information Administration

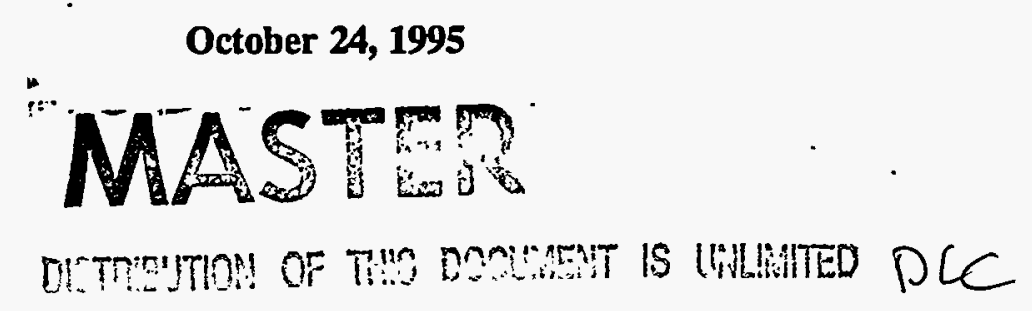




\section{Contents}

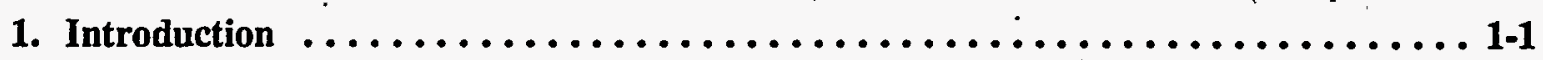

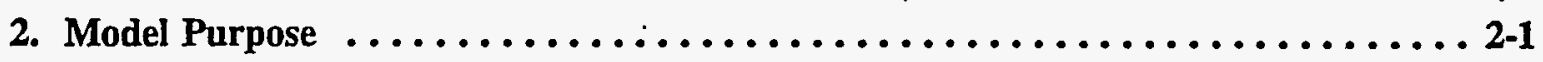

3. Model Overview and Rationale $\ldots \ldots \ldots \ldots \ldots \ldots \ldots \ldots \ldots \ldots \ldots \ldots \ldots \ldots$ 3-1

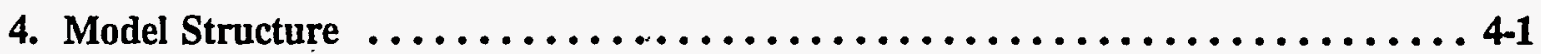

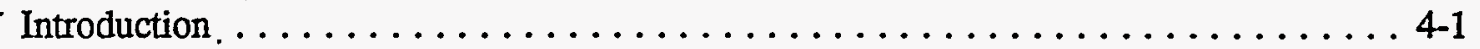

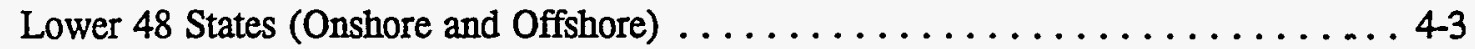

Enhanced Oil Recovery Supply Submodule $\ldots \ldots \ldots \ldots \ldots \ldots \ldots \ldots \ldots \ldots .4-29$

Alaska Oil and Gas Supply Submodule $\ldots \ldots \ldots \ldots \ldots \ldots \ldots \ldots \ldots \ldots .4,33$

Foreign Natural Gas Supply Submodule $\ldots \ldots \ldots \ldots \ldots \ldots \ldots \ldots \ldots \ldots .446$

Chapter 4 Appendices.$\ldots \ldots \ldots \ldots \ldots \ldots \ldots \ldots \ldots \ldots \ldots \ldots \ldots \ldots$

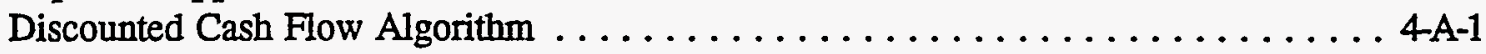

Liquefied Natural Gas Costing Methodology $\ldots \ldots \ldots \ldots \ldots \ldots \ldots \ldots \ldots$ 4-B-1

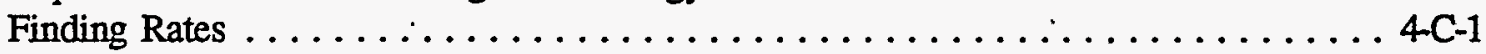

Calculation of VARPOIL, SKP, and CV . . . . . . . . . . . . .

Appendices

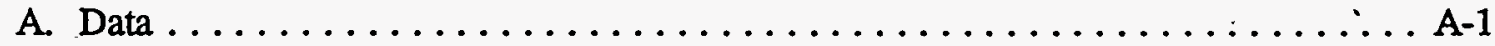

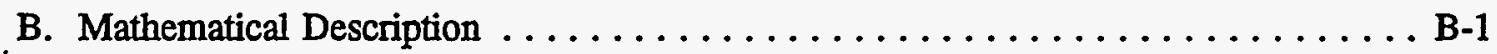

C. Bibliography $\ldots \ldots \ldots \ldots \ldots \ldots \ldots \ldots \ldots \ldots \ldots \ldots \ldots \ldots \ldots \ldots \ldots \ldots \ldots \ldots, 1$

D. Model Abstract $\ldots \ldots \ldots \ldots \ldots \ldots \ldots \ldots \ldots \ldots \ldots \ldots \ldots \ldots \ldots \ldots$ D-1

E. Data Quality and Estimation $\ldots \ldots \ldots \ldots \ldots \ldots \ldots \ldots \ldots \ldots \ldots \ldots \ldots \ldots \ldots \ldots \ldots$ 



\section{Tables}

1. Tax Treatment in Oil and Gas Production by Category of Company Under Tax

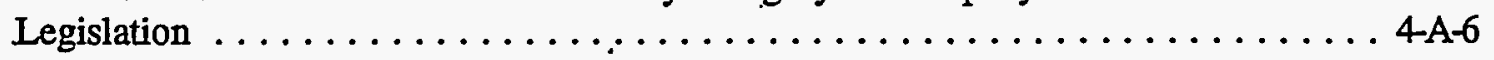

. 2. MACRS Schedules (percent) $\ldots \ldots \ldots \ldots \ldots \ldots \ldots \ldots \ldots \ldots \ldots \ldots \ldots \ldots$ 



\section{Figures}

1. OGSM Interface with Other Oil and Gas Modules $\ldots \ldots \ldots \ldots \ldots \ldots \ldots \ldots \ldots$

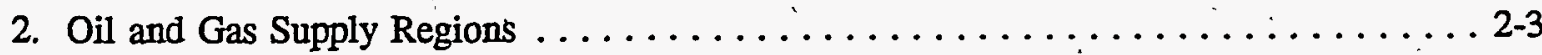

3. Submodules within the Oil and Gas Supply Module $\ldots \ldots \ldots \ldots \ldots \ldots \ldots \ldots$ 4-1

4. Flowchart for Lower 48 States Onshore and. Offshore Oil and Gas Submodules . . . . 4-4 •

5. Lower 48 Oil and Gas Supply Regions with Region Codes . . . . . . . . . . 4-7

6. Procedure for EOR Production from Proved Reserves $\ldots \ldots \ldots \ldots \ldots \ldots \ldots \ldots$ 4-31

7. Development of New EOR Projects $\ldots \ldots \ldots \ldots \ldots \ldots \ldots \ldots \ldots \ldots \ldots \ldots \ldots \ldots \ldots \ldots \ldots$

8. Flowchart for the Alaska Oil and Gas Supply Module ............... 4-34

9. Foreign Natural Gas Trade via Pipeline $\ldots \ldots \ldots \ldots \ldots \ldots \ldots \ldots \ldots \ldots \ldots$. $\ldots \ldots 7$

10. A General Outline of the Canadian Algorithm of the FNGSS . . . . . . . . . . 4-49

11. Basic Finding Rate Function $\ldots \ldots \ldots \ldots \ldots \ldots \ldots \ldots \ldots \ldots \ldots \ldots \ldots \ldots$

12. Reserve Additions $\ldots \ldots \ldots \ldots \ldots \ldots \ldots \ldots \ldots \ldots \ldots \ldots \ldots \ldots \ldots \ldots \ldots$

13. Minimum Economic Finding Rate $\ldots \ldots \ldots \ldots \ldots \ldots \ldots \ldots \ldots \ldots \ldots \ldots$

14. Technological Change $\ldots \ldots \ldots \ldots \ldots \ldots \ldots \ldots \ldots \ldots \ldots \ldots \ldots \ldots \ldots \ldots$

15. Technological Change: Incremental versus Full Benefit Approach . . . . . . . . 4-C-10 



\section{Introduction}

The purpose of this report is to define the objectives of the Oil and Gas Supply Model (OGSM), to describe the model's basic approach, and to provide detail on how the model works. This report is intended as a reference document for model analysts, users, and the public. It is prepared in accordance with the Energy Information Administration's (EIA) legal obligation to provide adequate documentation in support of its statistical and forecast reports (Public Law 93-275, Section 57(b)(2).

Projected production estimates of U.S. crude oil and natural gas are based on supply functions generated endogenously within National Energy Modeling System (NEMS) by the OGSM. OGSM encompasses domestic crude oil and natural gas supply by both conventional and nonconventional recovery techniques. Nonconventional recovery includes enhanced oil recovery (EOR), and unconventional gas recovery (UGR) from tight gas formations, Devonian shale and coalbeds. Crude oil and natural gas projections are further disaggregated by geographic region. OGSM projects U.S. domestic oil and gas supply for six Lower 48 onshore regions, three offshore regions, and Alaska. The general methodology relies on forecasted drilling expenditures and average drilling costs to determine exploratory and developmental drilling levels for each region and fuel type. These projected drilling levels translate into reserve additions, as well as a modification of the production capacity for each region.

OGSM also represents foreign trade in natural gas, imports and exports by entry region. Foreign gas trade may occur via either pipeline (Canada or Mexico), or via transport ships as liquefied natural gas (LNG). These import supply functions are critical elements of any market modeling effort.

OGSM utilizes both exogenous input data and data from other modules within NEMS. The primary exogenous inputs are resource levels, finding rate parameters, costs, production profiles, and tax rates all of which are critical determinants of the expected.returns from projected drilling activities. Regional projections of natural gas wellhead prices and production are provided by the Natural Gas Transmission and Distribution Module (NGTDM). From the Petroleum Market Model (PMM) come projections of the crude oil wellhead prices and production at the OGSM regional level. Important economic factors, namely interest rates and GNP(GDP) deflators flow to OGSM from the Macroeconomic Module. Controlling information (e.g., forecast year) and expectations information (e.g., expected price paths) come from the integrating, or system module.

Outputs from OGSM go to other oil and gas modules (NGTDM and PMM) and to other modules of NEMS. NGTDM and PMM employ short-term supply functions, the parameters for which are provided by OGSM for oil and gas production and natural gas imports. The short-term supply functions reflect potential oil or gas flows to the market for a one year period. These functions are used by NGTDM and PMM for the determination of equilibrium prices and quantities of crude oil and natural gas at the wéllhead. OGSM also provides projections of natural gas production to PMM to estimate the corresponding level of natural gas liquids production. Other NEMS modules receive projections of selected OGSM variables for various uses. Oil and gas production and resultant emissions are forwarded to the Systems Module. Forecasts of oil and gas production, as well as capital expenditures at the wellhead, go to the Macroeconomic Module to assist in forecasting aggregate measures of capital and output. 
OGSM is archived as part of the National Energy Modeling System (NEMS). The archival package of NEMS is located under the model acronym NEMS95. The version is that used to produce the Annual ${ }^{*}$ Energy Outlook 1995 (AEO95). The package is available through the National Technical Information Service. The inodel contact for OGSM is:

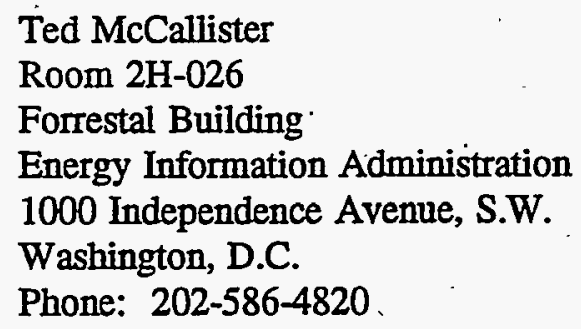

This OGSM documentation report presents the following major topics concerning the model.

- Model purpose

- Model overview and rationale

- Model structure

- Inventory of input data, parameter estimates, and model output

- Detailed mathematical description. 


\section{Model Purpose}

OGSM is a comprehensive framework with which to analyze oil and gas. supply potential and related issues. Its primary function is to produce forecasts of crude oil, natural gas production, and natural gas imports and exports in response to price data received endogenously (within NEMS) from the Natural Gas Transmission and Distribution Model (NGTDM) and the Petroleum Market Model (PMM). To accomplish this task, OGSM does not provide production forecasts per se, but rather parameter estimates for shortterm domestic oil and gas production functions and natural gas import functions that reside in PMM and NGTDM.

PMM and NGTDM utilize the OGSM supply functions during a solution process that deterinines regional wellhead market clearing prices and quantities. After equilibration is achieved in each forecast year, OGSM calculates revised parameter estimates for the supply functions for the next year of the forecast based on equilibrium prices and quantities received from PMM and NGTDM. OGSM then sends the revised parameters to NGTDM and PMM, which update the short-term supply functions for use in the following forecast year. The determination of the projected natural gas and crude oil wellhead prices and quantities supplied occurs within the NGTDM and PMM. As the supply component only, OGSM cannot project prices, which are the outcome of the equilibration of demand and supply. The basic interaction between OGSM and the other oil and gas modules is represented in Figure 1. Controlling information and expectations come from the System Module. Major exogenous inputs include resource levels, finding rate parameters, costs, production profiles, and tax rates - all of which are critical determinants of the oil and gas supply outlook of the OGSM.

OGSM operates on a regionally disaggregated level, further differentiated by fuel type. The basic geographic regions are Lower 48 onshore, Lower 48 offshore, and Alaska, each of which, in turn, is divided into a number of subregions (see Figure 2). The primary fuel types are crude oil and natural gas, which are further disaggregated based on type of deposition, method of extraction, or geologic formation. Crude oil supply comprises production from conventional. and enhanced oil recovery techniques. Natural gas is differentiated by nonassociated and associated-dissolved gas. ${ }^{1}$. Nonassociated natural gas is categorized by conventional and unconventional types. Conventional natural gas recovery is differentiated by depth between formations up to 15,000 feet and those at greater than 15,000 feet (in the context of OGSM, these depth categories are referred to as shallow or deep). The unconventional gas category in - OGSM consists of resources in tight sands, Devonian shale, and coal bed methane formations.

OGSM provides mid-term (15 to 20 year) forecasts, as well as serving as an analytical tool for the assessment of various policy alternatives. One publication that utilizes OGSM forecasts is the Annual Energy Outlook (AEO). Analytical issues OGSM can address involve policies that affect the profitability of drilling through impacts on certain variables including:

- drilling costs,

- production costs,

- regulatory or legislatively mandated environmental costs,

\footnotetext{
'Nonassociated'(NA) natural gas is gas not in contact with significant quantities of crude oil in a reservoir. Associateddissolved natural gas consists of the combined volume of natural gas that occurs in crude oil reservoirs either as free gas (associated) or as gas in solution with crude oil (dissolved).
} 
Figure 1. OGSM Interface with Other Oil and Gas Modules

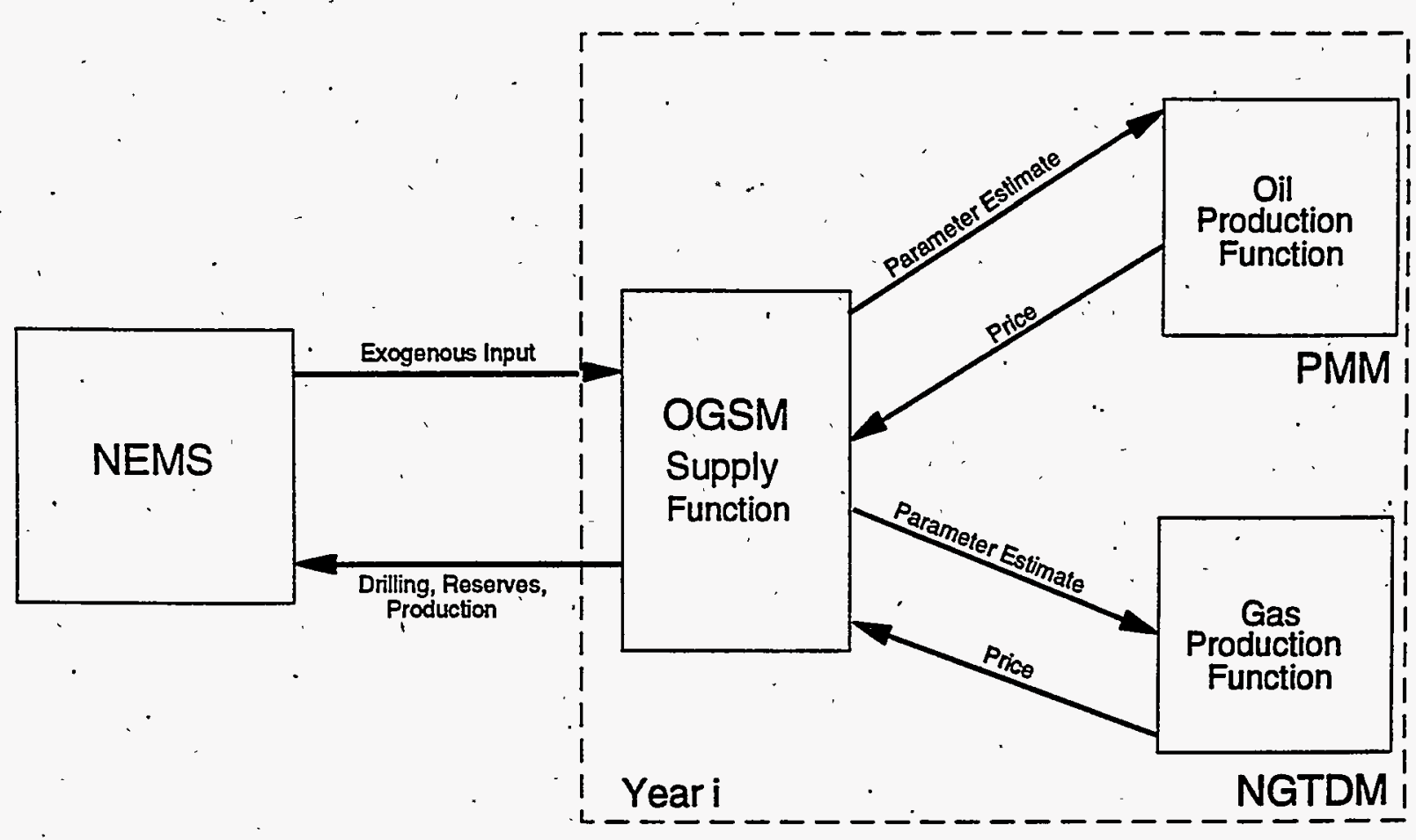

- key taxation provisions such as severance taxes, State or Federal income taxes, depreciation schedules and tax credits, and

- the rate of penetration for different technologies into the industry by fuel type.

The cash flow approach to the determination of national expenditure levels enables OGSM to address some issues that are financial in nature. In particular, the treatment of financial resources within OGSM allows for explicit consideration of the financial aspects of upstream capital investment in the petroleum 'industry.

OGSM is also useful for policy analysis of resource base issues. OGSM analysis is based on explicit estimates for economically recoverable oil and gas resources for each of the sources of domestic production (i.e., geographic region/fuel type combinations). This feature allows the model to be used for the analysis of issues involving:

- the uncertainty surrounding the economically recoverable oil and gas resource estimates, and

- access restrictions on much of the offshore Lower 48 states, the wilderness areas of the onshore Lower 48 states, and the 1002 Study Area of the Arctic National Wildlife Refuge (ANWR). 
Figure 2. Oil and Gas Supply Regions
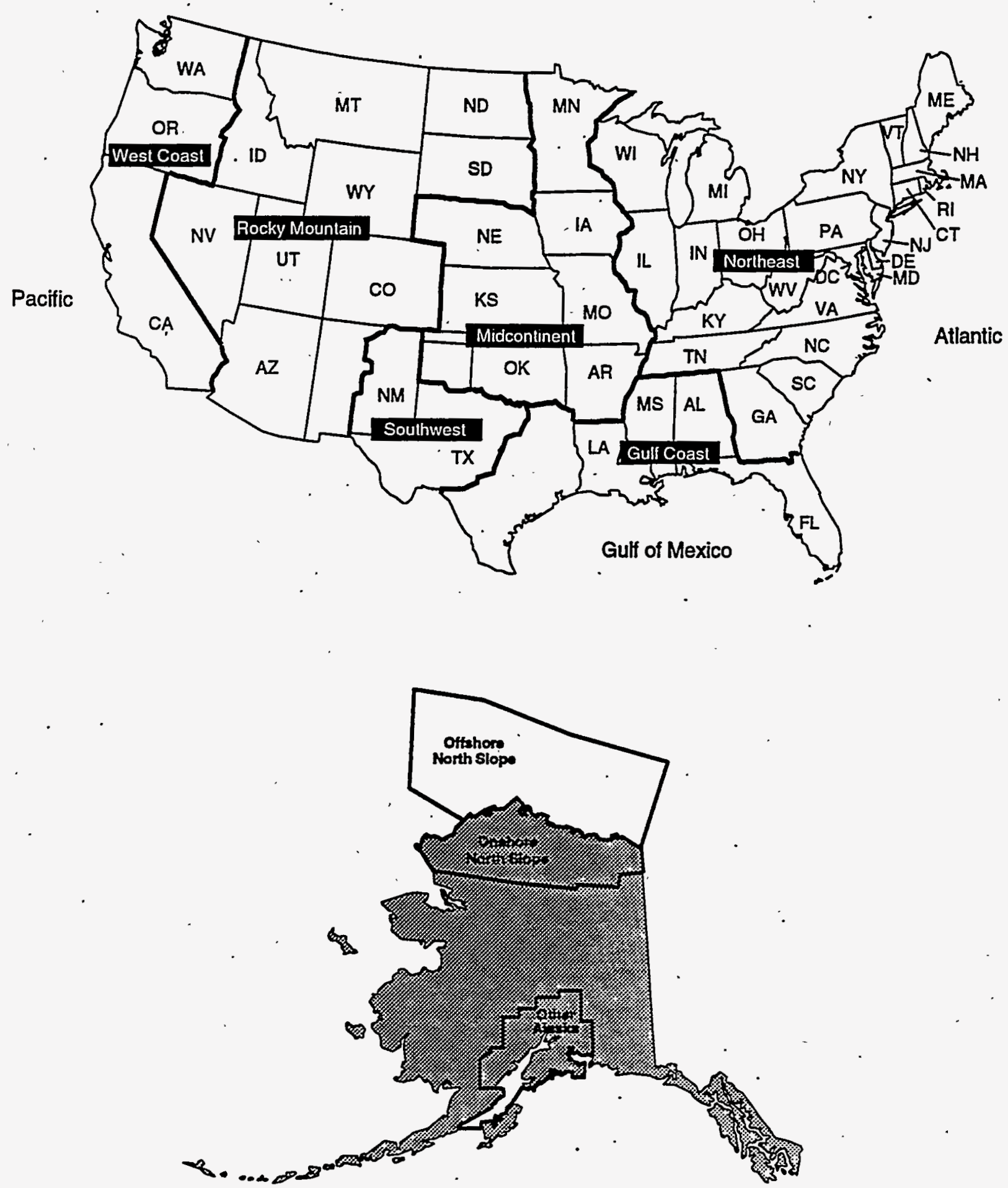
In general, OGSM will be used to foster a better understanding of the integral role that the oil and gas extraction industry plays with respect to the entire oil and gas industry, the energy subsector of the U.S... economy, and the total U.S. economy. 


\section{Model Rationale and Overview}

\section{Introduction}

This chapter provides a brief overview of the rationale and theoretical underpinnings of the methodology chosen for the Oil and Gas Supply Module (OGSM). First a classification of previous oil and gas supply modeling methodologies is discussed, with descriptions of relevant supply models and comments on their advantages and disadvantages. This leads to a discussion of the rationale behind the methodology adopted for OGSM and its various submodules, including the onshore and offshore Lower 48 states (excluding enhanced oil recovery), the foreign natural gas supply submodule, and the Alaska submodule.

\section{Overview of Oil and Gas Supply Modeling'Methods}

Oil and gas supply models have relied on a variety of techniques to forecast future supplies. These techniques can be categorized generally as geologic/engineering, econometric, "hybrid" - an approach that combines geologic and econometric techniques, and market equilibrium. The geologic/engineering models are further disaggregated into play analysis models and discovery process models.

\section{Geologic/Engineering Models}

\section{Play Analysis}

According to the U.S. Geological Survey (USGS), a play is a group of geologically related, known or undiscovered accumulations (prospects) having similar hydrocarbon sources, reservoirs, traps, and geologic histories. A prospect is a geologic feature having the potential for the trapping and accumulation of hydrocarbons. Prospects are the targets of exploratory drilling. Play analysis relies on detailed geologic data and subjective probability assessments of the presence of oil and gas. Seismic. information, expert assessments, and information from analog areas are combined in a Monte Carlo simulation framework to generate a probability distribution of the total volume of oil or gas present in the play. These models are primarily used as a source assessment tool, but they have been used with an economic component to generate oil and gas reserve additions and production forecasts.

An example of a play analysis model is EIA's Outer Continental Shelf Oil and Gas Supply Model $(\mathrm{OCSM})^{1}$, which was developed during the late 1970 s and early 1980s. The OCSM used a field-sizedistribution approach to evaluate Federal offshore supply (including production from the Gulf of Mexico, Pacific, and Atlantic offshore regions). The OCSM drew on a series of Monte Carlo models based on the work of Kaufman and Barouch. ${ }^{2}$ These models started with lognormal field-size distributions and examined the order in which fields are discovered. The OCSM also drew on an alternative approach taken by Drew et al., ${ }^{3}$ which was an extension of the Arps and Roberts approach to resource assessment, ${ }^{4}$

\footnotetext{
'Outer Continental Shelf(OCS) Oil and Gas Supply Model, Volume 1, Model Summary and Methodology Description, Energy Information Administration, Washington, D.C., December 1982, DOE/EIA-0372/1. and Farmer, Richard D., Harris, Carl M., Murphy, Frederic H., and Damuth, Robert J., "The Outer continental Shelf Oil and gas Supply model of the Energy Information Administration," North-Holland European Joumal Of Operation Research, 18 (1984), pages 184-197.

${ }^{2}$ Kaufman, G.M., and Barouch, E., "The Interface Between Geostatistical Modeling of Oil and Gas Discovery and Economics," Mathematical Geology, 10(5), 1978.

${ }^{3}$ Drew, L.J., Schuenemeyer, J.H., and Bawiec, W.J., Estimation of the Future Rate of Oil and Gas Discovery in the Gulf of Mexico, U.S. Geologic Survey Professional Paper, No. 252, Reston, VA, 1982.
} 
falling between simple extrapolation and Monte Carlo simulation. This alternative approach explicitly represented an exponentially declining exploration efficiency factor (in contrast to that of Kaufman and Barouch, in which declining efficiency was related solely to the assumed decline in field size). Under this approach; finding rates for the number of fields in a collection of size categories were estimated (as opposed to determining an aggregate finding rate)--an approach involving massive data requirements.

Key differences between the OCSM and other field-size-distribution models included the fact that OCSM was based on (a) geological data on undiscovered structures obtained from the U.S. Department of the Interior (as opposed to data simulated from aggregate regional information), (b) a highly detailed characterization of the supply process, (c) a relatively sophisticated treatment of uncertainty, and (d) explicit consideration of investment decisions at the bidding, development, and production stages, in addition to the exploration stage.

Although the OCSM had many superior qualities, it was highly resource intensive. In particular, the OCSM required (a) maintenance of a large database on more than 2000 prospects in thirty offshore plays, (b) considerable mainframe CPU time to execute completely, reflecting the highly complex algorithmic and programming routines, and (c) maintenance of a wide range of staffing skills to support both the model and the underlying data. Since all these problems violate basic key attributes required of an oil and gas supply model operating in the NEMS environment, adopting a similar play analysis approach for the OGSM was rejected.

\section{Discovery Process}

Kaufman, Balcer and Kruyt described discovery process modeling as "building a model of the physics of oil and gas field discovery from primitive postulates about discovery that are individually testable outside the discovery model itself." Unlike play analysis models, discovery process models can only be used in well developed areas where information on exploration activity and oil and gas discovery sizes is readily available. Discovery process models reflect the dynamics of the discovery process and do not require detailed geologic information. They rely instead on historical exploratory drilling and discoveries data.

Although the details of discovery process models vary, they all rely on the assumption that the larger the oil or gas field, the more likely it will be discovered. This assumption leads to discovery rates (the amount of oil or gas found per unit of exploratory effort) that typically decline as more of an area is explored. Discovery process models usually specify a finding rate.equation using a functional form such that discoveries decline with cumulative drilling.

Discovery process models have generally been applied to specific geologic basins, such as the DenverJulesburg basin (Arps and Roberts 1959). They have also been used in studies of the Permian Basin ${ }^{5}$ and the North Sea. Discovery process models do not usually incorporate economic variables such as costs, profits, and risk. Returns to exploratory effort are represented in terms of wells drilled or reserves discovered.

Since there are generally no economic components, discovery process models cannot project time paths of future drilling and reserve additions without using ad hoc constraints (for example constraints on rigs or expenditures). The constraints chosen become to some extent deciding factors in the model outcome.

\footnotetext{
${ }^{4}$ Arps, J.J., and Roberts, T.G., "Economics of Drilling for Cretaceous Oil on'East Flank of Denver-Julesburg Basin," American Association of Petroleum Geologists Bulletin 42, 1958.

'Future Supply; of Oil and Gas from the Permian Basin of West Texas and Southeastem New Mexico; U.S. Geological Survey, Washington DC, 1980
} 
Typically factors such as cash flow or the availability of rigs are constrained to enable the model to forecast satisfactorily.

The OGSM is intended to support the market analysis requirements of NEMS, thus it includes both an economic and a geologic component. A model of industry activity was developed for the OGSM that predicts expenditure and drilling levels each period of the forecast horizon. The estimated levels of drilling are used to determine oil and gas reserve additions in each period through a finding rate function. The modular nature of OGSM does allow for future consideration of an alternate geologic approach such as a pure discovery process model. Whereas many discovery process models specify one finding rate function, OGSM uses three to capture the varying influences of new field wildcat, other exploratory, and development drilling on the discovery process.

\section{Econometric Models}

Many econometric models do not include a description of geologic trends or characteristics -- for example, average discovery sizes do not vary systematically with cumulative exploratory drilling as in discovery process models. Additionally, these models, for the most part, have not been based on a dynamic optimization model of firm behavior and do not incorporate expectations of future economic variables a limitation that also applies, for the most part, to the geologic/engineering models:

Recent econometric models have made some inroads in overcoming these problems. Rational expectations econometric models have been developed by Hendricks and Novales and by Walls which are based on intertemporal optimization principles that incorporate uncertainty and inherently attempt to capture the dynamics of the exploration process. ${ }^{6}$ Geologic trends also are accounted for, though not in as much detail as they are in play analysis and discovery process models.

These improvements are not without cost. The theoretical specifications of rational expectations econometric models must be highly simplified in order to obtain analytic solutions to the optimization problems. This feature of these models means that it is impossible to describe the oil supply process with the level of detail that the more ad hoc approaches allow. In addition, a long time series of historical data is necessary in order to obtain consistent parameter estimates of these models. Such a time series does not exist in many cases, especially for frontier areas such as the offshore or at the regional levels required for NEMS. Finally, because of the degree of mathematical complexity in the models, forecasting and policy analysis often turn out to be intractable.

Econometric methods have been employed primarily for studies of a single region, either a relatively limited area such as a single state or more broad-based such as the entire Lower 48 states. An example of the former is the work by Griffin and Moroney (1985), which was used to study the effects of a state . severance tax in Texas. Recent work on large scale aggregate data appear in studies by Epple (1985) and Walls (1989). These studies link models of individual dynamic optimizing behavior under uncertainty to the use of econometric techniques. In general, the firm is assumed to maximize a quadratic objective function subject to linear constraints on the processes governing the stochastic variables that are outside the firm's control. In the Walls model, an oil exploration firm chooses the number of exploratory.wells to drill in each period to maximize the expected discounted present value from exploration, providing a clear link between a theory of the exploration firm's dynamic behavior under uncertainty and the econometric equations of the model. However, in addition to other considerations, the model is so

\footnotetext{
'Hendricks, Kenneth and Alfonso Novales, 1987, Estimation of dynamic investment function in oil exploration, Draft manuscript. Walls, Margaret A., 1989, Forecasting oil market behavior: Rational expectations analysis of price shocks, Paper EM87-03 (Resources for the Future, Washington, D.C.)
} 
mathematically complicated that "...it is impossible to describe the oil supply process with the same level of detail as the ad hoc models. In other words, it is difficult, if not impossible, to model all of the stages' of supply in a realistic way." ${ }^{17}$ Such a model would not be appropriate for the intended role of NEMS, although it can be quite useful in other applications.

\section{Hybrid Models}

Hybrid models are an improvement in some ways over both the pure process models and the econometric models. They typically combine a relatively detailed description of the geologic relationship between discoveries and drilling with an econometric component that estimates the response of drilling to economic. variables. In this way, a time path of drilling may.be obtained without sacrificing an accurate description of geologic trends. Such a hybrid approach has been directly implemented (or incorporated indirectly, using the results of hybrid models) under a variety of methodological frameworks. Such frameworks include the system dynamics methodology used in the FOSSIL2 model, which underlies the recent National Energy Strategy and numerous related ștudies.

The Gas Research Institute's (GRI) Hydrocarbon Supply Model (HSM) is one example of a hybrid model. The HSM employs an enhanced discovery process component to estimate discoveries from the underlying resource base and an economic component to provide costs for exploration, development and production of oil and gas accumulations. Overall industry activity is subject to an econometrically determined financial constraint.

The American Gas Association's Total Energy Resource Analysis model (TERA) employs an econometric appĩoach to determine changes in aggregate Lower 48 onshore drilling based on a profitability index. Offshore Lower 48 supply is evaluated offline for inclusion in the outlook. New supplies flow from discoveries that depend on a finding rate. This finding rate does not rely on an explicit resource estimate, but does reflect resource depletion given cumulative increases in reserves. Technology influences the finding rate, but it primarily manifests itself in lower costs by reducing the number of dry holes experienced in the supply process.

Data Resources Inc's oil and gas supply model also employs a hybrid approach. Lower 48 exploratory drilling depends on projected net revenues. Developmental drilling is a function of lagged exploratory wells. New supplies occur from discoveries that depend on a finding rate. The finding rate itself is based on an analysis of recent trends in observed data. The extrapolative technique used does not incorporate an explicit estimate for economically recoverable resources. Technology is not explicit within the model, but it is treated on an ad hoc basis.

\section{Market Equilibrium Models}

Market-equilibrium models connect supply and demand regions via a transportation network and solve for the most efficient regional allocation of quantities and corresponding prices. Market-equilibrium models tend to be single energy market models that concentrate on the economic forces that efficiently balance markets across regions without explicit representation of other fuel market conditions. Consideration of the processes that alter supply and demand are not necessarily modeled in detail; stylized regional supply and demand curves are postulated.

\footnotetext{
${ }^{7}$ Walls, Margaret A., Modeling and forecasting the supply of oil and gas: A survey of existing approaches, Resources and Energy 14 (1992), North Holland, p 301.
} 
An example of a market-equilibrium model is Decision Focus Incorporated's North American Regional Gas Model (NARG). Regional supplies of indigenous production are based on a representation of the gas * resource base as a continuous, ordered stream of reserve increments that will be discovered and developed over a range of prices. As prices rise, thus covering increasing costs, additional portions of the resource base systematically become available to the market. Regional supply curves also reflect an assessment of the expected cost characteristics of the technically recoverable resource base.

Supply regions are linked to demand regions throughout the United States and Canada by a network of existing and prospective pipelines, with specified capacity constraints and tariffs. Within the framework of this model, 17 supply regions are specified: 12 in the United States and 5 in Canada. ${ }^{8}$ Each region has its own gas supply curve based on estimates of the resource base and associated costs of discovery and development from the Potential Gas Committee (United States), the Canadian Energy Research Institute, and the Canadian National Energy Board.

The partial equilibrium nature of these models is contrary to the requirements of an oil and gas supply model operating within the integrated environment of NEMS. Moreover, the solution from a market equilibrium model consists of a volume of gas produced, rather than a supply schedule as required by the Natural Gas Transmission and Demand Model. Finally, the forecasting capabilities of this approach are open to question given that many of the key parameters are not subjected to the discipline of validation against historical data.

\section{OGSM Rationale}

None of the models described are able to address all the issues that would be required of the OGSM. For example, some models might have reasonable representations of the onshore supply process, but completely lack an offshore or unconventional fuel component. Some models only provide a representation of the gas supply industry while almost completely ignoring oil supplies. Some models provided only limited ability to be simulated under different fiscal and policy environments. OGSM had to be developed keeping in mind the overall goal of NEMS - the ability to address many of the likely physical and policy variables that might affect future U.S. oil and gas supplies.

An important consideration regarding many of the models discussed above is that they typically tend to be highly resource intensive, both (a) in terms of personnel requirements for development and maintenance and (b) in terms of execution time and other computational resource requirements. It was for these reasons that the OCSM model, the EIA's offshore play-analysis model, was ultimately retired.

Another difficulty with many of these models is that the relationships in the models are typically not subjected to the discipline of validation against historical data-in fact, there are usually too many parameters in the models to estimate econometrically. As a result, the models cannot project time paths of future oil and gas supply without the use of ad hoc constraints that turn out to be important determinants of the forecasts generated by the models.

Accordingly the OGSM uses some features of the discovery-process approach, but does not employ any of the traditional discovery process models discussed earlier because they are too data intensive. The chosen OGSM design helps to satisfy some of the specification requirements set forth for the NEMS,

\footnotetext{
${ }^{8}$ Mexico has been introduced into the model as a net import flow in recent work for the National Petroleum Council's Natural Gas Study.

${ }^{9}$ See, for example, Requirements for a National Energy Modeling System, December 1991, and Recommended Design for the National Energy Modeling System, October 1991.
} 
which emphasize, among other attributes, model transparency and model efficiency. The OGSM, as a regionally aggregated discovery-process model, does not determine activity levels on the basis of an. explicit economic evaluation of discrete production units, such as individual producing fields (oil and gas from Alaska is the exception). The requirements for performing a disaggregated field analysis were prohibitive in the context of the time and resources needed to develop and maintain such an approach, without necessarily affecting the modeling results appreciably. The OGSM, however, simulates endogenously separate discretionary levels for exploratory and developmental drilling in contrast to the fixed relationship between exploratory and developmental drilling that characterizes many other models. The Alaska Oil and Gas Supply Submodule (AOGSS) and the liquefied natural gas (LNG) component of the Foreign Natural Gas Supply Submodule (FNGSS) are the exceptions to the above paragraph. Both methodologies take more of an engineering approach. In the case of Alaska this is because of the relative low number of fields (compared to the Lower 48 states) expected to be economically viable in Alaska. The representation of LNG in OGSM is unique because field production is not part of domestic operations. The stages of the LNG process to be modeled primarily concern the receipt of LNG at importation facilities and its subsequent conversion into gaseous natural gas.

The remainder of this section provides a brief discussion of the rationales and methodologies of the OGSM's submodules.

\section{Lower 48 Oil and Gas Supply}

A hybrid econometric/discovery process approach was used to model Lower 48 states conventional oil and gas supply and UGR supply in the OGSM. ${ }^{10}$ The geology is represented in the model's discovery-process components, while the economics of exploration, development, and production are captured by the model's econometric equations component. The methodology was designed for two basic purposes: (1) to generate forecasts of future drilling activity, and oil and gas supplies under alternative scenarios and (2) to provide a framework for analyzing the potential impacts of policy changes on future drilling activities and oil and gas supplies. The OGSM was designed to meet these two requirements in a transparent and efficient manner, while simulating the supply behavior of the oil and gas industry and incorporating essential behavioral and physical relationships without resorting to extraordinarily complex functional forms and/or algorithms.

The Lower 48 states component is comprised of 119 equations, with 311 parameters. Exploration and development expenditures are determined using a partial recursive model, with oil and gas prices the principal driving variables as they affect expected profitability for drilling investments. Regional oil and gas prices are determined exogenousiy from the OGSM and are received from the Petroleum Market Module and the Natural Gas Transmission and Distribution Module respectively.

Drilling levels are determined by the industry's overall level of investment in exploration and development. Relying on basic research on the determinants of business investment, it is assumed that the industry's overall level of domestic exploration and developmental drilling expenditures is determined by several major factors, including: the expected profitability of domestic exploration and developmental drilling; the economic and geologic risk associated with exploration and developmental drilling; and the industry's financial position as proxied by industry cash flow. The allocation of investment expenditures to geographic regions and subsequently to specific types of drilling within regions is.a function of the overall level of expenditures and the relative profitability of the different types of regional drilling activities. This model thus assumes that the firms in the industry are profit maximizers and that resources

\footnotetext{
${ }^{10} \mathrm{~A}$ slightly different approach was employed to represent EOR supply activities and this method is described in the following section. 
tend to flow into activities with relatively higher expectèd profitability, ceteris paribus. The number of wells drilled in each region is derived by dividing regional expenditures by average drilling costs.

The expenditure determination and allocation algorithms are econometrically based. Specifically, the national, regional, and sub-regional levels of exploration and developmental expenditures are forecast on the basis of econometrically estimated equations that relate historical exploration and developmental drilling expenditures to the explanatory variables given above. The econometric approach was chosen over a linear programming approach or a hybrid linear programming/econometric approach of the type used in PROLOG, the OGSM's predecessor, for two major reasons. First, incurring the additional computational burden associated with solving a linear programming problem with multiple constraints seemed inefficient relative to forecasting directly from the estimated historical relationships. This is especially critical given that NEMS requirements include the goals of quick execution and the efficient utilization of computer resources. Second, the linear programming approach requires the explicit specification of the objective function while an econometrically based approach does not. If the true objective function is unknown or cannot be specified without adding undue complexity and computational burden to the model, then an econometric approach is more sensible. For empirical purposes, implementation of the econometric approach does not require specification of an explicit objective function, but only the identification of explanatory variables whose movements can be related, on average, to changes in investment that are driven by a particular behavioral objective, e.g, profit maximization.

The econometric method of determining drilling activity levels on the basis of exploration and developmental drilling expenditures, which in turn are based on expected profitability, is certainly in line with the methodologies of several other respected oil and gas supply models. For example, overall industry drilling activity in the Hydrocarbon Supply Model (HSM) of the Gas Research Institute (GRI) is subject to an econometrically determined financial constraint. The Total Energy Resource Analysis (TERA) model of the American Gas Association (AGA) employs an econometric approach to determine changes in aggregate lower 48 onshore drilling based on a profitability index. The DRI/McGraw-Hill (DRI) model forecasts exploratory drilling on the basis of projected net revenues. Though the specific details differ across the models, their unifying trait is an explicit recognition of the important linkages among profitability, exploration and developmental drilling expenditures (financial resources), and drilling activity levels.

The methodology also incorporates the fundamental economic principle that financial resources, i.e., investment funds, will flow to those activities that promise relatively higher returns ceteris paribus. In particular, in the scheme to allocate overall exploration and developmental drilling expenditures to the regional and sub-regional levels, a set of equations is used that relies on the total amount of drilling expenditures available and the profitability of the particular drilling activity relative to the weighted average profitability of all drilling activities. Again, this is consistent with other models, most notably the GRI's HSM. The HSM, however, does not use an econometrically based sharing algorithm. Rather, it employs an approach in which the parameters of the sharing functions are user determined. The choice of an econometrically based expenditure allocation procedure was made in order to incorporate the estimated historical relationship between allocations and relative profitability directly into the forecasts. It seemed more reasonable to use history. as a guide, if possible, rather than rely on user specification. Spending levels for each specific drilling activity are converted to the total number of wells drilled by dividing the expenditure levels by estimates of drilling costs per well, which vary by region and fuel type. Based on historical proportions, exploratory wells are separated into new field wildcats and other exploratory wells. Differentiation between types of exploratory drilling is a feature that is not found in most other hybrid models. It enables the discovery process component to more realistically model the reserves additions process. 
Proved reserves comprise the only source for production, and the discovery process is the means by which nonproducing resources (i.e., undiscovered economically recoverable resources or inferred reserves) are converted into proved reserves. The discovery process component in OGSM consists of a set of finding rate equations that relate the volume of reserve additions to drilling levels. Three discovery processes are specified: new field discoveries from new field wildcats, field extension volumes from other exploratory drilling, and reserve revisions due to developmental drilling. New field wildcat discovery volumes are separated into proved and inferred reserves based on the historical relationship between a field's ultimate recovery and its initial discovery size. Inferred reserves are converted into proved reserves in later periods through other exploratory and developmental drilling. This differentiation in finding rates provides a more accirate representation of the reserves discovery process in the oil and gas industry. Exogenous estimates of the undiscovered economically recoverable resource base are incorporated in the new field wildcat finding rates. This allows user assumptions concerning the resource base to be specified for purposes of policy analysis, such as offshore drilling moratoria. The distinction between proved and inferred reserves is also found in GRI's HSM, though the separate impacts of new field wildcats and other exploratory wells on the reserves discovery process is not modeled there.

\section{Enhanced Oil Recovery Supply}

The Enhanced Oil Recovery Supply Submodule (EORSS) uses a modified form of the previousiy described methodology, which is used for conventional oil supply and all natural gas recovery types. A more thorough description of the EORSS methodology is presented in Chapter 4 of this report. All submodules in the OGSM share the similar basic attributes, but the representation may differ in the particulars. This section presents a discussion of the general differences between the methodologies.

The basic supply process for both EOR and the other sources of crude oil and natural gas consists of essentially the same stages. The physical stages of the supply process involve the conversion of unproven resources into proved reserves, and then the proved reserves are extracted as flows of production. A key element of economics on the supply side is that investment funds are directed more heavily to exploration and development opportunities that have greater expected profitability.

The significant differences between the methodology of the EORSS and the other submodules of OGSM concern the conversion of unproven resources to proved reserves and the determination of supply activities. The transfer of resource stocks from unproven to proved status in OGSM is handled by use of finding rate functions that relate reserve additions to cumulative drilling levels. The EORSS uses discovery factors that convert a specified fraction of unproven resources into proved reserves. These factors depend on the expected profitability of EOR investment opportunities, and not on drilling levels.

Greater expected financial returns motivate the conversion of larger fractions of the resource base into . proved reserves. This is consistent with the principle that funds are directed toward projects with relatively higher returns. An explicit determination of expenditures for supply activities does not occur within the EORSS as it does in the OGSM. Given the role of the discovery factors in the supply process, the implicit working assumption is that EOR investment opportunities with positive expected profit will attract sufficient financial development capital. EOR investment does not compete with other oil and gas opportunities. EOR recovery is sufficiently different, and its product not entirely similar to the less heavy oil most often yielded by conventional projects, that this assumption is considered appropriate.

\section{Foreign Natural Gas Supply}

The Foreign Natural Gas Supply Submodule consists of three key components: Canadian gas trade, liquefied natural gas (LNG) trades and gas trade with Mexico. Different methodological approaches were taken for each component in recognition of inherent differences between the various modes of import and 
the different circumstances affecting both supply capacity in the source country and its potential availability to the United States. The process by which Canadian gas flows to the United States is essentially the same process as that for U.S. supplies in the Lower 48 states. LNG imports are very different however, with available regasification capacity and the unit costs of transportation, liquefaction, and regasification being the most important determinants of import volumes. Production costs in countries currently or potentially providing LNG are a relatively small portion of total unit costs for gas delivered into the U.S. transmission network. Gas has not been imported from Mexico in the eight year period ending in 1992. Mexico began exporting very small volumes of gas to the United States in 1993. Further development of Mexican gas production capability depends more on institutional rather than economic factors. Consequently a third, scenario-based approach was chosen to model gas imports from this source.

The Foreign Natural Gas Supply Submodule is comprised of approximately 23 equations, with 8 parameters. It is a recursive type model, with oil and gas prices as the principal driving variables. Regional oil and gas prices are determined exogenously from the OGSM and are received from the Petroleum Market Module and the Natural Gas Transmission and Distribution Module respectively.

\section{Canadian Gas Imports}

Gas imports from Canada are modeled using a hybrid approach similar to the one taken for the Lower 48 States. The model has two key components, a discovery process component and an economic component. The economic component forecasts drilling activity as a function of discounted cash flows constructed for a representative Canadian oil and gas project. Within the DCF, variables such as prices, flow rates, costs, and taxes are specified and can be manipulated for analysis purposes. The discovery process component relates reserve additions per period to wells drilled. Like the Lower 48 module, it is assumed that the size of the find declines exponentially with cumulative drilling.

A hybrid method was chosen for modeling Canadian gas.supplies since this approach most effectively meets the numerous analytical requirements of OGSM. Also, sufficient data are available for the Canadian oil and gas industry. Finally, although this approach is a somewhat simplified version of the Lower 48 methodology (for example, explicit drilling expenditures are not estimated in the Canadian model), the two models are methodologically consistent.

\section{Liquefied Natural Gas}

LNG has been included as an explicit element of some natural gas models. LNG is represented in one of two ways, depending on the basic nature of the model. It has been inciuded as a basic element in models such as the World Gas Trade Model (WGTM). ${ }^{11}$ It also has been added to an expanded version of the Hydrocarbon Supply Model (HSM) that was used for the National Petroleum Council Natural Gas Study (1992).

Global trade models are based on a disaggregation of the world, in which countries or groups of countries are separated into consuming and producing regions. Each region has a stylized representation of supply and demand. Regions are connected via a transportation network, characterized by interregional transportation costs and flow constraints. LNG is incorporated into global trade models as possible gas trade between two noncontiguous countries. The model solves for the most efficient regional allocation of quantities and corresponding prices. The extensive scope of these models (and commonly encountered limitations of the necessary data) does not allow for detailed representations of gas supply or demand.

\footnotetext{
${ }^{11}$ The World Gas Trade Model (WGTM) basically is a global expansion of the NARG, using the Generalized Equilibrium Modeling System (GEMS). This model will not be described in detail because of the extreme similarity of the two models.
} 
The incorporation of LNG trade into each model generally has occurred as an enhancement of established models. Both LNG imports and exports are included, with LNG exports from Alaska as an exogenous factor. LNG imports are represented as gas supply available to the appropriate U.S. regions according to a prespecified schedule reflecting industry announcements. The model solution includes an endogenous determination of flows through LNG facilities and new capacity in response to price..

The LNG. algorithm in OGSM differs from the OGSM supply approaches for domestic and Canadian production. It utilizes supply curves for LNG imports, but it does not model explicitly the exploration and development process. These supply curves are based on the estimated cost of delivering LNG into the pipeline network in the United State and include all costs associated with production, liquefaction, shipping, and regasification. The supply curves mark the unit costs, which serve as economic thresholds that must be attained before investment in potential. LNG projects will occur. Extensive operational assumptions were made on current import terminal capacity and the timing of planned capacity expansions.

\section{Gas Trade with Mexico}

Gas trade between the United States and Mexico tended to be overlooked in earlier modeling efforts. This treatment (or lack thereof) seemed justified for a number of reasons. Except for a brief 5 year period in the early 1980s, neither gross nor net flows of gas between the United States and Mexico were significant. Additionally, reliable data regarding Mexican gas potential were not readily available.

A scenario basis was chosen to handle gas imports from Mexico because of uncertainty and the significant influence of noneconomic factors that affect Mexican gas trade with the United States. Much of the source material for the construction of these scenarios was drawn from the National Petroleum Council's 1992 study, The Potential for Natural Gas in the United States. Many of the models described previously make use of such exogenous offline analyses to forecast certain variables. For example, DRI's offshore oil and gas production forecasts are handled offline and integrated later into their main forecasting model.

\section{Alaskan Oil and Gas Șupplies}

Alaska has a limited history as a source of significant volumes of crude oil and natural gas. Initial commercial flows of crude oil from the Alaskan North Slope began on June 17, 1977. Interest in analyzing the volumetric potential of Alaska as a source of oil or gas supplies arose after the late 1960 s discovery of the Prudhoe Bay field, which is the largest in North America. During the years since the mid 1970s, there have been numerous special studies of either a one-time nature or limited in scope. An early study by Mortada (1976) projected expected oil production through $2002 .^{12}$ The-results of this analysis were used in Congressional hearings regarding the construction and operation of the Trans-Alaska Pipeline System (TAPS). A Department of the Interior (DOI) study (1981) analyzed the supply potential of the National Petroleum Reserve - Alaska (NPRA). This work was used in the consideration of leasing the NPRA for exploration and development.

Generalized models that deal with both oil and gas potential for Alaska are not as common as those for the Lower-48 states. Most forecasting agencies, including the EIA, have not devoted a large amount of resources towards the development and maintenance of a detailed Alaskan oil and gas representation in their domestic production models. Generally, forecasting groups either adopted a projection from another agency, or utilized other projections as the basis for selected ad hoc modifications as appropriate. The latter approach occurs in EIA's previous modeling work regarding Alaskan supply in PROLOG.

${ }^{12}$ Mortada International, The Determination of Equitable Pricing Levels for North-Slope Alaskan Crude Oil, (October 1976). 
This seeming inattention to building an Alaska oil and gas supply model arose from the limited extent of the projection horizon that was needed until recently. Projections in EIA had been for periods of 10 to 15 years, and up to 20 years only recently. This period length limits the flexibility in Alaskan activities, where lags of 10 to 15 years affect the discovery and development process. Thus, the bulk of oil production for at least 15 years under virtually any scenario depends almost wholly on the recovery from currently known fields. Marketing of natural gas from the Alaskan North Slope is not expected prior to the beginning of the next decade at the earliest, because of the lack of facilities to move the gas to Lower 48 markets and the interest of the operators and the State of Alaska in using the natural gas to maximize recovery of oil from Prudhoe Bay.

The present methodology for the Alaska Oil and Gas Supply Submodule (AOGSS) differs from that of the Lower 48 States representation. A discovery process approach with ad hoc constraints was chosen for the AOGSS. This method was chosen because of the unique nature of industry operations in Alaska and the limited number of fields do not lend themselves readily to application of the Lower 48 approach.

The AOGSS is divided into three components: new field discoveries, development projects, and producing fields. A discounted cash flow method is used to determine the economic viability of each project at netback price. The netback price is determined as the market price less intervening transportation costs. The continuation of the exploration and development of multi-year projects, as well as the discovery of a new field, is dependent on profitability. Production is determined on the basis of assumed drilling schedules and production profiles for new fields and development projects, and historical production patterns and announced plans for currently producing fields.

The AOGSS is comprised of approximately 11 basic equations. Oil and gas prices are the principal driving variables and are received from the Petroleum Market Module and the Natural Gas Transmission and Distribution Module respectively. 



\section{Model Structure}

\section{Introduction}

This chapter describes the Oil and Gas Supply Module (OGSM), which consists of a set of submodules (Figure 3) that perform supply analysis regarding domestic oil and gas production and foreign trade in natural gas between the United States and other countries via pipeline or as liquefied natural gas. The OGSM provides parameter estimates representing crude oil and natural gas supplies by selected fuel types on a regional basis to support the market equilibrium determination conducted within other modules of the National Energy Modeling System (NEMS). The oil and gas supplies in each period are balanced against the regional derived demand for the produced fuels to solve simultaneously for the market clearing prices and quantities in the disjoint wellhead and enduse markets. The description of the market analysis models may be found in the separate methodology documentation reports for the Petroleum Market Module (PMM) and the Natural Gas Transmission and Distribution Model (NGTDM).

Figure 3. Submodules within the Oil and Gas Supply Module

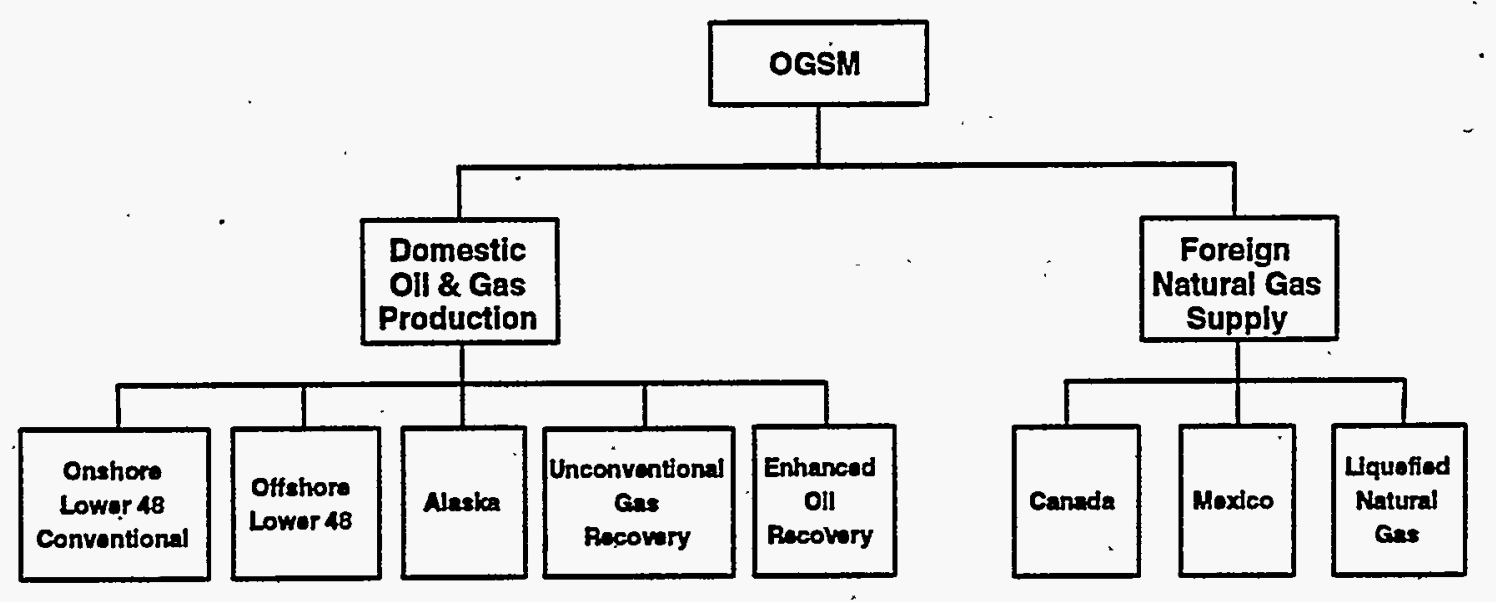

The OGSM mirrors the activity of numerous firms that produce oil and natural gas from domestic fieids throughout the United States or acquire natural gas from foreign producers.for resale in the United States or sell U.S. gas to foreign consumers. The OGSM encompasses domestic crude oil and natural gas supply by both conventional and nonconventional recovery techniques. Nonconventional recovery includes enhanced oil recovery (EOR), and unconventional gas recovery (UGR) from tight gas formations, Devonian shale and coalbeds. Crude oil and natural gas projections.are further disaggregated by geographic region. The OGSM represents foreign trade in natural gas as imports and exports by entry region of the United States. These foreign transactions may occur via either pipeline (Canada or Mexico), or via ships transported as liquefied natural gas (LNG).

Two unifying concepts shape the model methodology. First, the overall level of investment in exploration and development in the United States is dependent upon the expected profitability of upstream investments, the financial resources of the oil and gas industry, and the returns to foreign upstream investments. This treatment of the financial resources of the industry within the model allows the explicit recognition of financial constraints on investment for exploration and development. Second, the disaggregation of activity levels for each fuel by source type and region responds to the level of expected 
profitability of that activity relative to the alternatives. Specifically, the model incorporates the well established economic principle that resources tend to flow to those investments with the highest returns.

The OGSM includes an enhanced methodology for estimating short-term oil and gas supply functions. Short-term is defined as a one year period in the OGSM. This enhancement improves the procedure for equilibrating the natural gas and oil markets by allowing for the determination of regional market clearing prices for each fuel, as opposed to the previous modeling system that only equilibrates markets at a national market clearing price.

Output prices influence oil and gas supplies in distinctly different ways in the OGSM. Quantities supplied as the result of the annual market equilibration in the PMM and NGTDM are determined as a direct result of the observed market price in that period. Longer-term supply responses are related to investments required for subsequent production of oil and gas. Output prices affect the expected profitability of these investment opportunities as determined by use of a discounted cash flow evaluation of representative prospects.

The OGSM, compared to the previous EIA midterm model, incorporates a more complete and representative description of the processes by which oil and gas in the economically recoverable resource base $^{1}$ convert to proved reserves. ${ }^{2}$ The previous model treated reserve additions primarily as a function of undifferentiated exploratory drilling. The relatively small amount of reserve additions from other sources was represented as coming from developmental drilling.

The OGSM distinguishes between drilling for new fields and that for additional deposits within old fields. This enhancement recognizes important differences in exploratory drilling, both by its nature and in its physical and economic returns. New field wildcats convert resources in previously undiscovered fields ${ }^{3}$ into both proved reserves (as new discoveries) and inferred reserves. ${ }^{4}$ Other exploratory drilling and developmental drilling add to proved reserves from the stock of inferred reserves. The phenomenon of reserves appreciation is the process by which initial assessments of proved reserves from a new field discovery grow over.time through extensions and revisions. This improved resource accounting approach is more consistent with recent literature regarding resource recovery. ${ }^{5}$

The breadth of supply processes that are encompassed within OGSM results in methodological differences between the lower 48 methodology and that for Alaska oil and gas production and foreign gas trade. The present OGSM consequently comprises a set of three distinct approaches and corresponding submodules. The label OGSM as used in this report generally refers to the overall framework and the implementation of lower 48 oil and gas supply in both onshore and offshore regions. The Alaska Oil and Gas Supply

\footnotetext{
'Economically recoverable resources are those volumes considered to be of sufficient size and quality for their production to be commercially profitable by current conventional technologies, under specified economic assumptions. Economically recoverable volumes include proved reserves, inferred reserves, as well as undiscovered and other unproved resources. These resources may be recoverable by techniques considered either conventional or unconventional. Economically recoverable resources are a subset of technically recoverable resources, which are those volumes producible with current recovery technology and efficiency but without reference to economic viability.

${ }^{2}$ Proved reserves are the estimated quantities that analysis of geological and engineering data demonstrate with reasonable certainty to be recoverable in future years from known reservoirs under existing economic and operating conditions.

${ }^{3}$ Undiscovered resources are located outside of oil and gas fields in which the presence of resources has been confirmed by exploratory drilling, and thus exclude reserves and reserve extensions; however, they include resources from undiscovered pools within confirmed fields to the extent that such resources occur as unrelated accumulations controlled by distinctly separate structural features or stratigraphic conditions.

${ }^{4}$ Inferred reserves are that part of expected ultimate recovery from known fields in excess of cumulative production plus current reserves.

${ }^{5}$ See, for example, An Assessment of the Natural Gas Resource Base of the United States; R.J. Finley and W.L. Fisher, et al, 1988, and The Potential for Natural Gas in the United States, Volume II, National Petroleum Council, 1992.
} 
Submodule (AOGSS) represents industry supply activity in Alaska. The Foreign Natural Gas Supply Submodule (FNGSS) models trade in natural gas between the United States and other countries. These distinctions are reflected in the presentation of the methodology in this chapter.

The following sections describe OGSM grouped into four conceptually distinct divisions. The first section describes most oil and gas supply in the lower 48 states, including onshore lower 48 conventional oil and gas supply, offshore oil and gas supply, and Unconventional Gas Recovery. ${ }^{6}$ This is followed by the methodology of the Enhanced Oil Recovery Supply Submodule, then the Alaska Oil and Gas Supply Submodule. The chapter concludes with the presentation of the Foreign Natural Gas Supply Submodule. A set of four appendices are included following the chapter. These separate reports provide additional detail on special topics relevant to the methodology. The appendices present extended discussions on the discounted cash flow (DCF) calculation, the determination of unit costs for delivered LNG, the finding rate function, and special variables used in the coefficient estimation to represent uncertainty affecting „drilling investment behavior..

\section{Lower 48 Onshore and Offshore Supply Submodule}

\section{Introduction}

This section describes the structure of the models that comprise the lower 48 onshore (excluding EOR). and the lower 48 offshore submodule of the Oil and Gas Supply Module (OGSM). The general outline of the lower 48 submodule of the OGSM is provided in Figure 4. The overall structure of the submodule can be best described as recursive. The structure implicitly assumes a sequential decision making process. A general description of the submodule's principal features and relationships computations is provided first. This is followed by a detailed discussion of the key mathematical formulas and computations used in the solution algorithm.

The OGSM receives regional oil and gas prices from the PMM and NGTDM, respectively. The PMM calculates the regional oil prices as functions of the world oil price. Using demand functions received from the demand modules, data on transportation costs, and short-run supply functions of gas, the NGTDM determines the equilibrium wellhead price of natural gas for each region. Using these prices in conjunction with data on production profiles, co-product ratios, drilling costs, lease equipment costs, platform costs (for offshore only), operating costs, severance tax rates, ad valorem tax rates, royalty rates, state tax rates, federal tax rates, tax credits, depreciation schedules, and success rates, the discounted cash flow (DCF) algorithm calculates expected DCF values in each period associated with representative wells for each region, well type (exploratory, developmental), and fuel type (oil, shallow gas, deep gas, and unconventional gas). Regional DCF's by well type are constructed each period as a weighted average of the intraregional fuel specific DCF's. National onshore and offshore DCF's by well type are then calculated for each period as a weighted average of the regional DCF's. .

National exploration and development (E\&D) drilling expenditures are determined for each of four categories: onshore exploration, onshore development, offshore exploration, and offshore development. For each category, national E\&D drilling expenditures are calculated as a function of the national DCF's and other significant variables, including industry financial variables (estimated as a function of the world oil price), and two measures of price risk.

\footnotetext{
'Enhanced oil recovery (EOR) supply was not implemented as an endogenous source of produced oil as described in the Component Design Report for EOR. EOR production for the AEO94 was incorporated into the model as an exogenous input to OGSM.
} 
Figure 4. Flowchart for Lower 48 States Ọshore and Offshore Oil and Gas Submodules

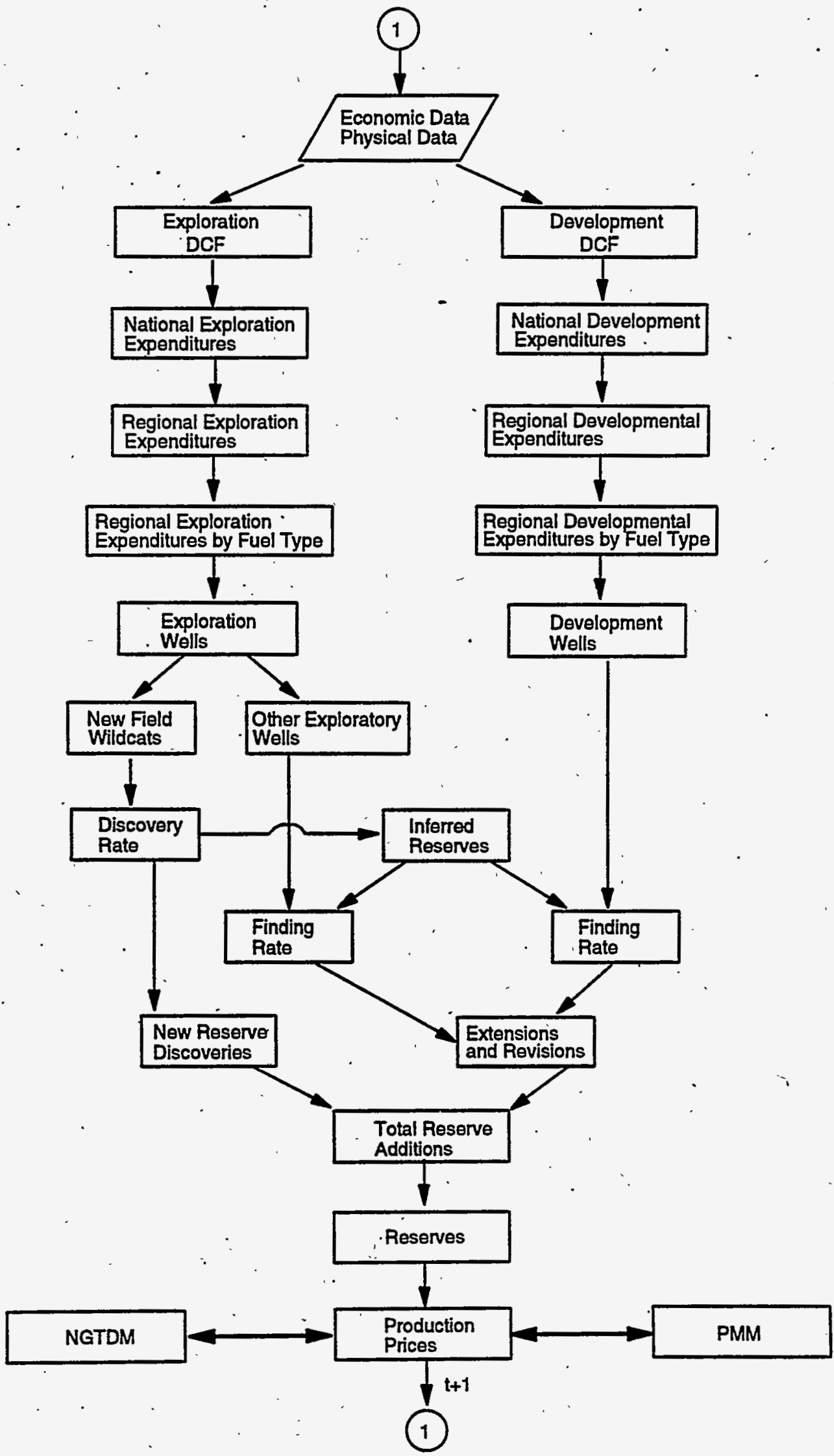


National E\&D drilling expenditures are allocated among and within the regions through a system of regional and intraregional fuel specific expenditure equations. Specifically, E\&D expenditures for a region * are forecasted as a function of the level of national expenditures and the relative profitability of drilling in the region. Relative profitability is measured by the ratio of the region's DCF to the national DCF.

Intraregional E\&D expenditures by fuel type are predicted as functions of regional expenditure levels and the relative profitabilities of the intraregional fuel specific drilling activity.

The intraregional fuel specific E\&D drilling expenditures are divided by regional estimates of average drilling costs to determine the number of wells drilled within each region per period for each well and fuel type. Based on region specific historical patterns, exploration wells are broken down into new field wildcats and other exploratory wells.

The forecasted numbers of new field wildcats, other exploratory wells, and developmental wells are used in a set of finding rate equations to determine additions to oil and gas reserves each period. New field wildcats determine new field discoveries. Based on the historical relationship between the initial quantity of proved reserves discovered in a field and the field's ultimate recovery, reserves from new field discoveries are categorized into additions to proved reserves and inferred reserves. Inferred reserves are converted into proved reserves (extensions and revisions) in later periods by drilling other exploratory wells and development wells:

Reserve additions are added to the end of year reserves for the previous period while the current period's production (determined in the NGTDM and the PMM) is subtracted to yield the end of year reserves for the current period. These reserves along with an estimate of the expected production to reserves ratio for the next period are passed to the NGTDM and the PMM for use in their short run supply functions.

\section{The Expected Discounted Cash Flow Algorithm}

For each year $t$, the algorithm calculates the expected DCF for a representative well of type $i$, in region $\mathrm{r}$, for fuel type $\mathrm{k}$. The calculation assumes only one source of uncertainty--geology. The well can be a success (wet) or a failure (dry). The probability of success is given by the success rate; the probability of failure is given by one minus the success rate. For expediency, the model first calculates the discounted cash flow for a representative project, conditional on a requisite number of successful wells. The conditional project discounted cash flow is then converted into the expected discounted cash flow of a representative well as shown below.

\section{Onshore Lower 48 Development}

A representative onshore developmental project ${ }^{7}$ consists of one successful developmental well along with the associated number of dry holes. The number of dry developmental wells associated with one successful development well is given by [(1/SR) - 1] where SR represents the success rate for a development well in a particular region $r$ and of a specific fuel type. Therefore, (1/SR) represents the total number of wells associated with one successful developmental well. All wells are assumed to be drilled in the current year with production from the successful well assumed to commence in the current year.

\footnotetext{
${ }^{7}$ Equations (1) through (6) in this section and the following one describe the computation of the expected discounted cash flow

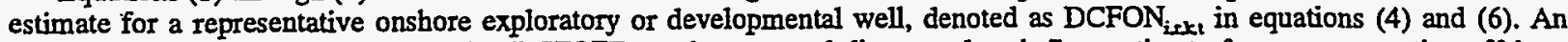

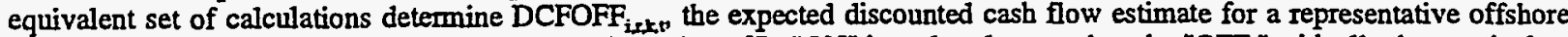
exploratory or developmental well. In these equations, the suffix "ON" is replaced everywhere by "OFF," with all other particulars remaining the same. These alternate equations are not shown to avoid redundancy in the presentation.
} 
For each year of the project's expected lifetime, the net cash flow is calculated as:

$$
\begin{aligned}
& \text { NCFON }_{i, r, k, s}=(\text { REV }- \text { ROY - PRODTAX - DRILLCOST - EQUIPCOST - } \\
&\text { OPCOST - DRYCOST - STATETAX - FEDTAX })_{i, r, k, s} \text { for } i=2, \\
& r=1 \text { thru } 6, k=1 \text { thru } 6, s=t \text { thru } t+L
\end{aligned}
$$

where,

$\begin{aligned} \text { NCFON } & =\text { annual undiscounted net cash flow for a representative onshore development } \\ \text { REV } & =\text { project } \\ \text { ROY } & =\text { royenue from the sale of the primary and co-product fuel } \\ \text { PRODTAX } & =\text { production taxes (severance plus ad valorem) } \\ \text { DRILLCOST } & =\text { the cost of drilling the successful developmental well } \\ \text { EQUIPCOST } & =\text { lease equipment costs } \\ \text { OPCOST } & =\text { operating costs } \\ \text { DRYCOST } & =\text { cost of drilling the dry. developmental wells } \\ \text { STATETAX } & =\text { state income tax liability } \\ \text { FEDTAX } & =\text { federal income tax liability } \\ \mathrm{i} & =\text { well type (1 =xploratory, } 2=\text { development) } \\ \mathbf{r} & =\text { subscript indicating onshore regions (see Figure } 5 \text { for OGSM region codes) } \\ \mathbf{k} & =\text { subscript indicating fuel type } \\ \mathbf{s} & =\text { subscript indicating year of project life } \\ \mathbf{t} & =\text { current year of forecast } \\ \mathrm{L} & =\text { expected project lifetime. }\end{aligned}$

The calculation of REV depends on expected production and prices: Expected production is calculated on the basis of individual wells. Flow from each successful well begins at a level equal to the historical average for production over the first-12 months. Production subsequently declines at a rate equal to the historical average production to reserves ratio. The default price expectation is that real prices will remain constant over the project's expected lifetime. The OGSM also can utilize an expected price vector provided from the NEMS system that reflects a user specified assumption regarding price expectations. The calculations of STATETAX and FEDTAX account for the tax treatment of tangible and intangible drilling expenses, lease equipment expenses, operating expenses, and dry hole expenses. The algorithm also incorporates the impact of unconventional fuel tax credits and has the capability of handling other forms of investment tax credits. For a detailed discuission of the discounted cash flow methodology, the reader is referred to Appendix 4.A at the end of this chapter.

The undiscounted net cash flows for each year of the project, calculated by Equation (1), are discounted and summed to yield the discounted cash flow for the representative onshore developmental project (PROJDCFON). This can be written as:

\footnotetext{
${ }^{8} \mathrm{Abandonment}$ of a project is expected to occur in that year of its life when the expected net revenue is less than expected operating costs. When abandonment does occur, expected abandonment costs are added to the calculation of the project's discounted cash flow.
} 
Figure 5. Lower 48 Oil and Gas Supply Regions with Region Codes

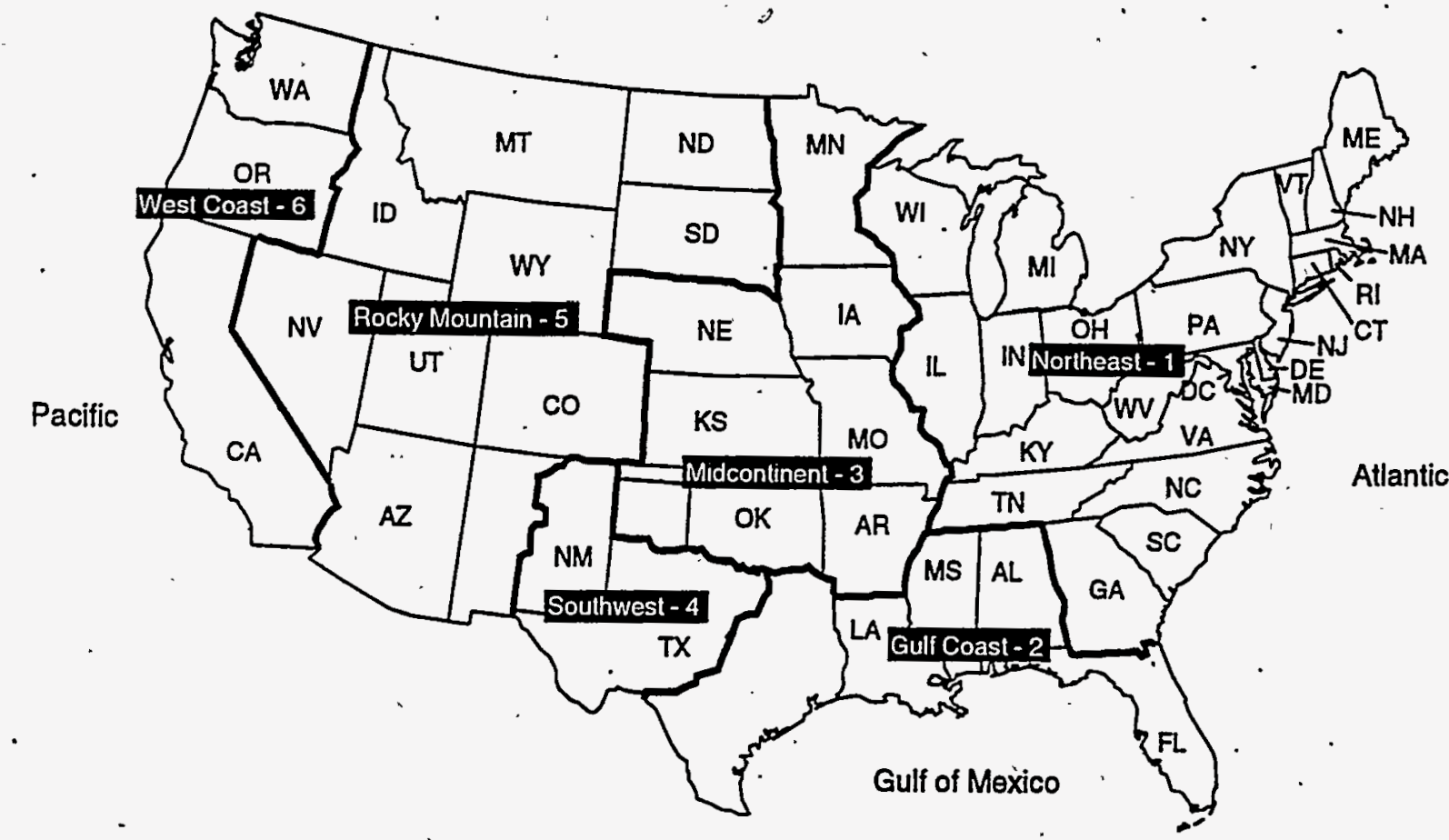

$$
\text { PŔOJDCFON }_{i, r, k, t}=\text { SUCDCFON }_{i, r, k, t}+\left[\left(\frac{1}{\operatorname{SR}_{i, r, k}}\right)-1\right] * \text { DRYDCFON }_{i, r, k, t}
$$

where,

$$
\begin{aligned}
& \text { SUCDCFON = } \text { the discounted cash flow associated with one successful onshore } \\
& \text { developmental well }
\end{aligned}
$$

Since the expected discounted cash flow for a representative onshore developmental well is equal to:

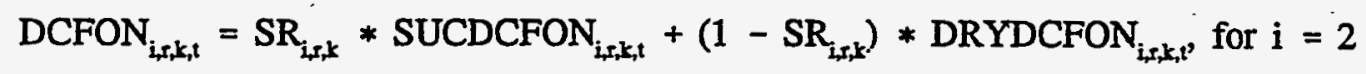

it is easily calculated as:

$$
\text { DCFON }_{i, r, i, i}=\text { PROJDCFON }_{i, r, k, t} * S_{i, r, j} \text {, for } \mathrm{i}=2, \mathrm{r}=1 \text { thru } 6, \mathrm{k}=1 \text { thru } 6
$$

where, - 
DCFON $=$ expected discounted cash flow for a representative onshore developmental well.

\section{Onshore Lower 48 Exploration}

A representative onshore exploration project consists of one successful exploratory well, $\left[\left(1 / \mathrm{SR}_{1, \mathrm{r}, \mathrm{k}}\right)-1\right] \mathrm{dry}$ exploratory wells, $m_{k}$ successful development wells, and $m_{*} *\left[\left(1 / \mathrm{SR}_{2, \mathrm{r}, \mathrm{k}}\right)-1\right]$ dry development wells. All exploratory wells are assumed to be drilled in the current year with production from the successful exploratory well assumed to commence in the current year. The developmental wells are assumed to be drilled in the second year of the project with production from the successful developmental well assumed to begin in the second year.

The calculations of the yearly net cash flows and the discounted cash flow for the exploratory project are identical to those described for the developmental project. The discounted cash flow for the exploratory project can be decomposed as:

$$
\begin{aligned}
& \text { PROJDCFON }_{1, r, k, t}= \text { SUCDCFON }_{1, r, k, t}+m_{1} *\left(\operatorname{SUCDCFON~}_{2, r, k, t}+\left(\left(\frac{1}{\operatorname{SR}_{2, s, k}}\right)-1\right) *\right. \\
&\text { DRYDCFON } \left._{2, r, k, t}\right]+\left(\left(\frac{1}{\operatorname{SR}_{1, r, k}}\right)-1\right) * \text { DRYDCFON }_{1, r, k, t}
\end{aligned}
$$

where,

$$
\mathrm{m}_{\mathbf{k}}=\text { number of successful developmental wells in a representative project. }
$$

The first two terms on the right hand side represent the discounted cash flows associated with the successful exploratory well drilled in the first year of the project and the successful and dry developmental wells drilled in the second year of the project. The third term represents the impact of the dry exploratory wells drilled in the first year of the project.

Again, as in the development case, the expected DCF for a representative onshore exploratory well is calculated by:

$$
\text { DCFON }_{1, r, k, t}=\text { PROJDCFON }_{1, r, k, t, 1} * \mathrm{SR}_{1, s, k}
$$

\section{Offshore Exploration and Development}

The calculations of the expected discounted cash flows for the lower 48 offshore regions (i.e., DCFOFF $F_{i, x, 1,}$ ) are identical to those described for the lower 48 onshore. In addition, the economic assessment of an offshore development well matches that in the onshore. The sole difference relates to the specific characterization of an offshore exploration project, which is reflected in the input data for the offshore.

Specifically, an offshore exploration project consists of: (1) two successful new field wildcat wells drilled in the first year of the project from which there is no production; (2) three, successful other exploratory wells that delineate the new field and begin producing in the second year of the project along with the - requisite number of dry other exploratory wells; (3) eight successful developmental wells that are drilled and begin producing in the third year of the project along with the requisite number of dry developmental 
wells; and (4) one successful developmental well that is drilled and begins producing in each of the next seven years of the project along with the requisite number of dry holes.

\section{Calculation of Regional and National Expected DCF's}

For éach well type i, weighted average expected DCF's for each lower 48 onshore and offshore region are calculated. The weights are equal to the share of total wells of type $i$ drilled in region $r$ of fuel type $\mathrm{k}$ in the previous period. Specifically,

$$
w_{i, r, k, t}=W_{E L L S} S_{i, r, k, t-1} / \sum_{k} W_{k L L} S_{i, r, k, t-1} \text {, for each } i, r, k
$$

where,

$$
\text { WELLS = wells drilled. }
$$

The regional onshore and offshore DCF's for a representative well are derived using the following equations:

$$
\operatorname{RDCFON}_{\mathrm{i}, \mathrm{r}, \mathrm{t}}=\sum_{\mathbf{k}} \mathrm{w}_{\mathrm{i}, \mathrm{r}, \mathrm{k}, \mathrm{t}} * \mathrm{DCFON}_{\mathrm{i}, \mathrm{r}, \mathrm{k}, \mathrm{t}} \text { for } \mathrm{i}=1,2, \mathrm{r}=\text { onshore regions, } \mathrm{k}=1 \text { thru } 6
$$

$$
\operatorname{RDCFOFF}_{\mathrm{i}, \mathrm{r}, \mathrm{t}}=\sum_{\mathbf{k}} \mathrm{w}_{\mathrm{i}, \mathrm{r}, \mathrm{k}, \mathrm{t}} * \mathrm{DCFOFF}_{\mathrm{i}, \mathrm{r}, \mathrm{k},} \text { for } \mathrm{i}=1,2, \mathrm{r}=\text { offshore regions, } \mathrm{k}=1,2
$$

where,

$$
\begin{aligned}
\text { RDCFON } & =\text { onshore regional expected discounted cash flow per well } \\
\text { RDCFOFF } & =\text { offshore regional expected discounted cash flow per well }
\end{aligned}
$$

Similarly, for each well type $i$, the national onshore and offshore DCF's are calculated as weighted averages of the regional DCF's. The weights are equal to the regional shares of total wells of type i drilled nationwide in the previous period. Algebraically, the weights are calculated as:

$$
w_{i, r, t}=W_{E L L S} S_{i, r, t-1} / \sum_{r} W_{E L L S} S_{i, r, t-1} \text {, for each } i, r
$$

The national onshore and offshore expected DCF's for each well type are equal to: 
$\mathrm{NDCFON}_{\mathrm{i}, t}=\sum_{\mathrm{r}} \mathrm{w}_{\mathrm{irr}, \mathrm{t}} * \mathrm{RDCFON}_{\mathrm{i}, \mathrm{r}, \mathrm{t}}$, for $\ddot{\mathrm{i}}=1,2, \mathrm{r}=$ onshore regions

$\mathrm{NDCFOFF}_{\mathrm{i}, \mathrm{t}}=\sum_{\mathrm{r}} \dot{\mathrm{w}}_{\mathrm{i}, \mathrm{r}, \mathrm{t}} * \mathrm{RDCFOFF}_{\mathrm{i}, \mathrm{r}, \mathrm{t}}$, for $\mathrm{i}=1,2, \mathrm{r}=$ offshore regions

where,

NDCFON $=$ national onshore expected discounted cash flow per well
NDCFOFF $=$ national offshore expected discounted cash flow per well.

\section{Industry Financial Variables: Cash Flow and Return on Foreign Production Operations}

Since the level of national spending on E\&D activities is likely to be influence by the industry's level of cash flow, the submodule includes an equation that forecasts industry cash flow per dollar of total assets as a function of the world oil price. The forecasting equation is given by:

$$
\mathrm{CF}_{\mathrm{t}}=\mathrm{e} 0 * \mathrm{WOP}_{\mathrm{t}}^{\mathrm{el}}
$$

where,

$$
\begin{aligned}
\text { CF } & =\text { industry cash flow per dollar of total assets measured at the beginning of the } \\
\text { WOP } & =\text { year } \\
\mathrm{e} 0, \mathrm{e} 1 & =\text { estimated parameters } \\
\mathrm{t} & =\text { year. }
\end{aligned}
$$

As well as industry cash flow, national exploration and development expenditures are dependent on overseas E\&D investment opportunities. To capture this effect, the submodule forecasts industry return on foreign investment using the following equation:

$$
\mathrm{RF}_{\mathrm{t}}=\mathrm{fO} * \mathrm{WOP}_{\mathrm{t}}^{\mathrm{n}}
$$

where,

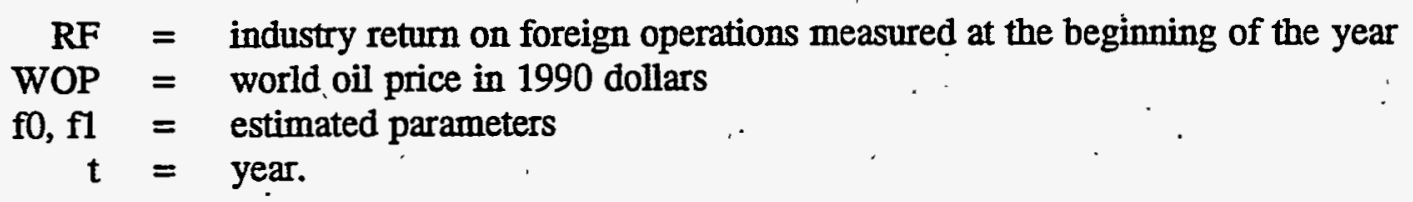

\section{National Exploration and Developmental Drilling Expenditures Determination}


National drilling expenditures for onshore exploration, onshore development, offshore exploration, and offshore development are forecasted as functions of the national DCF's and a dummy variable to capture " the effects of unobserved industry structural change. Additionally:

Onshore exploration expenditures are influenced by. industry cash flow and the return on foreign operations; .

- Onshore development expenditures are a function of industry cash flow; return on foreign operations, and price risk as measured by the skewness in observed oil prices;

- Offshore exploratory expenditures are affected by industry cash flow, price risk as measured by the variance in observed oil prices, and a time trend to capture the secular increase in offshore exploration activity. ${ }^{9} 10$

$$
\begin{aligned}
& \operatorname{NSPENDON}_{\mathrm{i}, \mathrm{t}}=\mathrm{a} 0 * \mathrm{NDCFON}_{\mathrm{i}, \mathrm{t}}^{\mathrm{al}} * \mathrm{CF}_{\mathrm{t}-1}^{\mathrm{a2}} * \mathrm{e}^{23 * \mathrm{DUMM}_{\mathrm{i}}} * \mathrm{RF}_{\mathrm{t}}^{24} \text {, for } \mathrm{i}=1
\end{aligned}
$$

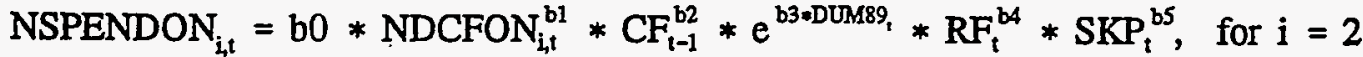

$$
\text { NSPENDOFF }_{i, t}=d 0 * \text { NDCFOFF }_{i, t}^{d 1} * e^{\text {DeDUMBg }_{i}} \text {, for } i=2
$$

where,

$$
\begin{aligned}
& \text { NSPENDON }=\text { national onshore drilling expenditures by well type } \\
& \text { NSPENDOFF }=\begin{array}{l}
\text { national offshore drilling expenditures by well type } \\
\text { CF }
\end{array} \\
& \text { industry cash flow from oil and gas operations per dollar of total assets } \\
& \text { measured at the beginning of the year }
\end{aligned}
$$

\footnotetext{
${ }^{9}$ Discussion of the variance and skewness in observed oil prices appears in Appendix 4.D at the end of the chapter.

${ }^{10}$ The national, regional, and fuel type expenditure forecasting equations shown in this section are specified in their general functional forms. They do not necessarily represent the forms in which the equations were econometrically estimated. For example, for estimation purposes many of the equations were estimated in log-linear form rather than the multiplicative form. Also, in some instances the equations were estimated with corrections for first order serial correlation. The details of the econometric estimations are provided in Appendix $E$ of this report.
} 


$$
\begin{aligned}
\mathrm{d} 0, \mathrm{~d} 1, \mathrm{~d} 2 & =\text { estimated parameters } \\
\dot{\mathbf{i}} & =\text { well type }(1=\text { exploratory, } 2=\text { development }) \\
\mathrm{t} & =\text { year. }
\end{aligned}
$$

\section{National Drilling Expenditure Disaggregation}

National drilling expenditures for each of the four drilling categories are disaggregated first by OGSM region. This is accomplished through a set of regional forecasting equations in which regional drilling expenditures for exploration and development are functions of the relevant national levels of drilling expenditures and a measure of the relative profitability of drilling in a specific region. A region's relative profitability for a drilling category is measured as the ratio of the regional DCF for the category to the national DCF for that category. Specifically,

$$
\begin{aligned}
& \text { RPROFON }_{i, r, i}=\frac{\operatorname{RDCFON}_{i, r, t}}{\operatorname{NDCFON~}_{i, t}} \text {, for } i=1,2, r=\text { onshore regions } \\
& \text { RPROFOFF }_{i, r, t}=\frac{\operatorname{RDCFOFF~}_{i, r, t}}{\operatorname{NDCFOFF}_{i, t}} \text {, for } i=1,2, r=\text { offshore regions }
\end{aligned}
$$

where,

$$
\begin{aligned}
& \text { RPROFON }=\text { regional lower } 48 \text { onshore profitability by well type } \\
& \text { RPROFOFF }=\text { regional lower } 48 \text { offshore profitability by well type } \\
& \text { RDCFON }=\text { regional discounted cash flow for a representative lower } 48 \text { onshore oil \& } \\
& \text { gas prospect by well type } \\
& \text { RDCFOFF }=\text { regional discounted cash flow for a representative lower } 48 \text { offshore oil \& } \\
& \text { gas prospect by well type } \\
& \text { NDCFON = national discounted cash flow for a representative lower } 48 \text { onshore oil \& } \\
& \text { gas prospect by well type } \\
& \text { NDCFOFF = national discounted cash flow for a representative lower } 48 \text { offshore oil \& } \\
& \text {. - gas prospect by -well type } \\
& \mathrm{i}=\text { well type }(1=\text { exploratory, } 2=\text { development }) \\
& r=\text { lower } 48 \text { regions, onshore and offshore } \\
& \mathrm{t}=\text { year. }
\end{aligned}
$$

Regional expenditures are calculated for the onshore and offshore lower 48 regions using the following equations. Generally, regional expenditures are a function of national expenditures and regional relative profitabilities as well as dummy variables to capture unobserved structural shifts.

\section{Lower 48 Onshore Regional Exploratory Equations}

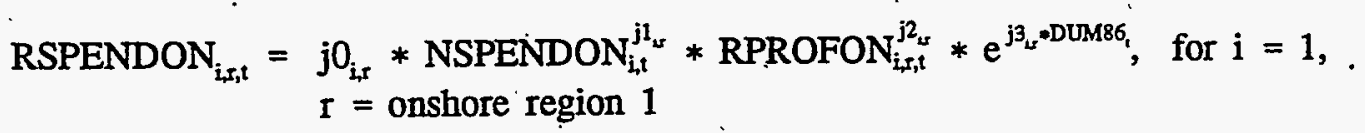




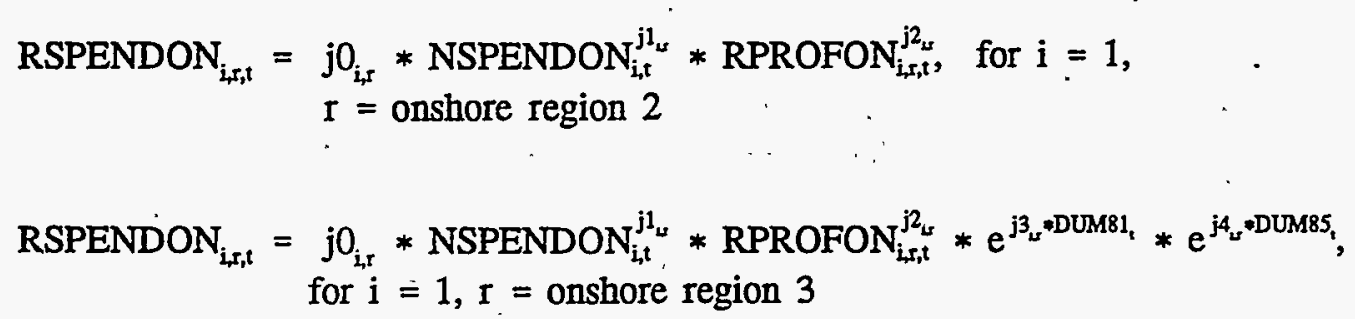

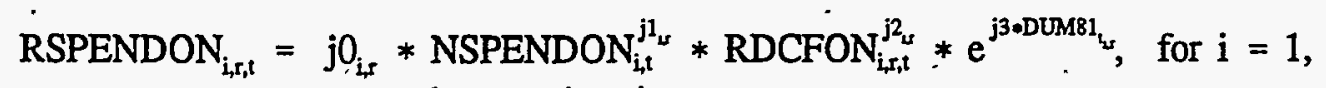

$$
\begin{aligned}
& \mathrm{r}=\text { onshore region } 4 \\
& \text { RSPENDON }_{\mathrm{i}, \mathrm{r}, \mathrm{t}}=\mathrm{j}_{\mathrm{i}, \mathrm{r}} * \text { NSPENDON }_{\mathrm{i}, \mathrm{t}}^{\mathrm{j} 1_{\mathrm{s}}} * \mathrm{RPROFON}_{\mathrm{i}, \mathrm{r}, \mathrm{s}}^{\mathrm{j} \mathrm{R}_{\mathrm{s}}} \text {, for } \mathrm{i}=1 \text {, } \\
& \mathrm{r}=\text { onshore region } 5
\end{aligned}
$$

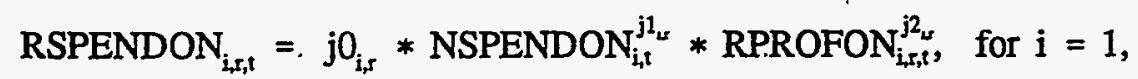

$$
\begin{aligned}
& \mathrm{r}=\text { onshore region } 6
\end{aligned}
$$

\section{Lower 48 Onshore Regional Development Equations}

$$
\operatorname{RSPENDON}_{i, t, t}=\underset{r=\text { onshore regions } 1,2,3,4,5}{j 0_{i, r}} * \operatorname{NSPENDON}_{i, t}^{j 1_{1}} * \operatorname{RDCFON}_{i, r, t}^{j j_{2}} * \operatorname{NDCFON}_{i, t}^{j 3_{s}} \text {, for } i=2,
$$

\section{Offshore Regional Explorațory Equations}

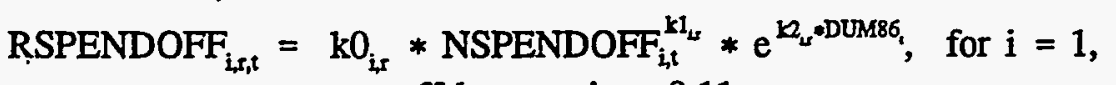

$$
\begin{aligned}
& \mathrm{I}=\text { offshore regions } 8,11
\end{aligned}
$$

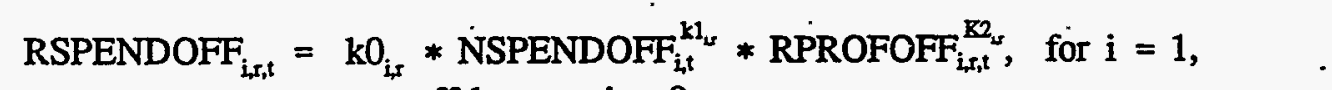

$$
\begin{aligned}
& I=\text { offshore region } 9
\end{aligned}
$$

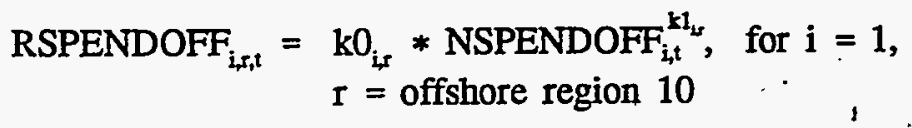

\section{Offshore Regional Development Equations}




$$
\begin{aligned}
\operatorname{RSPENDOFF}_{\mathrm{i}, \mathrm{rt}}= & \mathrm{LO}_{\mathrm{i}, \mathrm{r}} * \text { NSPENDOFF } \\
& \mathrm{r}=\text { offshore region } 8,10
\end{aligned}
$$

$$
\begin{aligned}
& \operatorname{RSPENDOFF}_{\mathrm{i}, \mathrm{r}, \mathrm{t}}=\mathrm{LO}_{\mathrm{i}, \mathrm{r}} * \mathrm{NSPENDOFF}_{\mathrm{i}, \mathrm{t}}^{\mathrm{L} 1_{\mathrm{s}}} * \mathrm{e}^{\mathrm{L2_{w }} * D U M B 6_{t}}, \text { for } \mathrm{i}=2 \text {, } \\
& \mathrm{I}=\text { offshore region } 9 \text {. }
\end{aligned}
$$

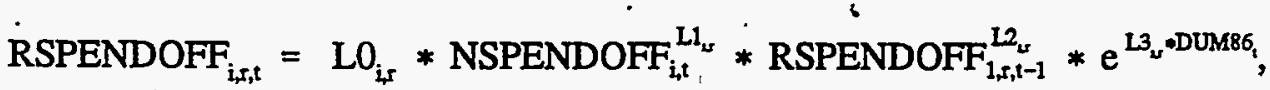

$$
\begin{aligned}
& \text { for } i=2, r=\text { offshore region } 11
\end{aligned}
$$

where,

$\begin{aligned} \text { RSPENDON } & =\text { regional lower } 48 \text { onshore drilling expenditures by well type } \\ \text { RSPENDOFF } & =\text { regional lower } 48 \text { offshore drilling expenditures by well type } \\ \text { NSPENDON } & =\text { national onshore drilling expenditures by well type } \\ \text { NSPENDOFF } & =\text { national offshore drilling expenditures by well type } \\ \text { RPROFON } & =\text { regional lower } 48 \text { onshore profitability by well type } \\ \text { RPROFOFF } & =\text { regional lower } 48 \text { offshore profitability by well type } \\ \text { RDCFON } & =\text { regional lower } 48 \text { onshore DCF by well type } \\ \text { DUM81 } & =\text { dummy variable equal to } 1 \text { after } 1981 \\ \text { DUM85. } & =\text { dummy variable equal to } 1 \text { after } 1985 \\ \text { DUM86 } & =\text { dummy variable equal to } 1 \text { after } 1986 \\ \text { j0, j1, j2 } & =\text { estimated parameters } \\ \mathrm{k} 0, \mathrm{k} 1, \mathbf{k} 2 & =\text { estimated parameters } \\ \mathrm{L} 0, \mathrm{~L} 1, \mathrm{~L} 2 & =\text { estimated parameters } \\ \mathbf{i} & =\text { well type }(1=\text { exploratory, } 2=\text { development) } \\ \mathbf{r} & =\text { lower } 48 \text { regions, onshore and offshore } \\ \mathrm{t} & =\text { year. }\end{aligned}$

The lower 48 onshore development expenditures for region 6 are calculated as national onshore development expenditures minus the sum of development expenditures for the other five onshore regions. If expenditures are less than actual expenditures in 1989 then the forecasted level of expenditures for region 6 is set equal to the 1989 value adjusted by the level of national expenditures. To preserve consistency between the regional and national forecast the expenditure levels for the other regions computed above are then normalized.

In addition, exploration expenditures for the deep Gulf are allocated entirely to oil. Exploration and development expenditures for offshore regions 7 and 12 (Atlantic and Eastern Gulf of Mexico) are user defined and set to zero for base runs, reflecting the influence of access restrictions and substantial geologic uncertainty.

Regional exploration and development drilling expenditures are disaggregated by fuel type using a set of intra-regional forecasting equations similar in form to the regional expenditure forecasting equations. In particular, drilling expenditures by fuel type in each well type in a given region are forecasted as a function of the relevant regional expenditure level and a measure of the relative profitability of drilling for the particular fuel type in the region. The measures of profitability are given by: 
PROFON $_{i, r, k, t}=\frac{\text { DCFON }_{i, r, k, i}}{\operatorname{RDCFON~}_{i, r, t}}$, for $i=1,2, r=$ onshore regions, $k=1$ thru 6

PROFOFF $_{i, r, k, t}=\frac{\text { DCFOFF }_{i, r, k, t}}{\text { RDCFOFF }_{i, r, t}}$, for $i=1,2, r=$ offshore regions, $k=1,2$

where,

PROFON $=$ lower 48 onshore profitability by fuel type, region, and well type

PROFOFF $=$ lower 48 offshore profitability. by fuel type, region and well type.

Regional drilling expenditures by fuel type are forecasted using the equations shown below. Expenditures. for the indicated "residual" fuel types are calculated by taking total regional expenditures (by well type) and subtracting the sum of the expenditures across all other fuel types in the region. However, if this figure is less than actual expenditures in 1989, then forecasted expenditures for the categories are set equal to their 1989 level weighted by the level of regional expenditures. To preserve consistency between the regional and category projections, the expenditure levels for each category generated by following equations are then normalized.

\section{Lower 48 Onshore Exploration Expenditures by Region and Fuel Type}

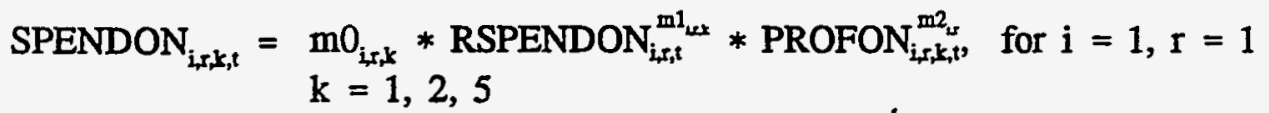

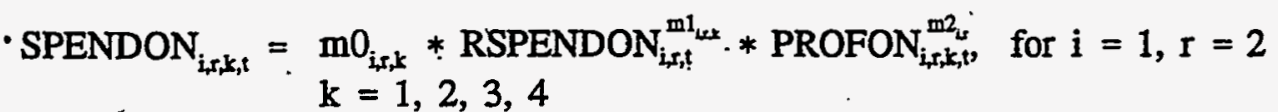

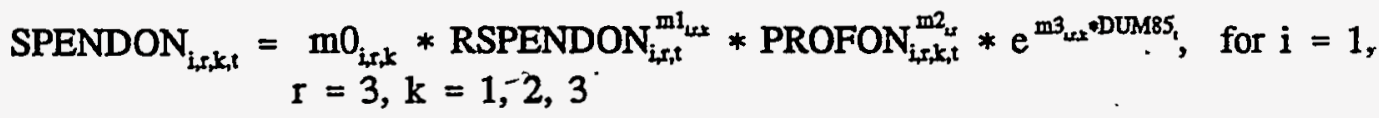

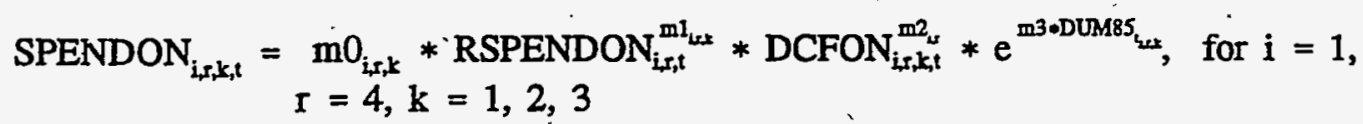

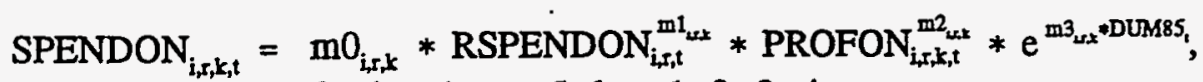

$$
\begin{aligned}
& \text { for } i=1, r=5, k=1,2,3,4
\end{aligned}
$$

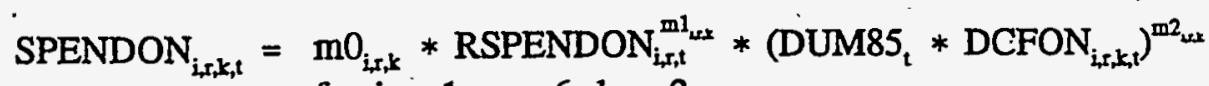

$$
\begin{aligned}
& \text { for } i=1, r=6, k=2
\end{aligned}
$$

\section{Lower 48 Onshore Development Expenditures by Region and Fuel Type}




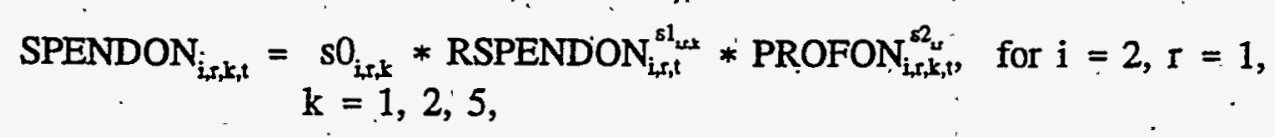

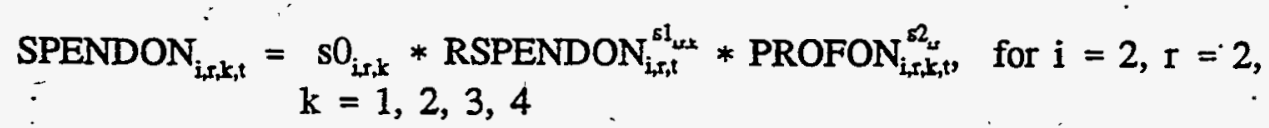

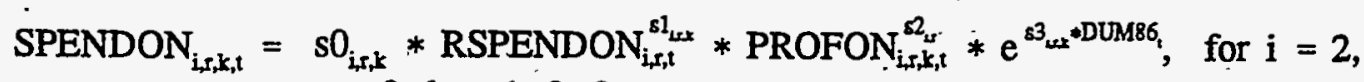

$$
\begin{aligned}
& r=3, k=1,2,3
\end{aligned}
$$

$$
\begin{aligned}
& \text { SPENDON }{ }_{i, r, k, t}=s 0_{i, r, k} * \text { RSPENDON }{ }_{i, r, t}^{8 i_{u x}} * \text { PROFON }_{i, r, k, t}^{s 2_{s, t}} \\
& \text { for } \mathrm{i}=2, \mathrm{r}=3, \mathrm{k}=1,2,3 \\
& \text { for } \mathrm{i}=2, \mathrm{r}=5, \mathrm{k}=1,2,3,4 \\
& \text { for } i=2, r=6, k=1
\end{aligned}
$$

Offshore Exploration Expenditures by Region and Fuel Type

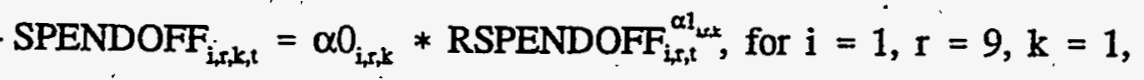

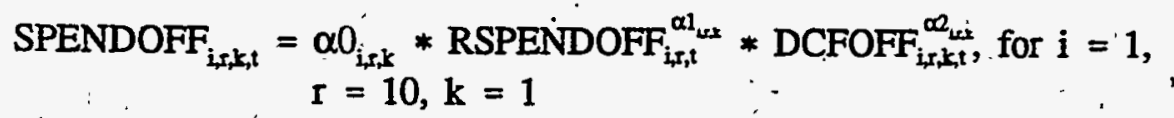

\section{Offshore Development Expenditures by Region and Fuel Type}

$$
\begin{aligned}
& \operatorname{SPENDOFF}_{i, r, \mathrm{r}, \mathrm{t}}=\alpha 0_{\mathrm{i}, \mathrm{r}, \mathrm{k}} * \mathrm{RSPENDOFF}_{\mathrm{irr,t}}^{\alpha 1_{\text {Lex }}}, \text { for } \mathrm{i}=2, \mathrm{r}=8, \mathrm{k}=1
\end{aligned}
$$

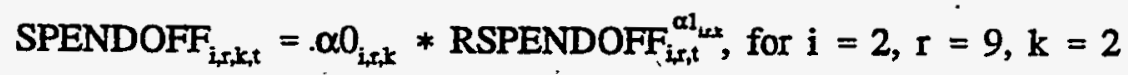

$$
\begin{aligned}
& \text { SPENDOFF }_{i, r, k, t}=\alpha 0_{i, s, k} * \operatorname{RSPENDOFF}_{i, r, t}^{\alpha a_{k x}}, \text { for } i=2, r=10, k=1
\end{aligned}
$$

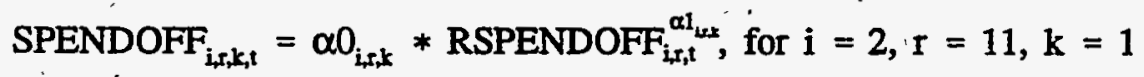

where,

$\begin{aligned} \text { SPENDON } & =\text { lower } 48 \text { onshore drilling expenditures by fuel type, region and well type } \\ \text { SPENDOFF } & =\text { lower } 48 \text { offshore drilling expenditures by fuel type, region and well type } \\ \text { RSPENDON } & =\text { regional lower } 48 \text { onshore drilling expenditures by well type } \\ \text { RSPENDOFF } & =\text { regional lower } 48 \text { offshore drilling expenditures by well type } \\ \text { PROFON } & =\text { lower } 48 \text { onshore profitability by fuel type, region, and well type } \\ \text { PROFOFF } & =\text { lower } 48 \text { offshore profitability by fuel type, region, and well type } \\ \text { DCFON } & =\text { expected DCF for a representative onshore well } \\ \text { DCFOFF } & =\text { expected DCF for a representative offshore well } \\ \text { DUM85 } & =\text { dummy variable equal to } 1 \text { after } 1985\end{aligned}$




$\begin{aligned} \text { DUM86 } & =\text { dummy variable equal to } 1 \text { after } 1986 \\ \mathrm{~m} 0, \mathrm{~m} 1, \mathrm{~m} 2, \mathrm{~m} 3 & =\text { estimated parameters } \\ \mathrm{s} 0, \mathrm{~s} 1, \mathrm{~s} 2, \mathrm{~s} 3 & =\text { estimated parameters } \\ \alpha 0, \alpha 1, \alpha 2 & =\text { estimated parameters } \\ \mathrm{i} & =\text { well type, } 1 \text { for exploratory, } 2 \text { for development } \\ \mathrm{r} & =\text { lower } 48 \text { regions, onshore and offshore } \\ \mathrm{k} & =\text { fuel type }(1=\text { oil, } 2=\text { shallow gas, } 3=\text { deep gas, } 4=\text { tight sands gas, } 5= \\ \mathrm{t} & =\text { Devonian shale gas, } 6=\text { coalbed methane) }\end{aligned}$

\section{Wells Determination}

The number of wells drilled in each region by class and fuel type is forecasted by dividing the relevant regional drilling expenditures by the corresponding drilling cost per well. Specifically,

$$
\begin{aligned}
\text { WELLSON }_{i, r, k, t}= & \frac{\operatorname{SPENDON}_{i, r, k, t}}{\operatorname{COST}_{i, r, k, t}} \text {, for } i=1,2, r=\text { onshore regions, } k=1 \text { thru } .6 \\
\text { WELLSOFF }_{i, r, k, t}= & \frac{\operatorname{SPENDOFF}_{i, r, k, t}}{\operatorname{COST}_{i, r, k, t}}, \text { for } i=1,2, r=\text { offshore regions, } k=1,2
\end{aligned}
$$

where,

$$
\begin{aligned}
& \text { WELLSON }=\text { onshore lower } 48 \text { wells drilled by fuel type, region, and well type } \\
& \text { WELLSOFF = offshore lower } 48 \text { wells drilled by fuel type, region, and well type } \\
& \text { SPENDON }=\text { onshore lower } 48 \text { drilling expenditures by fuel type, region and well type } \\
& \text { SPENDOFF }=\text { offshore lower } 48 \text { drilling expenditures by fuel type, region and well type } \\
& \text { COST. = expected drilling cost per well, the sum of successful and dry well drilling } \\
& \text { costs weighted respectively by the success rate and the failure rate } \\
& \mathrm{i}=\text { well type }(1=\text { exploratory, } 2=\text { development }) \\
& \mathrm{r}=\text { lower } 48 \text { regions, onshore and offshore } \\
& \mathrm{k}=\text { fuel type }(1=\text { oil, } 2=\text { shallow gas, } 3=\text { deep gas, } 4=\text { tight sands gas, } 5= \\
& \text { Devonian shale gas, } 6=\text { coalbed methane) } \\
& \mathrm{t}=\text { year. }
\end{aligned}
$$

The number of successful wells in each category is determined by multiplying the total wells drilled in the category by the corresponding success rates. Specifically,

$$
\begin{aligned}
& \text { SUCWELSON }_{\mathrm{i}, \mathrm{r}, \mathrm{k}, \mathrm{t}}=\text { WELLSON }_{\mathrm{i}, \mathrm{r}, \mathrm{k}, \mathrm{l}} * \mathrm{SR}_{\mathrm{i}, \mathrm{s}, \mathrm{s}} \text {, for } \mathrm{i}^{\prime}=1,2, \mathrm{r}=\text { onshore regions, } \\
& \mathrm{k}=1 \text { thru } 6 \\
& \text { SUCWELSOFF }_{\mathrm{i}, \mathbf{s}, \mathrm{t}}=\text { WELLSOFF }_{\mathrm{i}, \mathrm{k}, \mathrm{k}, \mathrm{t}} * \mathrm{SR}_{\mathrm{i}, \mathrm{r}, \mathrm{r}} ; \text { for } \mathrm{i}=1,2, \mathrm{r}=\text { offshore regions, } \mathrm{k}=1,2
\end{aligned}
$$

where, 


$\begin{aligned} \text { SUCWELSON } & =\text { successful onshore lower } 48 \text { wells drilled } \\ \text { SUCWELSOFF } & =\text { successful offshore lower } 48 \text { wells drilled } \\ \text { WELLSON } & =\text { onshore lower } 48 \text { wells drilled } \\ \text { WELLSOFF } & =\text { offshore lower } 48 \text { wells drilled } \\ \text { SR } & =\text { drilling success rate } \\ \mathrm{i} & =\text { well type }(1=\text { exploratory, } 2=\text { development }) \\ \mathrm{I} & =\text { lower } 48 \text { regions, onshore and offshore } \\ \mathrm{k} & =\text { fuel type }(1=\text { oil, } 2=\text { shallow gas, } 3=\text { deep gas, } 4=\text { tight sands gas, } 5= \\ \mathrm{t} & =\text { Devonian shale gas, } 6=\text { coalbed methane) }\end{aligned}$

Dry wells by class, region, and fuel type are calculated by:

$$
\begin{gathered}
\text { DRYWELON }_{i, r, k, t}=\text { WELISON }_{i, r, k, t}-\text { SUCWELSON }_{i, r, r, t}, \text { for } i=1,2, \\
r=\text { onshore regions, } k=1 \text { thru } 6
\end{gathered}
$$

$$
\begin{gathered}
\text { DRYWELOFF }_{i, r, k, t}=\text { WELLSOFF }_{i, r, t, t}-\text { SUCWELSOFF }_{i, r, k, t} \text { for } i=1,2, \\
r=\text { offshore regions, } k=1,2
\end{gathered}
$$

where,

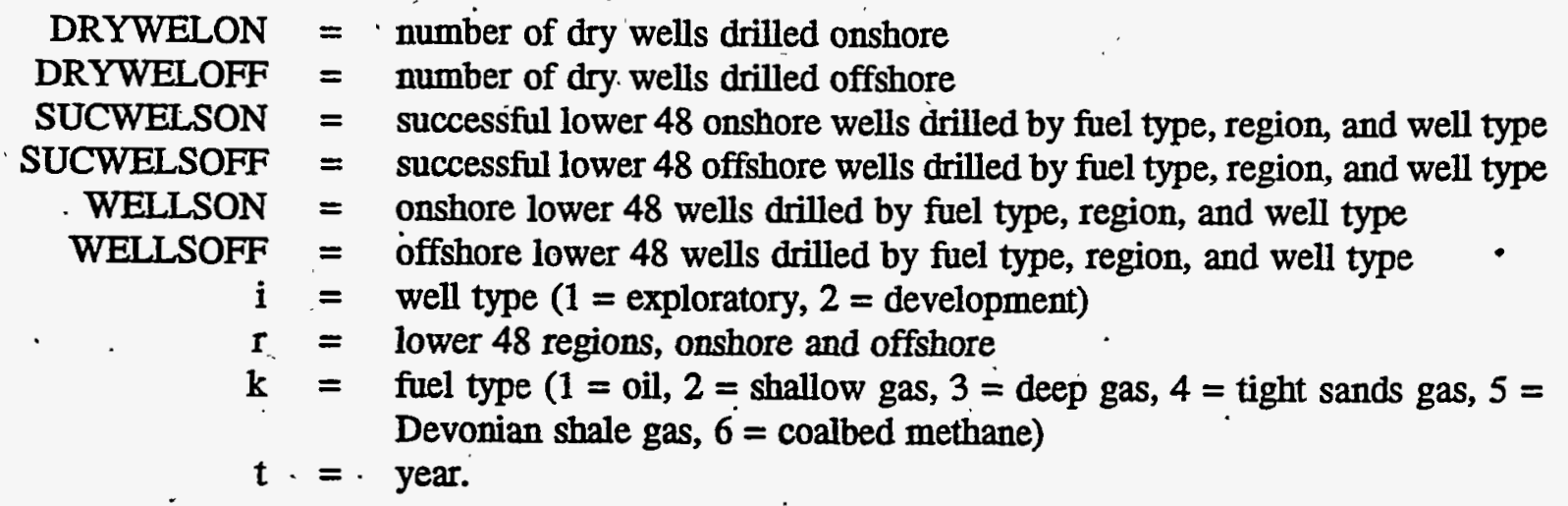

\section{Drilling, Lease Equipment, and Operating Cost Calculations}

The cost of complying with environmental regulations is accounted for in OGSM through adjustments to the drilling costs and operating costs. These adjustments are based on work done by Energy and Environmental Analysis, Inc. (EEA) in support of the National Petroleum Council (NPC) study "The Potential for Natural Gas Supply in the United States." EEA developed factors that could be applied to drilling and operating cost estimates to account for the additional costs of complying with impending environmental regulations. The factors are expressed as proportional adjustments to estimates of drilling costs and operating costs. These factors were developed by depth class and region, with the regions being those of the EEA's Hydrocarbon Supply Model (HSM).

These environmental compliance adjustment factors were incorporated into OGSM through a weighting scheme. Each state within an OGSM region was assigned the compliance factor of the HSM region in which the state is located. American Petroleum Institute (API) well data were used to weight each state level factor by that state's share of drilling within the OGSM region. 
The implementation in OGSM of the environmental cost adjustment factors occurs incrementally over the period 1992 to 1996. During each of these five years an equal share of the total proportional adjustment is introduced. After reaching their full magnitudes in 1996, the factors remain at those levels throughout the remainder of the forecast period.

The environmental cost adjustment factor for drilling costs is determined as specified below:

$$
\text { ECCDRL48 } 8_{r, k, t}=\left\{\begin{array}{l}
0 ; \text { if } \mathrm{t}<1992 \\
\text { ECCDRLA8 } 8_{r, k, t} *(t-1992+1) / 5 ; \text { if } 1992 \leq t \leq 1996 \\
\text { ECCDRLA8 } 8_{r, k, t} ; \text { if } t>1996
\end{array}\right\}
$$

where,

$$
\cdot \overline{\text { ECCDRLA8 }}=\begin{aligned}
& \text { incremental cost of environmental compliance measured as a fraction of } \\
& \text { drilling costs. }
\end{aligned}
$$

The environmental cost adjustment factor for operating costs is determined as shown below:

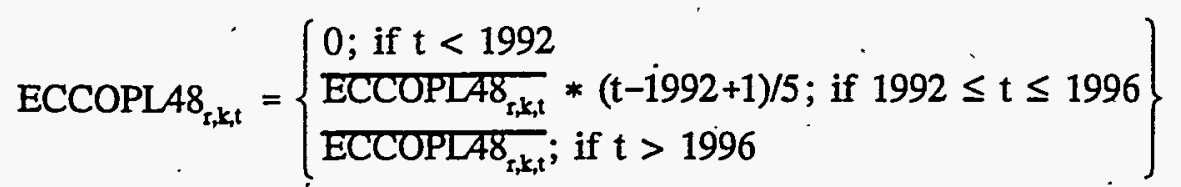

where,

$$
\overline{\text { ECCOPL48 }}=\begin{aligned}
& \text { incremental cost of environmental compliance measured as a fraction of } \\
& \text { operating costs. }
\end{aligned}
$$

In each period of the forecast, the drilling cost per successful well is determined by:

$$
\begin{aligned}
\operatorname{DRILLCOST}_{s, k, t}= & \mathrm{e}^{\ln (\delta 0)_{\mathrm{kx}}} * \text { WELLSON }_{\mathrm{t}-1}^{\delta 1_{\mathrm{k}}} * \mathrm{e}^{\delta 3_{\mathrm{k}} * \operatorname{TMM}} *\left(1+\operatorname{ECCDRLA8}_{\mathrm{r}, \mathrm{k}, \mathrm{t}}\right) \\
& \text { for } \mathrm{r}=2 \text { thru } 5, \mathrm{k}=1,2,3 \\
& \text { for } \mathrm{r}=1,6, \mathrm{k}=1,2
\end{aligned}
$$

where,

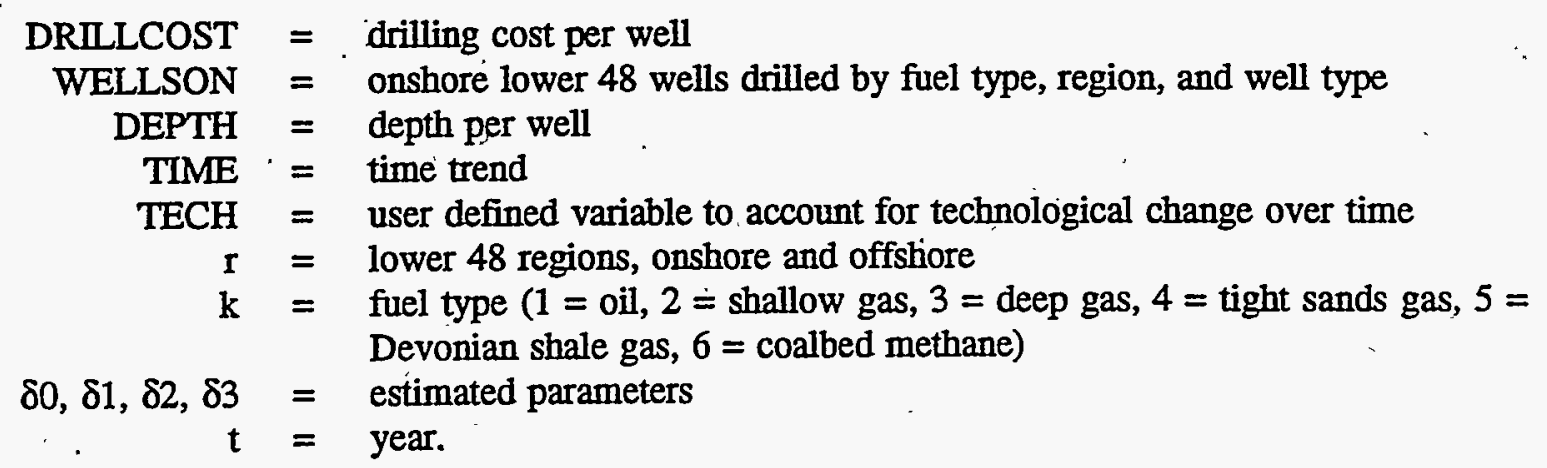

The effects of technological change also are reflected in adjustments to the resource base, as shown in equations in the section below that discusses the finding rates. 
In each period of the forecast, the drilling cost per dry well is determined by:

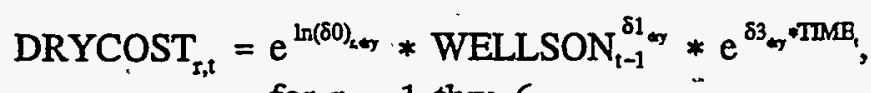

$$
\begin{aligned}
& \text { for } \cdot r-=1 \text { thru } 6
\end{aligned}
$$

where,

DRYCOŚT $=$ drilling cost per dry well.

\section{Lease equipment costs}

In each period of the forecast, lease equipment costs per successful well are determined by:

$$
\begin{aligned}
\text { LEQC }_{x, k, t}= & \mathrm{e}^{\ln (\varepsilon 0)_{r x}} * \operatorname{SUCWELL}_{1-1}^{\varepsilon 1_{x}} * \mathrm{e}^{\varepsilon_{x} * \operatorname{TMM}} \\
& \text { for } \mathrm{r}=2 \text { through } 5 ; \mathrm{k}=1,2,3 \\
& \text { for } \mathrm{r}=1,6 ; \mathrm{k}=1,2
\end{aligned}
$$

where,

$$
\begin{aligned}
\text { EQUIPCOST } & =\text { oil and gas well lease equipment costs } \\
\text { SUCWELL } & =\text { total lower } 48 \text { successful onshore wells } \\
\text { DUM } & =\text { regional dummy variable } \\
\text { TIME } & =\text { time trend - proxy for technology } \\
\varepsilon 0, \varepsilon 1, \varepsilon 2 & =\text { estimated parameters } \\
\mathbf{I} & =\text { OGSM region } \\
\mathbf{k} & =\text { fuel type, } 1=0 \mathrm{il}, 2=\text { gas } \\
\mathrm{t} & =\text { year. }
\end{aligned}
$$

\section{Operating Costs}

In each period of the forecast, operating costs per successful well are determined by:

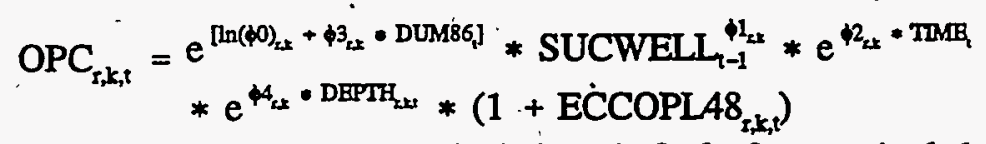

$$
\begin{aligned}
& \text { for } r=2 \text { through } 5, k=1,2,3 \text {; for } r=1,6, k=1,2
\end{aligned}
$$

where,

$$
\begin{aligned}
\text { OPCOST } & =\text { oil and gas well operating costs } \\
\text { SUCWELL } & =\text { total lower } 48 \text { successful onshore wells } \\
\text { DUM86 } & =\text { regional dummy variable } \\
\text { DEPTH } & =\text { average well depth } \\
\text { TIME } & =\text { time trend - proxy for technology } \\
\phi 0, \phi 1, \phi 2, \phi 3, \phi 4 & =\text { estimated parameters } \\
r & =\text { OGSM region } \\
\mathbf{k} & =\text { fuel type, } 1=0 \text { oil, } 2=\text { gas, } 3=\text { deep gas } \\
\mathrm{t} & =\text {-year. }
\end{aligned}
$$




\section{Reserve Additions}

The Reserve Additions algorithm calculates units of oil and gas added to the stocks proved and inferred reserves. ${ }^{\text {"l }}$ Reserve additions are calculated through a set of equations accounting for new field - discoveries, discoveries in known fields, and incremental increases in volumetric recovery that arise during the development phase. There is a 'finding rate' equation for each phase in each region and for each fuel type.

Discoveries of previously unknown fields per period are modeled as a function of the number of new field wildcats drilled per period. Each newly discovered field not only adds proved reserves but also a much larger amount of inferred reserves. Proved reserves are reserves that can be certified using the original discovery wells, while inferred reserves are those hydrocarbons that require additional drilling before they are termed proved. Additional drilling takes the form of other exploratory drilling and development drilling. Within the model, other exploratory drilling accounts for proved reserves added through new pools or extensions, and development drilling accounts for reserves added through revisions.

The volumetric yield from a successful new field wildcat well is divided into proved reserves and inferred reserves. The proportions of reserves allocated to these categories are based on historical reserves growth statistics. Specifically, the allocation of reserves between proved and inferred reserves is based on the ratio of the initial reserves estimated for a newly discovered field relative to ultimate recovery from the field. ${ }^{12}$

\section{Functional Forms}

Oil or gas reserve additions from new field wildcats are a function of the cumulative number of successful new field wildcats drilled, the initial estimate of economically recoverable resources for the fuel, and the rate of technological change..$^{13}$

Total successful exploratory wells are disaggregated into successful new field wildcats and other exploratory wells based on a historical ratio. For the rest of the chapter, successful new field wildcats will be designated by the variable SW1, other successful exploratory: wells by SW2, and successful development wells by SW3.

The major inputs to the new field reserve addition equation are new field wildcats drilled and the resource base.

This approach relies on the finding rate equation:

$$
F R 1_{r, k, t}=F R 1_{s, x, t-1} * \exp \left(-\delta 1_{x, k, t} * S W 1_{x, k, t}\right)
$$

where,

FR1 = new field wildcats finding rate

SW1 = successful new field wildcats

\footnotetext{
"An important advantage inherent in OGSM's design is its modularity. The present finding rate specification of OGSM was developed to meet the analytical requirements and schedule for NEMS. Modifications will be made to the present discovery process methodology and resource accounting in the future.

${ }^{12} \mathrm{~A}$ more complete discussion of the topic of reserve growth for producing fields can be found in Chapter 3 of The Domestic Oil and Gas Recoverable Resource Base: Supporting Analysis for the National Energy Strategy.

${ }^{13} \mathrm{~A}$ more complete discussion of the finding rate equations and the enhancement to include technological change is available in Appendix 4-C of this report.
} 


$$
\begin{aligned}
\delta 1 & =\text { finding rate decline parameter } \\
\mathrm{r} & =\text { region } \\
\mathrm{k} & =\text { fuel type (oil or gas) } \\
\mathrm{t} & =\text { year. }
\end{aligned}
$$

The yield from new field wildcat drilling begins at the initial finding rate, FR1, and declines exponentially thereafter, for a given specification of the initial finding rate, FR1, and the decline parameter, $\delta 1{ }^{14}$ The decline parameter, however, is conditional on the remaining economically recoverable resource estimate which varies in each period because of technological change. Technological change expands the economically recoverable resource volume beyond the initial estimate. The expansion of recoverable resources affects the finding rate decline parameter, $\delta 1$. It reflects the assumptions that technological change occurs over time and its effect is partly realized in the expansion of the recoverable resource estimate, thus enhancing drilling productivity in successive periods by lessening the decline rate affecting the finding rate; the effects of technological change are also reflected in costs, as shown in Equation (42). The growing recoverable volume necessitates'recomputing $\delta 1$ in each period as shown in the following equation:

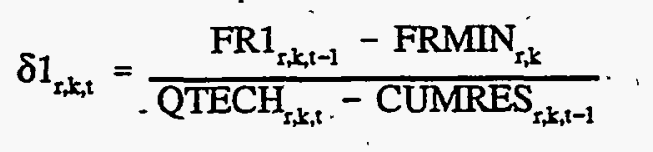

where,

$$
\begin{aligned}
\text { FR1 } & =\text { new field wildcats finding rate } \\
\text { FRMIN } & =\text { minimum economic finding rate } \\
\text { QTECH } & =\text { undiscovered economically recoverable resource estimate adjusted for } \\
\text { CUMRES } & =\begin{array}{l}
\text { expansion due to technological change } \\
\text { cumulative proved and inferred reserve discoveries over the projection period } \\
\text { (initial value }=0)
\end{array} \\
& =\text { forecast year. }
\end{aligned}
$$

In the numerator, the minimum economic finding rate is set as a percentage of the initial finding rate. The percentage is constant over the forecast, but varies among fuels and regions. The denominator represents the remaining economically recoverable resource estimate in undiscovered fields, so the cumulative reserves found over time must be deducted. $\delta 1$ is constrained not to fall below 0 .

The above equations provide a rate at which undiscovered resources convert into proved and inferred reserves as a function of the number of new field wildcats drilled. Given an estimate for the ratio of ultimate recovery from a field relative to the initial proved reserve estimate, $X_{x, k}$, the $X_{r, k}$ reserve growth factor is used to separate newly discovered resources into either proved or inferred reserves. Specifically, the change in proved reserves from new field discoveries for each period is given by integrating the finding rate with respect to wells drilled each period.

where,

$$
\begin{aligned}
X & =\text { reserves growth factor } \\
\Delta R & =\text { additions to proved reserves. }
\end{aligned}
$$

\footnotetext{
${ }^{14}$ An exponentially declining finding rate is a feature common to a number of traditional discovery process models, none of which were'employed primarily because of the extensive data requirements involved. One might note, however that since the determination of expenditures and the allocation of drilling effort within each period is done independently of the determination of physical returns to drilling, a traditional discovery-process model could be modulary substituted at some future date.
} 


$$
\begin{aligned}
& \Delta R_{r, 1, t}=\frac{1}{X_{r, k}} \int_{0}^{s W 1_{r, w i}} F R 1_{s, k, t} d(S W 1) \\
& \frac{1}{X_{r, k}} \int_{0}^{S W 1_{1, t s}} F R 1_{r, k, t-1} * \exp \left(-\delta 1_{x, k, t} * S W 1_{r, k, t}\right) d(S W 1)
\end{aligned}
$$

The terms in equation (55) are all constants in period $t$, except for the SW1. $X$ is derived from historical data and it is assumed to be constant during the forecast period. $F R 1_{r, k, t-1}$ and $\delta 1_{r, k, t}$ are calculated, prior to period $t$, based on lagged variables and fixed parameters as shown in equations (53) and (54).

Reserves move from the realm of inferred to proved with the drilling of other exploratory wells or developmental wells in much the same way as proved and inferred reserves are modeled as moving from the resource base as described above. The volumetric return to other exploratory wells and developmental wells is shown in the following equations:

$$
\mathrm{FR} 2_{\mathrm{r}, \mathrm{k}, \mathrm{t}}=\mathrm{FR} 2_{\mathrm{r}, \mathrm{k}, \mathrm{t}-\mathrm{I}} * \exp \left(-\delta 2_{\mathrm{r}, \mathrm{k}, \mathrm{t}} * \mathrm{SW} 2_{\mathrm{r}, \mathrm{r}, \mathrm{t}}\right)
$$

where,

$$
\begin{aligned}
\begin{aligned}
\mathrm{FR} 2 & =\text { other exploratory wells finding rate } \\
\mathrm{SW} 2 & =\text { successful other exploratory wells. }
\end{aligned} \\
\mathrm{FR}_{\mathrm{r}, \mathrm{k}, \mathrm{t}}=\mathrm{FR} 3_{\mathrm{r}, \mathrm{k}, \mathrm{t}-1} * \exp \left(-\delta 3_{\mathrm{r}, \mathrm{k}, \mathrm{t}} * \mathrm{SW} 3_{\mathrm{r}, \mathrm{t}, \mathrm{t}}\right)
\end{aligned}
$$

where,

FR3 = developmental wells finding rate

SW3 = successful development wells.

The derivation of updated decline factors for the exponentially declining functions are shown in the following equations for other exploratory drilling and developmental drilling, respectively.

$$
\begin{aligned}
& \delta 2_{\mathrm{r}, \mathrm{k}, \mathrm{l}}=\left[\frac{\mathrm{FR} 2_{\mathrm{r}, \mathrm{k}, \mathrm{t}-1} * \mathrm{DECFAC}}{\mathrm{I}_{\mathrm{r}, \mathrm{l}}(1+\mathrm{TECH})^{\mathrm{t}-\mathrm{T}}+\sum_{\mathrm{T}+1}^{\mathrm{t}-1}\left(\frac{\mathrm{X}-1}{\mathrm{X}}\right) / \mathrm{FR} 1_{\mathrm{r}, \mathrm{k}, \mathrm{t}} \mathrm{d}(\mathrm{SW} 1)-\sum_{\mathrm{T}+1}^{\mathrm{t}-1}\left[\int \mathrm{FR} 2_{\mathrm{r}, \mathrm{k}, \mathrm{t}} \mathrm{d}(\mathrm{SW} 2)+\int \mathrm{FR} 3_{\mathrm{r}, \mathrm{k}, \mathrm{d}} \mathrm{d}(\mathrm{SW} 3)\right]}\right](69) \\
& \delta 3_{r, k, t}=\left[\frac{F R 3_{r, k, t-1} * D E C F A C}{I_{r, k}(1+T E C H)^{t-T}+\sum_{T+1}^{t-1}\left(\frac{X-1}{X}\right) \int F R 1_{s, t, t} d(S W 1)-\sum_{T+1}^{t-1}\left[\int F R 2_{r, k, t}^{r} d(S W 2)+\int F R 3_{r, t, t} d(S W 3)\right]}\right]
\end{aligned}
$$

where, 


$$
\begin{aligned}
I & =\text { initial inferred reserves estimate } \\
\text { DECFAC } & =\text { Decline rate adjustment factor. }
\end{aligned}
$$

The conversion of inferred reserves into proved reserves occurs as both other exploratory wells and developmental wells exploit a single stock of inferred reserves. The specification of equations (58) and (59) has the characteristic that the entire stock of inferred reserves can be exhausted through either the other exploratory wells or developmental wells alone. This extreme result is unlikely given reasonable drilling levels in any one year. Nonetheless, the simultaneous extraction from inferred reserves by both drilling types is expected to affect the productivity of each other. Specifically, the more one drilling type draws down the inferred reserve stock, there should be a corresponding acceleration in the productivity decline of the other type, because the remaining recoverable resource value (i.e., the denominator expression in the derivation of $\delta_{2}$ and $\delta_{3}$ ) is less than it otherwise would be.

DECFAC is present in the computation of $\delta_{2}$ and $\delta_{3}$ to account for the simultaneous drawdown from inferred reserves by both other exploratory wells and developmental wells. DECFAC is a user-specified parameter that should be greater than or equal to 1.0. Values gieater than 1.0 accelerate the productivity decline in finding rates: The parameter values for the Annual Energy Outlook 1994 are 1.0 for the onshore and 1.5 for the offshore. The relative drawdown of inferred reserves in any year was judged insufficient to significantly impact the onshore resource accounting. Offshore drilling productivity, however, is high enough that results under certain conditions indicated a possible problem with the exhaustion of inferred reserves. This portion of the model would benefit from additional work regarding the specification of the equations and the determination of the parameters.

Total reserve additions in period $t$ are given by the following equation:

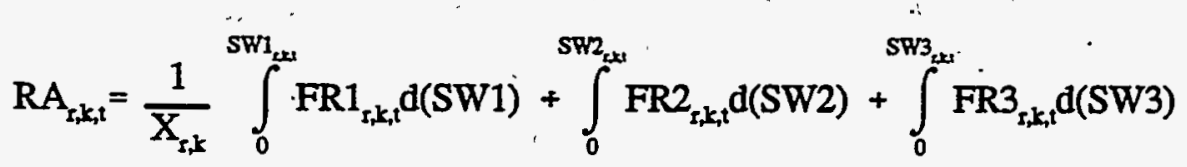

Finally, total end of year proved reserves for each period equals:

$$
R_{r, k, t}=R_{r, k, t-1}-Q_{r, k, t}+R A_{r, k, t}
$$

where,

$$
\begin{aligned}
\mathbf{R} & =\text { reserves measured as of the end-of-year } \\
\mathrm{Q} & =\text { production } \\
\mathrm{RA} & =\text { reserve additions. }
\end{aligned}
$$

\section{Production to Reserves Ratio}

The production to reserves ratio, as the relative measure of reserves drawdown, represents the rate of extraction, given any stock of reserves. For each year $t$, it is calculated as: 


$$
P R_{1}=\frac{Q_{t}}{R_{t-1}}
$$

where,

$$
\begin{aligned}
P R_{t} & =\text { production to reserves ratio for year } t \\
Q_{t} & =\text { production in year } t \text { (received from the NGTDM and the PMM) } \\
R_{t-1} & =\text { end of year reserves for year }(t-1) \text { or equivalently, beginning of year reserves } \\
& \text { for year } t .
\end{aligned}
$$

$\mathrm{PR}_{\mathrm{t}}$ represents the rate of extraction from all wells drilled up to year $t$ (through year $t-1$ ). To calculate the expected rate of extraction in year $(t+1)$, the model combines production in year $t$ with the reserve additions and the expected extraction rate from new wells drilled in year $t$. The calculation is given by:

$$
\mathrm{PR}_{\mathrm{t}+1}=\frac{\left(\mathrm{R}_{\mathrm{t}-1} * \mathrm{PR}_{\mathrm{t}} *(1-\mathrm{PR})\right)+(\mathrm{PRNEW} * \mathrm{RA})}{\mathrm{R}_{\mathrm{t}}}
$$

where,

$$
\begin{aligned}
\mathrm{PR}_{t+1}= & \text { expected production to reserves ratio for year }(t+1) \\
\text { PRNEW } & \text { long-term expected production to reserves ratio for all wells drilled in } \\
R_{4}= & \text { forecast } \\
& \text { year }(t+1) .
\end{aligned}
$$

The numerator, representing expected total production for year $t+1$, comprises the sum of two components. The first represents production from proved reserves as of the beginining of year $t$. This production is the expected production in year $t, R_{t-1} * P R_{t}$, adjusted by $1-P R_{t}$ to reflect the normal decline from year $t$ to $t+1$. The second represents production from reserves discovered in year $t$. No production in year $t+1$ is assumed from reserves discovered in year $t+1$.

$\mathrm{PR}_{1}$ is constrained not to vary from $\mathrm{PR}_{i-1}$ by more than 5 percent. It is also constrained not to exceed 30 percent.

The values for $R_{t}$ and $P R_{t+1}$ are passed to the NGTDM and the PMM for use in their market equilibration algorithms which solve for equilibrium production and prices for year $(t+1)$ of the forecast using the following short-term supply function:

$$
\mathrm{Q}_{\mathrm{r}, \mathrm{k}, \mathrm{t},+1}=\left[\mathrm{R}_{\mathrm{r}, \mathrm{k}, \mathrm{t},}\right] *\left[\mathrm{PR}_{\mathrm{r}, \mathrm{k}, \mathrm{l}} *\left(1+\beta_{\mathrm{s}, \mathrm{k}} * \Delta \mathrm{P}_{\mathrm{t}, \mathrm{k}, \mathrm{t}+1}\right)\right]
$$

where,

$$
\begin{aligned}
R_{t} & =\text { end of year reserves in period } t \\
P R_{t} & =\text { extraction rate in period } t \\
\beta & =\text { estimated short run price elasticity of supply } \\
\Delta P_{t+1} & =\left(P_{t+1}-P_{\downarrow}\right) / P_{t} \text { proportional change in price from } t \text { to } t+1
\end{aligned}
$$


The $P / R$ ratio for period $t, P R_{t}$, is assumed to be the approximate extraction rate for period $t+1$ under normal operating conditions. The product $\left(\mathrm{R}_{\mathrm{t}, \mathrm{k}, \mathrm{t}} * \mathrm{PR}_{\mathrm{t}}\right.$ is the expected, or normal, operating level of. production for period $t+1$. Actual production in $t+1$. will deviate from expected depending on the proportionate change in price from period $t$ and on the value of short run price elasticity. The OGSM passes estimates of $\beta$ to the NGTDM and PMM that can be used in solving for the market equilibria. Documentation of the equations used to estimate $\beta$ is provided in Appendix E, pp. E-52 through E-60.

\section{Emissions from Oil and Gas Production}

Emission levels associated with oil and gas extraction activities are provided for in OGSM by the use of emission coefficients. These coefficients relate the approximate amount of emissions associated with the activities required to produce a given amount of production. The coefficients vary by region (onshore versus offshore), fuel type (oil versus gas), and drilling methodology (conventional versus unconventional). The emissions projected by this method are $\mathrm{NO}_{x}, \mathrm{SO}_{x}$, carbon, $\mathrm{CO}, \mathrm{CO}_{2}$, and volatile organic compounds (VOC).

The emission coefficients in OGSM represent the emissions that occur as a result of fuel combustion associated with drilling and production, as well as those emissions released during the field level processing of crude oil and natural gas. For the Annual Energy Outlook 1994 (AEO94), only emissions from combustion were considered. Accordingly, for the AE094, projections of emissions from oil and gas extraction activities came not from OGSM, but from the Industrial Demand Module. For that exercise, all such emissions were subsumed in the aggregate projections of combustion-related emissions. for the industrial category encompassing oil and gas extraction activities.

\section{Enhanced Oil Recovery Supply Submodule}

This section describes the structure of the Enhanced Oil Recovery Supply Submodule (EORSS). The EORSS is designed to project regional oil production in the onshore lower 48 states extracted by use of . tertiary recovery techniques. This section provides an overview of the basic approach including a discussion of the procedure for projecting production from base year reserves and the methodology for development and subsequent production from previously unproven reserves.

\section{Introduction}

All submodules in the OGSM share similar basic attributes, but the EOR representation differs in the particulars. The EORSS uses a modified form of the previously described methodology, which is used for conventional oil supply and all natural gas recovery types in the lower 48 states. This section presents a discussion of the general differences in the EOR methodology.

The basic supply process for both EOR and the other sources of crude oil and natural. gas consists of essentially the same stages. The physical stages of the supply process involve the conversion of unproven resources into proved reserves, and then the proved reserves are extracted as flows of production. The significant differences between the methodology of the EORSS and the other submodules of OGSM concern the conversion of unproven resources to proved reserves, the extraction of proved reserves for production, and the determination of supply activities.

The EORSS uses discovery factors that convert a specified fraction of unproven resources into proved reserves. These factors depend on the expected profitability of EOR investment opportunities. This 
approach is a substitute for the approach used elsewhere in OGSM in which the transfer of resource stocks from umproven to proved status is accomplished by use of finding rate functions that relate reserve additions to cumulative drilling levels. Greater expected financial returns motivate the conversion of larger fractions of the resource base into proved reserves. This is consistent with the principle that funds are directed toward projects with relatively higher returns.

An explicit determination of expenditures for supply activities does not occur within the EORSS as it does elsewhere in the OGSM. Given the role of the discovery factors in the supply process, the implicit working assumption is that EOR investment opportunities with positive expected profit will attract sufficient financial development capital. The exploitation of economic EOR resources without an explicit budget constraint is consistent with the view that EOR investment does not compete directly with other oil and gas opportunities. This assumption is considered acceptable because EOR extraction is unlike the other oil and gas production processes, and its product differs sufficiently from the less heavy oil most often yielded by conventional projects.

\section{EOR Production from Proved Reserves}

Input: reserves differentiated by unit operating costs (constitutes price-supply table) ${ }^{15}$

For every year of the forecast horizon, the remaining proved reserves in the price-supply table that continue to be economic are identified. Proved reserves that have unit operating costs that exceed the current net price do not contribute to current production. The net price is the current price less royalty payments and severance taxes, which are unavoidable costs per unit. Thus, the net price measures the unit revenue that accrues to the producing firms.

Production from a given stock of proved reserves is determined by the application of an assumed production-to-reserves ratio (Figure 6).

\section{New EOR Projects}

Input: reserves differentiated by unit operating costs (constitutes price-supply table)

Use current year price to identify the economic portion of remaining unproven inferred reserves (Figure 7). Economic projects are transferred to undeveloped inferred reserves status. The economic portion of undeveloped inferred reserves become proved reserves based on net difference between price and unit cost. The rate of conversion is a fraction determined as the inverse of the expected number of years for development (see table below). The new additions to this stock are economic given the current price as indicated by the economic test in the previous step. Subeconomic portions of the preexisting undeveloped stock are not developed, because the development fractions (i.e., the inverse of the expected years for . development) are zero if unit costs exceed the net current price.

\footnotetext{
${ }^{15}$ The EOR price-supply tables used in this submodule are of critical importance to any outlook. The estimates provided in these tables are generated from an elaborate preprocessor routine, that performs economic evaluations intended to be consistent with the detailed geological, engineering,and economic information maintained in the Tertiary Oil Recovery Information System (TORIS). TORIS is a large analysis system maintained by the Bartlesville Project Office of the DOE Office of Fossil Energy (OFE). TORIS originally was developed for use in the analysis sponsored by the National Petroleum Council in their comprehensive 1984 study on EOR. A complete description of the EORSS preprocessor and its relationship to the EORSS will be published in the spring of 1995 as a special appendix to this document.
} 
Figure 6. Procedure for EOR Production from Proved Reserves

Depictions of processing steps in each period

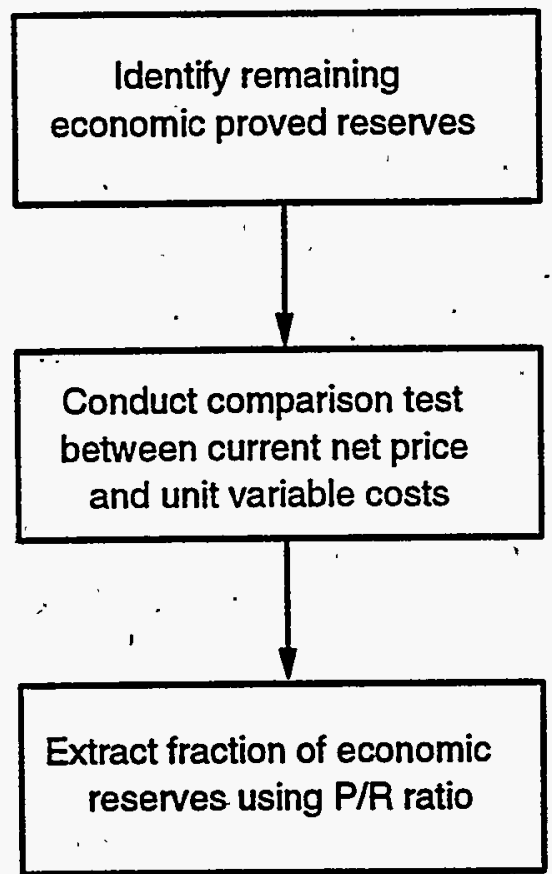


Figure 7. Development of New EOR Projects

Depictions of processing steps in each period

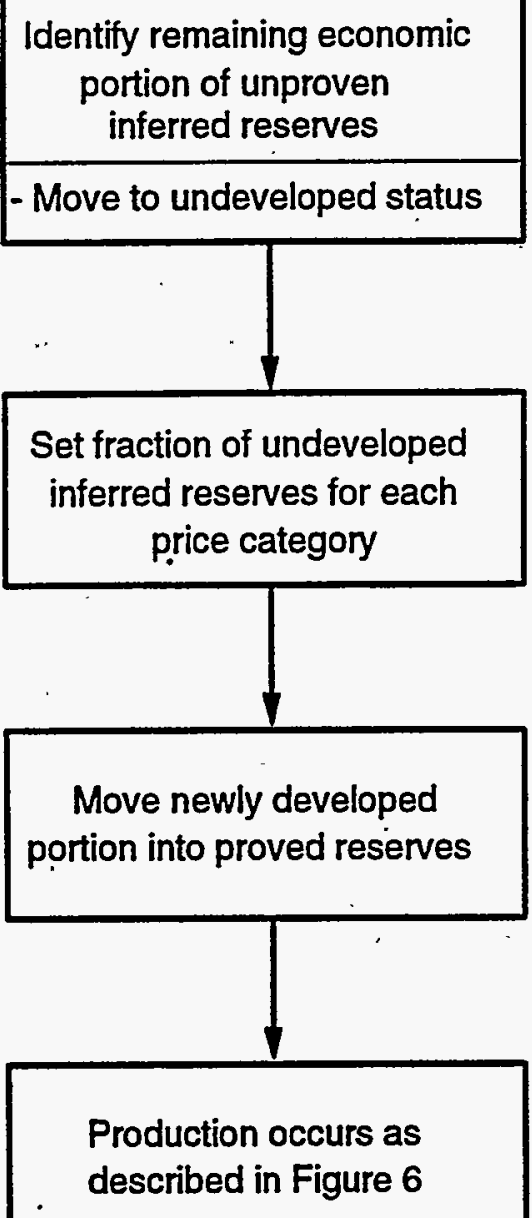




\begin{tabular}{|c|c|}
\hline \multicolumn{2}{|c|}{$\begin{array}{l}\text { Expected Development Schedule for Economic Undeveloped } \\
\text { Inferred Reserves EOR Projects }\end{array}$} \\
\hline $\begin{array}{l}\text { Difference in Price over Unit } \\
\text { Cost }\end{array}$ & $\begin{array}{l}\text { Expected Years for } \\
\text { Development }\end{array}$ \\
\hline$\$ 0-1.00$ & 40 \\
\hline$\$ 1.01-2.00$ & 36 \\
\hline$\$ 2.01-3.00$ & 32 \\
\hline$\$ 3.01-4.00$ & 28 \\
\hline$\$ 4.01-5.00$ & 24 \\
\hline 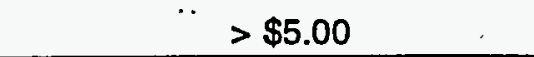 & 20 \\
\hline
\end{tabular}

The conversion of the appropriate volume of undeveloped reserves into proved reserves is followed by the extraction of a fraction of proved reserves as production. Production from a given stock of proved reserves is determined by use of the assumed production-to-reserves ratio.

\section{Cogeneration}

Cogeneration of electricity by EOR projects is determined by a streamlined algorithm. This method assigns a level of new congeneration capacity based on the EOR expansion from new projects. Electricity from existing capacity occurs according to assumed utilization factors.

\section{Emissions}

Carbon emissions from EOR supply activities are determined by a streamlined algorithm. This method uses historical yield factors that measure emissions per unit of crude oil produced via EOR techniques. Emissions in each period are directly related to production in that period.

\section{Alaska Oil and Gas Supply Submodule}

This section describes the structure for the Alaska Oil and Gas Supply Submodule (AOGSS). The AOGSS is designed to project field-specific oil and gas production from the Onshore North Slope, Offshore North Slope, and Other Alaska (primarily the Cook Inlet area.) This section provides an overview of the basic approach including a discussion of the discounted cash flow (DCF).method:

\section{AOGSS Overview}

The AOGSS is divided into three components: new field discoveries, development projects, and producing fields (Figure 8). Transportation costs are used in conjunction with the relevant market price of oil or gas to calculate the estimated net price received at the wellhead, sometimes called the netback price. A discounted cash flow (DCF) method is used to determine the economic viability of each project at the netback price. Alaskan oil and gas supplies are modeled on the basis of discrete projects, in contrast to 
Figure 8. Flowchart for the Alaska Oil and Gas Supply Submodule

For each periód t:

Economic \& Physical Data

NEW FIELDS ---------

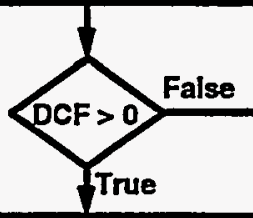

Determine outcome for allowable number of New Field Wildcats

Add any successes to inventory of development projects

Record

- Drilling

- Reserve additions

- Finąncial expenditures

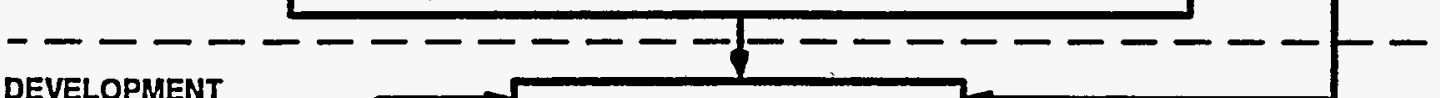

PROJECTS

Compute DCF for project.

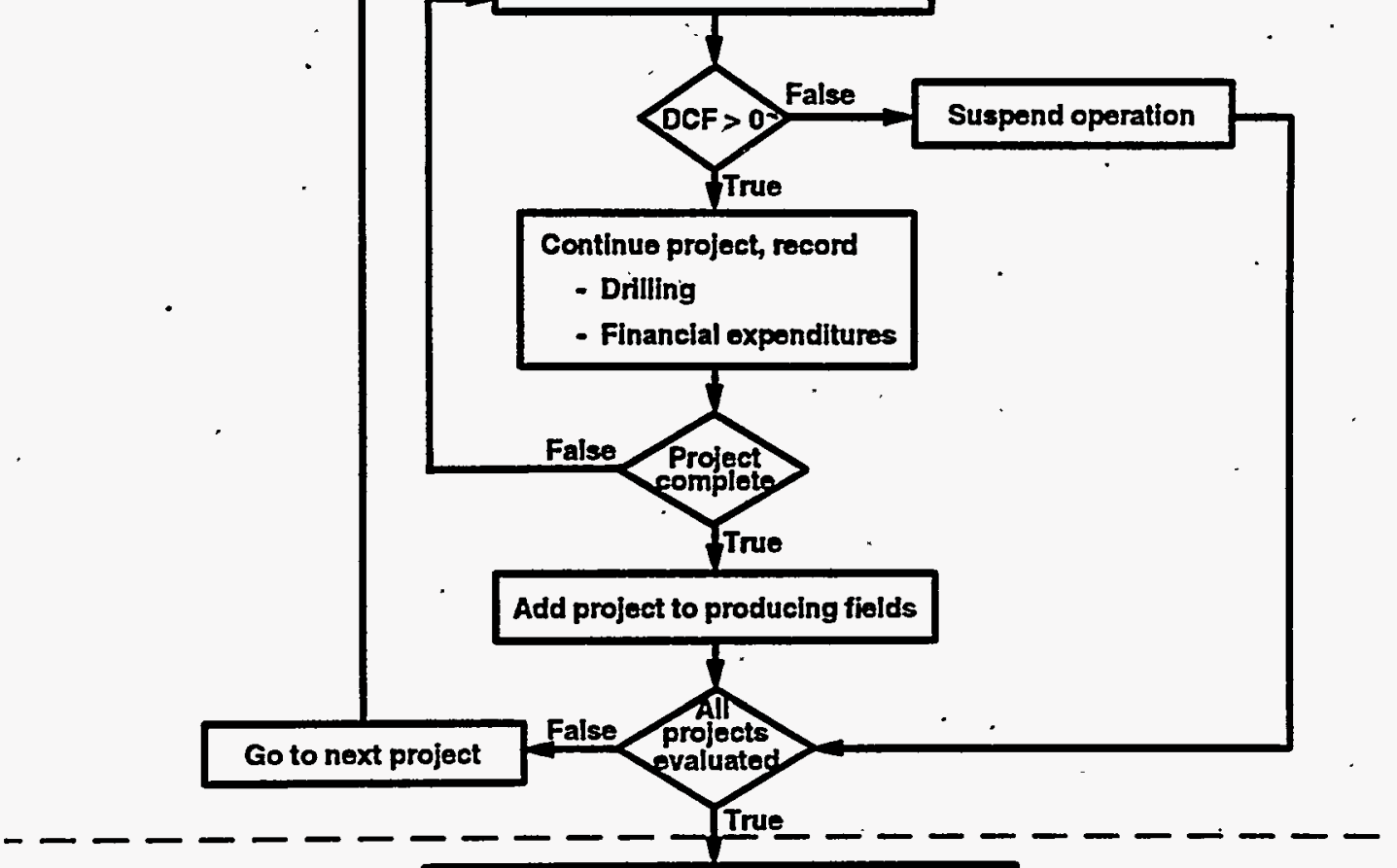

PRODUCING FIELDS

For all fields, compute production (PROD)

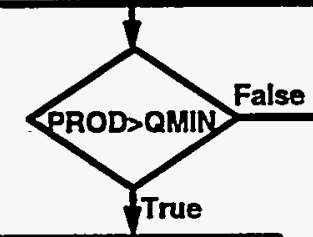

Record production

Shut down; remove field 
the Onshore Lower 48 conventional oil and gas supplies, which are modeled on an aggregate level. The continuation of the exploration and development of multi-year projects, as well as the discovery of a new field is dependent on its profitability. Production is determined on the basis of assumed drilling schedules and production profiles for new fields and developmental projects, and historical production patterns and announced plans for currently producing fields.

\section{Calculation of Costs}

Costs differ within the model for successful wells and dry holes. Costs are categorized functionally within the model as:

- Drilling costs

- Lease equipment costs

- Operating costs (including production facilities and general and administrative costs).

All costs in the model incorporate the estimated impact of environmental compliance. Whenever environmental regulations preclude a supply activity outright, that provision is reflected in other adjustments to the model. For example, environmental regulations that preclude drilling in certain locations within a region is modeled by reducing the recoverable resource estimates for the total region.

Each cost function includes a variable that reflects the cost savings associated with technological improvements. Such declines would be relative to what costs would otherwise be. Technological improvements lower average costs of the affected phase of activity. As such, the lower costs reflect changes in the cost of either the supply activity or environmental compliance. The value of this variable is a user option in the model. The equations used to estimate the costs are similar to those used for the lower 48 but include costs of elements that are particular to Alaska. For example, lease equipment includes gravel pads.

\section{Drilling Costs}

Drilling costs represent the expenditures for drilling successful wells or dry holes and for equipping successful wells through the "Christmas tree", the valves and fittings assembled at the top of a well to control the fluid flow. Elements that are included in drilling costs are labor, material, supplies and direct overhead for site preparation, road building, erecting and dismantling derricks and drilling rigs, drilling, running and cementing casing, machinery, tool changes, and rentals. Drilling costs for exploratory wells include costs of support equipment such as ice pads. Lease equipment required for production is included

- as a separate cost calculation; and covers equipment installed on the lease downstream from the Christmas tree.

The average cost of drilling a well in any field located within region $\mathrm{r}$ in year $\mathrm{t}$ is given by:

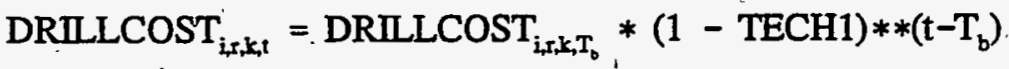

where,

$\mathrm{i}=$ well class(exploratory $=1$, developmental $=2$ )

$\mathbf{r}^{\prime \prime}=$, region 


$\begin{aligned} \mathrm{k} & =\text { fuel type (oil=1, gas=2) } \\ \mathrm{t} & =\text { forecast year } \\ \text { DRILLCOST } & =\text { drilling costs } \\ \mathrm{T}_{\mathrm{b}} & =\text { base year of the forecast } \\ \mathrm{TECH} 1 & =\text { annual decline in drilling costs due to improved technology. }\end{aligned}$

The above function specifies that drilling costs decline at the annual rate TECH1. Observe that drilling . costs are not modeled as a function of the activity level as they are in the' Onshore Lower 48 methodology. The justification for this is the relative constancy of activity in Alaska as well as the specialized nature of drilling inputs in Alaska.

\section{Lease Equipment Costs}

Lease equipment costs include the cost of all equipment extending beyond the christmas tree, directly used to obtain production from a drilled lease. Costs include: producing equipment, the gathering system, processing equipment, and production related infrastructure such as gravel pads. Producing equipment costs include tubing and pumping equipment. Gathering system costs consist of flowlines and manifolds. Processing equipment costs account for the facilities utilized by successful wells. The lease equipment cost estimate for a new oil or gas well is given by:

$$
\text { EQUIP } P_{t, k, t}=E_{\text {EUIP }}, k, T_{\mathrm{o}} *(1-\mathrm{TECH} 2) * *\left(\mathrm{t}-\mathrm{T}_{\mathrm{b}}\right)
$$

where,

$$
\begin{aligned}
\mathbf{r} & =\text { region } \\
\mathbf{k} & =\text { fuel type (oil=1, gas=2) } \\
\mathrm{t} & =\text { forecast year } \\
\mathrm{EQUIP} & =\text { lease equipment costs } \\
\mathrm{T}_{\mathrm{b}} & =\text { base year of the forecast } \\
\mathrm{TECH} 2 & =\text { anmual decline in lease equipment costs due to improved technology. }
\end{aligned}
$$

\section{Operating Costs}

EIA operating cost data, which are reported on a per well basis for each region, include three main categories of costs: normal daily operations, surface maintenance, and subsurface maintenance. Normal daily operations are further broken down into supervision and overhead, labor, chemicals, fuel, water, and supplies. Surface maintenance accounts for all labor and materials necessary to keep the service equipment functioning efficiently and safely. Costs of stationary facilities, such as roads, also are included. Subsurface maintenance refers to the repair and services required to keep the downhole equipment functioning efficiently.

The estimated operating cost curve is:

$$
, \mathrm{OPCOST}_{\mathrm{x}, \mathrm{k}, \mathrm{t}}=\mathrm{OPCOST}_{\mathrm{s}, \mathrm{k}, \mathrm{T}_{\mathrm{b}}} *(1-\mathrm{TECH} 3) * *\left(\mathrm{t}-\mathrm{T}_{\mathrm{b}}\right)
$$

where,

$$
\begin{aligned}
& I=\text { region } \\
& \mathbf{k}=\text { fuel type }(\text { oil }=1, \text { gas }=2)
\end{aligned}
$$




$\begin{aligned} \mathrm{t} & =\text { forecast year } \\ \text { OPCOST } & =\text { operating cost } \\ \mathrm{T}_{\mathrm{b}} & =\text { base year of the forecast } \\ \text { TECH3 } & =\text { anmual decline in operating costs due to improved technology. }\end{aligned}$

Drilling costs, lease equipment costs, and operating costs are integral components of the following discounted cash flow analysis. These costs are assumed to be uniform across all fields within a region.

\section{Treatment of Costs in the Model for Income Tax Purposes}

All costs are treated for income tax purposes as either expensed or capitalized. The tax treatment in the DCF reflects the applicable provisions for oil and gas producers. The DCF assumptions are consistent with standard accounting methods and with assumptions used in similar modeling efforts. The following assumptions, reflecting current tax law, are used in the calculation of costs.

- All dry-hole costs are expensed.

- A portion of drilling costs for successful wells are expensed. The specific split between expensing and amortization is determined on the basis of the data.

- Operating costs are expensed.

- . All remaining successful field development costs are capitalized.

- The depletion allowance for tax purposes is not included in the model, because the current regulatory limitations for invoking this tax advantage are so restrictive as to be insignificant in the aggregate for future drilling decisions.

- Successful versus dry-hole cost estimates are based on historical success rates of successful versus dry-hole footage.

- Lease equipment for existing wells is in place before the first forecast year of the model.

\section{Tariff Routine}

In general, tariffs are designed to enable carriers to recover operating and capital costs for a given after-tax rate of return. The Trans Alaska Pipeline System (TAPS) tariff is determined by dividing the total revenue requirement for a year by the projected throughput for that year. The total revenue requirement is composed of eight elements as defined in the Settlement.Agreement dated June 28; 1985 between the State of Alaska and ARCO Pipe Line Company, BP Pipelines Inc., Exxon Pipeline Company, Mobil Alaska Pipeline Company, and Union Alaska Pipeline Company. The determination of costs conforms to the specification as provided in the Settlement Agreement.

$$
\begin{aligned}
& \text { TRR }_{t}= \text { OPERCOST }_{t}+\text { DRR }_{t}+\text { TOTDEP }_{t}+\text { MARGIN }_{t}+\text { DEFRETREC }_{t}+\text { TXALLW }_{t} \\
& \text { NONTRANSREV } \\
&+ \text { CARRYOVER }_{t}
\end{aligned}
$$

where,

$$
\begin{aligned}
\begin{aligned}
\text { TRR } & = \\
\text { OPERCOST } & =\text { total revenue requirement } \\
\therefore & \text { total operating costs (fixed and variable) }
\end{aligned} \\
\text { Energy Information Administration/Oll and Gas Supply Model Documentation }
\end{aligned}
$$




$$
\begin{aligned}
\text { DRR } & =\text { dismantling, removal, and restoration allowance } \\
\text { TOTDEP } & =\text { total depreciation (original and new.property) } \\
\text { MARGIN } & =\text { total after-tax margin (original and new property) } \\
\text { DEFRETREC } & =\text { total recovery of deferred return (original and new property) } \\
\text { TXALLW } & =\text { income tax allowance } \\
\text { NONTRANSREV } & =\text { non-transportation revenues } \\
\text { CARRYOVER } & =\text { net carryover. }
\end{aligned}
$$

Four of the elements are associated with the recovery of a TAPS carrier's costs: (1) operating expenses, (2) dismantling, removal, and restoration (DR\&R) allowance, (3) depreciation, and (4) income tax allowance. Two elements, after-tax margin and recovery of deferred return, provide for a return on unrecovered capital and an incentive to continue to operate the pipeline. The last two components, nontransportation revenues and net carryover are adjustment items.

Operating Costs. Operating costs include both the fixed and variable operating costs. The fixed portion is based on an assumed cost of $\$ 325$ million (in 1991 dollars). If the expected throughput for the year is greater than 1.4 million barrels per day, the variable cost is $\$ 0.28$ per barrel in 1991 dollars; otherwise, the variable cost is $\$ 0.24$ per barrel in 1991 dollars. ${ }^{16}$ These assumed costs exclude any incurred or . expected DR\&R expenses, any depreciation or amortization of capitalized cost, and any settlements with shippers for lost or undelivered oil due to normal operations during transportation.

DR\&R Allowance. The annual DR\&R allowance to be included in the revenue requirement calculation for years 1984 through 2011 is given in Exhibit E: DR\&R Allowance Schedule of the Settlement Agreement.

Depreciation. Total depreciation is the sum of depreciation from original property and depreciation from new property as given by

$$
\text { TOTDEP }_{t}=\text { DEP }_{t} *\left(\text { DEPPROP }_{t-2}+\text { ADDS }_{t-1}-\text { PROCEEDS }_{t-1}-\text { TOTDEP }_{t-1}\right)
$$

where,

$$
\begin{aligned}
\text { TOTDEP } & =\text { total depreciation } \\
\text { DEP } & =\text { depreciation factor } \\
\text { DEPPROP } & =\text { total (original and new) depreciable property in service } \\
\text { ADDS } & =\text { additions to both original and new property in service } \\
\text { PROCEEDS } & =\text { proceeds from both original and new depreciable property in service. }
\end{aligned}
$$

After-Tax Margin. The after-tax margin is designed to provide the TAPS carrier with an after-tax real return on 'capital. This margin has two components: (1) the product of the allowance per barrel and the projected throughput and (2) the allowed rate of return on the rate base associated with new property in service. The allowance per barrel is set at $\$ 0.35$ in 1983 dollars and the allowed rate of return at 6.4 percent.

${ }^{16}$ The variable cost was converted from 1983 dollars as specified in the Settlement Agreement to 1991 dollars. 


$$
\text { MARGIN }_{t}=\text { ALLOW }_{t} * \text { THRUPUT }_{t}+0.064 *\left(\text { DEPPROP }_{\text {NEW }, t}+\text { DEFRET }_{N E W, t}-\text { DEFTAX }_{\text {NEW }, t}\right)
$$

where,

\begin{tabular}{|c|c|c|}
\hline MARGIN & $=$ & total after-tax margin \\
\hline ALLOW & $=$ & allowance per barrel \\
\hline THRUPUT & $=$ & projected net deliveries \\
\hline DEPPROP $_{\text {NEW }}$ & $=$ & new depreciable property in service \\
\hline DEEFRET $_{\mathrm{NEW}}$ & $=$ & new deferred return \\
\hline DEFTAX $_{\mathrm{NEW}}$ & $=$ & new deferred tax. \\
\hline
\end{tabular}

Recovery of Deferred Return. Deferred returns represent amounts which could be rightfully collected and turned over to the owners but, for tariff profile purposes, are collected at a later date. For example, Construction Work in Progress (CWIP) is not added in the company's rate base until the end of the construction period. As a result, it is not included in the return on capital and not recovered in current rates. Instead, an Allowance for Funds Used During Construction (AFUDC) is added to the book value of the construction. This deferred return is then recovered through depreciation of the pipeline's cost over its economic life. The recovery of this deferred return has two components, the conventional AFUDC and the inflation portion of the return on rate base. The calculation of the recovery of deferred returns is given by

$$
\text { DEFRETREC }_{t}=\text { DEP }_{t} *\left(\text { DEFRET }_{t-2}+\text { INFLADJ }_{t-1}+\text { AFUDC }_{t-1}-\text { DEFRETREC }_{t-1}\right)
$$
where,

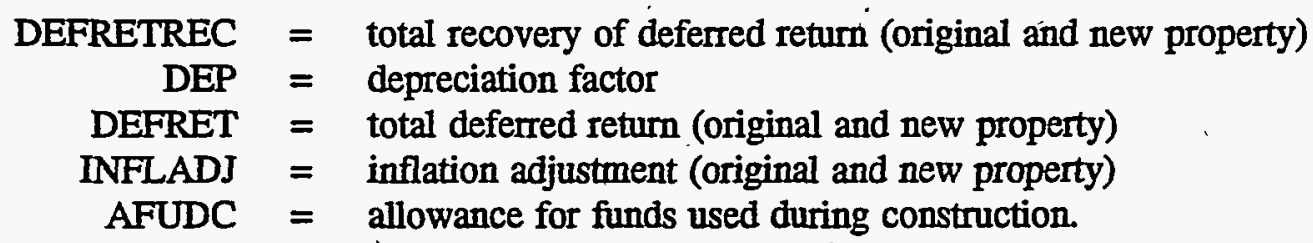

Income Tax Allowance. The income tax allowance is equal to the income tax allowance factor multiplied by the sum of the after-tax margin and recovery. of deferred return. The income tax allowance factor is the amount of tax allowance necessary to provided a dollar of after tax income at the composite Federal and State tax rates, adjusted for the deductibility of State income tax in Federal tax calculations.

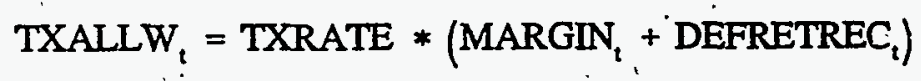

where,

$$
\begin{aligned}
\text { TXALLW } & =\text { income tax allowance } \\
\text { TXRATE } & =\text { income tax allowance factor } \\
\text { MARGIN } & =\text { total after-tax margin } \\
\text { DEFRETREC } & =\text { total recovery of deferred return. }
\end{aligned}
$$

Non-transportation Revenues. A TAPS owner receives revenues from the use of carrier property in addition to the tariff revenue. These incidental revenues include payments received directly or indirectly from penalties paid by shippers who were delinquent, in taking delivery of crude oil at Valdez. By 
subtracting these revenues from the total revenue requirement, the economic benefit to these nontransportation revenues is passed on to other shippers through the lower tariff for TAPS transportation.

Net Carryover. The net carryover reflects any difference between the expected revenues calculated by this tariff routine and revenues actually received.

\section{Discounted Cash Flow Analysis}

A discounted cash flow (DCF) calculation is used to determine the profitability of oil and gas projects. ${ }^{17}$ A positive DCF is necessary to continue operations for a known field, whether exploration, development, or production. Selection of new prospects for initial exploration occurs on the basis of the profitability index which is measured as the ratio of the expected discounted cash flow-to expected capital costs for a potential project.

A key variable in the DCF calculation is the transportation cost to lower 48 markets. Transportation costs of either oil or gas reflect delivery costs to an oil import facility or the citygate for natural gas. Transportation costs for oil include both pipeline and tanker shipment costs, and natural gas transportation costs are pipeline costs (tariffs). Transportation costs are specified for each field, although groups of fields may be subject to uniform transportation costs for that region. This cost directly affects the expected revenues from the production of a field as follows.: ${ }^{18}$

$$
\mathrm{REV}_{\mathrm{f}, \mathrm{t}}=\mathrm{Q}_{\mathrm{f}, \mathrm{t}} *\left(\mathrm{MP}_{\mathrm{t}}-\mathrm{TRANS}_{\mathrm{f}, \mathrm{t}}\right)
$$

where,

$$
\begin{aligned}
\mathbf{f} & =\text { field } \\
\mathrm{t} & =\text { year } \\
\mathrm{REV} & =\text { expected revenues } \\
\mathrm{Q} & =\text { expected production volumes } \\
\mathrm{MP} & =\text { market price in the lower } 48 \text { states } \\
\text { TRANS } & =\text { transportation cost. }
\end{aligned}
$$

The expected discounted cash flow associated with a representative oil or gas project in a field $f$ at time $t$ is given by:

$$
\begin{aligned}
\text { DCF }_{f, t}= & (\text { PVREV - PVROY - PVDRILLCOST - PVEQUIP - TRANSCAP - } \\
& \text { PVOPCOST - PVPRODTAX - PVSIT - PVFIT - PVWPT })_{f, t}
\end{aligned}
$$

where,

$$
\begin{aligned}
\text { PVREV } & =\text { present value of expected revenues } \\
\text { PVROY } & =\text { present value of expected royalty payments } \\
\text { PVDRILLCOST } & =\text { present value of all exploratory and developmental drilling expenditures } \\
\text { PVEQUIP } & =\text { present value of expected lease equipment costs } \\
\text { TRANSCAP } & =\text { cost of incremental transportation capacity }
\end{aligned}
$$

\footnotetext{
${ }^{17}$ See Appendix 4.A at the end of this chapter for a detailed discussion of the DCF methodology.

${ }^{19}$ This formulation assumes oil production only. It can be easily expanded to incorporate the sale of natural gas.
} 
PVOPCOST $=$ present value of operating costs

PVPRODTAX $=$ present value of expected production taxes (ad valorem and severance taxes) ${ }^{*}$

PVSIT $=$ present value of expected state corporate income taxes

PVFIT $=$ present value of expected federal corporate income taxes

PVWPT $^{-}=$present value of expected windfall profits tax ${ }^{19}$

The expected capital costs for the proposed field $\mathrm{f}$ located in region $\mathrm{r}$ are:

$$
\operatorname{COST}_{f, t}=(\text { PVEXPCOST }+ \text { PVDEVCOST +PVEQUIP }+ \text { TRANSCAP })_{f, t}
$$

where,

$$
\begin{aligned}
\text { PVEXPCOST } & =\text { present value exploratory drilling costs } \\
\text { PVDEVCOST } & =\text { present value developmental drilling costs } \\
\text { PVEQUIP } & =\text { present value lease equipment costs } \\
\text { TRANSCAP } & =\text { cost of incremental transportation capacity }
\end{aligned}
$$

The profitability indicator from developing the proposed.field is therefore equal to:

$$
\text { PROF } \mathrm{PR}_{f, \mathrm{t}}=\mathrm{DCF}_{\mathrm{f}, \mathrm{t}} / \mathrm{COST}_{\mathrm{f}, \mathrm{t}}
$$

The field with the highest positive PROF in time $t$ is then eligible for exploratory drilling in the same year. The profitability indices for Alaska also are passed to the basic framework module of the OGSM.

\section{New Field Discovery}

Development of estimated recoverable resources, which are expected to be in currently undiscovered fields, depends on the schedule for the conversion of resources from unproved to reserve status. The conversion of resources into reserves requires a successful new field wildcat well. The discovery procedure requires needed information, which can be determined endogenously or supplied at the option of the user. The procedure requires data regarding:

- technically recoverable oil and gas resource estimates by region

- distribution of technically recoverable field sizes ${ }^{20}$ within each region

- the maximum number of new field wildcat wells drilled in any year

- new field wildcat success rate

- any restrictions on the timing of drilling.

The endogenous procedure generates:

- the set of individual fields to be discovered, specified with respect to size and location

\footnotetext{
${ }^{19}$ Since the Windfall Profits Tax was repealed in 1988, this variable would nomally be set to zero: It is included in the DCF calculation for completeness.

${ }^{20 m}$ Size" of a field is measured by the volume of recoverable oil or gas. 
- an order for the discovery sequence

- a schedule for the discovery sequence.

The new field discovery procedure divides the estimate for technically recoverable oil and gas resources into a set of individual fields. The field size distribution data was gathered from the U.S. Geological Survey work for the national resource assessment. ${ }^{21}$ The field size distribution is used to determine a largest field size based on the volumetric estimate corresponding to an acceptable percentile of the distribution. The remaining fields within the set are specified such that the distribution of estimated sizes conform to the characteristics of the input distribution. Thus, this estimated set of fields is consistent with

- the expected geology with respect to expected aggregate recovery and the relative frequency of field sizes.

New field wildcat drilling depends on the estimated expected DCF for the set of remaining undiscovered recoverable prospects. If the DCF for each prospect is not positive, no new drilling occurs. Positive DCF's motivate additional new field wildcat drilling. Drilling in each year matches the maximum number of new field wildcats. A discovery occurs as indicated by the success rate; i.e., a success rate of 12.5 percent means that there is one discovery in each sequence of 8 wells drilled. By assumption, the first new field well in each sequence is a success. The requisite number of dry holes must be drilled prior to the next successful discovery.

The execution of the above procedure can be modified to reflect restrictions on the timing of discovery for particular fields. Restrictions may be warranted for enhancements such as delays necessary for technological development needed prior to the recovery of relatively small accumulations or heavy oil deposits. This refinement is implemented by declaring a start date for possible exploration. For example, development of the West Sak field is expected to be delayed until technology can be developed that will enable the heavy crude oil of that field to be economically extracted.

The discovery procedure generates data on projected drilling and reserve additions for each period $t$ as described above. Estimated exploration and developmental drilling expenditures for Alaska also are passed to the main OGSM module. Drilling expenditures by field are calculated by:

$$
\text { SPENDDV } \mathrm{f}_{\mathrm{f}, \mathrm{t}}=(\mathrm{NDEV} *(\mathrm{DEVCOST}+\mathrm{EQUIP})+\mathrm{NDRYDEV} * \mathrm{DRYDEVCOST})_{\mathrm{f}, \mathrm{t}}
$$

$$
\text { SPENDEX }{ }_{\mathrm{f}, t}=(\mathrm{NEXP} * \mathrm{EXPCOST}+\mathrm{NDRYEXP} * \mathrm{DRYEXPCOST})_{\mathrm{f}, \mathrm{t}}
$$

where,

$\begin{aligned} \text { NDEV } & =\text { number of successful developmental wells drilled in time } t \\ \text { DEVCOST } & =\text { drilling cost per successful developmental well } \\ \text { EQUIP } & =\text { lease equipment costs per successful well } \\ \text { NDRYDEV } & =\text { number of developmental dry holes drilled in time } t \\ \text { DRYDEVCOST } & =\text { drilling cost per developmental dry hole } \\ \text { NEXP } & =\text { number of successful exploratory wells drilled in time } t \\ \text { EXPCOST } & =\text { drilling cost per successful exploratory well } \\ \text { NDRYEXP } & =\text { number of exploratory dry holes drilled in time } t \\ \text { DRYEXPCOST } & =\text { drilling cost per exploratory dry hole. }\end{aligned}$

\footnotetext{
${ }^{21}$ Estimates of Undiscovered Conventional Oil and Gas Resources in the United States -- A Part of the Nation's Energy
} Endowment, USGS (1989). 


\section{Development Projects}

Development projects are those projects in which a successful new field wildcat has been drilled. As with the new field discovery process, the DCF calculation plays an important role.in the timing of development and exploration of these multi-year projects.

Every year, the DCF is calculated for each development project. Initially, the drilling schedule is determined by the user or some set of specified rules. However, if the DCF for a given project is negative, then exploration and development of this project is suspended in the year in which this occurs. The DCF for each project is evaluated in subsequent years for a positive value; at which time, exploration and development will resume.

Production from developing projects follows the generalized production profile developed for and described in previous work conducted by DOE staff. ${ }^{22}$ The specific assumptions used in this work are as follows:

- a two to four year build-up period from initial production to peak rate,

- peak rate sustained for three to eight years, and

- production rates decline by 12 or 15 percent after peak rate is no longer maintained.

The pace of development and ultimate number of wells drilled for a particular field is based on the historical field-level profile adjusted for field size and other characteristics of the field (e.g. API gravity.) Based on this adjusted profile total expected drilling expenditures for each year are computed (Equations (70) and (71)) and passed to the framework submodule of the OGSM.

After all exploratory and developmental wells have been drilled for any given project, development of the project is complete. For this version of the AOGSS, no constraint is placed on the number of exploratory or developmental wells that can be drilled for any project. All completed projects are added to the inventory of producing fields.

\section{Producing Fields}

Oil and natural gas production from fields producing as of the base year (including Prudhoe Bay, Kuparuk, Lisburne, Endicott, and Milne Point) are based on historical production patterns, remaining estimated recovery, and announced development plans. Production ceases when flow becomes subeconomic; i.e., attains the assumed minimum economic production level.

Natural gas production from the North Slope for sale to end-use markets is dependent on the construction of a major transportation facility to move natural gas to lower 48 markets. ${ }^{23}$ In addition, the reinjection of North Slope gas for increased oil recovery poses an operational/economic barrier limiting its early extraction: Nonetheless, there are no extraordinary regulations or legal constraints interfering with the recovery and use of this gas. Thus, the modeling of natural gas production for marketing in the lower 48

\footnotetext{
${ }^{22}$ Potential Oil Productionfrom the Coastal Plain of the Arctic National Wildlife Refuge, EIA (1987) and Alaska Oil and Gas Energy Wealth of Vanishing Opportunity?, DOE/D/0570-H1 (January 1991).

${ }^{23}$ Initial natural gas production from the North Slope for Lower 48 markets is affected by a delay reflecting a reasonable period for construction.
} 
states recognizes the expected delay to maximize oil recovery, but it does not require any further modifications from the basic procedure. ${ }^{24}$

\section{Foreign Natural Gas Supply Submodule}

This chapter describes the proposed structure for the Foreign Natural Gas Supply Submodule (FNGSS) within the Oil and Gas Supply Module (OGSM). FNGSS includes U.S. trade in foreign natural gas via either the North American pipeline network or ocean-going tankers. ${ }^{25}$ Gas is traded with Canada and Mexico via pipelines. Gas trade with other, nonadjacent, countries is in the form of liquefied natural gas (LNG) and involves liquefaction, transportation by tanker and subsequent regasification. To date, the United States has imported LNG almost exclusively from Algeria.

A detailed representation of Canadian gas trade has been developed. Since forecasts of fixed volumes are not adequate for the purposes of equilibrating supply and demand, the submodule provides the Natural Gas Transmission and Distribution Module (NGTDM) with supply functions of Canadian gas at the U.S./Canadian border points. Natural gas imports via pipeline from Mexico are handled with less detail. LNG imports are modeled on the basis of importation costs, including production, liquefaction, transportation, and regasification. Projected pipeline imports from Canada and LNG imports are subject to user assumptions regarding the timing and size of available import capacity. Natural gas exports, via pipeline or as LNG, are included in the National Energy Modeling System (NEMS) as a set of exogenous assumptions. This section presents descriptions of the separate methodological approaches for Canadian, Mexican, and LNG natural gas trade.

\section{Canadian Gas Trade}

This submodule determines net Canadian natural gas supplies over a range of gas prices to the United States at the six border crossing locations identified in Figure 9. The initial step in this procedure produces projections of regional Canadian drilling activity and supply. Canadian demand is subtracted from supply to determine gas available for export. Gas supply is allocated to regional Canadian/U.S border crossing points using an allocation algorithm that accounts for the associated pipeline capacities and the price responsiveness of supplies at the border points. The determination of the import volumes themselves occurs in the equilibration process of the NGTDM.

The approach taken to determine Canadian gas supply differs from that used in the domestic submodules of the OGSM. Drilling activity is determined using an econometric model. Drilling activity, measured as the number of successful wells drilled, is estimated directly as a function of expected profitability rather than being derived from a process of estimating and allocating drilling expenditures. Successful wells are disaggregated by two fuel types: oil and gas. No distinction is made between exploration and development.

Production from three Canadian regions is estimated -- the Western Canadian Sedimentary Basin (WCSB) (Alberta, British Columbia, and Saskatchewan), the Northern Frontier (Arctic Islands and Mackenzie Delta), and Eastern Canada. Drilling activity for the WCSB is determined using an econometric model.

\footnotetext{
24The currently proposed version of AOGSS does not include plans for an explicit method to deal with the issue of marketing ANS gas as liquefied natural gas (LNG) exports to Pacific Rim countries. The working assumption is that sufficient recoverable gas resources are present to support the economic operation of both a marketing system to the Lower 48 states and the LNG export project.

${ }^{25}$ The issue of foreign gas trade generally is viewed as one of supply (to the United States) because the United States is currently a net importer of natural gas by a wide margin, a situation that is expected to continue.
} 
Figure 9. Foreign Natural Gas Trade via Pipeline

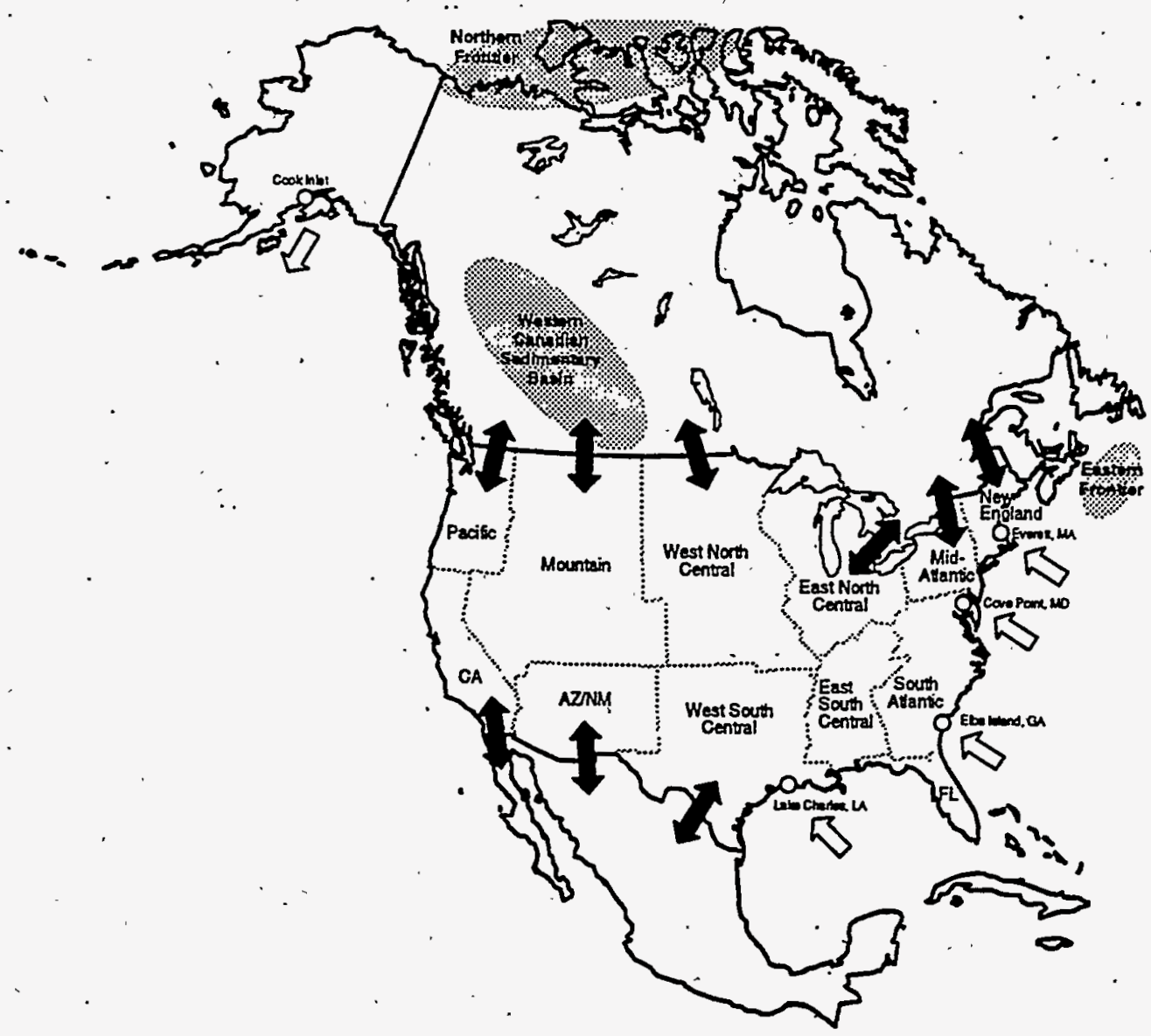

Finding rate equations are used to determine reserve additions; a reserves accounting procedure yields reserve estimates; and an estimated extraction rate determines production potential for the WCSB. Production from the Northern Frontier and Eastern Canada regions, for which there are very limited data, is determined exogenously from resource supply curves that relate resource availability to price. Annual production from these regions is combined with WCSB production, yielding total Canadian domestic production. Total Canadian supply includes natural gas received from the United States.

Forecasts of Canadian gas demand are based on estimates made by the Canadian National Energy Board. Western Canadian gas demand is subtracted from total Canadian supply to determine available export supply. The general methodology employed for estimating Canadian gas trade is depicted in Figure 10.

\section{Western Canadian Sedimentary Basin.}

\section{Calculation of Discounted Cash Flows}

Expected discounted cash flows (DCF) associated with drilling representative oil and gas wells in the WCSB are calculated for each year $t^{26}$ The DCF reflects expected revenues, less expected costs and taxes, all in present value terms. Expected revenue is based on expected production, over the life of the well, and expected prices. Expected production over the life of a representative well is based on the well's

\footnotetext{
${ }^{26}$ See Appendix 4.A at the end of this chapter for a detailed discussion of the basic DCF methodology. The tax provisions described in this appendix are based on U.S. tax laws. The applicable provisions of Canadian tax law bave been incorporated into the implemented DCF routine in the FNGSS.
} 
Figure 10. A General Outline of the Canadian Algorithm of the FNGSS

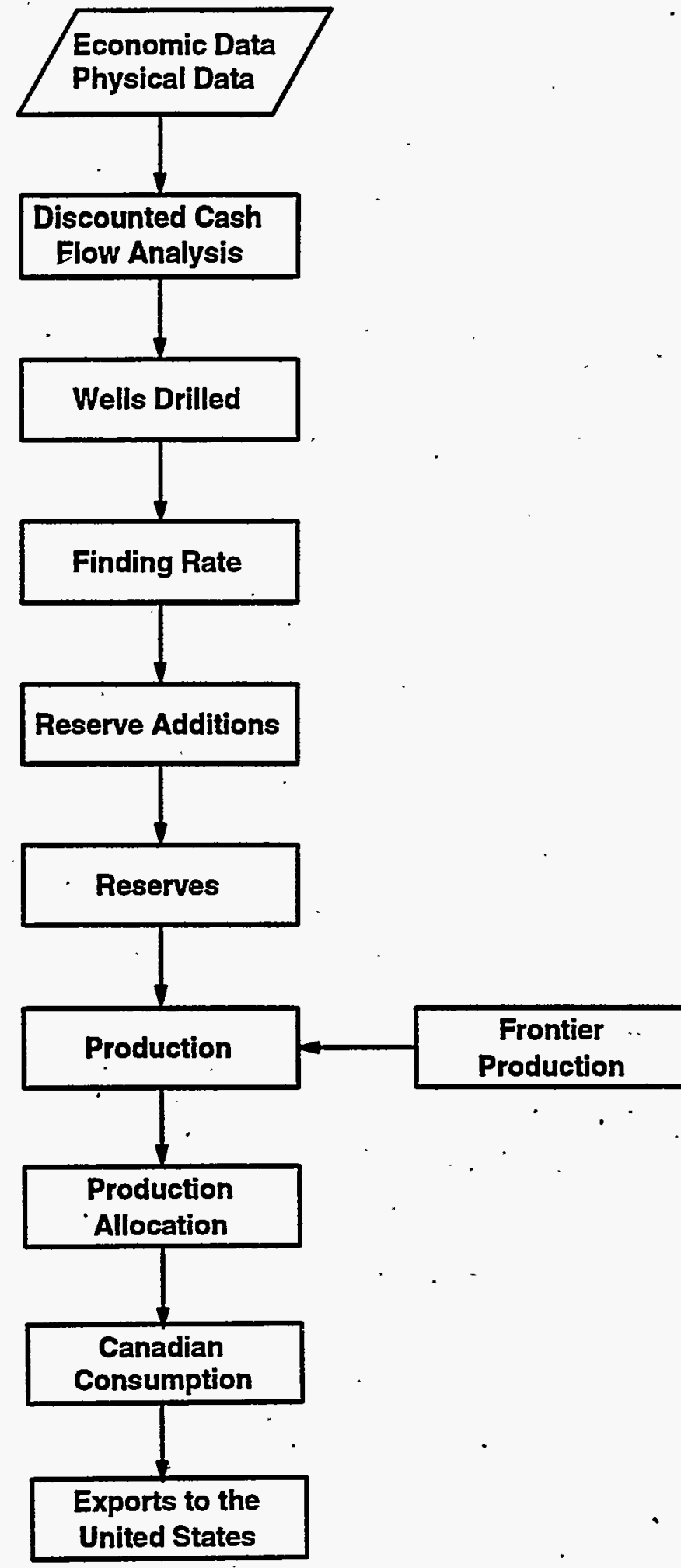


first year of production and the associated decline rate, by fuel type.

The world oil price and regional gas prices at the U.S.JCanadian border for year $t$ are received from the Petroleum Marketing Module (PMM) and the NGTDM respectively. An average Canadian wellhead gas price is determined as the weighted average of border prices less the markups from the field to the border crossing points. The weights are based on the flows of gas from the field to each border crossing point in the prior period. The Canadian wellhead prices for oil and gas, together with the expectations assumed, generate future price streams on which expected revenues are based. The subject of price expectations is presented in Appendix 4-A.

Drilling, lease equipment, and operating costs per well for year $t$ are received from the cost routines described below. The drilling and lease equipment costs per well constitute the initial capital costs and are assumed to be incurred entirely in year $t^{27}$ Operating costs are incurred over the life of the well beginning with a half year of operation (assuming uniform occurrence of initial production for each new well throughout the year). The estimate of operating costs per well in year $t$ yields the future stream of expected operating costs per well.

\section{Calculation of Costs}

Costs differ within the model for successful wells and dry holes. Costs are categorized functionally within the model as:

- Drilling costs

- Lease equipment costs

- Operating costs (including production facilities and general and administrative costs).

Relevant cost functions include TECH factors that proportionately adjust costs to reflect an annual decline due to technological improvements over time measured from the base year of the model. Such declines would be relative to what costs would otherwise be. TECH is a user specific input in the model with a prespecified default value. Enhancements to this approach is an area for consideration in later data and model development.

Drilling Costs. Drilling costs represent the expenditures for drilling successful wells or dry holes and for equipping successful wells through to the "Christmas tree" installation. The "Christmas tree" refers to the valves and fittings assembled at the top of a well to control the fluid flow. Elements that are included in drilling costs are labor, material, supplies, direct overhead for site preparation, road building, erecting and dismantling derricks and drilling rigs, drilling, running and cementing casing, machinery, tool changes, and rentals. Lease equipment required for production is included as a separate cost component, and covers equipment installed on the lease downstream from the Christmas tree.

The average cost of drilling a well in the WCSB in year $t$ is given by:

$$
\operatorname{DRILLCOST}_{k, t}=\operatorname{DRILLCOST}_{k, t-1} *(1-\mathrm{TECH} 1)
$$

where,

${ }^{27}$ Western Canadian Sedimentary Basin oil and gas prospects will be modeled as single year investments. 


$\begin{aligned} \mathbf{t} & =\text { forecast year } \\ \mathbf{k} & =\text { fuel type }(1 \text { for oil; } 2 \text { for gas) } \\ \text { DRILLCOST } & =\text { drilling costs, in Canadian dollars, of a successful oil or gas well } \\ \text { TECH1 } & =\text { assumed annual decline in costs due to improved technology. }\end{aligned}$

The costs of drilling a dry hole are formulated in a like fashion:

$$
\mathrm{DRYCOST}_{\mathrm{t}}=\mathrm{DRYCOST}_{\mathrm{t}-1} *(1-\mathrm{TECH} 1)
$$

where,

$$
\begin{aligned}
t & =\text { forecast year } \\
\text { DRYCOST } & =\text { drilling costs for a dry well in Canadian dollars } \\
\text { TECH1 } & =\text { assumed annual decline in costs due to improved technology. }
\end{aligned}
$$

Lease Equipment Costs. Lease equipment costs include the cost of all equipment extending beyond the Christmas tree, directly used to obtain production from a drilled lease. Three categories of costs are included: producing equipment, the gathering system, and processing equipment. Producing equipment costs include tubing, rods, and pumping equipment. Gathering system costs consist of flowlines and manifolds. Processing equipment costs account for the facilities utilized by successful wells. The lease equipment cost estimate for a new oil or gas well is given by:

$$
\text { LEQUIPCOST }_{\mathrm{k}, \mathrm{t}}=\mathrm{LEQUIPCOST}_{\mathrm{k}, \mathrm{t}-1} *(1-\mathrm{TECH} 2)
$$

where,

$$
\begin{aligned}
\mathbf{t} & =\text { forecast year } \\
\mathbf{k} & =\text { fuel type }(1 \text { for oil, } 2 \text { for gas) } \\
\text { LEQUIPCOST } & =\text { lease equipment costs in Canadian dollars } \\
\text { TECH2 } & =\text { assumed annual decline in lease equipment costs due to improved } \\
& \text { technology. }
\end{aligned}
$$

Operating Costs. Operating cost data, which are input on a per well basis, include three main categories of costs: normal daily operations, surface maintenance, and subsurface maintenance. Normal daily operations are further broken down into supervision and overhead, labor, chemicals, fuel, water, and supplies. Surface maintenance accounts for all labor and materials necessary to keep the service equipment functioning efficiently and safely. Costs of stationary facilities, such as roads, are also included. Subsurface maintenance refers to the repair and services required to keep the downhole equipment functioning efficiently. .

The cost of operating a well is given by:

$$
\mathrm{OPCOST}_{x, 1}=\mathrm{OPCOST}_{x, 1-1} *(1-\mathrm{TECH} 3)
$$

where,

$$
\begin{aligned}
\mathrm{t} & =\text { forecast year } \\
\mathrm{k} & =\text { fuel type (1 for oil, } 2 \text { for gas) }
\end{aligned}
$$




$$
\begin{aligned}
\text { OPCOST } & =\text { operating cost in Canadian dollars } \\
\text { TECH3 } & =\text { assumed annual decline in operating costs due to improved technology. }
\end{aligned}
$$

Drilling costs, lease equipment costs, and operating costs are integral components of the discounted cash flow analysis.

Treatment of Costs in the Model for Tax Purposes. The applicable provisions of Canadian tax law for oil and gas producers ${ }^{28}$. have been incorporated into the discounted cash flow (DCF) analysis. The DCF assumptions are consistent with standard accounting methods and with assumptions used in similar modeling efforts.

\section{Disçounted Cash Flow Analysis}

For each year $t$, the discounted cash flow for a-successful well of fuel type $\mathrm{k}$ is calculated as the present value of revenues less the present value to costs and taxes: That is,

$$
\begin{aligned}
\text { SUCDCF }_{k, t}= & (\text { PVREV - PVROY - DRILLCOST - LEQUIPCOST - PVOPCOST } \\
& - \text { PVPROVTAX - PVFEDTAX })_{k, t}
\end{aligned}
$$

where,

$$
\begin{aligned}
\mathbf{t} & =\text { 'forecast year } \\
\mathbf{k} & =\text { fuel type (1 for oil, } 2 \text { for gas) } \\
\text { SUCDCF }_{\mathrm{k}, \mathrm{t}} & =\text { discounted cash flow for a successful well } \\
\text { PVREV } & =\text { present value of expected revenues including the expected revenues from the } \\
\text { PVROY } & =\text { sale of the co-product fuel } \\
\text { DRILLCOST } & =\text { drilling cost in expected royalty payments } \\
\text { LEQUIPCOST } & =\text { lease equipment costs in year } \mathrm{t} \\
\text { PVOPCOST } & =\text { present value of expected operating cost. } \\
\text { PVPROVTAX } & =\text { present value of expected income taxes to Canadian Provinces } \\
\text { PVFEDTAX } & =\text { present value of expected federal corporate income taxes. }
\end{aligned}
$$

The associated DCF for an unsuccessful well in year $t$ is equal to:

$$
\text { DRYDCF }_{t}=-(1-\text { FEDTXR }) *(1-\text { PROVTXR }) * \text { DRYCOST }_{t}
$$

where,

$$
\begin{aligned}
\text { DRYDCF } & =\text { discounted cash flow for a dry well } \\
\text { FEDTXR } & =\text { Canadian corporate tax rate } \\
\text { PROVTXR } & =\text { weighted average provincial corporate tax rate } \\
\text { DRYCOST } & =\text { dry hole costs. }
\end{aligned}
$$

\footnotetext{
${ }^{28}$ Applicable provisions include such factors as determination and depreciation. The identification of relevant provisions and their representation with the DCF methodology will occur as part of a research effort that is not yet complete. 
The expected DCF from drilling a representative prospect of fuel type $k$ is a weighted sum of the representative DCF's of a successful and unsuccessful well, where the weights are the respective * probabilities. In other words,

$$
\mathrm{DCF}_{\mathrm{k}, \mathrm{t}}=\mathrm{SR} * \mathrm{SUCDCF}_{\mathrm{r}, \mathrm{t}}+(1-\mathrm{SR}) * \mathrm{DRYDCF}_{\mathrm{t}}
$$

where,

$$
\text { - } \mathrm{SR}=\text { success rate. }
$$

This expression accounts for the expected discounted cash flow from a representative oil (gas) well, and incorporates expected revenues, expected costs (capital and operating), expected taxes, and the risk associated with drilling an oil (gas) well.

\section{Wells Determination: Econometric model}

The total number of successful wells drilled by fuel type in each year $t$ is forecasted econometrically using the representative DCF's for each fuel type. Specifically,

$$
\begin{aligned}
\text { WELLS }_{\mathrm{k}, \mathrm{t}}= & \beta 0_{\mathrm{k}}+\beta 1_{\mathrm{k}} * \mathrm{DCF}_{\mathrm{k}, \mathrm{t}}+\beta 2_{\mathrm{k}} * \mathrm{DUM} 83_{\mathrm{t}}+\rho_{\mathrm{k}} * \text { WELLS }_{\mathrm{k}, \mathrm{t}-1}-\rho_{\mathrm{k}} * \\
& \beta 0_{\mathrm{k}}-\rho_{\mathrm{k}} * \beta 1_{\mathrm{k}} * \mathrm{DCF}_{\mathrm{k}, \mathrm{t}-1}-\rho_{\mathrm{k}} * \beta 2_{\mathrm{k}} * \mathrm{DUM}_{\mathrm{t}-1}, \\
& \text { for } \mathrm{k}=\text { oil, gas }
\end{aligned}
$$

where,

$$
\begin{aligned}
& \text { WELLS } S_{k, t}=\text { number of successful wells of fuel type } k \text { (both exploration- and } \\
& \text { development) drilled in time period } t \text {, } \\
& \mathrm{DCF}_{\mathrm{k}, \mathrm{t}}=\text { expected discounted cash flow from drilling a representative prospect of fuel } \\
& \text { type } \mathrm{k} \text { in time period } \mathrm{t} \\
& \text { DUM83 = dummy variable equal to } 1 \text { after } 1982 \\
& \beta_{\mathrm{o}}, \beta_{1}, \beta_{2}=\text { econometrically estimated parameters. }
\end{aligned}
$$

\section{Reserve Additions}

The Reserve Additions algorithm calculates units of oil and gas added to Western Canadian Sedimentary Basin proved reserves. The methodology for conversion of oil or gas resources into proved reserves is a critically important aspect of supply modeling. The actual process through which oil and gas become proved reserves is a highly complex one. This section presents a methodology that is representative of the major phases that occur, although, by necessity, it is a simplification from a highly complex reality.

Oil and gas reserve additions are calculated using a finding rate equation. Typical finding rate equations relate reserves added to wells or feet drilled in such a way that the rate of reserve additions declines as more wells are drilled. The reason for this is, all else being constant, the larger prospects typically are drilled first. Consequently, the finding rate can be expected to decline as a region matures, although the rate of decline and the functional forms are a subject of considerable debate.

Functional Forms. The proposed model adopts the basic structure of the previous EIA Canadian supply model to determine Canadian reserve additions. Specifically, Canadian oil or gas reserve additions are a 
function of the cumulative number of successful wells drilled, the estimated economically recoverable resource base for the fuel, and the rate of technological change.

The finding rate equation for each fuel type is defined by:

$$
\mathrm{FR}_{\mathrm{k}, \mathrm{t}}=\mathrm{FR}_{\mathrm{k}, \mathrm{t}-1} * \exp \left(-\delta_{\mathrm{k}, \mathrm{t}} * \mathrm{SUCWELLS} \mathrm{S}_{\mathrm{k}, \mathrm{t}}\right)
$$

whère,

$$
\begin{aligned}
\mathrm{k} & =\text { fuel type (1 for oil, } 2 \text { for gas) } \\
\mathrm{FR} & =\text { finding rate } \\
\text { SUCWELLS } & =\text { successful wells of type } \mathrm{k} \text { drilled in time period } \mathrm{t} \\
\delta & =\text { finding rate decline parameter }(\delta>0) .
\end{aligned}
$$

In this specification, the yield from successful drilling begins at the initial finding rate for each period, $\mathrm{FR}_{\mathrm{x}, \mathrm{t-1}}$, and declines exponentially thereafter. This form is consistent with assumed characteristics of the factors relevant to drilling: lognormal field size distribution and probability of discovery proportional to size. The decline parameter, $\delta$, is estimable from the finding rate equation, given an estimate for ultimate recovery. A smaller estimate for the economically recoverable resource base would result in a more rapid decrease in productivity for the same level of cumulative drilling: a larger value of $\delta$.

$$
\delta_{k, i}=\frac{\text { FR }_{k, 1-1}-\text { FRMIN }_{k}}{\mathrm{Q}_{k} *\left(1.0+\mathrm{TECH}^{t-\mathrm{T}}-\text { CUMRES }_{\mathrm{k}, t-1}\right.}
$$

where,

$$
\begin{aligned}
\mathbf{t} & =\text { forecast year } \\
\mathbf{k} & =\text { fuel type (1 for oil, } 2 \text { for gas) } \\
\mathrm{FR} & =\text { finding rate (millions of barrels in the case of oil, billion of cubic feet in the } \\
\text { FRMIN } & =\text { minimum economic finding rate } \\
\mathbf{Q} & =\text { economically recoverable resource estimate } \\
\text { TECH } & =\text { technology factor } \\
\mathrm{T} & =\text { base year of the forecast } \\
\text { CUMRES } & =\text { cumulative reserve discoveries over the projection period (initial value }=0 \text { ). }
\end{aligned}
$$

The denominator is the remaining economically recoverable resource estimate in a given period, so the cumulative reserves found over time must be deducted.

The minimum economic finding rate, FRMIN, is incorporated into equation (84) so that the cumulative reserve discoveries match the economically recoverable resource estimate when the yield from wells drilled falls to the economic minimum. Equation (84) also incorporates the benefits of technological change. Technological change-is expected to improve the productivity of drilling by increasing the physical returns per drilling unit from what it otherwise would have been. Technological change is introduced through modifications of the initial economically recoverable resource estimate, thus affecting the value of the finding rate decline parameter, $\delta$. It reflects the assumptions that technological change occurs over time and its effect is realized in the expansion of the resource estimate, thus lessening the decline rate of 
productivity and resulting in higher yields to drilling, relative to what they otherwise would have been. The growing recoverable volume necessitates recomputing $\delta$ in each period.

Total reserve additions in period $t$ is given by:

$$
\mathrm{RA}_{\mathrm{k}, \mathrm{t}}=\int_{\text {WELLLS }}^{\text {WELLS }} \mathrm{FR}_{\mathrm{k}, \mathrm{l}-\mathrm{t}} \mathrm{d}(\mathrm{WELLS})
$$

Finally, total end-of-year proved reserves for each period equals proved reserves from the previous period - plus new reserve additions less production.

$$
\mathrm{R}_{\mathrm{k}, \mathrm{l}}=\mathrm{R}_{\mathrm{k}, \mathrm{l}-\mathrm{l}}+\mathrm{RA}_{\mathrm{k}, \mathrm{t}}-\mathrm{Q}_{\mathrm{k}, \mathrm{t}}
$$

where,

$$
\begin{aligned}
t & =\text { forecast year } \\
\mathrm{k} & =\text { fuel type }(1 \text { for oil, } 2 \text { for gas) } \\
\mathrm{R} & =\text { end-of-year reserves } \\
\mathrm{Q} & =\text { production } \\
\mathrm{RA} & =\text { reserve additions. }
\end{aligned}
$$

(All volumes in millions of barrels or billions of cubic feet.)

\section{Gas Production}

Production is commonly modeled using a production to reserves ratio. A major advantage to this approack is its transparency. Additionally, the performance of this function in the aggregate is consistent with its application on the micro level. The production to reserves ratio, as the relative measure of reserves drawdown, represents the rate of extraction, given any stock of reserves.

Canadian gas production in year $\mathrm{t}$ is given by:

$$
\mathrm{Q}_{\mathrm{gas}, \mathrm{t}}=\mathrm{R}_{\mathrm{gas,t-1}} * \Omega_{\mathrm{gas}, \mathrm{t}} *\left(\dot{1}+\beta_{\mathrm{gas}} * \frac{\Delta \mathrm{P}_{\mathrm{gas,i}}}{\mathrm{P}_{\mathrm{gas,t-1}}}\right)
$$

where,

$$
\begin{aligned}
\dot{R}_{\text {gas, },-1} & =\text { end-of-year gas reserves in period } t-1 \\
\Omega_{\text {gas, }} & =\text { gas extraction rate in period } t-1 \text { (measured as the production to reserves ratio } \\
P_{G a s, t} & =\text { at the end of period } t-1) \\
\beta & =\text { gas netback price at the wellhead in period } t \\
\Delta P_{\text {gas, } t} & =\left(P_{\text {gas }, t}-P_{\text {gas, },-1}\right), \text { the change in price from } t-1 \text { to } t
\end{aligned}
$$

The proposed production equation relies on price induced variation in the extraction rate to determine short run supplies. The producible -stock of reserves equals reserves at the end of the previous period. The 
extraction rate for the current period, $\Omega_{\mathrm{gas}, \mathrm{t}}$, is assumed as the approximate extraction rate for the current period under normal operating conditions. The product of $R_{g a s, 1-1}$ and $\Omega_{g a s, t}$ is the expected, or normal, operating level of production for period $t$.

\section{Supplies from the Northern Canadian Frontier and Eastern Canada}

Frontier production in FNGSS was to be determined as.a sequence of predetermined estimates drawn from analysis of other analysis groups, such as the National Energy Board (NEB) of Canada ${ }^{29}$ and the National Petroleum Council (NPC). The NEB work published in June 1991 indicates that the economics of frontier gas recovery and transportation prevent the occurrence of frontier flows until at least 2004. Subsequent communication with NEB staff indicate that their reassessment of frontier potential would delay frontier development until after 2010. Similarly, NPC analysis ${ }^{30}$ showed that northern frontier gas would not be developed until after 2010 under most scenarios. Eastern Canada gas would occur only at the end of this period.

The present implementation of OGSM reflects the assumption that neither the northern nor eastern frontier Canadian gas sources will be developed until after 2010. This assumption appears reasonable in light of the results that other productive areas show sufficient productiye potential to meet expected internal Canadian as well as U.S. demands.

\section{Allocation of Natural Gas Production to Canada and the Canadian/U.S. Border}

Canadian natural gas production for export to the United States is estimated in several stages. First, an initial estimate of the wellhead price $\left(\mathrm{P}_{\mathrm{gas}, \mathrm{t}}\right)$ is used to determine aggregate Canadian gas production at the wellhead and aggregate Canadian demand. Total gas production available for export is estimated as,

$$
Q_{\text {ex, }}=Q_{\text {gas, }}-D_{\text {ges, }}
$$

where,

$$
\begin{aligned}
& Q_{\text {aa, }}=\text { Canadian gas available for export } \\
& Q_{\text {gas, }}=\text { Canadian gas production } \\
& D_{\text {gas,t }}=\text { Canadian gas consumption. }
\end{aligned}
$$

The second stage of the procedure determines the allocation of the gas available for export among the six Canadian/U.S. border points. This aspect of the methodology is intrinsic to the U.S. market equilibration that occurs in the NGTDM. The details of this procedure are provided in the methodology documentation for that module.

\section{Capacity Expansion}

The model treats expansion of border crossing pipeline capacity as an exogenous input. An exogenous schedule of potential capacity expansion projects has been developed that provides the incremental capacity and the build date. During execution, the submodule checks whether the period of the model run

\footnotetext{
${ }^{29}$ See, for example, Supply and Demand: 1990-2010, June 1991.

${ }^{30}$ The Potential for Natural Gas in the United States, December 1992.

${ }^{31}$ Consumption will be determined endogenously from demand functions, depending on availability of appropriate functional forms and.parameter estimates from external sources, such as the Canadian National Energy Board. If these analytical elements are not available, Canadian consumption will be an exogenous input based on published outlooks from other agencies.
} 
is greater than or equal to the specified build date in the schedule. If the result is positive, the incremental capacity is added for subsequent use in the system.

\section{Mexican Gas Trade}

Mexican gas trade is a highly complex issue. A range of noneconomic factors will influence, if not determine, future flows of gas between the United States and Mexico. Uncertainty surrounding Mexican/U.S. trade is so great that not only is the magnitude of flow for any future year in doubt, but also the direction of flow. Reasonable scenarios have been developed and defended in which Mexico may be either a net importer or exporter of hundreds of billions of cubic feet of gas by $2010 .^{32}$

The vast uncertainty and the significant influence of noneconomic factors that influence Mexican gas trade with the United States suggest that these flows should be handled on a scenario basis. A method to handle user-specified path of future Mexican imports and exports has been incorporated into FNGSS. This outlook has been drawn from the recent National Petroleum Council study on natural gas (1992). Outlooks alternatively may be developed from an assessment of current and expected industry and market circumstances as indicated in industry announcements, or articles or reports in relevant publications. The outlook, regardless of its source, is fixed, and so it will not be price responsive.

\section{Liquefied Natural Gas}

Liquefaction is a process whereby natural gas is converted into a liquid that can be shipped to distant markets that otherwise are inaccessible. Prospects for expanded imports of LNG into the United States are beginning to improve in spite of difficulties affecting the industry until recent years. Various factors contributed to the recent reemergence of LNG as an economically viable source of energy, including contracts with pricing and delivery flexibility, a growing preference toward natural gas due to the lesser environmental consequences for burning it versus other fossil fuels, and diversification and security of energy supply. The outlook for LNG imports also depends on customers' perceptions regarding supply reliability and price uncertainty.

\section{Determining U.S. Imports and Exports of LNG}

Supply costs are input to the FNGSS. These supply, or delivery, costs of LNG measure all costs including regasification; that is, gas made ready for delivery into a pipeline. These values serve as economic thresholds that must be achieved before investment in the potential LNG projects occurs.

Imported LNG costs do not compete with the wellhead price of domestically produced gas; rather, these costs compete with the purchase price of gas prevailing in the vicinity of the import terminal. This is a significant element in evaluating the competitiveness of LNG supplies, since LNG terminals vary greatly in their proximity to domestic producing areas. Terminals closer to major consuming markets have an inherent economic advantage over distant competing producing areas because of the lower transportation costs incurred.

In addition to the cost estimates, however, certain operational assumptions are required to complete the picture. Dominant factors affecting the outlook are: expected use of existing capacity, expansion at sites

\footnotetext{
${ }^{32}$ For example, the National Petroleum Council study, The Potential for Natural Gas in the United States, December 1992.
} 
with existing facilities, and construction at additional locations. The FNGSS requires specification of a combination of factors: available gasification capacity, scheduled use of existing capacity, schedules for and lags between constructing and opening a facility, expected utilization rates, and worldwide liquefaction capacity. The current version of the FNGSS implicitly assumes that tanker capacity becomes available as needed to meet the transportation requirements.

A key assumption for any LNG outlook from FNGSS is that all major operational or institutional difficulties have been incorporated into the recognized allowable schedule for capacity operation and expansion. No other difficulties arise that are not resolved expeditiously.

\section{LNG Imports from Existing Capacity}

There are four existing LNG terminal facilities in the United States, one each at Everett, Massachusetts; Lake Charles, Louisiana; Cove Point, Maryland; and Elba Island, Georgia. The latter two terminals'are currently idle (Figure 9).

Given the rather low variable costs (generally under $\$ 1.00$ for liquefaction, tanker transportation, and regasification, 'but not including production), one can argue that the import volumes for these facilities have not been, and are not expected to be, determined on the basis of full cost recovery. The schedule for reopening these facilities are drawn from the announced plans for each import terminal, and modifications can be readily introduced at the user's request.

\section{LNG Imports from Capacity Expansion}

Capacity expansion refers to additional capacity at the four sites that have capacity at present. The presence of a facility may be judged as reliable evidence that the local community has demonstrated tolerance for the facility and associated operations. The continuation of such tolerance is accepted as a working assumption.

The costs of capacity expansion are assumed to be consistent with those for new construction. Required operational assumptions include the lag in capacity expansion and the buildup period for full utilization of the incremental capacity. The difference in timing between the attainment of prices adequate to initiate capacity expansion and the initial operation of that expanded capacity is assumed to be one year. Given a required construction period likely exceeding one year, this assumption is consistent with some degree of anticipation of the growth in prices by the operators of the facility.

\section{New Construction}

Increases in LNG deliveries beyond expanded capacity at existing sites require capacity expansion at sites other than those where facilities are currently located. New capacity construction requires a set of working assumptions that are either user specified or default parameters. Major operational assumptions include:

- Selected start dates before which construction of LNG terminals on new sites would not be allowed

- Design capacity and utilization rates for the newly constructed capacity 
- Regional locations for new construction sites ${ }^{33}$

- Price increments that would bring forth additional LNG import capacity.

\footnotetext{
${ }^{33}$ The siting of new facilities in the United States is a controversial issue that is not addressed analytically.
} 


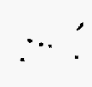


Appendix 4-A. Discounted Cash Flow Algorithm 



\section{Introduction}

The basic DCF methodology used in the Oil and Gas Supply Module (OGSM) is applied for a broad range of oil or natural gas projects, including single well projects or multiple well projects within a field. It is designed to capture the affects of multi-year capital investments (eg., offshore platforms). The expected discounted cash flow value asssociated with exploration and/or development of a project with oil or gas as the primary fuel in a given region evaluated in year $\mathrm{T}$ may be presented in a stylized form (Equation (1)).

$$
\begin{aligned}
& \text { DCF }_{\mathrm{T}}=\left(\mathrm{PVTREV}^{-}\right. \text {- PVROY - PVPRODTAX - PVDRILLCOST - PVEQUIP - } \\
& \text { PVKAP - PVOPCOST - PVABANDON - PVSIT - PVFIT) }{ }_{T}
\end{aligned}
$$

where,

$$
\begin{aligned}
\text { T. } & =\text { year of evaluation } \\
\text { PVTREV } & =\text { present value of expected total revenues } \\
\text { PVROY } & =\text { present value of expected royalty payments } \\
\text { PVPRODTAX } & =\text { present value of expected production taxes (ad valorem and severance taxes) } \\
\text { PVDRILLCOST } & =\text { present value of expected exploratory and developmental drilling } \\
\text { PVEQUIP } & =\text { expenditures } \\
\text { PVKAP } & =\text { present value of expected lease equipment costs } \\
\text { PVOPCOST } & =\text { platforms) } \\
\text { PVABANDON } & =\text { present value of expected operating costs } \\
\text { PVSIT } & =\text { present value of expected state corporate income taxes } \\
\text { PVFIT } & =\text { present value of expected federal corporate income taxes. }
\end{aligned}
$$

Costs are assumed constant over the investment life but vary across both region and primary fuel type. This assumption can be changed readily if required by the user. Relevant tax provisions also are assumed unchanged over the life of the investment. Operating losses incurred in the initial investment period are carried forward and used against revenues generated by the project in later years.

The following sections describe each component of the DCF calculation. Each variable of Equation (1) is discussed starting with the expected revenue and royalty payments, followed by the expected costs, and lastly the expected tax payments.

\section{Present Value of Expected Revenues, Royalty Payments, and Production Taxes}

Revenues from an oil or gas project are generated from the production and sale of both the primary fuel as well as any co-products. The present value of expected revenues measured at the wellhead from the production of a representative project is defined as the summation of yearly expected net wellhead price ${ }^{1}$

\footnotetext{
'The DCF methodology accommodates price expectations that are myopic, adaptive, or perfect. The default is myopic expectations, so prices are assumed to be constant throughout the economic evaluation period.
} 
times expected production ${ }^{2}$ discounted at an assumed rate. The present value of expected revenue for either the primary fuel or its co-product is calculated as follows:

$$
\text { PVREV }_{T, k}=\sum_{t=T}^{T+n}\left[Q_{t, k} * \lambda * P_{t, k} *\left[\frac{1}{1+d i s c}\right]^{1-T}\right], \lambda=\left\{\begin{array}{cc}
1 & \text { if primary fuel } \\
\text { COPRD if secondary fuel }
\end{array}\right.
$$

where,

$$
\begin{aligned}
\mathbf{k} & =\text { fuel type (oil or natural gas) } \\
\mathrm{t} & =\text { time period } \\
\mathbf{n} & =\text { number of years in the evaluation period } \\
\text { disc } & =\text { expected discount rate } \\
\mathrm{Q} & =\text { expected production volumes } \\
\mathrm{P} & =\text { expected net wellhead price } \\
\text { COPRD } & =\text { co-product factor. }
\end{aligned}
$$

Net wellhead price is equal to the market price minus any transportation costs. Market prices for oil and gas are defined as: the price at the receiving refinery for oil, the first purchase price for onshore natural gas, the price at the coastline for offshore natural gas, and the price at the Canadian border for Alaskan gas.

The present value of the total expected revenue generated from the representative project is:

$$
\text { PVTREV }_{\mathrm{T}}=\mathrm{PVREV}_{\mathrm{T}, 1}+\mathrm{PVREV}_{\mathrm{T}, 2}
$$

where,

PVREV $_{\mathrm{T}, 1}=$ present value of expected revenues generated from the primary fuel PVREV $_{T, 2}=$ present value of expected revenues generated from the secondary fuel.

The present value of expected royalty payments (PVROY) is simply a percentage of expected revenue and is equal to:

$$
\text { PVROY }_{\mathrm{T}}=\mathrm{ROYRT}_{1} * \mathrm{PVREV}_{\mathrm{T}, 1}+\mathrm{ROYRT}_{2} * \mathrm{PVREV}_{\mathrm{T}, 2}
$$

where,

$$
\text { ROYRT = royalty rate, expressed as a fraction of gross revenues. }
$$

Production-taxes consist of ad valorem and severance taxes. The present value of expected production tax is given by:

\footnotetext{
${ }^{2}$ Expected production is determined outside the DCF subroutine. The determination of expected production is described in Chapter 4.

${ }^{3}$ The OGSM determines coproduct production as proportional to the primary product production. COPRD is the ratio of units of coproduct per unit of primary product.
} 
PVPRODTAX $_{\mathrm{T}}=$ PVREV $_{\mathrm{T}, 1} *\left(1-\mathrm{ROYRT}_{1}\right) *$ PRODTAX $_{1}+\mathrm{PVREV}_{\mathrm{T}, 2} *$

where,

$$
\text { PRODTAX : = production tax rate. }
$$

PVPRODTAX is computed as net of royalty payments because the investment analysis is conducted from the point of view of the operating firm in the field. Net production tax payments represent the burden on the firm because the owner of the mineral rights generally is liable for his/her share of these taxes. .

\section{Present Value of Expected Costs}

Costs are classified within the OGSM as drilling costs, lease equipment costs, other capital costs, operating costs (including production facilities and general/administrative costs) and abandonment costs. These costs differ among successful exploratory wells, successful developmental wells, and dry holes. The present value calculations of the expected costs are computed in a similar manner as PVREV (i.e., costs are discounted at an assumed rate and then summed across the evaluation period.)

\section{Present Value of Expected Drilling Costs}

Drilling costs represent the expenditures for drilling successful wells or dry holes and for equipping successful wells through the Christmas tree installation ${ }^{4}$ Elements included in drilling costs are labor, material, supplies and direct overhead for site preparation, road building, erecting and dismantling derricks and drilling rigs, drilling, running and cementing casing, machinery, tool changes, and rentals.

The present value of expected drilling costs is given by:

$$
\begin{aligned}
\operatorname{PVDRILLCOST}_{\mathrm{T}}=\sum_{\mathrm{t}=\mathrm{T}}^{\mathrm{T}+\mathrm{n}}[ & {\left[\operatorname{COSTEXP}_{\mathrm{T}} * \mathrm{SR}_{1} * \operatorname{NUMEXP}_{\mathrm{t}}+\operatorname{COSTDEV}_{\mathrm{T}} * \mathrm{SR}_{2} *\right.} \\
& \operatorname{NUMDEV}_{\mathrm{T}}+\operatorname{COSTDRY}_{\mathrm{T}, 1} *\left(1-\mathrm{SR}_{1}\right) * \mathrm{NUMEXP}_{\mathrm{t}}+ \\
& \left.\left.\operatorname{COSTDRY}_{\mathrm{T}, 2} *\left(1-\mathrm{SR}_{2}\right) * \mathrm{NUMDEV}_{\mathrm{t}}\right] *\left(\frac{1}{1+\text { disc }}\right)^{\mathrm{t}-\mathrm{T}}\right]
\end{aligned}
$$

where,

$$
\begin{aligned}
\text { COSTEXP } & =\text { drilling cost for a successful exploratory well } \\
\text { SR } & =\text { success rate (1=exploratory, } 2=\text { developmental }) \\
\text { COSTDEV } & =\text { drilling cost for a successful developmental well } \\
\text { COSTDRY } & =\text { drilling cost for a dry hole (1=exploratory, } 2=\text { developmentai). }
\end{aligned}
$$

${ }^{4}$ The Christmas tree refers to the valves and fittings assembled at the top of a well to control the fluid flow. 
NUMEXP $=$ number of exploratory wells drilled in a given period

NUMDEV $=$ number of developmental wells drilled in a given period.

The number and schedule of wells drilled for a oil or gas project are supplied as part of the assumed production profile. This is based on historical drilling activities.

\section{Present Value of Expected Lease Equipment Costs}

Lease equipment costs include the cost of all equipment extending beyond the Christmas tree, directly used to obtain production from a drilled lease. Three categories of costs are included: producing equipment, the gathering system, and processing equipment. Producing equipment costs include tubing, rods, and pumping equipment. Gathering system costs consist of flowlines and manifolds. Processing equipment costs account for the facilities utilized by successful wells. The present value of expected lease equipment cost is

$$
\text { PVEQUIP }_{T}=\sum_{t=T}^{T+n}\left[\text { EQUIP }_{T} *\left(\operatorname{SR}_{1} * N_{U N E X P}+\operatorname{SR}_{2} * N U M D E V_{t}\right) *\left[\frac{1}{1+\text { disc }}\right]^{t-T}\right]
$$

where,

$$
\text { EQ́UIP }=\text { lease equipment costs per well. }
$$

\section{Present Value of Other Expected Capital Costs}

Other major capital expenditiures include the cost of gravel pads in Alaska, and offshore platforms. These costs are exclusive of lease equipment costs. The present value of other expected capital costs is calculated. as:

$$
\operatorname{PVKAP}_{\mathrm{T}}=\sum_{t=\mathrm{T}}^{\mathrm{T}+\mathrm{n}}\left[\mathrm{KAP}_{\mathrm{t}} *\left[\frac{1}{1+\text { disc }}\right]^{t-\mathrm{T}}\right]
$$

where,

$$
\mathrm{KAP}=\text { other major capital expenditures, exclusive of lease equipment. }
$$

\section{Present Value of Expected Operating Costs}

Operating costs include three main categories of costs: normal daily operations, surface maintenance, and subsurface maintenance. Normal daily operations are further broken down into supervision and overhead, labor, chemicals, fuel, water, and supplies. Surface maintenance accounts for all labor and materials necessary to keep the service equipment functioning efficiently and safely. Costs of stationary facilities, such as roads, also are included. Subsurface maintenance refers to the repair and services required to keep the downhole equipment functioning efficiently. 
Total operating cost in time $t$ is calculated by multiplying the cost of operating a well by the number of producing wells in time $t$. Therefore, the present value of expected operating costs is as follows:

$$
\begin{aligned}
\operatorname{PVOPCOST}_{T}=\sum_{\mathrm{t}=\mathrm{T}}^{\mathrm{T}+\mathrm{n}} & {\left[\operatorname{OPCOST}_{\mathrm{T}} * \sum_{\mathrm{k}=1}^{t}\left[\mathrm{SR}_{1} * \operatorname{NUMEXP}_{\mathrm{k}}+\mathrm{SR}_{2} * \mathrm{NUMDEV}_{\mathrm{k}}\right] *\right.} \\
& \left.\left(\frac{1}{1+\text { disc }}\right)^{\mathrm{t}-\mathrm{T}}\right]
\end{aligned}
$$

where,

$$
\text { OPCOST }=\text { operating costs per well. }
$$

\section{Present Value of Expected Abandoniment Costs}

Producing facilities are eventually abandoned and the cost associated with equipment removal and site restoration is defined as

$$
\text { PVABANDON }_{T}=\sum_{t=T}^{T+n}\left[\operatorname{CosTABN~}_{T} *\left[\frac{1}{1+\text { disc }}\right]^{t-T}\right]
$$

where,

$$
\text { COSTABN = abandonment costs. }
$$

Drilling costs, lease equipment costs, operating costs, abandonment costs and other capital costs incurred in each individual year of the evaluation period, are integral components of the following determination of State and Federal corporate income tax liability.

\section{Present Value of Expected Income Taxes}

An important aspect of the DCF calculation concerns the tax treatment. All expenditures are divided into depletable ${ }^{5}$, depreciable, or expensed costs according to current tax laws. All dry hole and operating costs are expensed. Lease costs (i.e., lease acquisition and geological and geophysical costs) are capitalized and then amortized at the same rate at which the reserves are extracted (cost depletion). Drilling costs are split between tangible costs (depreciable) and intangible drilling costs (IDC's) (expensed). IDC's include wages, fuel, transportation, supplies, site preparation, development, and repairs. Depreciable costs are amortized in accord with schedules established under the Modified Accelerated Cost Recovery System (MACRS).

Key changes in the tax provisions under the tax legislation of 1988 include:

- Windfall Profits Tax on oil was repealed.

\footnotetext{
${ }^{5}$ The DCF methodology does not include lease acquisition or geological \& geophysical expenditures because they are not relevant to the incremental drilling decision.
} 
- Investment Tax Credits were eliminated.

- Depreciation schedules shifted to a Modified Accelerated Cost Recovery System.

Tax provisions vary with type of producer (major, large independent, or small independent) as shown in Table 1. A major oil company is one that has integrated operations from exploration and development through refining or distribution to end users. An independent is any oil and gas producer or owner of an interest in oil and gas property not involved in integrated operations. Small independent producers are those with less than 1,000 barrels per day of production (oil and gas equivalent). The present DCF methodology reflects the tax treatment provided by current tax laws for large independent producers.

Table 1. Tax Treatment in Oil and Gas Production by Category of Company Under Current Tax Legislation

\begin{tabular}{|c|c|c|c|c|}
\hline \multicolumn{2}{|c|}{ Costs by Tax Treatment } & Majors & Large Independents & Small Independents \\
\hline \multicolumn{2}{|l|}{ Depletable Costs } & $\begin{array}{l}\text { Cost Depletion } \\
\text { - } \dot{G} \dot{\&} G^{\mathrm{n}} \\
\text { - Lease Acquisition }\end{array}$ & $\begin{array}{l}\text { Cost Depletion'. } \\
\text { - G\&G } \\
\text { - Lease Acquisition }\end{array}$ & $\begin{array}{l}\text { Maximum of Percentage } \\
\text { or Cost Depletion } \\
\text { - G\&G } \\
\text { - Lease Acquisition }\end{array}$ \\
\hline Depreciable Costs & & $\begin{array}{l}\text { MACRS } \\
\text { - Lease Equipment } \\
\text { - Other Capital } \\
\text { Expenditures } \\
\text { - Successful Well } \\
\text { Drilling Costs Other } \\
\text { than IDC's }\end{array}$ & \multirow[t]{2}{*}{$\begin{array}{l}\text { MACRS } \\
\text { - Lease Equipment } \\
\text { - Other Capital } \\
\text { Expenditures } \\
\text { - Successful Well } \\
\text { Drilling Costs Other } \\
\text { than IDC's }\end{array}$} & \multirow[t]{2}{*}{$\begin{array}{l}\text { MÁCRS } \\
\text { : Lease Equipment } \\
\text { - Other Capital } \\
\text { Expenditures } \\
\text { - Successful Well } \\
\text { Drilling Costs Other } \\
\text { than IDC's }\end{array}$} \\
\hline & . & $\begin{array}{l}\text { 5-year SLMd } \\
\text { - } 20 \text { percent of IDC's }\end{array}$ & & \\
\hline \multicolumn{2}{|l|}{ Expensed Costs } & $\begin{array}{l}\text { Dry Hole Costs } \\
80 \text { percent of IDC's } \\
\text { Operating Costs }\end{array}$ & $\begin{array}{l}\text { Dry Hole Costs } \\
100 \text { percent of IDC's } \\
\text { Operating Costs }\end{array}$ & $\begin{array}{l}\text { Dry Hole Costs } \\
100 \text { percent of IDC's } \\
\text { Operating Costs }\end{array}$ \\
\hline
\end{tabular}

Geological and geophysical.

'Applicable to marginal project evaluation; first 1,000 barrels per day depletable under percentage depletion.

'Modified Accelerated Cost Recovery System; the period of recovery for depreciable costs will vary depending on the type of depreciable asset.

'Straight Line Method.

Source:

The resulting present value of expected taxable income (PVTAXBASE) is given by: 


$$
\begin{array}{r}
\text { PVTAXBASE }_{T}=\sum_{t=T}^{T+n}\left[\left(\text { TREV }_{t}-\text { ROY }_{t}-\text { PRODTAX }_{t}-\text { OPCOST }_{t}-\text { ABANDON }_{t}-X_{1} \text { IDC }_{t}-\right.\right. \\
\left.\left.\operatorname{AIDC}_{t}-\text { DEPREC }_{t}-\text { DHC }_{t}\right) *\left(\frac{1}{1+\text { disc }}\right)^{t-T}\right]
\end{array}
$$

where,

$$
\begin{aligned}
\mathrm{T} & =\text { year of evaluation } \\
\mathrm{t} & =\text { time period } \\
\mathrm{n} & =\text { number of years in the evaluation period } \\
\text { TREV } & =\text { expected revenues } \\
\mathrm{ROY} & =\text { expected royalty payments } \\
\text { PRODTAX } & =\text { expected production tax payments } \\
\text { OPCOST } & =\text { expected operating costs } \\
\text { ABANDON } & =\text { expected abandonment costs } \\
\text { XIDC } & =\text { expected expensed intangible drilling costs } \\
\text { AIDC } & =\text { expected amortized intangible drilling costs } \\
\text { DEPREC } & =\text { expected depreciable tangible drilling; lease equipment costs, and other } \\
\text { DHC } & =\text { expected dry hole costs } \\
\text { disc } & =\text { expected discount rate: }
\end{aligned}
$$

TREV, ROY $_{t}$, PRODTAX $_{\text {, OPCOST }}$, and ABANDON $\mathrm{N}_{\mathrm{t}}$ are the nondiscounted individual year values as defined in equations (6), (7), (8), (12), and (13) respectively. The following sections describe the treatment of expensed and amortized costs for purpose of determining corporate income tax liability at the State and Federal level.

\section{Expected Expensed Costs}

Expensed costs are intangible drilling costs, dry hole costs, operating costs, and abandonment costs. Expensed costs and taxes (including royalties) are deductible from taxable income.

\section{Expected Intangible Drilling Costs}

For large independent producers, all intangible drilling costs are expensed. However, this is not true across the producer category (as shown in Table 1). In order to maintain analytic flexibility with respect to changes in tax provisions, the variable XDCKAP (representing the portion of intangible drilling costs that must be depreciated) is included. Expected expensed IDC's are defined as follows:

$$
\begin{aligned}
\mathrm{XIDC}_{\mathrm{t}}= & \operatorname{COSTEXP}_{\mathrm{T}} *\left(1-\mathrm{EXKAP} *\left(1-\mathrm{XDCKAP} * \mathrm{SR}_{1} * \mathrm{NUMEXP}_{\mathrm{t}}+\right.\right. \\
& . \mathrm{COSTDEV}_{\mathrm{T}} *(1-\mathrm{DVKAP}) *\left(1-\mathrm{XDCKAP} * \mathrm{SR}_{2} * \mathrm{NUMDEV}_{\mathrm{t}}\right.
\end{aligned}
$$

where,

'This variable is included only for completeness.' For large independent producers, all intangible drilling costs are expensed. 


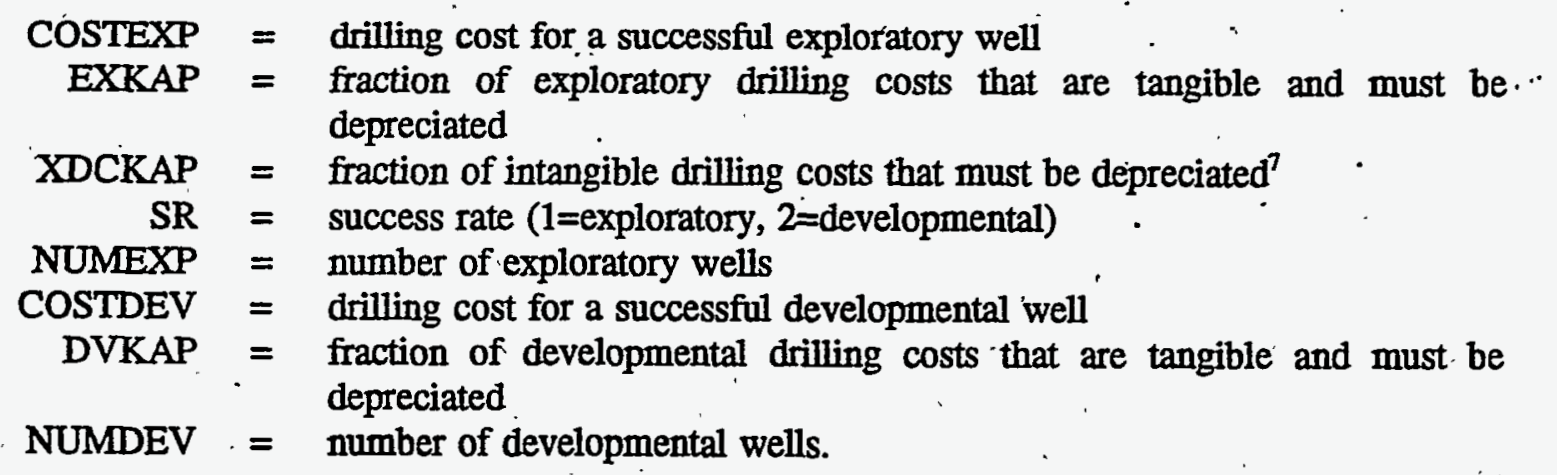

If only a portion of IDC's are expensed (as is the case for major producers), the remaining IDC's must be depreciated. These costs are recovered at a rate of 10 percent in the first year, 20 percent annually for four years, and 10 percent in the sixth year, referred to as the 5-year Straight Line Method (SLM) with half year convention. If depreciable costs accrue when fewer than 6 years remain in the life of the project, then costs are recovered using a simple straight line method over the remaining period.

Thus, the value of expected depreciable IDC's is represented by:

$$
\begin{aligned}
& \operatorname{AIDC}_{t}=\sum_{j=1}^{t}\left[\left(\operatorname{COSTEXP}_{\mathrm{T}} *(1-\mathrm{EXKAP}) * X D C K A P * \mathrm{SR}_{1} * \mathrm{NUMEXP}_{\mathrm{j}}+\right.\right. \\
& \left.\operatorname{cosTDEV}_{\mathrm{T}} *(1-\mathrm{DVKAP}) * \mathrm{XDCKAP} * \mathrm{SR}_{2} * \mathrm{NUMDEV}_{\mathrm{j}}\right) \text { * } \\
& \left.\mathrm{DEPIDC}_{t-j+1} *\left(\frac{1}{1+\mathrm{infl}}\right)^{t-j} *\left(\frac{1}{1+\text { disc }}\right)^{t-j}\right] \text {, } \\
& \dot{\beta}=\left\{\begin{array}{l}
T \text { for } t \leq T+m-1 \\
t-m+1 \text { for } t>T+m-1
\end{array}\right.
\end{aligned}
$$

where,

$$
\begin{aligned}
j & =\text { year of recovery } \\
\beta & =\text { index for write-off schedule } \\
\text { DEPIDC } & =\text { for } t \leq n+T-m, 5 \text {-year SLM recovery schedule with half year convention; } \\
\text { infl } & =\text { otherwise, } 1 /(n+T-t) \text { in each period } \\
\text { disc } & =\text { expected inflation rate } \\
\text { m } & =\text { number of years in standard recovery period. }
\end{aligned}
$$

AIDC will equal zero by default since the DCF methodology reflects the tax treatment pertaining to large independent producers.

\footnotetext{
${ }^{7}$ The fraction of intangible drilling costs that must be depreciated is set to zero as a default to conform with the tax perspective of a large independent firm.

${ }^{2}$ The write-off schedule for the 5-year.SLM give recovered amounts in nominal dollars. Therefore, recovered costs are adjusted for expected inflation to give an amount in expected constant dollars since the DCF calculation is based on constant dollar values for all other variables.
} 


\section{Expected Dry Hole Costs}

All dry hole costs are expensed. Expected dry hole costs are defined as

$$
\mathrm{DHC}_{\mathrm{t}}=\operatorname{COSTDRY}_{\mathrm{T}, 1} *\left(1-\mathrm{SR}_{1}\right) * \mathrm{NUMEXP}_{\mathrm{t}}+\operatorname{COSTDRY}_{\mathrm{T}_{2}, 2} *\left(1-\mathrm{SR}_{2}\right) * N U M D E V_{\mathrm{t}}
$$

where,

$$
\text { COSTDRY }=\text { drilling cost for a dry hole (1=exploratory, } 2=\text { developmental }) .
$$

Total expensed costs in any year equals the sum of $\mathrm{XIDC}_{\mathfrak{t}}, \mathrm{OPCOST}_{\mathfrak{t}}, \mathrm{ABANDON}_{\mathrm{t}}$, and $\mathrm{DHC}_{\mathrm{t}}$.

\section{Expected Depreciable Tangible Drilling Costs, Lease Equipment Costs and Other Capital Expenditures}

Amortization of depreciable costs, excluding capitalized IDC's, conforms to the Modified Accelerated Cost Recovery System (MACRS) schedules. The schedules under differing recovery periods appear in Table 2. The particular period of recovery for depreciable costs will conform to the specifications of the tax code. These recovery schedules are based on the declining balance method with half year convention. If depreciable costs accrue when fewer years remain in the life of the project than would allow for cost recovery over the standard period, then costs are recovered using a straight line method over the remaining period.

The expected tangible drilling costs, lease equipment costs, and other capital expenditures is defined as

$$
\begin{aligned}
& \text { DEPREC }_{t}=\sum_{j \neq \beta}^{t}\left[\left[\left(\operatorname{COSTEXP} P_{T} * E_{X K A P}+E_{Q U U P}\right) * \text { SR }_{1} * \operatorname{NUMEXP}_{j}+\right.\right. \\
& \left.\left(\operatorname{COSTDEV}_{\mathrm{T}} * \mathrm{DVKAP}+\mathrm{EQUIP}_{\mathrm{T}}\right) * \mathrm{SR}_{2} * \mathrm{NUMDEV}_{\mathrm{j}}+\mathrm{KAP}_{\mathrm{j}}\right] * \\
& \left.\operatorname{DEP}_{t-j+1} *\left(\frac{1}{1+\text { infl }}\right)^{t-j} *\left(\frac{1}{1+\text { disc }}\right)^{t-j}\right] \text {, } \\
& \beta=\left\{\begin{array}{l}
T \text { for } t \leq T+m-1 \\
t-m+1 \text { for } t>T+m-1
\end{array}\right.
\end{aligned}
$$

where,

$$
\begin{aligned}
\mathbf{j} & =\text { year of recovery } \\
\boldsymbol{\beta} & =\text { index for write-off schedule } \\
\mathrm{m} & =\text { number of years in standard recovery period } \\
\text { COSTEXP } & =\text { drilling cost for a successful exploratory well } \\
\text { EXKAP } & =\text { fraction of exploratory drilling costs that are tangible and must be } \\
\text { EQUIP } & =\text { depreciated } \\
\text { SR } & =\text { success rate }(1=\text { exploratory, } 2=\text { developmental })
\end{aligned}
$$




\begin{tabular}{|c|c|c|c|c|c|c|}
\hline Year & $\begin{array}{l}\text { 3-year } \\
\text { Recovery } \\
\text { Period }\end{array}$ & $\begin{array}{l}\text { 5-year } \\
\text { Recovery } \\
\text { Period }\end{array}$ & $\begin{array}{c}\text { 7-year } \\
\text { Recovery } \\
\text { Period }\end{array}$ & $\begin{array}{l}\text { 10-year } \\
\text { Recavery } \\
\text { Period }\end{array}$ & $\begin{array}{l}\text { 15-year } \\
\text { Recovery } \\
\text { Period }\end{array}$ & $\begin{array}{l}\text { 20-year } \\
\text { Recovery } \\
\text { Period }\end{array}$ \\
\hline 1 & 33.33 & $20.00^{\circ}$ & 14.29 & 10.00 & $5.00^{\circ}$ & 3.750 \\
\hline 2 & 44.45 & 32.00 & 24.49 & 18.00 & 9.50 & 7.219 \\
\hline 3 & 14.81 & 19.20 & 17.49 & 14.40 & 8.55 & 6.677 \\
\hline 4 & 7.41 & . 11.52 & 12.49 & 11.52 & 7.70 & 6.177 \\
\hline 5 & & -11.52 & 8.93 & 9.22 & $6.93^{\circ}$ & 5.713 \\
\hline 6 & . & 5.76 & 8.92 & 7.37 & 6.23 & 5.285 \\
\hline 7 & & . & 8.93 & 6.55 & 5.90 & 4.888 \\
\hline 8 &.$:$ & & 4.46 & 6.55 & 5.90 & 4.522 \\
\hline 9 & ' & & & 6.56 & 5.91 & 4.462 \\
\hline 10 & & & & 6.55 & 5.90 & 4.461 \\
\hline 11 & & . & & 3.28 & 5.91 & 4.462 \\
\hline 12 & & & v & - & 5.90 & 4.461 \\
\hline 13 & & · & & & 5.91 & 4.462 \\
\hline 14 & . & & & & .5 .90 & 4.461 \\
\hline 15 & $\cdot$ & & & - & 5.91 & 4.462 \\
\hline 16 & & & & & 2.95 & 4.461 \\
\hline 17 & $\because$ & & & & $\cdot$ & 4.462 \\
\hline 18 & & $\cdot$ & & & & 4.461 . \\
\hline$\cdot 19$ & · & & & . & & 4.462 \\
\hline 20 & & & & $\cdot$ & & 4.461 \\
\hline 21 & . & . & & & & 2.231 \\
\hline
\end{tabular}

Source: U.S. Master Tax Guide.

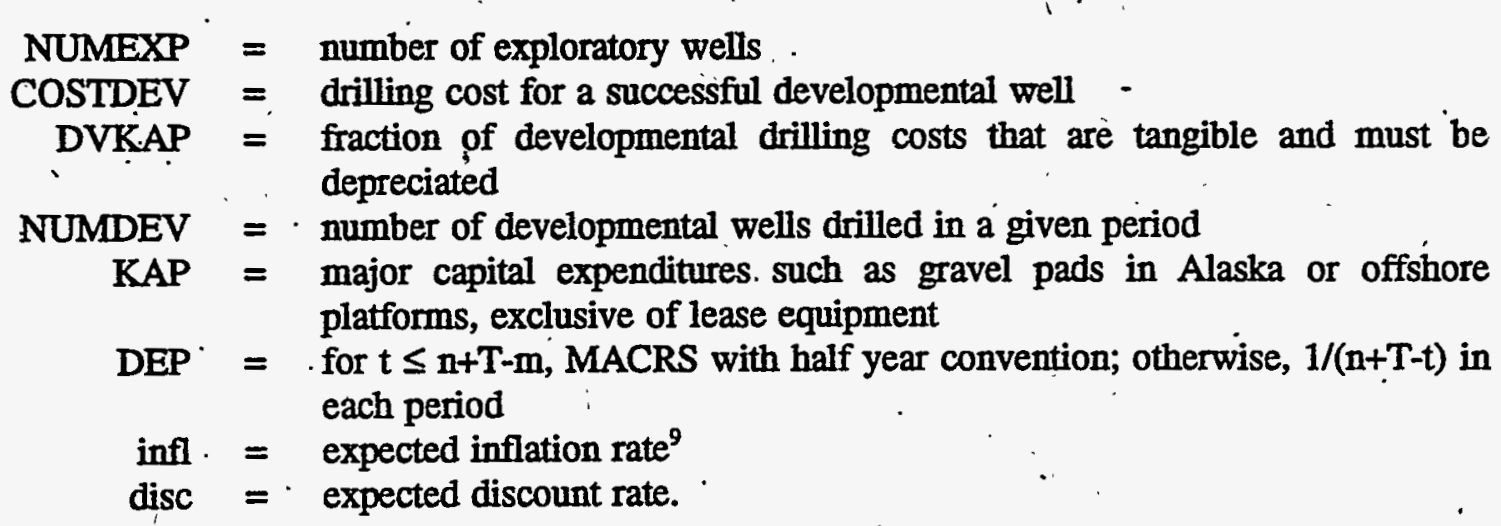

${ }^{9}$ Each of the write-off schedules give recovered amounts in nominal dollars. Therefore, recovered costs are adjusted for expected inflation to give an amount in expected constant dollars since the DCF calculation is based on constant dollar values for all other variables. 


\section{Present Value of Expected State and Federal Income Taxes}

The present value of expected state corporate income tax is determined by

$$
\text { PVSIT }_{\mathrm{T}}=\text { PVTAXBASE }_{\mathrm{T}} * \text { STRT }
$$

where,

$$
\begin{aligned}
\text { PVTAXBASE } & =\text { present value of expected taxable income (Equation (14)) } \\
\text { STRT } & =\text { state income tax rate. }
\end{aligned}
$$

The present value of expected federal corporate income tax is calculated using the following equation:

$$
\text { PVFIT }_{\mathrm{T}}=\text { PVTAXBASE }_{\mathrm{T}} *(1-\mathrm{STRT}) * \mathrm{FDRT}^{2}
$$

where,

$$
\text { FDRT }=\text { federal corporate income tax rate. }
$$

\section{Summary}

The discounted cash flow calculation is a useful tool for evaluating the expected profit or loss from an oil or gas project. The calculation reflects the time value of money and proyides a good basis for assessing and comparing projects with different degrees of profitability. The timing of a project's cash inflows and outflows has a direct affect on the profitability of the project. As a result, close attention has been given to the tax provisions as they apply to costs.

The discounted cash flow is used in each submodule of the OGSM to determine the economic viability of oil and gas projects. Various types of oil and gas projects are evaluated using the proposed DCF calculation, including single well projects and multi-year investment projects. Revenues generated from the production and sale of co-products also are taken into account.

The DCF routine requires important assumptions, such as costs and tax provisions. Drilling costs, lease equipment costs, operating costs, and other capital costs are integral components of the discounted cash flow analysis. The default tax provisions applied to the costs follow those used by independent producers. Also, the decision to invest does not reflect a firm's comprehensive tax plan that achieves aggregate tax benefits that would not accrue to the particular project under consideration. 

Appendix 4-B. LNG Cost Determination Methodology 



\section{Introduction}

The expected LNG import volumes will respond to the projected gas prices at the point of delivery into the U.S. pipeline network. That is, the unit cost of imported $\mathrm{LNG}^{1}$ will be compared to the cost of other gas available to the pipeline network at that location. Unit LNG costs will be computed as the project revenue at the breakeven point, averaged over expected throughput. The proposed methodology comprises a generalized computation of LNG project costs. These costs serve as the minimum price at which the associated volumes would flow.

The LNG project investment will have a positive expected discounted cash flow when the price exceeds the computed delivered cost (including taxes), which is comprised of three components distinguished with respect to the separate operational phases: liquefaction, shipping, and regasification. Each cost component will be expressed as the cost incurred at each phase to supply a unit of LNG.

The proposed method is intended to be transparent, representative of economic costs, and accounting for some degree of tax liability. The specific level of costs may be affected by local factors that vary costs or tax liability between countries. The sole operational phase on U.S. soil is the regasification terminals. The cost of taxes for these facilities will be determined on the basis of the relevant tax law provisions, including the Modified Accelerated Cost Recovery System (MACRS). Operational phases involving nonU.S. capital (liquefaction facilities and tankers) will represent the tax liability associated with these facilities as property taxes. ${ }^{2}$

$$
\operatorname{DCST}_{t}=\mathrm{LIQCST}_{t}+\operatorname{SHPCST}_{t}+\operatorname{RGASCST}_{t}
$$

where;

$$
\begin{aligned}
\mathbf{t} & =\text { forecast year } \\
\text { DCST }_{\mathbf{t}} & =\text { delivered cost per unit of } \mathrm{LNG} \\
\mathrm{LIQCST}_{\mathbf{t}} & =\text { liquefaction cost per unit of } \mathrm{LNG} \\
\text { SHPCST }_{\mathbf{t}} & =\text { shipping cost per unit of } \mathrm{LNG} \\
\text { RGASCST }_{\mathrm{t}} & =\text { regasification cost per unit of } \mathrm{LNG} .
\end{aligned}
$$

A brief description of these components is presented below, followed by the actual formulas used for these estimations.

\section{Liquefaction}

The liquefaction revenue requirement is composed of capital costs, operation and maintenance costs, and miscellaneous costs, as follows:

\footnotetext{
'A unit of LNG will be measured as a thousand cubic feet equivalent of the regasified LNG.

${ }^{2}$ This approach, while a severe simplification of a highly complex reality, is a practical altemative that is consistent with the method used in a Gas Research Institute study (1988) and the recent National Petroleum Council study (1992).
} 


$$
\operatorname{LIQCST}_{t}=\frac{\text { CAPCSTS }_{\mathrm{Lt}}+\mathrm{OMCSTS}_{\mathrm{L}, t}+\operatorname{MSCSTS}_{\mathrm{Lt}}}{\mathrm{UTIL}_{\mathrm{L}, t} * \operatorname{CPCTY}_{\mathrm{L}, t}}
$$

where,

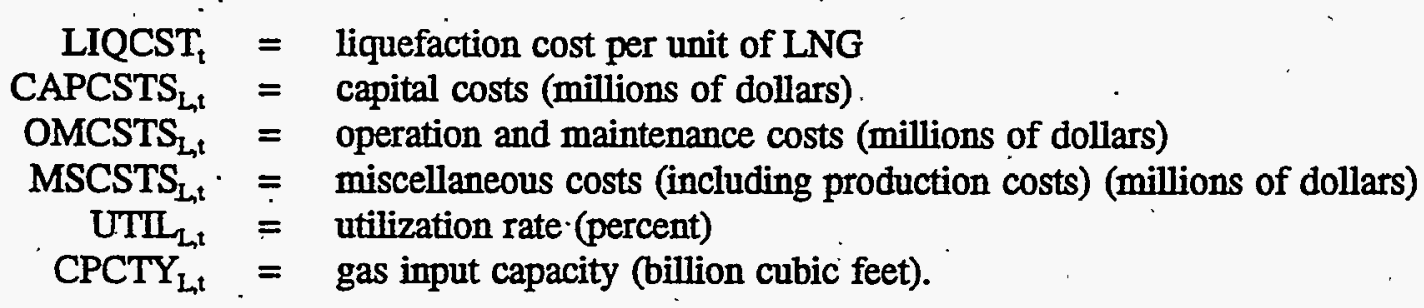

Capital costs are derived from a rate base that includes equipment costs for gas pretreatment, liquefaction process, utilities, storage, loading facilities, marine facilities, overhead, engineering, fees, and infrastructure costs. The debt/equity ratio, cost of capital, and the tax rate are essential in calculating these costs. Additionally, a method of depreciation, such as the straight line method, must be established for the investment. Capital costs are represented by the following equation:

$$
\operatorname{CAPCSTS}_{\mathrm{L}, t}=\mathrm{DEP}_{\mathrm{L}, \mathrm{t}}+\mathrm{INTR}_{\mathrm{L}, t}+\mathrm{ROE}_{\mathrm{L}, \mathrm{t}}+\mathrm{TAX}_{\mathrm{L}, \mathrm{t}}
$$

where,

$$
\begin{aligned}
& \text { CAPCSTS }_{\mathrm{L}, \mathrm{t}}{ }^{\prime}=\text { capital costs } \\
& \cdot \operatorname{DEP}_{\mathrm{L}, \mathrm{t}}=\text { depreciation (INVST } \mathrm{I}_{\mathrm{L}} \mathrm{n}_{\mathrm{L}} \text { ) } \\
& \mathrm{NVVT}_{\mathbf{L}}=\text { capital investment (millions of dollars) } \\
& n_{L}=\text { useful life of investment } \\
& \text { INTR } \left._{\mathrm{L}, \mathrm{t}}=\text { interest on debt (RBASE } \mathrm{R}_{\mathrm{L},} * \mathrm{~d}_{\mathrm{L}} * \mathrm{kd}_{\mathrm{L}}\right) \\
& \text { RBASE }_{\mathrm{L}, \mathrm{t}}=\text { rate base }\left(\mathrm{INVST}_{\mathrm{L}}-\mathrm{ACCDEP}_{\mathrm{L}, \mathrm{t}}\right) \\
& \operatorname{ACCDEP}_{\mathrm{L}, t}=\text { accumulated depreciation }\left(\sum_{y=1}^{+} \mathrm{DEP}_{\mathrm{L}, \mathrm{y}}\right) \\
& \mathrm{d}_{\mathrm{L}}=\text { debt financing amount (fraction) } \\
& \mathrm{kd}_{\mathrm{L}}=\text { cost of debt (percent) } \\
& \mathrm{y}=\text { year of investment } \\
& \left.\mathrm{ROE}_{\mathrm{L}, \mathrm{t}}=\text { return on equity (RBASE } \mathrm{R}_{\mathrm{L}, \mathrm{t}} * \mathrm{e}_{\mathrm{L}} * \mathrm{ke}_{\mathrm{I}}\right) \\
& \mathrm{e}_{\mathrm{L}}=\text { equity financing amoiunt }\left(1-\mathrm{d}_{\mathrm{L}}\right) \text { (fraction) } \\
& \mathrm{ke}_{\mathrm{L}}=\cdot \text { cost of equity (percent) } \\
& \text { TAX }_{\mathrm{L}, \mathrm{t}}=\text { tax on capital (INVST } * \text { TRATE }_{\mathrm{L}} \text { ) } \\
& \operatorname{TRATE}_{\mathrm{L}}=\text { tax rate (percent). }
\end{aligned}
$$

Operation and maintenance costs include raw materials, labor, materials, general plant, direct costs, and insurance. Miscellaneous costs include production and feed gas costs.

The utilization rate is represented as a percentage of the sustainable capacity. For both liquefaction and regasification, a buildup period toward the maximum utilization rate may be included as an assumption to reflect a scenario that is more consistent with the historical experience of LNG projects. 


\section{Shipping}

The shipping component of the delivered cost also consists of capital costs, operation and maintenance costs, and miscellaneous costs, as represented by the following:

$$
\text { SHPCST }_{t}=\frac{\text { CAPCSTS }_{t, t}+\operatorname{OMCSTS}_{t, t}+\text { MSCSTS }_{t, t}}{\text { VOLYR }_{t, t}}
$$

where,

$$
\begin{aligned}
\text { SHPCST }_{t} & =\text { shipping cost per unit of } \mathrm{LNG} \\
\text { CAPCSTS }_{t, t} & =\text { capital costs (millions of dollars) } \\
\text { OMCSTS }_{b, t} & =\text { operation and maintenance costs (millions of dollars) } \\
\text { MSCSTS }_{s, t} & =\text { miscellaneous costs (millions of dollars) } \\
\text { VOLYR }_{b, t} & =\text { shipping volume per year (billion cubic feet) }
\end{aligned}
$$

Again, key components in calculating capital costs are the type of financing and the cost of financing. Capital costs are represented as follows:

$$
\operatorname{CAPCSTS}_{\mathrm{s}, t}=\mathrm{DEP}_{\mathrm{s}, \mathrm{t}}+\mathrm{INTR}_{\mathrm{t}, \mathrm{t}}+\mathrm{ROE}_{\mathrm{s}, \mathrm{t}}+\mathrm{TAX}_{\mathrm{t}, \mathrm{t}}
$$

where,

$$
\begin{aligned}
& \text { CAPCSTS }_{\mathrm{k}, \mathrm{t}}=\text { capital costs } \\
& \left.\operatorname{DEP}_{\mathrm{s}, \mathrm{t}}=\text { depreciation (INVST } \sqrt{\sqrt{n}} \mathrm{n}_{\mathrm{a}}\right) \\
& \text { INVST }_{s}=\text { capital investment (millions of dollars) } \\
& n_{s}=\text { useful life of investment }
\end{aligned}
$$

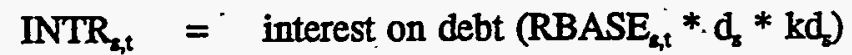

$$
\begin{aligned}
& \text { RBASE }_{a, t}=\text { rate base }\left(\text { INVST }_{z}-\text { ACCDEP }_{z, t}\right) \\
& \operatorname{ACCDEP}_{s, t}=\text { accumulated depreciation }\left(\sum_{y=1}^{t} \mathrm{DEP}_{s, y}\right) \\
& d_{\delta}=\text { debt financing amount (fraction). } \\
& \mathrm{kd}_{\mathrm{z}}=\text { cost of debt (percent) } \\
& \mathrm{y}=\text { year of investment } \\
& \text { ROE } \left._{s, t}=\text { return on equity (RBASE } \text { R }_{s, t} * e_{s} * \mathrm{ke}_{\mathrm{s}}\right) \\
& e_{s}=\text { equity financing amount }\left(1-d_{\varepsilon}\right) \text { (fraction) } \\
& \text { - } \mathbf{k e}_{\mathrm{s}}=\text { cost of equity (percent) } \\
& \text { TAX }_{s, t}=\operatorname{tax} \text { on capital (INVST } \text { (TRATE }_{s} \text { ) } \\
& \text { TRATE }_{\mathrm{s}}=\text { tax rate (percent). }
\end{aligned}
$$

Operation and maintenance costs for shipping include those for crew, repair, administrative and general overhead, and insurance.

A key element in the operating costs for shipping is the distance that the LNG must travel. This distance will affect the amount of LNG that can be transported annually, and ultimately will affect the annual unit 
cost of transporting gas. Assumptions about average speed, operating days per year, and boiloff LNG used for fuel also affect the calculation of shipping volume per year. The calculation for finding the volume that can be shipped per year is represented as follows:

$$
\text { VOLYR }_{t, t}=\text { VLTRIP }_{s, t} * \operatorname{TRIPS}_{\mathrm{s}, \mathrm{t}} \text {. }
$$

where,

$$
\begin{aligned}
& \text { VOLYR } R_{s, t}=\text { shipping volume per year (billion cubic feet) } \\
& \text { VLTRIP }_{s, t} .=\text { volume per trip }\left(\text { CPCTY }_{s, t}-\text { BOILTRP }_{s, t}\right) \text { (billion cubic feet) } \\
& \mathrm{CPCTY}_{s, t}=\text { shipping capacity (billion cubic feet) } \\
& \text { BOILTRIP } \left._{s, t}=\text { boiloff per trip [BOILDAY }{ }_{s, t} *\left(\text { HOURS }_{s, t} / 24\right)\right] \text { (billion cubic feet) } \\
& \text { BOILDAY }_{s, t}=\text { boiloff per day (billion cubic feet) } \\
& \text { HOURS } \left._{s, l}=\text { hours per round-trip ( } 2 * \text { MILES }_{s, l} / \text { SPEED }_{s, t}\right) \\
& \text { MILES }_{s, t}=\text { one-way distance (nautical miles) } \\
& \text { SPEED }_{s, t}=\text { average speed of trip (nautical miles per hour) } \\
& \text { TRIPS } \left._{t, t}=\text { trips per year (OPDAYS } \text { (DAYS }_{k, t}\right) \quad \therefore \\
& \text { OPDAYS }_{\mathrm{s}, \mathrm{t}}=\text { operating days per year. } \\
& \text { DAYS }_{\mathrm{s}, \mathrm{t}}=\text { days per trip (HOURS } \mathrm{s}, \mathrm{l} 24+\mathrm{PORT}_{\mathrm{s}, \mathrm{t}} \text { ) } \\
& \text { PORT }_{s, t}=\text { port days per round-trip }
\end{aligned}
$$

Miscellaneous costs include tankers fuel costs (nitrogen and bunker) and port costs.

\section{Regasification}

Regasification terminals consist of capital and operation and maintenance costs, as shown in the following:

$$
\text { RGASRR }_{t}=\frac{\text { ĆAPCSTS }_{s, t}+\text { OMCSTS }_{r, t}}{\text { UTLL }_{t, t} * \operatorname{CPCTY}_{r, t}}
$$

where,

$$
\begin{aligned}
\text { RGASRR }_{t} & =\text { regasification cost per unit of } L N G \\
\text { CAPCSTS }_{x, t} & =\text { capital costs (millions of dollars) } \\
\text { OMCSTS }_{r, t} & =\text { operation and maintenance costs (millions of dollars) } \\
\text { UTIL }_{t, t} & =\text { utilization rate (percent) } \\
\text { CPCTY }_{t, t} & =\text { terminal capacity (billion cubic feet). }
\end{aligned}
$$

For existing terminals, original capital expenditures are considered sunk costs. The capital outlays for both re-activation and expansion are examined, along with costs of capital, method of financing, and tax rates. These capital costs can be represented as follows:

$$
\operatorname{CAPCSTS}_{r, t}=\operatorname{RSCAP}_{x, t}+\operatorname{EXCAP}_{x, t}
$$

where, 
$\operatorname{RSCAP}_{\mathrm{r}, \mathrm{t}}=$ restart capital costs.

$\operatorname{EXCAP}_{r, t}=$ expansion capital costs.

Both of these capital expenditures ${ }^{3}$ can be represented in the same way as the capital costs for liquefaction or shipping. The formulae are as follows:

$$
\operatorname{RSCAP}_{t, t}=\operatorname{RSDEP}_{s, t}+\operatorname{RSINTR}_{\mathrm{r}, \mathrm{t}}+\mathrm{RSROE}_{t, t}+\operatorname{RSTAX}_{\mathrm{r}, \mathrm{t}}
$$

whère,

$$
\begin{aligned}
& \text { RSDEP }_{z, t}=\text { depreciation (RSINVST }{ }_{r}^{*} \text { RSDRATE }_{r, \text { }} \text { ) } \\
& \text { RSINVST }_{r}=\text { capital investment in re-activation (millions of dollars) } \\
& \text { RSDRATE }_{r, t}=\text {.depreciation rate } \\
& \left.\operatorname{RSINTR}_{\mathrm{d}, \mathrm{f}}=\text { interest on debt (RSRBASE } \mathrm{R}_{\mathrm{t}, \mathrm{t}} * \mathrm{~d}_{\mathrm{r}} * \mathrm{kd}_{\mathrm{f}}\right) \\
& \text { RSRBASE }_{s, t}=\text { rate base }\left(\text { RSINVST }_{r}-\text { RSACCDEP }_{r, 2}\right) \\
& \operatorname{RSACCDEP}_{s, t}=\text {. accumulated depreciation }\left(\sum_{y=1}^{t} \operatorname{RSDEP}_{\mathrm{r}, \mathrm{y}}\right) \\
& \mathrm{d}_{\mathrm{r}}=\text { debt financing amount (fraction) } \\
& \mathrm{kd}=\text { cost of debt. (percent) } \\
& y=\text { year of re-activation } \\
& \operatorname{RSROE}_{\mathrm{r}, \mathrm{t}}=\text { return on equity (RSRBASE } \mathrm{R}_{\mathrm{s}, \mathrm{e}} * \mathbf{e}_{\mathrm{r}} * \mathrm{ke}_{\mathrm{s}} \text { ) } \\
& \mathrm{e}_{\mathrm{s}}=\text { equity financing amount }\left(1-\mathrm{d}_{\mathrm{s}}\right) \text { (fraction) } \\
& \mathrm{ke}_{\mathrm{r}}=\text { cost of equity (percent) } \\
& \text { RSTAX }_{r, t}=\text { tax on capital (RSINVST } \text { R }_{\mathbf{r}} \text { RSTRATE }_{\mathrm{r}} \text { ) } \\
& \text { RSTRATE }_{\mathrm{r}}=\text { tax rate (percent). }
\end{aligned}
$$

and,

$$
\operatorname{EXCAP}_{t, t}=\operatorname{EXDEP}_{x, t}+\operatorname{EXINTR}_{r, t}+\operatorname{EXROE}_{r, t}+\operatorname{EXTAX}_{x, t}
$$

where,

$$
\begin{aligned}
& \text { EXDEP } \left._{r, t}=\text { depreciation (EXINVST }{ }_{r}^{*} \text { EXDRATE }_{r, t}\right) \\
& \text { EXINVST }_{r}=\text { capital investment in expansion (millions of dollars) } \\
& \text { EXDRATE }_{x, t}=\text { depreciation rate } \\
& \text { EXINTR } \left._{x, t}=\text { interest on debt (EXRBASE }{ }_{r, t} * \mathbf{d}_{r} * \mathrm{kd}_{\mathrm{r}}\right) \\
& \text { EXRBASE }_{r, t}=\text { rate base }\left(\text { EXINVST }_{r}-\text { EXACCDEP }_{r, t}\right) \\
& \operatorname{EXACCDEP}_{\mathrm{r}, t} \cdot=\text { accumulated depreciation }\left(\sum_{\mathrm{y}=1}^{t} \operatorname{EXDEP}_{s, \mathrm{y}}\right) \\
& \mathrm{d}_{\mathrm{I}}=\text { debt financing amount (fraction) }
\end{aligned}
$$

${ }^{3}$ In practice, it is not expected that both restarting an existing facility and capacity expansion at the same site would occur in the same year. Thus, RSCAP and EXCAP are not expected to both be nonzero in the same year. 


$$
\begin{aligned}
& \mathrm{kd}_{\mathbf{1}}=\text { cost of debt (percent) } \\
& \text {. } y=\text { year of expansion } \\
& \text { EXROE }_{t, t}=\text { return on equity (EXRBASE } \mathrm{E}_{\mathrm{s}, \mathrm{t}} * \mathrm{e}_{\mathrm{s}} * \mathrm{ke}_{\mathrm{r}} \text { ) } \\
& e_{s}=\text { equity financing amount }\left(1-d_{r}\right) \text { (fraction) } \\
& \mathrm{ke}_{\mathrm{r}}=\text { cost of equity (percent) } \\
& \left.\operatorname{EXTAX}_{s, t}=\cdot \operatorname{tax} \text { on capital (EXINVST }{ }_{\mathrm{r}} * \text { EXTRATE }_{\mathrm{r}}\right) \\
& \text { EXTRATE }=\text { tax rate (percent). }
\end{aligned}
$$

Operating and maintenance costs for a regasification terminal include: terminaling and processing, labor, storage, administrative and general overhead. 
Appendix 4-C. Finding Rate Methodology 



\section{Introduction}

The purpose of this appendix is to describe the finding rate methodology in the Oil and Gas Supply Module (OGSM). The finding rate methodology represents the process by which oil and gas in the unproved portion of the economically recoverable resource base ${ }^{1}$ convert to proved reserves ${ }^{2}$. This appendix begins with a discussion of the basic finding rate methodology utilized in OGSM. This includes a presentation of a simple finding rate equation, as well as successive adaptations to accommodate the particular nature of the resource estimates and to incorporate the effects of technological change. Next, there is a description of the implementation of this methodology in OGSM, focusing on modifications consistent with the model's resource accounting system.

\section{Basic Finding Rate Methodology}

The finding rate measures the yield from exploratory drilling, that is, the amount of reserves discovered per unit of exploratory drilling. A basic assumption underlying the finding rate methodology in OGSM is that the larger the oil or gas field, the greater the probability that it will be discovered. Another is that large oil and gas fields, though fewer in number, contain a disproportionate amount of total resources. These assumptions suggest that finding rates will decline as drilling progresses. The exact nature of this decline is subject to debate, but one or another form of exponential decline has been utilized by several well known discovery process models ${ }^{3}$. OGSM borrows from these models in assuming an exponentially declining finding rate relationship between cumulative reserves discovered and cumulative exploratory. drilling. The basic finding rate equation in OGSM reflects this relationship. Given an initial finding rate, FR0, an increase in the cumulative drilling leads to an exponential decline in the finding rate. ${ }^{4}$ This may be expressed in equation form as:

$$
\mathrm{FR}=\mathrm{FRO} * \exp (-\delta * S W)
$$

where,

$$
\begin{aligned}
\text { FR } & =\text { finding rate (Mbbl per well or.MMcf per well) } \\
\text { SW } & =\text { cumulative successful exploratory wells } \\
\delta, F R 0 & =\text { parameters. }
\end{aligned}
$$

The derivation of the parameter $\delta$, the exponential decline factor, is based on the properties inherent in Equation (1). In the limit, the amount of economic oil or gas discovered equals the level of undiscovered

\footnotetext{
${ }^{1}$ Economically recoverable resources are those volumes considered to be of sufficient size and quality for their production to be commercially profitable by current conventional technologies, under specified economic assumptions. Economically recoverable volumes include proved reserves, inferred reserves, as well as undiscovered and other unproved resources. These resources may be recoverable by techniques considered either conventional or unconventional. On the other hand, technically recoverable resources are those volumes producible with current recovery technology and efficiency but without reference to economic viability.

${ }^{2}$ Proved reserves are the estimated quantities that analysis of geological and engineering data demonstrate with reasonable certainty to be recoverable in future years from known reservoirs under existing economic and operating conditions.

${ }^{3}$ See, for example, Arps, J.J. and T.G. Roberts. 1958.

${ }^{4}$ As will be shown, the finding rate implemented in OGSM declines exponentially within each period, but not exponentially over the entire forecast, as $\delta$ is recalculated each year based on a different estimate for the remaining economically recoverable resource biase.
} 
oil or gas (Q). This relationship can be expressed as the integral of the finding rate over an infinite number of successful wells (Equation (2)).

$$
\mathrm{Q}=\int_{0}^{\infty} \mathrm{FRO} * \exp (-\delta * \mathrm{SW}) \mathrm{d}(\mathrm{SW})
$$

It follows that the rate of decline ( $\delta$ ) can be expressed as the simple ratio of the initial finding rate (FR0) to the remaining undiscovered resource base (Q). From Equation (2),

$$
\begin{aligned}
\mathrm{Q} & =\int_{0}^{\infty} \mathrm{FR} 0 * \exp (-\delta * \mathrm{SW}) \mathrm{d}(\mathrm{SW}) \\
& =\frac{\mathrm{FR} 0}{-\delta} \int_{0}^{\infty} \exp (-\delta * \mathrm{SW}) *(-\delta) * \mathrm{~d}(\mathrm{SW}) \\
& =\left.\left(-\frac{\mathrm{FR} 0}{\delta}\right) * \exp (-\delta * \mathrm{SW})\right|_{S W=0} \\
& =\left(-\frac{\mathrm{FR} 0}{\delta}\right) *(0-1) \\
& =\frac{\mathrm{FR} 0}{\delta}
\end{aligned}
$$

or,

$$
\delta=\frac{F R 0}{Q}
$$

From Equation (4) one can see that a smaller resource base estimate would result in a more rapid decrease in productivity, indicated by a larger value of $\delta$. An important aspect of Equation (4) is that the denominator represents remaining recoverable resources as of the period comesponding to the origin for the specified function. This attribute is especially germane to the introduction of technology into the finding rate, which is discussed later in this appendix.

The basic finding rate methodology in OGSM can be further illustrated by a-simple graphic presentation of the preceding concepts. The curve FC in Figure 11 represents the finding rate function described by Equation (1). The point at which FC intersects with the $y$-axis is the initial finding rate, FRO. In accordance with the previous discussion; the finding rate decreases exponentially along the $x$-axis, which represents cumulative drilling (SW). The decline in the finding rate curve $\mathrm{FC}$ is determined by the exponential rate of decline ( $\delta$ ), derived in Equation (4) above as a function of the initial finding rate and the ultimate resource target, $\mathrm{Q}$. 
Figure 11. Basic Finding Rate Function

1

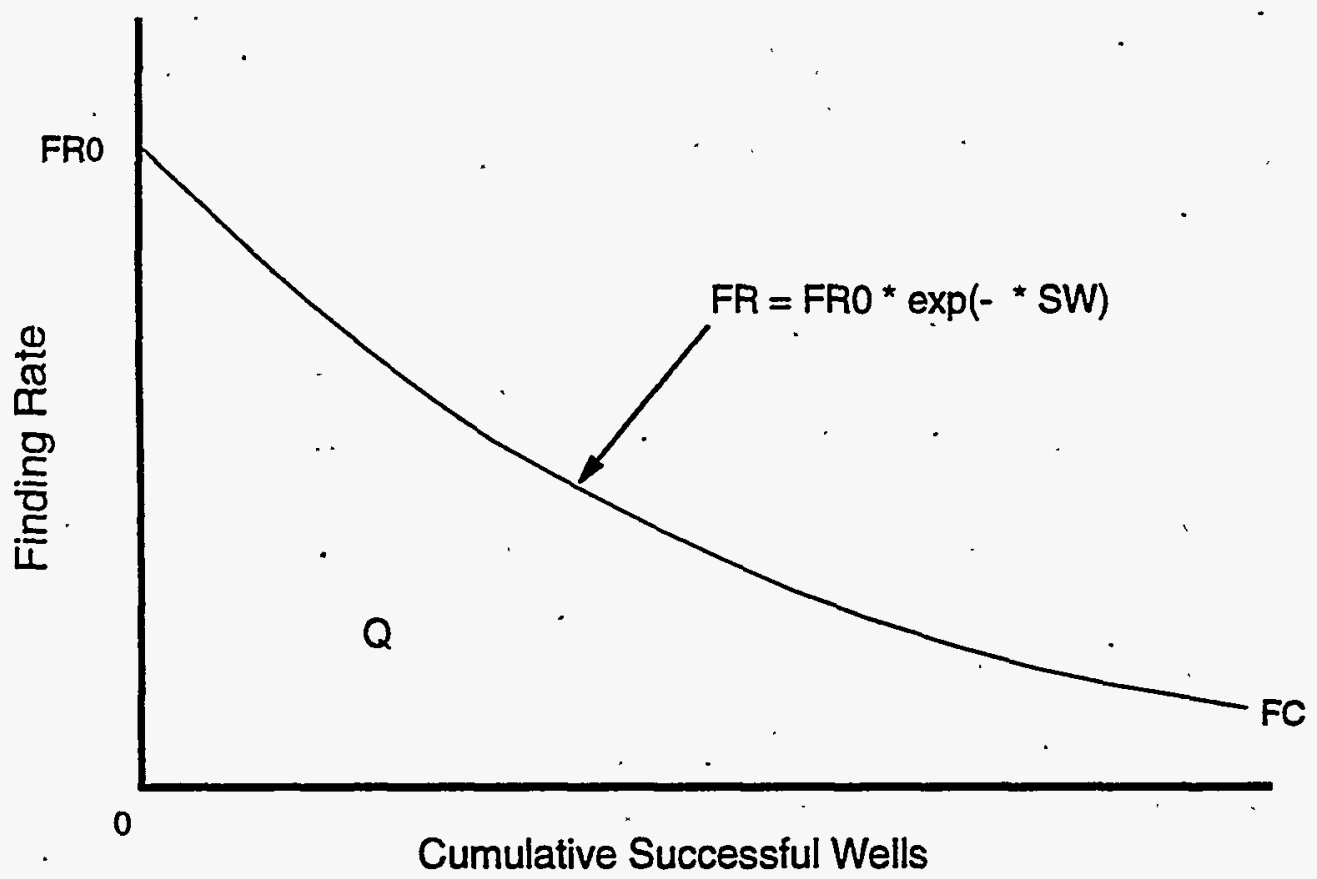

Given this methodology, the level of reserve additions in period $t$ can be calculated as the integral of the finding rate Equation (1) over the range of cumulative successful exploratory wells from the previous period, $t-1$, through the current forecast year. This may be expressed in equation form as:

$$
R A_{t}=\left(\frac{F R 0}{\delta}\right) *\left[\exp \left(-\delta \cdot S W_{t-1}\right)-\exp \left(-\delta * S W_{t}\right)\right]
$$

where,

$$
\begin{aligned}
\mathbf{t} & =\text { forecast year } \\
\mathrm{RA} & =\text { reserve additions from exploratory drilling } \\
\mathrm{SW} & =\text { cumulative successful exploratory wells } \\
\delta, \mathrm{FR} 0 & =\text { parameters. }
\end{aligned}
$$

Reserve additions are graphically represented in Figure 12 . The area beneath the curve FC in Figure 10 stands for the remaining undiscovered resource base (Q). Any segment of this total area, as determined by movement along the $x$-axis, represents the amount of reserve additions (RA) discovered as a result of the indicated change in cumulative drilling. Accordingly, an increase in cumulative drilling from $S W_{1}$ to $\mathrm{SW}_{2}$ would result in a quantity of discoveries defined by the segment $A-B-S W_{2}-S W_{1}$. In this case the finding rate declines from $F R_{1}$ to $F R_{2}$ as drilling increases from $S W_{1}$ to $S W_{2}$. 
Figure 12. Reserve Additions

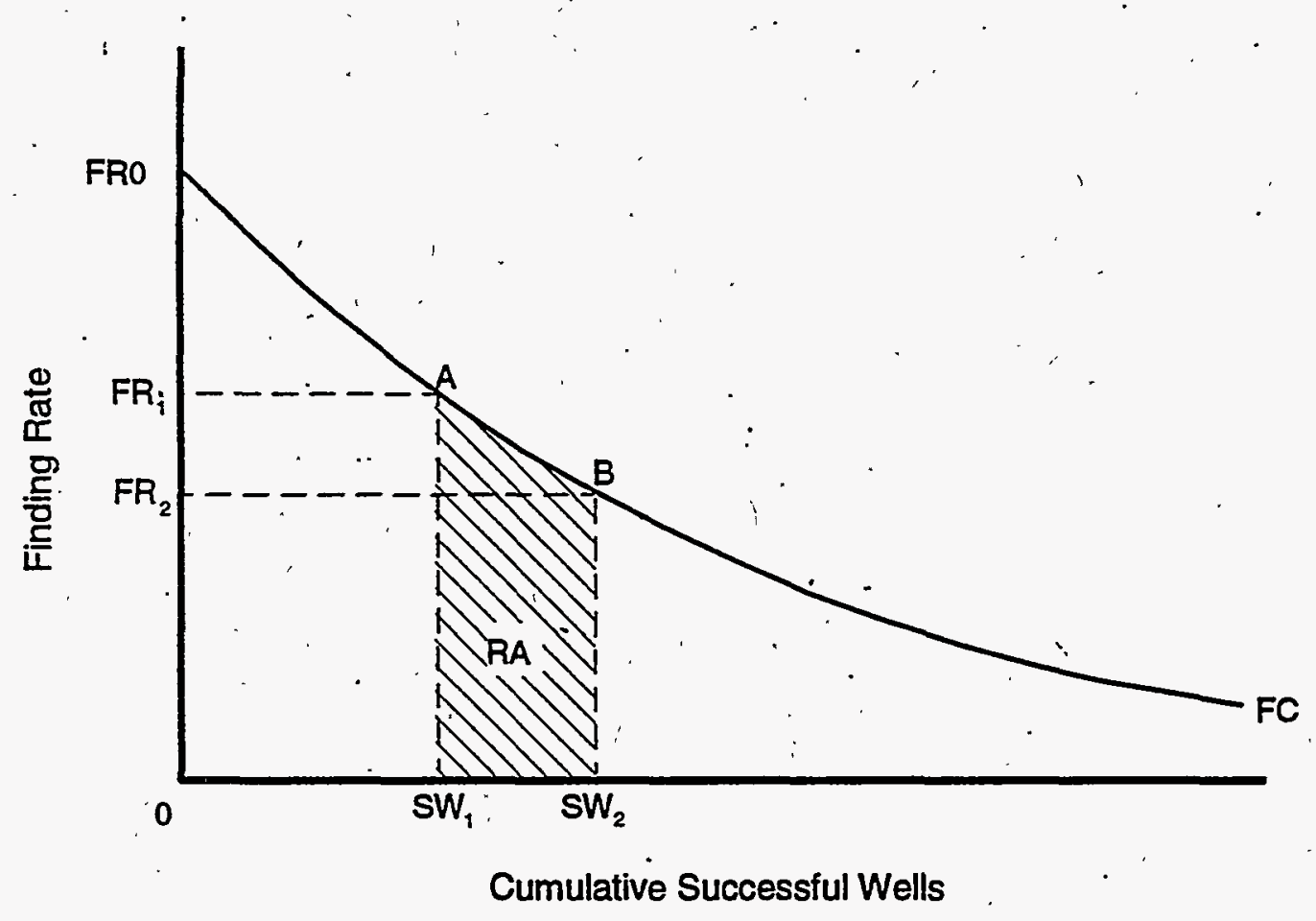

\section{Minimum Economic Finding Rate}

The $Q$ parameter as described previously is the total resource base, which is recoverable only with an infinite number of wells. The resource estimates employed in OGSM, however, represent only the resources that are economically recoverable. Implicit in these estimates is the existence of some minimum physical return to exploratory drilling that would make such activities profitable enough to be undertaken. This concept is represented in OGSM in the form of a minimum economic finding rate (FRMIN). The minimum economic finding rate is presented in Figure 13. FRMIN is reached when cumulative successful wells increase to $S W^{*}$. The undiscovered economically recoverable resource base $\left(Q^{\mathrm{E}}\right)$ is represented by the shaded area beneath the finding rate curve (FC) and left of the drilling level at which the curve intersects with FRMIN.

By utilizing the concept of a minimum economic finding rate, it is possible to obtain an estimate of $\delta$ that is based on the economically recoverable resource base, yet is consistent with the methodology proposed in Equations (3) and (4). Equation (3) now becomes: 
Figure 13. Minimum Economic Finding Rate

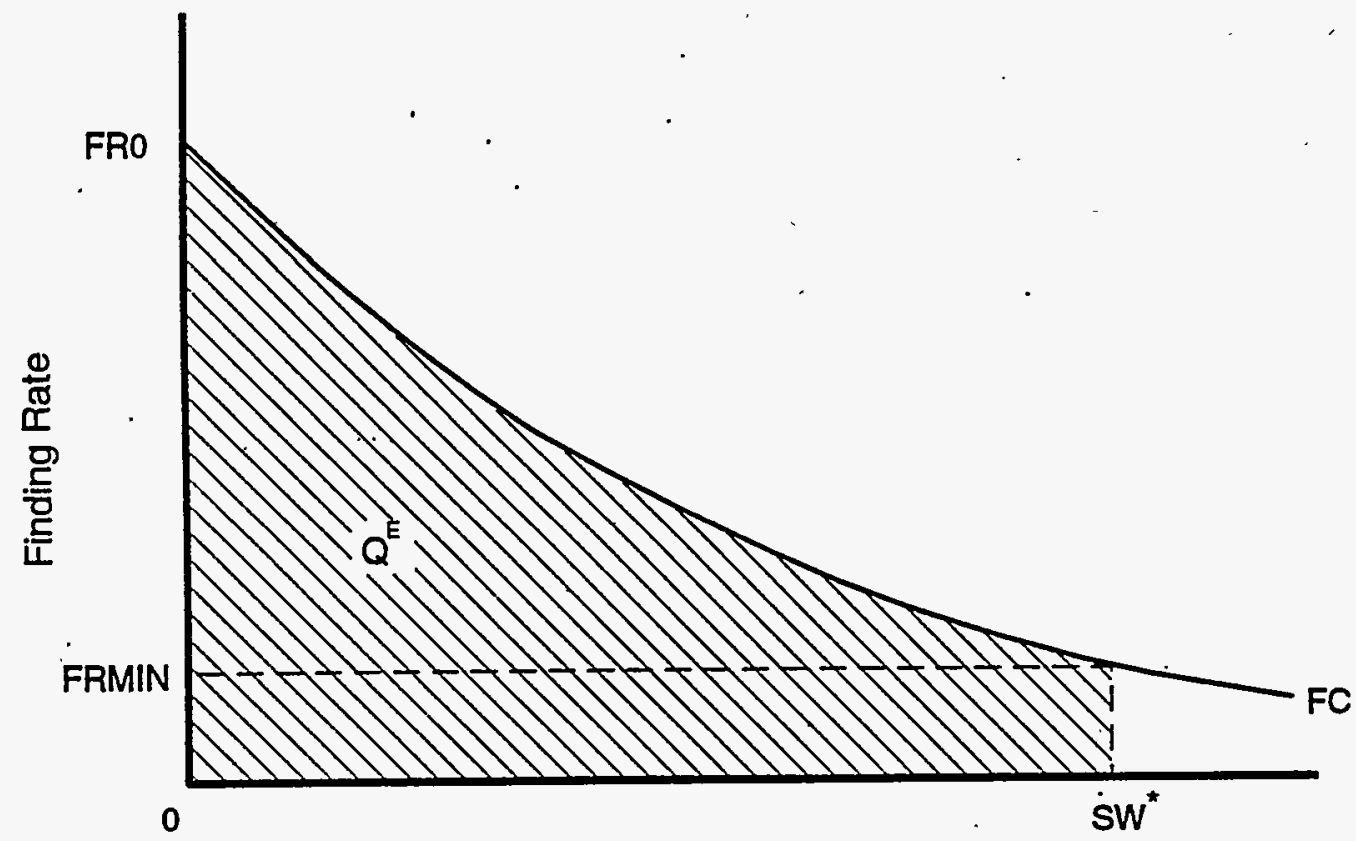

Cumulative Successful Wells

$$
\begin{aligned}
Q^{B} & =\int_{0}^{S W^{\bullet}} \mathrm{FR} 0 * \exp (-\delta * S W) \mathrm{d}_{\mathrm{SW}} \\
& =\frac{\mathrm{FR} 0}{-\delta} \int_{0}^{\mathrm{SW}} \exp (-\delta * \mathrm{SW}) *(-\delta) * \mathrm{~d}_{\mathrm{SW}} \\
& =\left(-\frac{\mathrm{FR} 0}{\delta}\right) * \exp (-\delta * \mathrm{SW})_{\mathrm{SW}-0} \\
& =\left(-\frac{\mathrm{FR} 0}{\delta}\right) *\left(\exp \left(-\delta * S W^{*}\right)-1\right) \\
& =\frac{\mathrm{FR} 0-\mathrm{FR} 0 *\left(\exp \left(-\delta * \mathrm{SW}^{*}\right)\right)}{\delta}
\end{aligned}
$$

where,

$$
\begin{aligned}
& \mathrm{SW}^{*}= \text { level of cumulative drilling at which minimum } \\
& \text { economic finding rate is attained }
\end{aligned}
$$

and, since FR0* $\exp \left(-\delta * S W^{*}\right)$ is equivalent to FRMIN, Equation (4) converts to: 


$$
\delta=\frac{(\text { FRO }- \text { FRMIN) }}{Q^{E}}
$$

\section{Technological Change}

The OGSM methodology incorporates the benefits of technological change into the finding rate. Technological change is expected to improve the productivity of drilling by increasing the physical returns per unit drilling from what it otherwise would have been. The treatment of technological change is illustrated in Figure 14. Given an initial economically recoverable resource base $Q^{B}$, the section $A-B-S W_{2}-$ $S W_{1}$ represents the reserves that would be added as a result of a drilling increase from $S W_{1}$ to $S W_{2}$. If, concurrent to this increase in drilling, there are technological advances that cause the remaining economically recoverable resource base to expand by an amount $\Delta_{1} Q^{\mathbb{B}}$, the operative finding rate curve becomes $F_{1} . F C_{1}$ reflects the decrease in the rate of decline in the finding rate brought about by the expanded resource base. The amount of extra reserve additions due to technological change is then defined by the section A-B-C. Similarly, when drilling increases from $S W_{2}$ to $S_{3}$, and accompanying advances in technology cause the remaining economically recoverable resource base to.expand by an amount $\Delta_{2} Q^{\mathrm{B}}$, there is a further decrease in the rate of decline that produces the new finding rate curve, $\mathrm{FC}_{2}$. Reserve additions are again increased over what would have been achieved under preexisting technology, this time by an amount defined by the section C-E-F. This latter increase is incremental to the extra reserves discovered as a result of the technological advances that transpired as drilling progressed from $\mathrm{SW}_{1}$ to $\mathrm{SW}_{2}$ (the section defined by B-D-E-C).

Technological change is introduced through modifications of the initial economically recoverable resource estimate in Equation (7). The specific change affects the role of the finding rate decline parameter, $\delta$. It reflects the assumptions that technological change occurs over time and its effect is realized in the expansion of the resource estimate, thus lessening the decline rate of productivity. Because the remaining recoverable volume is expanding relative to what it otherwise would have been, $\delta$ must be recalculated in each period as shown in Equation (8). Note that the continual recalculation of the equation parameter $\delta$ requires a respecification of the initial finding rate. The fixed constant, FRO, is replaced with FR ${ }_{t-1}$, the marginal finding rate for the last well drilled in the previous period. This procedure is equivalent to specifying a new function in each period $t$, the origin of which is located at $\mathrm{SW}_{\mathrm{t}-1}$. The denominator is the remaining economically recoverable resource estimate, and it is calculated as the initial economically recoverable resource base adjusted for expansion due to technological change, less the cumulative reserves found over time.

$$
\delta_{t}=\frac{F R_{t-1}-F R M I N}{\text { QTECH }_{t}-\text { CUMRES }_{t-1}}
$$

where,

$\mathrm{FR}=$ finding rate at the beginning of period

FRMIN $=$ minimum economic finding rate

QTECH = initial economically recoverable resource base adjusted for expansion due to technological change

$\mathrm{t}=$ forecast year

$\mathrm{T}=$ base year

4-C-6 - Energy Information Administration/Oil and Gas Supply Model Documentation 
Figure 14. Technological Change

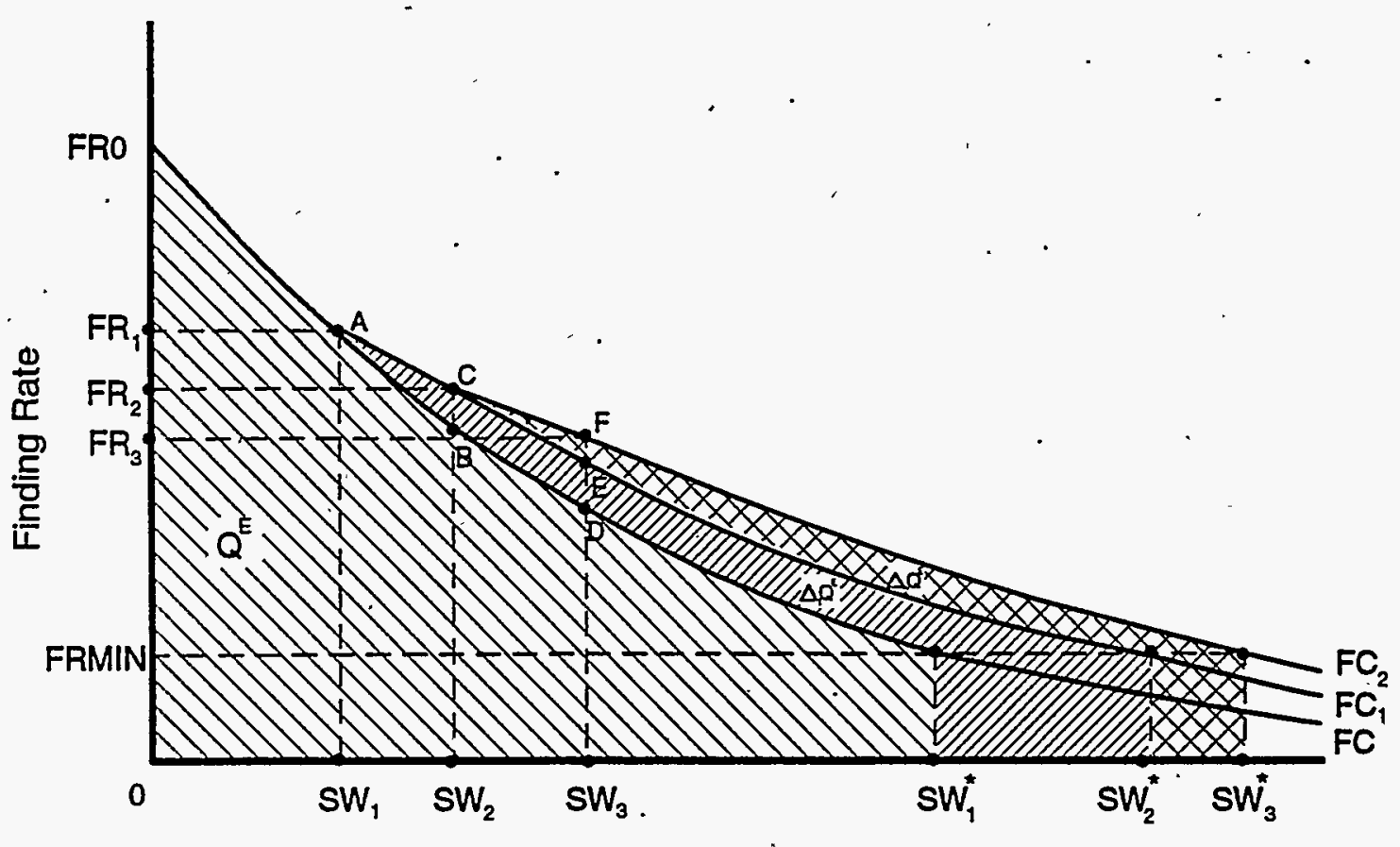

Cumulative Successfui Wells

CUMRES $=$ cumulative reserve discoveries over the projection period (initial value $=0$ ).

As indicated in Equation (8) the resource base is assumed to expand over time due to the development of new discovery and extraction technologies, as well as the increased penetration of existing technologies. This technologically induced expansion is modeled in two ways in OGSM's.

One method of modeling technological expansion involves-simply. allowing the initial resource base to exparid each year at an assumed constant rate. This methodology is used in OGSM to expand inferred reserves, those unproven resources converted to proven reserves by developmental and other exploratory (non-new field wildcat) drilling. In this case the representation of the technologically expanded resource base becomes:

$$
\mathrm{QTECH}_{\mathrm{t}}=\mathrm{I} *(\cdot 1+\mathrm{TECH})^{\mathrm{t}-\mathrm{T}}
$$

where,

\footnotetext{
${ }^{5}$ Use of two approaches for representing technology in the present version of OGSM raises an issue of methodological consistency. The current implementation for new field discoveries resolves a concern raised by reviewers of the model regarding infinite expansion of the recoverable resource base. Limitations of time and data did not allow addressing this issue in the case of other exploratory and developmental drilling. OGSM development plans inciude review and likely modification of the finding rates prior to the next Annual Energy Outlook.
} 


$\begin{aligned} \mathrm{I} & =\text { initial inferred reserves estimate in year } \mathrm{T} \\ \mathrm{TECH} & =\text { annual percentage expansion of resource base due to technological change. }\end{aligned}$

A different method is used to represent the effect of technology upon undiscovered economically recoverable resources, the resource base from which reserves are added in OGSM by the drilling of new field wildcats. In order to not allow undiscovered recoverable resources to expand infinitely yet at the same time allow for a reasonable degree of technologically induced growth, these resources expand asymptotically toward a target resource value. The target represents the ultimate long-term 'expansion that is expected to occur in the undiscovered economically recoverable resource base as a result of technological progress. The functional form shows continuous expansion of the recoverable resource base, but at diminishing rates. This specification is consistent with a view of the endless potential of technological improvement and the increasing difficulties encountered with additional recovery from a finite resource base. The OGSM representation of this new field resource base, as adjusted for technological expansion, is as follows:

$$
\mathrm{QTECH}_{\mathrm{t}}=\mathrm{Q}^{\mathrm{E}}+\left(\mathrm{Q}^{*}-\mathrm{Q}^{\mathrm{B}}\right) *(1-\exp (-\gamma * \mathrm{t}))
$$

where,

$$
\begin{gathered}
Q^{*}=\begin{array}{l}
\text { ultimate undiscovered economically recoverable resource level given long- } \\
\text { term technological change }
\end{array} \\
\gamma=\begin{array}{l}
\text { parameter that determines the incremental expansion of the undiscovered } \\
\text { economically recoverable resource base due to technological change }
\end{array}
\end{gathered}
$$

The value of $\gamma$ in Equation (10) can be derived based on several assumptions. The first assumption is that the expanded resource base will in the last forecast year $(2010 ; t-T=20)$ reflect an implied rate of annual percentage expansion, $\mathrm{TECH}^{6}$, such that:

$$
\mathrm{QTECH}_{20}=\mathrm{Q}^{\mathrm{B}} *(1+\mathrm{TECH})^{20}
$$

The second assumption is that the expanded recoverable resource base in 2010 equals a given fraction, $\phi$, of the ultimate expansion target. This relation can be expressed as:

$$
\mathrm{QTECH}_{20}=\dot{\phi} * \mathrm{Q}^{*}
$$

Which implies:

$$
\mathrm{Q}^{*}=\frac{\mathrm{QTECH}_{20}}{\phi}
$$

Substituting the right side of Equation (11) into Equation (13), and using that expression to replace for $Q^{*}$ in Equation (10), yields:

\footnotetext{
- The value of TECH is generally equivalent to the rate utilized to determine resource expansion for other types of drilling within the same fuel category. For those drilling types, developmental and other exploratory, the representation of technological expansion is as indicated in equation (9).
} 


$$
\mathrm{QTECH}_{20}=\mathrm{Q}^{\mathrm{B}}+\left(\mathrm{Q}^{\mathrm{B}} *(1+\mathrm{TECH})^{20} / \phi-\mathrm{Q}^{\mathrm{B}}\right) *(1-\exp (-\gamma * \mathrm{t}))
$$

Because $\mathrm{QTECH}_{20}=\mathrm{Q}^{\mathrm{B} *}(1+\mathrm{TECH})^{20}$, Equation (14) for 2010 appears as the following equation:

$$
\mathrm{Q}^{\mathrm{B}} *(1+\mathrm{TECH})^{20}=\mathrm{Q}^{\mathrm{B}}+\left(\mathrm{Q}^{\mathrm{B}} *(1+\mathrm{TECH})^{20} / \phi-\mathrm{Q}^{\mathrm{B}}\right) *(1-\exp (-\gamma * 20))
$$

One can then solve for $\gamma$ as follows:

$$
\begin{aligned}
& \mathrm{Q}^{\mathrm{E}_{*}}\left((1+\mathrm{TECH})^{20}-1\right)=\mathrm{Q}^{\mathrm{B}} *\left(\left((1+\mathrm{TECH})^{20} / \phi-1\right) *(1-\exp (-\gamma * 20))\right. \\
& \frac{(1+\mathrm{TECH})^{20}-1}{(1+\mathrm{TECH})^{20} / \phi-1}=1-\exp (-\gamma * 20) \\
& \exp (-\gamma * 20)=1-\frac{(1+\mathrm{TECH})^{20}-1}{(1+\mathrm{TECH})^{20} / \phi-1} \\
& \therefore \\
& \left.\gamma=-\frac{\ln \left[1-\frac{(1+\mathrm{TECH})^{20}-1}{(1+\mathrm{TECH})^{20} / \phi-1}\right.}{20}\right] .
\end{aligned}
$$

As illustrated above (Figure 14), the total expected expansive effect of advancing technology upon the recoverable resource base is introduced in increments. This treatment for technological change provides for a gradual introduction of technology over time. This approach is superior to one in which a larger initial resource value is used to determine a $\delta$ that remains constant over time. With that approach, the complete expected benefits of technological change appear even in the early years of the forecast horizon, which would be an inappropriate attribute of such analysis. Figure 15 provides a graphical comparison of these two approaches in the early years. $\mathrm{FC}_{x}$ is the finding rate curve derived by calculating a constant $\delta$ based on FRO and a resource base, $\mathrm{QTECH}_{20}\left(=\mathrm{Q}^{\mathrm{B} *}(1+\mathrm{TECH})^{20}\right)$, that reflects the full expected benefits of technological change for the entire forecast horizon. In this case the section defined by FRO-A-C-F-G represents the excess reserve additions that would be estimated as a result of the overcounting inherent in the "full benefit" approach. .

\section{Implementation of the Finding Rate Methodology}

The finding rate process actually implemented in OGSM is somewhat more complex than the simple structure portrayed above, although the underlying concepts remain the same. The changes to the basic design mostly reflect the reserve accounting system instituted in OGSM. In the previous Energy 
Figure 15. Technological Change: Incremental versus Full Benefit Approach

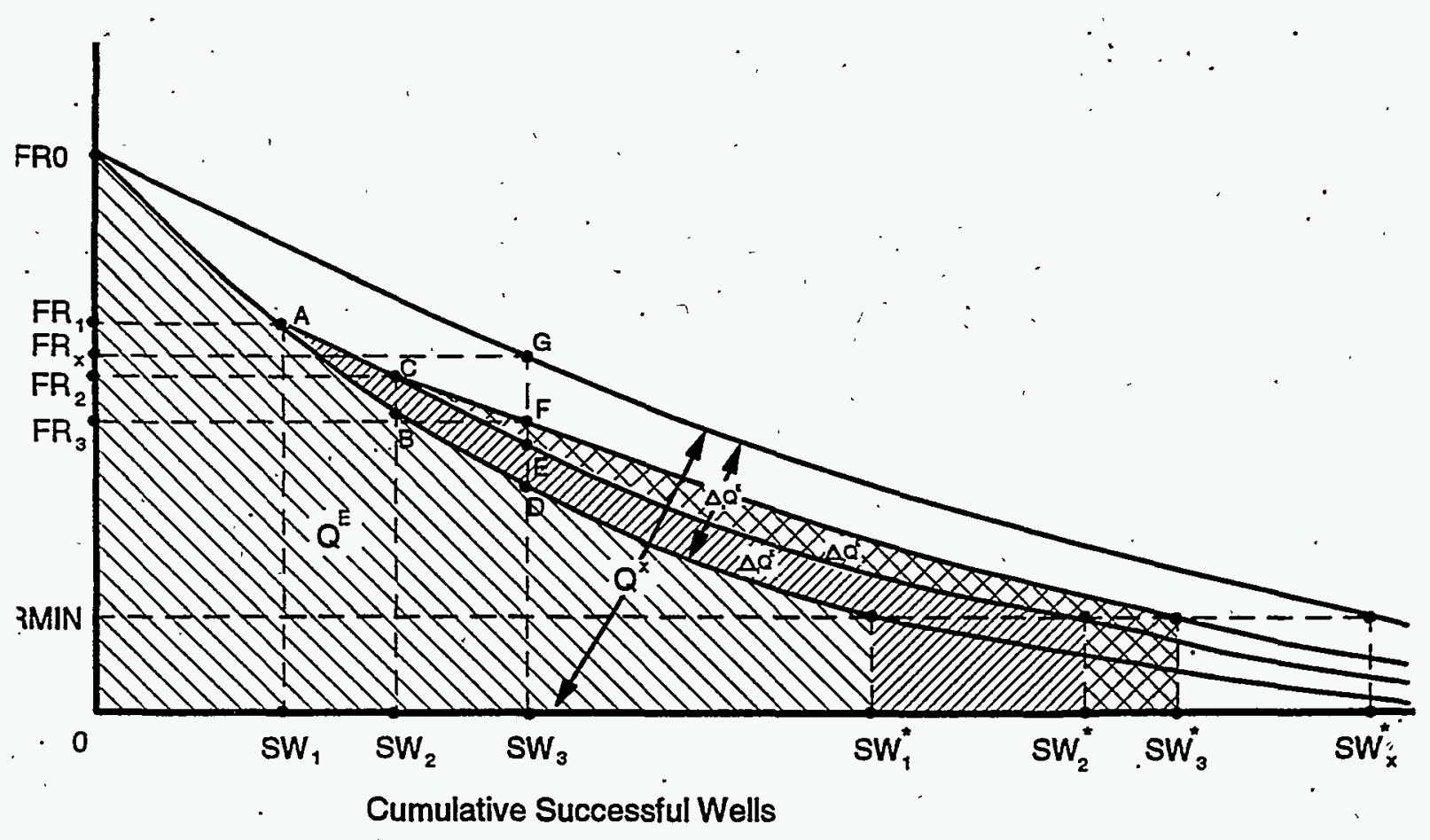

Information Administration (EIA) supply model, the Production of Onshore Lower 48 Oil and Gas Model (PROLOG), reserve additions were treated primarily as a function of undifferentiated exploratory drilling. The relatively small amount of reserve additions from other sources was represented as coming from developmental drilling. Reserve additions from developmental drilling were not related directly to exploratory activity.

In the Oil and Gas Supply Model (OGSM) there is a distinction between exploratory drilling for new fields and exploratory drilling for additional deposits within old fields. ${ }^{7}$ This enhancement recognizes important differences in exploratory drilling, both by nature and in its physical and economic returns. New field wildcats convert resources in previously undiscovered fields into both proved reserves (as new discoveries) and inferred reserves. ${ }^{8}$ Other exploratory drilling and developmental drilling add to proved reserves from the stock of inferred reserves by a phenomenon termed reserves growth, the process by which initial assessments of proved reserves from a new field discovery grow over time. The volumetric returns to other exploratory and developmental drilling in OGSM are referred to as extensions and revisions, respectively. Other exploratory drilling accounts for proved reserves added through new pools or extensions (generally referred to only as extensions within the context of the model), and development drilling accounts for reserves added as net revisions (including adjustments). The finding rate equations

\footnotetext{
${ }^{7}$ Exploratory wells are drilled in relatively untested or unproven areas and can result in the discovery of new fields or new pools within known fields. Exploratory drilling in OGSM is divided between two major types. New field wildcats are exploratory wells drilled for a new field on a structure or in an environment never before productive. Other exploratory wells are those drilled in already productive locations. Developmental wells are primarily within, or near proven areas and can result in extensions or revisions.

${ }^{8}$ Inferred reserves are that part of expected ultimate recovery from known fields in excess of cumulative production plus current reserves.
} 
vary in OGSM among new field.wildcats, other exploratory drilling, and developmental drilling. Finding rates are defined separately for each fuel type category $(k)$ in each region $(r)$.

\section{New Field Wildcat Finding Rates}

The finding rate equation (Equation (20)) for new field wildcats ${ }^{9}$ follows rather closely the basic methodology described above. In the OGSM specification, the yield from new field wildcat drilling begins at the initial finding rate, FR1, and declines exponentially thereafter. This specification conforms to the design of Equation (1).

$$
F R 1_{r, k, l}=F R 1_{r, k, t-1} * \exp \left(-\delta 1_{r, k, t} * S W 1_{r, k, t}\right)
$$

where,

$$
\begin{aligned}
\text { FR1 } & =\text { finding rate (Mbbl per well or MMcf per well) } \\
\text { SW1 } & =\text { successful new field wildcats } \\
\delta 1 & =\text { finding rate decline parameter } \\
\mathbf{r} & =\text { region } \\
\mathbf{k} & =\text { fuel type (oil or gas). }
\end{aligned}
$$

New field reserve additions are determined as the integral of the finding rate function over the given drilling interval, $\left(S W 1_{z, k, t}\right)$. The resource base enters the equation as an exogenous input that influences the derivation of $\delta 1$, the finding rate decline parameter. The decline parameter, $\delta 1$, is estimable from Equation (8) in combination with the terms of Equations (10) and (13). Substituting values specific to new field wildcat wells yields the following equation:

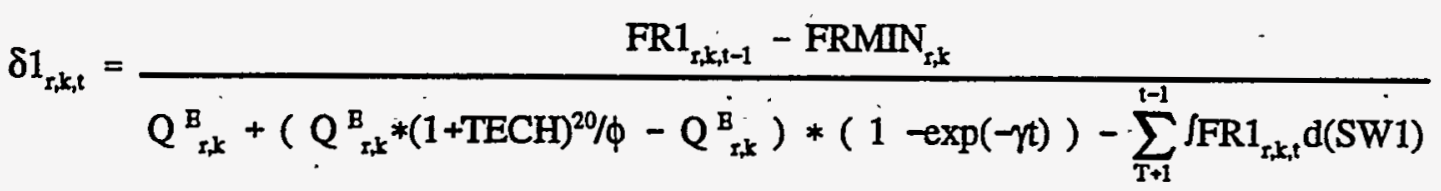

The initial estimate for proved reserves are reserves that can be certified using mainly the original discovery wells, while inferred reserves are those hydrocarbons that will require additional drilling before they can be considered proved. Subsequent drilling takes the form of 'other exploratory' drilling and development drilling. The finding rates for these latter two types of drilling are based on the same methodology described above, with appropriate modifications to account for differences in the nature of the resource target and the process by which it is converted to proved reserves.

The volumetric yield from a successful new field wildcat well is divided into proved reserves and inferred reserves based on historical reserves growth statistics. More specifically, the allocation of reserves between proved and inferred reserves is based on the average ratio of initial reserves estimated for a newly discovered field relative to ultimate recovery from the field. ${ }^{10}$ Given an estimate for the ratio of ultimate recovery from a field relative to the initial proved reserve estimate, $\mathrm{X}_{x, k}$, the $\mathrm{X}_{\mathbf{x}, \mathrm{s}}$ reserve growth factor is

\footnotetext{
${ }^{2}$ Total successful exploratory wells as described previously are disaggregated into successful new field wildcats and other exploratóry wells. The disaggregation is based on average historical ratios of successful new field wildcats to total successful exploratory wells. For the rest of this appendix, successful new field wildcats will be designated by the variable SWl, other successful exploratory wells by SW2, and successful development wells by SW3.'

${ }^{30} \mathrm{~A}$ more complete discussion of the topic of reserve growth for producing fields can be found in Chapter 3 of The Domestic Oil and Gas Recoverable Resource Base: Supporting Analysis for the National Energy Strategy.
} 
used to separate newly discovered resources into either proved or inferred reserves. The new. fields discovered by new field wildcats yield not only proved reserves but also a much larger amount of inferred reserves. Specifically, the change in proved reserves from new field discoveries for each period is given by:

$$
\begin{aligned}
\Delta R_{r, k, t}= & \frac{1}{X_{r, k}} \int_{0}^{S W 1_{2, k}} F R 1_{r, k, t} d(S W 1) \\
& \frac{1}{X_{r, k}} \int_{0}^{S W 1_{r, s}} F R 1_{s, k, t-1} * \exp \left(-\delta 1_{r, k, t} * S W 1_{r, k, t}\right) d(S W 1)
\end{aligned}
$$

where,

$$
\begin{aligned}
X & =\text { reserves growth factor } \\
\Delta R & =\text { additions to proved reserves. }
\end{aligned}
$$

The terms in Equation (22) are all constants in period $t$, except for the SW1. $X$ is derived from the historical data and it is assumed to be constant during the forecast period. $F R 1_{r, k, t-1}$ and $\delta 1_{x, k, t}$ are calculated prior to period t, based on lagged variables and fixed parameters as shown in Equations (20) and (21).

\section{Finding Rates for Other Types of Drilling}

Reserves are assumed to move from the realm of inferred to proved with the drilling of other exploratory wells or developmental wells in much the same way as volumes of both proved and inferred reserves are modeled as moving from the undiscovered economically recoverable resource base as described above. The volumetric return to other exploratory wells and developmental wells is shown in Equations (23) and and (24), respectively.

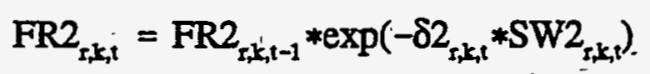

where,

$$
\begin{aligned}
& \text { FR2 }=\text { other exploratory wells finding rate } \\
& \mathrm{SW} 2=\text { successful other exploratory wells. } \\
& F R 3_{r, k, t}=F R 3_{r, k, t-1} * \exp \left(-\delta 3_{r, k, t} * S W 3_{r, k, t}\right)
\end{aligned}
$$

where,

$$
\begin{aligned}
\text { FR3 } & =\text { development well finding rate } \\
\text { SW3 } & =\text { successful development wells. }
\end{aligned}
$$

The derivation of updated decline factors for the exponentially declining functions are shown in Equations (25) and (26) for other exploratory drilling and developmental drilling, respectively. 


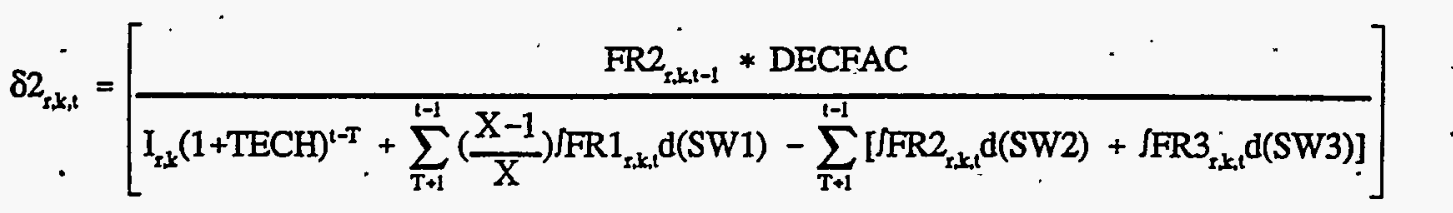

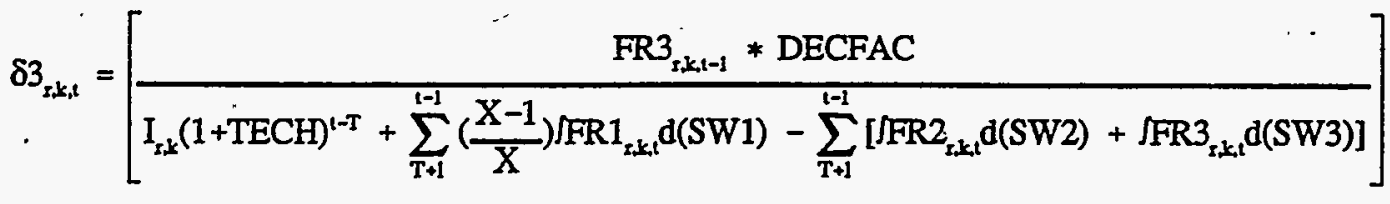

where,

$$
\begin{aligned}
I & =\text { initial inferred reserves estimate } \\
\text { DECFAC } & =\text { decline rate adjustment factor. }
\end{aligned}
$$

The conversion of inferred reserves into proved reserves occurs as both other exploratory wells and developmental wells exploit a single stock of inferred reserves. The specification of Equations (25) and (26) has the characteristic that the entire stock of inferred reserves can be exhausted through sufficiently large numbers of either the other exploratory wells or developmental wells alone. This extreme result is unlikely given reasonable drilling levels in any one year. Nonetheless, the simultaneous extraction from inferred reserves by both drilling types is expected to affect the productivity of each other. Specifically, the more one drilling type draws down the inferred reserve stock, there should be a corresponding acceleration in the productivity decline of the other type, because the remaining recoverable resource value (i.e., the denominator expression in the derivation of $\delta_{2}$ and $\delta_{3}$ ) is less than it otherwise would be. DECFAC is present in the computation of $\delta_{2}$ and $\cdot \delta_{3}$ to account for the simultaneous drawdown from inferred reserves by both other exploratory wells and developmental wells. DECFAC is a user-specified parameter that should be greater than or equal to 1.0. Values greater than 1.0 accelerate the productivity decline in the finding rate.

Integration of the preceding finding rate functions with the new field wildcat function yields the following equation for total reserve additions in period $t$ :

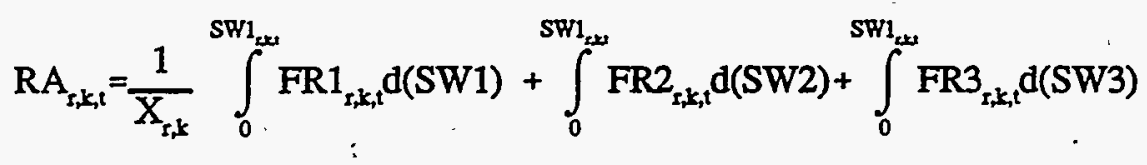

\section{Conclusion}

This completes a description of the finding rate methodology utilized in OGSM. A simple basic methodology was presented upon which the OGSM finding rate functions are based. Included in this discussion were descriptions of two modifications to that basic structure-one to account for the economic nature of the resource estimates and another to incorporate the effect of technological advancements. Subsequently, the implementation of this methodology in OGSM was described, with the resulting finding rate functions shown to vary from the basic structure primarily because of the resource accounting system employed in OGSM. 
The methodology for conversion of oil or gas resources into proved reserves is a critically important aspect of supply modeling. While the actual process through which oil and gas become proved reserves is a highly complex one, the methodology presented here is representative only of the major phases that occur. By necessity, it is a simplification from a highly complex reality. 
Appendix 4-D. Calculation of VARPOIL, SKP, and CV 



\section{Variance in the Price of Oil (VARPOIL)}

The mean monthly price of oil in year $\mathrm{t}$ is given by: ${ }^{i}$

$$
\operatorname{pmean}_{\mathrm{t}}=\frac{\sum_{s} \mathrm{p}_{\mathrm{s}, \mathrm{t}}}{12} .
$$

where,

$$
\mathrm{p}_{s, \mathrm{t}}=\text { the price of oil in month } \mathrm{s} \text { of year } \mathrm{t}
$$

The variance (VARPOIL) is given by:

$$
\text { VARPOL }_{t}=\frac{\sum_{s}\left(p_{s, t}-\text { pmean }_{1}\right)^{2}}{12}
$$

\section{Coefficient of Skewness in the Price of Oil (SKP)}

The SKP characterizes the degree of asymmetry of the distribution of the oil prices in a year around its mean value for the year. It is calculated in the following manner:

$$
\operatorname{SKP}_{t}=\frac{12}{(11 * 10)} * \sum_{s}\left(\frac{p_{s, t}-p_{\text {pmean }}}{p s t d_{t}}\right)^{3}
$$

\section{Relative Coefficient of Variation in the Discounted Cash Flow (CV)}

The calculation of the coefficient of variation in the discounted cash flow assumes a single source of uncertainty--geology. Specifically, the outcome of drilling a well can be a success (wet) or failure (dry). The probability of success is given by the success rate (SR) and the probability of failure is given by (1SR). If the outcome is a success the discounted cash flow will be equal to SUCDCF; if the outcome is a failure the discounted cash flow will be equal to DRYDCF. The expected value and variance of the discounted cash flow, DCF and VARDCF, respectively, are equal to: ${ }^{2}$

'Data for monthly oil prices was taken from various editions of EIA's Monthly Energy Review, Table 9.1, column 1 (Domestic First Purchase Price).

${ }^{2}$ These formulae are consistent with the general exposition provided in Kaufman, Gordon, "Exploration Activity via Portfolio Analysis," mimeo, February 1993, pp. 4-6. 


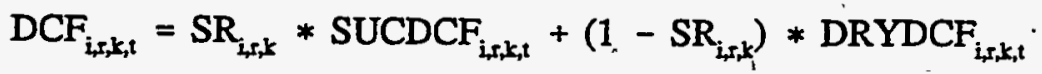

$$
\begin{aligned}
& \operatorname{VARDCF}_{i, r, k, t}^{\cdot}=\left(\operatorname{SUCDCF}_{i, r, k, t}+\operatorname{DRYDCF}_{i, r, k, t}\right)^{2} * \operatorname{SR}_{i, r, k} *\left(1-\operatorname{SR}_{i, r, k}\right)
\end{aligned}
$$

where,

$$
\begin{aligned}
i & =\text { well type } \\
r & =\text { region } \\
k & =\text { fuel type } \\
t & =\text { year. }
\end{aligned}
$$

The coefficient of variation (CVDCF), defined as the standard deviation divided by the expected value, is therefore given by:

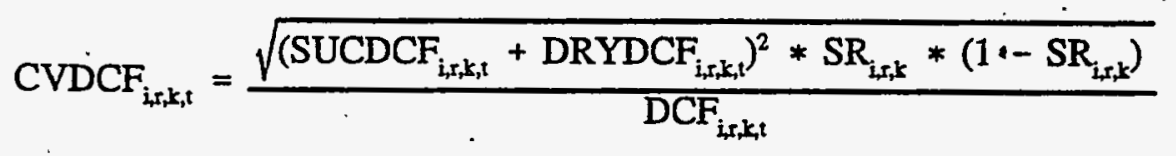

For computational convenience, the model calculates CVDCF by an equivalent formula given by:

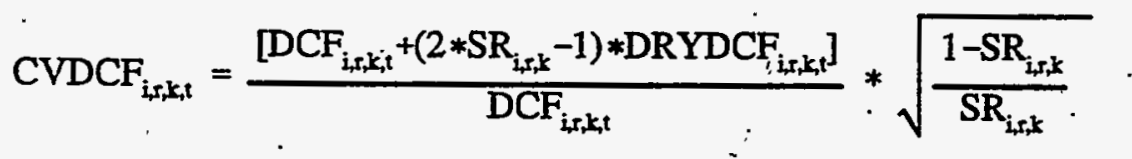

Equation (8) is derived by solving equation (5) for SUCDCF $_{\mathrm{i}, \mathrm{r}, \mathrm{r}, \mathrm{i}}$, substituting the result into equation (7), and simplifying.

Regional coefficients of variation in the DCF (RCVDCF) for each well type are calculated as weighted averages of the intraregional CVDCF's. Specifically, the RCVDCF's are calculated by:

$$
\operatorname{RCVDCF}_{i, r, t}=\sum_{k} w_{i, r, k, t} * \mathrm{CVDCF}_{i, r, k, t} \text { for each } \mathrm{i}
$$

The weights are equal to:

$$
w_{i, r, k, t}=\frac{\text { WELLS }_{i, r, k, t-1}}{\sum_{k} \text { WELLS }_{i, r, k, t-1}} \text { for each } \mathbf{i}, \mathbf{k}
$$

where,

$$
\text { WELLS }=\text { wells drilled. }
$$

The coefficient of variation variable (CV) used in equations (26), (28), (31), and (32) of Chapter 4 is therefore defined by: :

$$
\dot{C V_{i, k, t}}=\frac{\mathrm{CVDCF}_{i, r, \mathrm{t}, \mathrm{t}}}{\mathrm{RCVDCF}_{i, i, t}}
$$


Appendix A. Data Inventory 

An inventory of OGSM variables is presented in the following tables. These variables are divided into four categories:

Variables: Variables calculated in OGSM

Data: Input data

Parameters: Estimated parameters

Output: $\quad$ OGSM outputs to other modules in NEMS.

All regions specified under classification are OGSM regions unless otherwise noted. 


\begin{tabular}{|c|c|c|c|c|c|c|}
\hline \multirow{3}{*}{$\begin{array}{l}\text { Appendlx } B \\
\text { Equation }\end{array}$} & \multicolumn{6}{|c|}{ Variables } \\
\hline & \multirow{2}{*}{ Subroutine } & \multicolumn{2}{|c|}{ Varlable Name } & \multirow{2}{*}{ Description } & \multirow{2}{*}{ Unit. } & \multirow{2}{*}{ Classiffeatlon } \\
\hline & & Code & Text & & & \\
\hline 1 & $\begin{array}{l}\text { OGFOR_L48 } \\
\text { OGFOR_OFF } \\
\text { OGCOST_AK }\end{array}$ & $\begin{array}{l}\text { DRILLLL48 } \\
\text { DRILLOFF } \\
\text { DRILLAK } \\
\end{array}$ & DRILLCOST & Successful well drilling costs & $1987 \$$ per well & $\begin{array}{l}\text { Class(Exploratory,Developmental); } 6 \\
\text { Lower } 48 \text { onshore regions,Fuel(oil,5 } \\
\text { gas);8 Lower } 48 \text { offshore } \\
\text { regions,Fuel(oil,gas);3 Alaska } \\
\text { regions,Fuel(oil,gas) }\end{array}$ \\
\hline 2 & $\begin{array}{l}\text { OGFOR_L48 } \\
\text { OGFOR_OFF } \\
\text { OGCOST_AK }\end{array}$ & $\begin{array}{l}\text { DRYL48 } \\
\text { DRYOFF } \\
\text { DRYAK }\end{array}$ & DRYCOST & Dry well drilling costs & $1987 \$$ per wẹll & $\begin{array}{l}\text { Class(Exploratory,Developmental); } 6 \\
\text { Lower } 48 \text { onshore regions,Fuel(oil,5 } \\
\text { gas);8 Lower } 48 \text { offshore } \\
\text { regions,Fuel(oil,gas);3 Alaska } \\
\text { regions,Fuel(oil,gas) }\end{array}$ \\
\hline 3 & $\begin{array}{l}\text { OGFOR_L48 } \\
\text { OGFOR_OFF } \\
\text { OGCOST_AK }\end{array}$ & $\begin{array}{l}\text { LEASL48 } \\
\text { LEASOFF } \\
\text { EQUIPAK }\end{array}$ & LEQC & $\begin{array}{c}\text { Lease equipment costs } \\
\qquad:\end{array}$ & $1987 \$$ per well & $\begin{array}{l}\text { Class(Exploratory, Developmental); } 6 \\
\text { Lower } 48 \text { onshore regions,Fuel(oil,5 } \\
\text { gas);8 Lower } 48 \text { offshore } \\
\text { regions,Fuel(oil,gas);3 Alaska } \\
\text { regions,Fuel(oil,gas) }\end{array}$ \\
\hline 4 & $\begin{array}{l}\text { OGFOR_L48 } \\
\text { OGFOR_OFF } \\
\text { OGCOST_AK }\end{array}$ & $\begin{array}{l}\text { OPERL48 } \\
\text { OPEROFF } \\
\text { OPERAK }\end{array}$ & OPC & Operaling costs & $1987 \$$ per well & $\begin{array}{l}\text { Class(Exploralory, Developmental); } 6 \\
\text { Lower } 48 \text { onshore regions, Fuel(oil,5 } \\
\text { gas);8 Lower } 48 \text { offshore } \\
\text { regions,Fuel(oil,gas);3 Alaska } \\
\text { regions,Fuel(oil,gas) }\end{array}$ \\
\hline 5 & OG_DCF & CF & NCF & Net cash flow & $1987 \$$ per project & (Above) \\
\hline 6 & OG_DCF & DCFTOT & PROJDCF & $\begin{array}{l}\text { Discounted cash flow for a } \\
\text { representative project }\end{array}$ & $1987 \$$ per project & (Above) \\
\hline 7 & OG_DCF & PVSUM(1) & PVREV & $\begin{array}{l}\text { Present value of expected } \\
\text { revenue .. }\end{array}$ & $1987 \$$ per project & (Above) \\
\hline 8 & OG_DCF. & PVSUM(2) & PVROY & $\begin{array}{l}\text { Present value of expected } \\
\text { royally payments }\end{array}$ & $1987 \$$ per project & (Above) \\
\hline 9 & OG_DCF & PVSUM(3) & PVPRODTAX & $\begin{array}{l}\text { Present valye of expected } \\
\text { production taxes. }\end{array}$ & $1987 \$$ per project & (Above) \\
\hline 10 & OG_DCF & PVSUM(4) & PVDRILLCOST & $\begin{array}{l}\text { Present value of expected } \\
\text { drilling costs }\end{array}$ & $1,987 \$$ per project & (Above) \\
\hline 11 & OG_DCF & PVSUM(5) & PVEQUIP & $\begin{array}{l}\text { Present value of expected lease } \\
\text { equipment costs }\end{array}$ & $1987 \$$ per project & (Above) \\
\hline
\end{tabular}




\begin{tabular}{|c|c|c|c|c|c|c|}
\hline \multirow{3}{*}{$\begin{array}{l}\text { Appendlx B } \\
\text { Equation }\end{array}$} & \multicolumn{6}{|c|}{ Varlables } \\
\hline & \multirow{2}{*}{ Subroutlne } & \multicolumn{2}{|c|}{ Varlable Name } & \multirow{2}{*}{ Description } & \multirow{2}{*}{ Unit } & \multirow{2}{*}{ Classification } \\
\hline & & Code & Text & & & \\
\hline 12 & OG_DCF & PVSUM(8) & PVKAP & $\begin{array}{l}\text { Present value of expected } \\
\text { capital costs }\end{array}$ & $1987 \$$ per project & (Above) \\
\hline 13 & OG_DCF & PVSUM(6). & PVOPERCOST & $\begin{array}{l}\text { Present value of expected } \\
\text { operating costs }\end{array}$ & $1987 \$$ per project & (Above) \\
\hline 14 & OG_DCF & PVSUM(7) & PVABANDON & $\begin{array}{l}\text { Present value of expected } \\
\text { abandonment costs }\end{array}$ & $1987 \$$ per project & (Above) \\
\hline 15 & OG_DCF & PVSUM(13) & PVTAXBASE & $\begin{array}{l}\text { Present value of expected tax } \\
\text { base }\end{array}$ & $1987 \$$ per project & (Abovo) \\
\hline 16 & OG_DCF & $\mathrm{XIDC}$ & XIDC & Expensed Costs & $1987 \$$ per project & (Above) \\
\hline 17 & OG_DCF & DHC & $\mathrm{DHC}$ & Dry hole costs & $1987 \$$ per projedt & (Above) \\
\hline 18 & OG_DCF & DEPAEC & DEPREC & Depreciable costs & $1987 \$$ per project & (Above) \\
\hline 19 & OG_DCF & PVSUM(15) & PVSIT : - & $\begin{array}{l}\text { Expected value of state income } \\
\text { taxes }\end{array}$ & $1987 \$$ per project & (Above) \\
\hline 20 & OG_DCF & PVSUM(16) & PVFIT & $\begin{array}{l}\text { Expected value of federal } \\
\text { income taxes }\end{array}$ & $1987 \$$ per project & (Above) \\
\hline $21-22$ & OG_DCF & OG_DCF & DCF & $\begin{array}{l}\text { Discounted cash flow for a } \\
\text { representalive well }\end{array}$ & $1987 \$$ per well & (Above) \\
\hline 23 & OGEXP_CALC & CASHFLOW & CF & Industry cash flow & Million $1987 \$$ & NA \\
\hline 24 & OGEXP_CALC & RETURN & RF & Retum on foreign operations & Million $1987 \$$ & NA \\
\hline 25 & OGEXP_CALC & W1 & w1 & $\begin{array}{l}\text { Share of total Lower } 48 \text { onshore } \\
\text { wells at class,region level }\end{array}$ & Fraction & $\begin{array}{l}\text { Class(Exploratory, Developmental); } 6 \\
\text { Lower } 48 \text { onshore regions; Fuel(oil, } 5 \text { gas) }\end{array}$ \\
\hline 26 & OGEXP_CALC & WDCFIR & RDCFON & $\begin{array}{l}\text { Lower } 48 \text { onshore discounted } \\
\text { cash flow }\end{array}$ & $1987 \$$ & $\begin{array}{l}\text { Class(Exploratory, Developmental) ;6 } \\
\text { Lower } 48 \text { onshore regions }\end{array}$ \\
\hline 27 & OGEXP_CALC & W2 & w2 & $\begin{array}{l}\text { Share of total Lower } 48 \text { onshore } \\
\text { wells at class,region, fuel level }\end{array}$ & Fraction & $\begin{array}{l}\text { Class(Exploratory,Developmental); } 6 \\
\text { Lower } 48 \text { onshore regions }\end{array}$ \\
\hline 28 & OGEXP_CALC & WDCFL48 & NDCFON & $\begin{array}{l}\text { Lower } 48 \text { onshore discounted } \\
\text { cash flow }\end{array}$ & $1987 \$$ & Class(Exploratory,Developmental) \\
\hline $29-30$ & OGEXP_CALC & SPEND_L48 & NSPENDON & Lower 48 onshore expenditures & Million 1987\$ & Class(Exploratory,Developmental) \\
\hline
\end{tabular}




\begin{tabular}{|c|c|c|c|c|c|c|}
\hline \multirow{3}{*}{$\begin{array}{l}\text { Appendix B } \\
\text { Equatlon }\end{array}$} & \multicolumn{6}{|c|}{ Varlables } \\
\hline & \multirow{2}{*}{ Sụbroutine } & \multicolumn{2}{|c|}{ Varlable Name } & \multirow{2}{*}{ Descrlption } & \multirow{2}{*}{ Unit } & \multirow{2}{*}{ Classification } \\
\hline & & Code & Text & & & \\
\hline $31-37$ & OGEXP_CALC & SPEND_RGN & RSPENDON & Lower 48 onshore expenditures & Million $1987 \$$ & $\begin{array}{l}\text { 'Class(Exploratory,Developmental) ;6 } \\
\text { Lower } 48 \text { onshore regions }\end{array}$ \\
\hline $38-61$ & OGEXP_CALC & SPENDIRK_L48 & SPENDON & Lower 48 onshore expenditures & Million $1987 \$$ & $\begin{array}{l}\text { Class(Exploratory,Developmental) ; } 6 \\
\text { Lower } 48 \text { onshore regions, Fuell(oil, } 5 \text { gas) }\end{array}$ \\
\hline 62 & OGEXP_CALC & WELLSL48 & WELLSON & Lower 48 onshore wells drilled & Wells & $\begin{array}{l}\text { Class(Exploratory,Developmental) ; } 6 \\
\text { Lower } 48 \text { onshore regions, Fuel(oil, } 5 \text { gas) }\end{array}$ \\
\hline 63 & OGEXP_CALC & SUCWELLL48 & SUCWELSON & $\begin{array}{l}\text { Successful Lower } 48 \text { onshore } \\
\text { wells drilled }\end{array}$ & Wells & $\begin{array}{l}\text { Class(Exploratory,Developmental) ;6 } \\
\text { Lower } 48 \text { onshore regions,Fuel(oil, } 5 \text { gas) }\end{array}$ \\
\hline 64 & $\begin{array}{l}\text { OGEXP_CALC } \\
\text { OGEXP_FIX }\end{array}$ & DRYWELLL48 & DRYWELON & $\begin{array}{l}\text { Dry Lower } 48 \text { onshore wells } \\
\text { drilled. }\end{array}$ & Wells & $\begin{array}{l}\text { Class(Exploratory, Developmental);6 } \\
\text { Lower } 48 \text { onshore regions,Fuel(oil,5 gas) }\end{array}$ \\
\hline 65 & OGEXP_CALC & W3 & w3 & $\begin{array}{l}\text { Share of total Lower } 48 \text { offshore } \\
\text { wells at class, region level }\end{array}$ & Fraction & $\begin{array}{l}\text { Class(Exploratory, Developmental); } 8 \\
\text { Lower } 48 \text { offshore regions;Fuel(oil,gas) }\end{array}$ \\
\hline 66 & OGEXP_CALC & WDCFOFFIR & RDCFOFF & $\begin{array}{l}\text { Lower } 48 \text { offshore discounted } \\
\text { cash flow }\end{array}$ & $1987 \$$ & $\begin{array}{l}\text { Class(Exploratory,Developmental);8 } \\
\text { Lower } 48 \text { offshore regions. }\end{array}$ \\
\hline 67 & OGEXP_CALC & W4 & w4 & $\begin{array}{l}\text { Share of total Lower } 48 \text { oftshore } \\
\text { wells at class, region, fuel level }\end{array}$ & Fraction & $\begin{array}{l}\text { Class(Exploratory,Developmental);8 } \\
\text { Lower } 48 \text { offshore regions }\end{array}$ \\
\hline 68 & OGEXP_CALC & WDCFOFF & NDCFOFF & $\begin{array}{l}\text { Lower } 48 \text { offshore discounted } \\
\text { cash flow }\end{array}$ & $1987 \$$ & Class(Exploratory,Developmental) \\
\hline $69-70$ & OGEXP_CALC & SPEND_OFF & NSPENDOFF & Lower 48 offshore, expenditures & Million $1987 \$$ & Class (Exploralory, Developmental) \\
\hline $71-77$ & OGEXP_CALC & SPENDOFF_RGN & RSPENDOFF & Lower 48 offshore expenditures & Million $1987 \$$ & $\begin{array}{l}\text { Class(Exploralory,Developmental) :8 } \\
\text { Lower } 48 \text { offshore regions }\end{array}$ \\
\hline $78-82$ & OGEXP_CALC & SPENDIRK_OFF & SPENDOFF. & Lower 48 offshore expenditures & Million 1987\$ & $\begin{array}{l}\text { Class(Exploratory, Developmental) :8 } \\
\text { Lower } 48 \text { offshore regions, Fuel(oll,gas) }\end{array}$ \\
\hline 83 & OGEXP_CALC & WELLSOFF & WELLSOFF & Lower 48 offishore wells drilled & Wells & $\begin{array}{l}\text { Class(Exploratory,Developmental) ; } 8 \\
\text { Loẉer } 48 \text { offshore regions,Fuel(oil,gas) }\end{array}$ \\
\hline 84 & OGEXP_CALC & SUCWELLOFF & SUCWELSOFF & $\begin{array}{l}\text { Successful Lower } 48 \text { offshore } \\
\text { wells drilled }\end{array}$ & Wells & $\begin{array}{l}\text { Class(Exploratory,Developmental);8} \\
\text { Lower } 48 \text { oflshore regions, Fuel(oil,gas) }\end{array}$ \\
\hline 85 & OGEXP_CALC & DRYWELLOFF & DRYWELOFF & $\begin{array}{l}\text { Dry Lower } 48 \text { offshore wells } \\
\text { drilled }\end{array}$ & Wells & $\begin{array}{l}\text { Class(Exploratory,Developmental); } 8 \\
\text { Lower } 48 \text { offshore regions,Fuel(oil,gas) }\end{array}$ \\
\hline
\end{tabular}




\begin{tabular}{|c|c|c|c|c|c|c|}
\hline \multirow{3}{*}{$\begin{array}{l}\text { Appendix B } \\
\text { Equation }\end{array}$} & \multicolumn{6}{|c|}{ Varlables } \\
\hline & \multirow{2}{*}{ Subroutlne } & \multicolumn{2}{|c|}{ Varlable Name } & \multirow{2}{*}{ Description } & \multirow{2}{*}{ Unit } & \multirow{2}{*}{$\begin{array}{c}\text { Classification } \\
.\end{array}$} \\
\hline & & Code & Text & & & \\
\hline 86 & $\begin{array}{l}\text { OGOUT_L48 } \\
\text { OGOUT_OFF }\end{array}$ & $\begin{array}{l}\text { FR1L48 } \\
\text { FR1OFF }\end{array}$ & FR1 & $\begin{array}{l}\text { Finding rates for new field } \\
\text { wildcat drilling }\end{array}$ & $\begin{array}{l}\text { Oil-MMB per well } \\
\text { Gas-BCF per well }\end{array}$ & $\begin{array}{l}6 \text { Lower } 48 \text { onshore regions, Fuel(oil, } 5 \\
\text { gas); } 8 \text { Lower } 48 \text { offshore } \\
\text { regions,Fuel(oil,gas) }\end{array}$ \\
\hline 87 & $\begin{array}{l}\text { OGOUT_L48 } \\
\text { OGOUT_OFF }\end{array}$ & $\begin{array}{l}\text { DELTA1L48 } \\
\text { DELTA1OFF }\end{array}$ & $\delta 1$ & $\begin{array}{l}\text { Finding rate decline parameters } \\
\text { for new field wildcat drilling }\end{array}$ & Fraction & $\begin{array}{l}6 \text { Lower } 48 \text { onshore regions, Fuel(oil, } 5 \\
\text { gas); } 8 \text { Lower } 48 \text { offshore } \\
\text { regions,Fuel(oil,gas) }\end{array}$ \\
\hline 88 & $\begin{array}{l}\text { OGOUT_L48 } \\
\text { OGOUT_OFF }\end{array}$ & $\begin{array}{l}\text { CUMR1L48 } \\
\text { CUMR1OFF }\end{array}$ & CUMRESI & $\begin{array}{l}\text { Cumulative proved reserves } \\
\text { added by new field discoveries }\end{array}$ & $\begin{array}{l}\text { Oil-MMB } \\
\text { Gas-BCF }\end{array}$ & $\begin{array}{l}6 \text { Lower } 48 \text { onshore regions, Fuel(oil, } 5 \\
\text { gas); } 8 \text { Lower } 48 \text { offshore } \\
\text { regions, Fuel(oil,gas) }\end{array}$ \\
\hline 89 & $\begin{array}{l}\text { OGOUT_L48 } \\
\text { OGOUT_OFF }\end{array}$ & $\begin{array}{l}\text { NDRL48 } \\
\text { NDROFF }\end{array}$ & NRD & $\begin{array}{l}\text { Proved reserves added by new } \\
\text { field discoveries }\end{array}$ & $\begin{array}{l}\text { Oil-MMB } \\
\text { Gas-BCF }\end{array}$ & $\begin{array}{l}6 \text { Lowèr } 48 \text { onshore regions, Fuel(oil, } 5 \\
\text { gas); } 8 \text { Lower } 48 \text { offshore } \\
\text { regions, Fuel(oil,gas) }\end{array}$ \\
\hline 90 & $\begin{array}{l}\text { OGOUT_L48 } \\
\text { OGOUT_OFF }\end{array}$ & $\begin{array}{l}\text { NDIRL48 } \\
\text { NDIROFF }\end{array}$ & 1 & $\begin{array}{l}\text { Inferred reserves added by new } \\
\text { field discoveries }\end{array}$ & $\begin{array}{l}\text { Oil-MMB } \\
\text { Gas-BCF }\end{array}$ & $\begin{array}{l}6 \text { Lower } 48 \text { onshore regions, Fuel(oil, } 6 \\
\text { gas); } 8 \text { Lower } 48 \text { offshore } \\
\text { regions, Fuel(oil,gas) }\end{array}$ \\
\hline 91 & $\begin{array}{l}\text { OGOUT_L4E } \\
\text { OGOUT_OFF }\end{array}$ & $\begin{array}{l}\text { FR2L48 } \\
\text { FR2OFF }\end{array}$ & FR2 & $\begin{array}{l}\text { Finding rates for developmental } \\
\text { wells }\end{array}$ & $\begin{array}{l}\text { Oil-MMB per well } \\
\text { Gas-BCF per well }\end{array}$ & $\begin{array}{l}6 \text { Lower. } 48 \text { onshore regions,Fuel(oil, } 5 \\
\text { gas);8 Lower } 48 \text { offshore } \\
\text { reglons,Fuel(oil,gas) }\end{array}$ \\
\hline 92 & $\begin{array}{l}\text { OGOUT_L48 } \\
\text { OGOUT_OFF }\end{array}$ & $\begin{array}{l}\text { DELTA2L48 } \\
\text { DELTA2OFF }\end{array}$ & & $\begin{array}{l}\text { Finding rate decline parameters } \\
\text { for developmental wells }\end{array}$ & Fraclion & $\begin{array}{l}6 \text { Lower } 48 \text { onshore regions, Fuel(oil, } 5 \\
\text { gas); } 8 \text { Lower } 48 \text { offshiore } \\
\text { regions,Fuel(oil,gas) }\end{array}$ \\
\hline 93 & $\begin{array}{l}\text { OGOUT_L48 } \\
\text { OGOUT_OFF }\end{array}$ & $\begin{array}{l}\text { CUMR2L } 48 \\
\text { CUMR2OFF }\end{array}$ & CUMRES2 & Cumulative reserve revisions & $\begin{array}{l}\text { Oil-MMB } \\
\text { Gas-BCF }\end{array}$ & $\begin{array}{l}6 \text { Lower } 48 \text { onshore regions, Fuel(oil, } 5 \\
\text { gas); } 8 \text { Lower } 48 \text { offshore } \\
\text { regions,Fuel(oil,gas) }\end{array}$ \\
\hline 94 & $\begin{array}{l}\text { OGOUT_L48 } \\
\text { OGOUT_OFF }\end{array}$ & $\begin{array}{l}\text { REVLA8 } \\
\text { REVOFF }\end{array}$ & REV & Reserve revisions & $\begin{array}{l}\text { Oil-MMB } \\
\text { Gas-BCF }\end{array}$ & $\begin{array}{l}6 \text { Lower } 48 \text { onshore regions, Fuel(oll, } 5 \\
\text { gas); } 8 \text { Lower } 48 \text { offshore } \\
\text { regions,Fuel(oil,gas) }\end{array}$ \\
\hline 95 & $\begin{array}{l}\text { OGOUT_L48 } \\
\text { OGOUT_OFF }\end{array}$ & $\begin{array}{l}\text { FR3L48 } \\
\text { FR3OFF }\end{array}$ & FR3 & $\begin{array}{l}\text { Finding rates for other } \\
\text { exploratory drilling } \\
\end{array}$ & $\begin{array}{l}\text { Oil-MMB per well } \\
\text { Gas-BCF per well }\end{array}$ & $\begin{array}{l}6 \text { Lower } 48 \text { onshore regions,Fuel(oil, } 5 \\
\text { gas); } 8 \text { Lower } 48 \text { offshore } \\
\text { regions,Fuel(oil,gas) }\end{array}$ \\
\hline 96 & $\begin{array}{l}\text { OGOUT_L48 } \\
\text { OGOUT_OFF }\end{array}$ & $\begin{array}{l}\text { DELTA3L48 } \\
\text { DELTA3OFF }\end{array}$ & 83 & $\begin{array}{l}\text { Finding rate decline parameters } \\
\text { for other exploratory wells }\end{array}$ & Fraction & $\begin{array}{l}6 \text { Lower } 48 \text { onshore regions,Fuel(oil, } 5 \\
\text { gas);8 Lower } 48 \text { offshore } \\
\text { regions,Fuel(oil,gas) }\end{array}$ \\
\hline
\end{tabular}




\begin{tabular}{|c|c|c|c|c|c|c|}
\hline \multirow{3}{*}{$\begin{array}{l}\text { Appendlx } B \\
\text { Equation }\end{array}$} & \multicolumn{6}{|c|}{ Varlables } \\
\hline & \multirow{2}{*}{ Subroutine } & \multicolumn{2}{|c|}{ Varlable Name } & \multirow{2}{*}{ Desćription } & \multirow{2}{*}{ Unlt } & \multirow{2}{*}{ Classification } \\
\hline & & Code & Text & & & \\
\hline 97. & $\begin{array}{l}\text { OGOUT_L48 } \\
\text { OGOUT_OFF }\end{array}$ & $\begin{array}{l}\text { CUMR3L48 } \\
\text { CUMR3OFF }\end{array}$ & CUMRES3 & Cumulative reserve extensions & $\begin{array}{l}\text { Oil-MMB } \\
\text { Gas-BCF . }\end{array}$ & $\begin{array}{l}6 \text { Lower } 48 \text { onshore regions, Fuel(oil, } 5 \\
\text { gas); } 8 \text { Lower } 48 \text { offshore } \\
\text { regions,Fuel(oil,gas) }\end{array}$ \\
\hline 98 & $\begin{array}{l}\text { OGOUT_L48 } \\
\text { OGOUT_OFF }\end{array}$ & $\begin{array}{l}\text { EXTL48 } \\
\text { EXTOFF }\end{array}$ & EXT & Reserve extensions & $\begin{array}{l}\text { Oil-MMB } \\
\text { Gas-BCF }\end{array}$ & $\begin{array}{l}6 \text { Lower } 48 \text { onshore regions, Fuel(oil, } 5 \\
\text { gas); } 8 \text { Lower } 48 \text { offshore } \\
\text { regions,Fuel(oil,gas) }\end{array}$ \\
\hline 99 & $\begin{array}{l}\text { OGOUT_L48 } \\
\text { OGOUT_OFF }\end{array}$ & $\begin{array}{l}\text { RESADL48 } \\
\text { RESADOFF }\end{array}$ & RA & $\begin{array}{l}\text { Total additions to proved } \\
\text { reseives }\end{array}$ & $\begin{array}{l}\text { Oill-MMB } \\
\text { Gas-BCF }\end{array}$ & $\begin{array}{l}6 \text { Lower } 48 \text { onshore regions,Fuel(oil, } 5 \\
\text { gas); } 8 \text { Lower } 48 \text { olfshore } \\
\text { regions,Fuel(oil,gas) }\end{array}$ \\
\hline 100 & $\begin{array}{l}\text { OGOUT_L48 } \\
\text { OGOUT_OFF } \\
\text { OGFOR_AK }\end{array}$ & $\begin{array}{l}\text { RESBOYL48 } \\
\text { RESBOYOFF } \\
\text { BOYRESCOAK } \\
\text { BOYRESNGAK }\end{array}$ & $\mathbf{R}$ & $\begin{array}{l}\text { End of year reserves for current } \\
\text { year }\end{array}$ & $\begin{array}{l}\text { Oil-MMB } \\
\text { Gas-BCF }\end{array}$ & $\begin{array}{l}6 \text { Lower } 48 \text { onshore regions,Fuiel(oil,5 } \\
\text { gas);8 Lower } 48 \text { offshore } \\
\text { reglons,Fuel(oiligas);3 Alaska } \\
\text { regions,Fuel(oil,gas) }\end{array}$ \\
\hline 101 & $\begin{array}{l}\text { OGOUT_L48 } \\
\text { OGOUT_OFF }\end{array}$ & $\begin{array}{l}\text { PRRATL48 } \\
\text { PRAATOFF }\end{array}$ & PA & Production to reserves ratios. & Fraction & $\begin{array}{l}\text { Class(Exploratory,Developmental);6 } \\
\text { Lower } 48 \text { onshore regions,Fuel(oil, } 5 \\
\text { gas);8 Lower } 48 \text { offshore } \\
\text { regions,Fuel(oil,gas) }\end{array}$ \\
\hline 102 & OGFOR_AK & SPEND_AK(2) & SPENDDV & $\begin{array}{l}\text { Alaska developmental } \\
\text { expenditures : }\end{array}$ & Million $1987 \$$ & NA \\
\hline 103 & OGFOR_AK & SPEND_AK(1) & SPENDEX & Alaska exploratory expenditures & Million $1987 \$$ & NA \\
\hline 104 & OGFOR_AK & TOTGRR & TRR & $\begin{array}{l}\text { Alaskia tolal gross revenue } \\
\text { requirements }\end{array}$ & Million 1987\$ & NA \\
\hline 105 & OGFOR_AK & TOTDEP & TOTDEP & Alaska total depreciation & Million 1987 \$ & NA \\
\hline 106 & OGFOR_AK & MARTOT & MARGIN & Alaska total after tax margin & Million $1987 \$$ & NA \\
\hline 107 & OGFOR_AK & RECTOT & DEFRETREC & $\begin{array}{l}\text { Alaska total recovery of differed } \\
\text { relums }\end{array}$ & Million $1987 \$$ & NA \\
\hline 108 & OGFOR_AK & TXALLW & TXALLW & Alaska income tax allowance & Million $1987 \$$ & NA \\
\hline 109 & OGCAN_DCF & CF & NCF & Nel cash flow & $1987 \$$ per project & $\begin{array}{l}\text { Class(exploratory,developmental); } \\
\text { Fuel(oil,gas) }\end{array}$ \\
\hline 110 & OGCAN_DCF & OGCAN_DCF & PROJDCF & Discounted cash flow & $1987 \$$ per project & $\begin{array}{l}\text { Class(exploratory, developmental); } \\
\text { Fuel(oil,gas) }\end{array}$ \\
\hline
\end{tabular}




\begin{tabular}{|c|c|c|c|c|c|c|}
\hline \multirow{3}{*}{$\begin{array}{l}\text { Appendix B } \\
\text { Equation }\end{array}$} & \multicolumn{6}{|c|}{ Varlables } \\
\hline & \multirow{2}{*}{ Subroutlne } & \multicolumn{2}{|c|}{ Varlable Name } & \multirow{2}{*}{ Descriptlon } & \multirow{2}{*}{ Unit. } & \multirow{2}{*}{ Classiffcation } \\
\hline & & Code & Text & & & \\
\hline 111 & OGCAN_DCF & REV & REV & Revenues _. & $1987 \$$ per project & $\begin{array}{l}\text { Class(exploratory, developmental); } \\
\text { Fuel(oil,gas) }\end{array}$ \\
\hline 112 & OGCAN_DCF & ROY & ROY & Royalty payments & $1987 \$$ per project & $\begin{array}{l}\text { Class(exploratory,developmental); } \\
\text { Fuel(oil,gas) }\end{array}$ \\
\hline 113 & OGCAN_DCF & DRILL & DAILLCOST & Successful well drilling costs & $1987 \$$ per project & $\begin{array}{l}\text { Class(exploralory, developmental); } \\
\text { Fuel(oil,gas) }\end{array}$ \\
\hline 114 & OGCAN_DCF & DRILL & DRYC̣OST & Dry hole drilling costs & $1987 \$$ per project & $\begin{array}{l}\text { Class(exploratiory, developmental); } \\
\text { Fuel(oil,gas) }\end{array}$ \\
\hline 115 & OGCAN_DCF & EQUIP & EQUIP & Lease equipment costs & $1987 \$$ per project & $\begin{array}{l}\text { Class(exploratory, developmental); } \\
\text { Fuel(oil,gas) }\end{array}$ \\
\hline$i 16$ & OGCAN_DCF & OPER & OPERCOST & Operating costs & $1987 \$$ per project & $\begin{array}{l}\text { Class(exploratory, developmental); } \\
\text { Fuel(oil,gas) }\end{array}$ \\
\hline 117 & OGCAN_DCF & FTI & FII & Federal tax base & $1987 \$$ per project. & $\begin{array}{l}\text { Class(exploratory, developmental); } \\
\text { Fuel(oil,gas) }\end{array}$ \\
\hline .118 & OGCAN_DCF & $\mathrm{XIDC}$ & XIDC & Expensed costs & $1987 \$$ per project & $\begin{array}{l}\text { Class(exploratory, developmental); } \\
\text { Fuel(oil,gas) }\end{array}$ \\
\hline 119 & OGCAN_DCF & AIDC & DEPREC & Depreciable costs & $1987 \$$ per project & $\begin{array}{l}\text { Class(exploratory, developmental); } \\
\text { Fuel(oil,gas) }\end{array}$ \\
\hline 120 & OGC̨AN_DCF & RA & RA & Resource allowance & $1987 \$$ per project & $\begin{array}{l}\text { Class(exploratory, developmental); } \\
\text { Fuel(oil,gas) }\end{array}$ \\
\hline 121. & OGCAN_DCF & $\mathrm{DA}^{\prime}$ & DA & Depletion allowance & $1987 \$$ per project & $\begin{array}{l}\text { Class(exploralory, developmental); } \\
\text { Fuel(oll,gas) }\end{array}$ \\
\hline 122 & OGCAN_DCF & PTI & PTI & Provincial tax base & $1987 \$$ per project & $\begin{array}{l}\text { Class(exploratory, developmental); } \\
\text { Fuel(oil,gas) - }\end{array}$ \\
\hline 123 & OGCAN_DCF & PROVTAX & PROVTAX & Provincial income taxes & $1987 \$$ per projéct & $\begin{array}{l}\text { Class(exploralory, developmental); } \\
\text { Fuel(oll,gas) }\end{array}$ \\
\hline 124 & OGCAN_DCF & FEDTAX & FEDTAX & Federal income taxes & $1987 \$$ per project & $\begin{array}{l}\text { Class(exploratory, developmental); } \\
\text { Fuel(oil,gas) }\end{array}$ \\
\hline 125 & OGOUT_IMP & WELLSCAN & WELLS & Canadian wells drilled & Wells & Fuel(oill,gas) \\
\hline 126 & OGOUT_IMP & FRCAN & FR & Canadian finding rato & $\begin{array}{l}\text { Oil:MMB per well } \\
\text { Gas:BCF per well }\end{array}$ & Fuel(oil,gas) \\
\hline
\end{tabular}




\begin{tabular}{|c|c|c|c|c|c|c|}
\hline \multirow{3}{*}{$\begin{array}{l}\text { Appendix } B \\
\text { Equation }\end{array}$} & \multirow{3}{*}{ Subroutine } & \multicolumn{4}{|c|}{ Varlables } & - \\
\hline & & \multicolumn{2}{|c|}{ Varlable Name } & \multirow{2}{*}{ Descriptlon } & \multirow{2}{*}{ Unit } & \multirow{2}{*}{ Classification } \\
\hline & & Code & Text & & & \\
\hline 127 & OGOUT_IMP & DELTACAN & $\delta$ & $\begin{array}{l}\text { Canadian finding rate decline } \\
\text { parameter }\end{array}$ & Fraction & Fuel(oil,gas) \\
\hline 128 & OGOUT_IMP & RESADCAN & RA & Canadian reserve additions & $\begin{array}{l}\text { Oil:MMB } \\
\text { Gas:BCF }\end{array}$ & Fuel(oil,gas) \\
\hline 129 & OGOUT_IMP & CUMRCAN & CUMRES & $\begin{array}{l}\text { Cumulative Canadian reserve } \\
\text { additions. }\end{array}$ & $\begin{array}{l}\text { Oil:MMB } \\
\text { Gas:BCF }\end{array}$ & Fuel(oil,gaș) \\
\hline 130 & OGOUT_IMP & RESBOYCAN & A & Canadian reserves & $\begin{array}{l}\text { Oll:MMB } \\
\text { Gas:BCF }\end{array}$ & Fuel(oil,gas) \\
\hline 131 & OGOUT_IMP & PRRATCAN & PR & $\begin{array}{l}\text { Canadian production to } \\
\text { reserves ratio }\end{array}$ & Fraction & Fuel(oil,gas) \\
\hline
\end{tabular}




\begin{tabular}{|c|c|c|c|c|c|c|}
\hline \multicolumn{7}{|c|}{ Data } \\
\hline \multirow{2}{*}{ Subroutlne } & \multicolumn{2}{|c|}{ Varlable Name } & \multirow{2}{*}{ Description } & \multirow{2}{*}{ Unit } & \multirow{2}{*}{ Classiflcation } & \multirow{2}{*}{ Source } \\
\hline & Code & Text & & & & \\
\hline $\begin{array}{l}\text { OGFOR_L48 } \\
\text { OGINIT_L48 }\end{array}$ & ADVLTXL48 & PRODTAX & Lower 48 onshore ad valorem tax rates & Fraction & $\begin{array}{l}6 \text { Lower } 48 \text { onshore } \\
\text { regions; } \\
\text { Fuel (oil; } 5 \text { gas) } \\
\end{array}$ & $\begin{array}{l}\text { Colorado School of Mines. Oil } \\
\text { Propert Evaluation, 1983, p. 9-7 }\end{array}$ \\
\hline $\begin{array}{l}\text { OGFOR_OFF } \\
\text { OGINIT_OFF }\end{array}$ & ADVLTXOFF & PRODTAX & Offshore ad valorem tax rates & Fraction & $\begin{array}{l}8 \text { Lower } 48 \text { offshore } \\
\text { subregions; } \\
\text { Fuel (oil, gas) }\end{array}$ & $\begin{array}{l}\text { Colorado School of Mines. Oil } \\
\text { Propert Evaluation, 1983, p. 9-7 }\end{array}$ \\
\hline $\begin{array}{l}\text { OGINIT_AK } \\
\text { OGPIP_AK }\end{array}$ & ANGTSMAX & -- & ANGTS maximum flow & BCF/D & Alaska & National Petroleum Council \\
\hline $\begin{array}{l}\text { OGINIT_AK } \\
\text { OGPIP_AK }\end{array}$ & ANGTSPRC & $\cdots$ & $\begin{array}{l}\text { Minimum economic price for ANGTS } \\
\text { start up. }\end{array}$ & $1987 \$ / M C F$ & Alaska & National Petroleum Council \\
\hline $\begin{array}{l}\text { OGINIT_AK } \\
\text { OGPIP_AK }\end{array}$ & ANGTSRES & $-\bullet$ & ANGTS reserves & BCF & Alaska & \begin{tabular}{|c} 
National Petroleum Council \\
\end{tabular} \\
\hline $\begin{array}{l}\text { OGINIT_AK } \\
\text { OGPIP_AK }\end{array}$ & ANGTSYR & - & Earliest start year for ANGTS flow & Year & NA & National Petroleum Council \\
\hline $\begin{array}{l}\text { OGINIT_EOR } \\
\text { OGOUT_EOR }\end{array}$ & BGAEORCOGC & -- & $\begin{array}{l}\text { EOR cogeneration electric capacity } \\
\text { (reference case) }\end{array}$ & MW & $\begin{array}{l}6 \text { Lower } 48 \text { onshore } \\
\text { regions; } 2 \text { usages } \\
\text { (utility,non-ulility) }\end{array}$ & $\begin{array}{l}\text { Office of Integrated Analysis and } \\
\text { Forecasting }\end{array}$ \\
\hline $\begin{array}{l}\text { OGINIT_EOR } \\
\text { OGOUT_EOR }\end{array}$ & BGQEORCOGG & -- & $\begin{array}{l}\text { EOR cogeneration electric generation } \\
\text { (reference case) }\end{array}$ & MWh & $\begin{array}{l}6 \text { Lower } 48 \text { onshore } \\
\text { regions; } 2 \text { usages } \\
\text { (utility,non-ulility) }\end{array}$ & $\begin{array}{l}\text { Olfice of Integrated Analysis and } \\
\text { Forecasting }\end{array}$ \\
\hline $\begin{array}{l}\text { OGINIT_EOR } \\
\text { OGOUT_EOR }\end{array}$ & BGQEORCON & $\cdots$ & $\begin{array}{l}\text { EOR crude oll consumption (reference } \\
\text { case) }\end{array}$ & MB & $\begin{array}{l}6 \text { Lower } 48 \text { onshore } \\
\text { regions }\end{array}$ & Not Used \\
\hline $\begin{array}{l}\text { OGINIT_EOR } \\
\text { OGOUT_EOR }\end{array}$ & BGQEORNGC & -- & $\begin{array}{l}\text { EOR natural gas consumption } \\
\text { (reference case) }\end{array}$ & MCF & $\begin{array}{l}6 \text { Lower } 48 \text { onshore } \\
\text { regions; } 2 \text { EOR } \\
\text { technologies } \\
\text { (primary,other) }\end{array}$ & $\begin{array}{l}\text { Office of Integrated Analysis and } \\
\text { Forecasting }\end{array}$ \\
\hline $\begin{array}{l}\text { OGINIT_EOR } \\
\text { OGOUT_EOR }\end{array}$ & BGQEORNGP & - & $\begin{array}{l}\text { EOR natural gas production (reference } \\
\text { case) }\end{array}$ & MCF & $\begin{array}{l}6 \text { Lower } 48 \text { onshore } \\
\text { regions }\end{array}$ & $\begin{array}{l}\text { Office of Integrated Analysis and } \\
\text { Forecasting }\end{array}$ \\
\hline $\begin{array}{l}\text { OGINIT_EOR } \\
\text { OGOUT_EOR }\end{array}$ & BGQEORPR & - & $\begin{array}{l}\text { EOR crude oil production (relerence } \\
\text { case) } \quad\end{array}$ & MB & $\begin{array}{l}6 \text { Lower } 48 \text { onshore } \\
\text { regions }\end{array}$ & $\begin{array}{l}\text { Office of Integrated Analysis and } \\
\text { Forecasting }\end{array}$ \\
\hline $\begin{array}{l}\text { OGEXPAND_LNG } \\
\text { OGINIT_LNG }\end{array}$ & BUILDLAG & - & $\begin{array}{l}\text { Buildup period for expansion of LNG } \\
\text { lacilities }\end{array}$ & Year & NA & $\begin{array}{l}\text { Office of Integrated Analysis and } \\
\text { Forecasting }\end{array}$ \\
\hline
\end{tabular}




\begin{tabular}{|c|c|c|c|c|c|c|}
\hline \multirow{3}{*}{ Șubroutlne. } & \multicolumn{5}{|c|}{ Data } & \multirow{3}{*}{ Source } \\
\hline & \multicolumn{2}{|c|}{ Varlable Name } & \multirow{2}{*}{ Description } & \multirow{2}{*}{ Unit } & \multirow{2}{*}{ Classiffcation } & \\
\hline & Code & Text & & & & \\
\hline $\begin{array}{l}\text { OGFOR_IMP } \\
\text { OGINIT_IMP }\end{array}$ & CPRDCAN & COPRD & Canadian coproduct rale & Fraction & Canada; Fuel (oll, gas) & $\begin{array}{l}\text { Derived using data from the } \\
\text { Canadian Pelroleum Association }\end{array}$ \\
\hline $\begin{array}{l}\text { OGFOR_L48 } \\
\text { OGINIT_L48 }\end{array}$ & CPRDL48 & COPAD & Lower 48 onshore coproduct rate & Fraction & $\begin{array}{l}6 \text { Lower } 48 \text { onshore } \\
\text { regions; } \\
\text { Fuel (oil, } 5 \text { gas) } \\
\end{array}$ & $\begin{array}{l}\text { Office of Integrated Analysis and } \\
\text { Forecasting }\end{array}$ \\
\hline $\begin{array}{l}\text { OGFOR_OFF } \\
\text { OGINIT_OFF }\end{array}$ & CPRDOFF & COPAD & Offshore coproduct rate & Fraction & $\begin{array}{l}8 \text { Lower } 48 \text { offshore } \\
\text { subregions; } \\
\text { Fuel (oil, gas) } \\
\end{array}$ & $\begin{array}{l}\text { Office of Integrated Analysis and } \\
\text { Forecasting }\end{array}$ \\
\hline $\begin{array}{l}\text { OGINIT_IMP } \\
\text { OGINIT_RES } \\
\text { OGOUT_IMP }\end{array}$ & CURPRRCAN & omega & Canadian 1989 P/A ratio & Fraction & Canada; Fuel (oil, gas) & $\begin{array}{l}\text { Derived using data from the } \\
\text { Canadian Petroleum Association }\end{array}$ \\
\hline $\begin{array}{l}\text { OGINIT_L48 } \\
\text { OGINIT_RES } \\
\text { OGOUT_L48 }\end{array}$ & CURPAAL48 & omega & Lower 48 initilal P/R ratios & Fraction & $\begin{array}{l}6 \text { Lower } 48 \text { onshore } \\
\text { regions: } \\
\text { Fuel (oil, } 5 \text { gas). }\end{array}$ & $\begin{array}{l}\text { Office of Integrated Analysis and } \\
\text { Forecasting }\end{array}$ \\
\hline $\begin{array}{l}\text { OGINIT_OFF } \\
\text { OGINIT_RES } \\
\text { OGOUT_OFF }\end{array}$ & CURPRROFF & omega & Offshore initial P/R ratios & Fraction & $\begin{array}{l}8 \text { Lower } 48 \text { offshore } \\
\text { subregions; } \\
\text { Fuel (oil, gas) }\end{array}$ & $\begin{array}{l}\text { Olfice of Integraled Analysis and } \\
\text { Forecasting }\end{array}$ \\
\hline $\begin{array}{l}\text { OGINIT_L48 } \\
\text { OGOUT_L48 }\end{array}$ & CURPRRTDM & $-\cdot$ & $\begin{array}{l}\text { Lower } 48 \text { initial P/R ratios at NGTDM } \\
\text { level }\end{array}$ & Fraclion & $\begin{array}{l}17 \text { OGSM/NGTDM } \\
\text { regions; Fuel (oil, } 5 \text { gas) }\end{array}$ & $\begin{array}{l}\text { Office of Integraled Analysis and } \\
\text { Forecasting }\end{array}$ \\
\hline $\begin{array}{l}\text { OGINIT_IMP } \\
\text { OGINIT_RES } \\
\text { OGOUT_IMP }\end{array}$ & CURRESCAN & R & Canadian 1989 end of year reserves & $\begin{array}{l}\text { MMB } \\
\text { BCF }\end{array}$ & Canada; Fuel (oill, gas) & Canadian Petroloum Association \\
\hline $\begin{array}{l}\text { OGINIT_L48 } \\
\text { OGINIT_RES } \\
\text { OGOUT_L48 }\end{array}$ & CURAESL48 & $\mathbf{R}$ & Lower 48 onshore initial reserves & $\begin{array}{l}\text { MMB } \\
\text { BCF }\end{array}$ & $\begin{array}{l}6 \text { Lower } 48 \text { onshore, } \\
\text { regions; } \\
\text { Fuel (oil, } 5 \text { gas) } \\
\end{array}$ & $\begin{array}{l}\text { Derived from Annual Reserves } \\
\text { Report Data }\end{array}$ \\
\hline $\begin{array}{l}\text { OGINIT_OFF } \\
\text { OGINIT_AES } \\
\text { OGOUT_OFF }\end{array}$ & CURRESOFF & $R$ & Offshore initial reserves & $\begin{array}{l}\text { MMB } \\
\text { BCF }\end{array}$ & $\begin{array}{l}8 \text { Lower } 48 \text { offshore } \\
\text { subregions; } \\
\text { Fuel (oil, gas) } \\
\end{array}$ & $\begin{array}{l}\text { Derived from Annual Reserves } \\
\text { Report Data }\end{array}$ \\
\hline $\begin{array}{l}\text { OGINIT_L48 } \\
\text { OGINIT_RES } \\
\text { OGOUT_L48 }\end{array}$ & CURAESTDM & -- & $\begin{array}{l}\text { Lower } 48 \text { natural gas reserves at } \\
\text { NGTDM level }\end{array}$ & $\begin{array}{l}\text { MMB } \\
\text { BCF }\end{array}$ & $\begin{array}{l}17 \text { OGSM/NGTDM } \\
\text { regions; Fuel (oil, } 5 \text { gas) }\end{array}$ & $\begin{array}{l}\text { Office of Integrated Analysis and } \\
\text { Forecasting }\end{array}$ \\
\hline OGOUT_L48 & DECFAC & DECFAC & $\begin{array}{l}\text { Inferred resource simultaneous draw } \\
\text { down decline rate adjustment factor }\end{array}$ & Fraction & NA & $\begin{array}{l}\text { Office of Integrated Analysis and } \\
\text { Forecasting }\end{array}$ \\
\hline
\end{tabular}




\begin{tabular}{|c|c|c|c|c|c|c|}
\hline \multicolumn{7}{|c|}{ Dala } \\
\hline \multirow{2}{*}{ Subroutlne } & \multicolumn{2}{|c|}{ Varlable Name } & \multirow{2}{*}{ Description } & \multirow{2}{*}{ Unit } & \multirow{2}{*}{ Classiflcation } & \multirow{2}{*}{ Source } \\
\hline & Code ${ }^{-}$ & Text & & & & \\
\hline $\begin{array}{l}\text { OGFOR_IMP } \\
\text { OGINIT_IMP }\end{array}$ & DECLCAN & - & Canadian decline rates & Fraction & Canada; Fuel (oil, gas) & $\begin{array}{l}\text { Office of Integraled Analysis and } \\
\text { Forecasting }\end{array}$ \\
\hline $\begin{array}{l}\text { OGFOR_L48 } \\
\text { OGINIT_L48 } \\
\text { WELL. }\end{array}$ & DECLL48 & 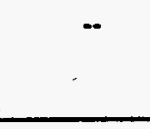 & Lower 48 onshore decline rates & Fraction & $\begin{array}{l}6 \text { Lower } 48 \text { onshore } \\
\text { regions: } \\
\text { Fuel (oil, } 5 \text { gas) }\end{array}$ & $\begin{array}{l}\text { Office of Integraled Analysis and } \\
\text { Forecasting }\end{array}$ \\
\hline $\begin{array}{l}\text { OGFOR_OFF } \\
\text { OGINIT_OFF } \\
\text { WELL }\end{array}$ & DECLOFF & - & Olfshore decline rates & Fraction & $\begin{array}{l}8 \text { Lower } 48 \text { offshore } \\
\text { subregions; } \\
\text { Fuel (oil, gas) }\end{array}$ & $\begin{array}{l}\text { Office of Integraled Analysis and } \\
\text { Forecasting }\end{array}$ \\
\hline $\begin{array}{l}\text { OGINIT_AK } \\
\text { OGPRO_AK }\end{array}$ & DECLPRO & - & $\begin{array}{l}\text { Alaska decline rates for currently } \\
\text { producing fields }\end{array}$ & Fraction & Fiold & $\begin{array}{l}\text { Office of Integrated Analysis and } \\
\text { Forecasting }\end{array}$ \\
\hline $\begin{array}{l}\text { OGFOR_IMP } \\
\text { OGINIT_IMP }\end{array}$ & DEPLETERT & DEPLAT & Depletion rate & Fraction & NA & $\begin{array}{l}\text { Office of Integrated Analysis and } \\
\text { Forecasting }\end{array}$ \\
\hline $\begin{array}{l}\text { OGDEV_AK } \\
\text { OGINIT_AK } \\
\text { OGSUP_AK }\end{array}$ & DEV_AK & - & $\begin{array}{l}\text { Alaska drilling schedule for } \\
\text { devolopmental wells }\end{array}$ & $\begin{array}{l}\text { Wells per } \\
\text { year }\end{array}$ & $\begin{array}{l}3 \text { Alaska regions; Fuel } \\
\text { (oil, gas) }\end{array}$ & $\begin{array}{l}\text { Office of Integrated Analysis and } \\
\text { Forecasting }\end{array}$ \\
\hline $\begin{array}{l}\text { OGDCF_AK } \\
\text { OGFOR_L48 } \\
\text { OGFOR_OFF } \\
\text { OGINIT_BFW }\end{array}$ & DISC & disc & Discount rate & Fraction & National & $\begin{array}{l}\text { Office of Integrated Analysis and } \\
\text { Forecasting }\end{array}$ \\
\hline $\begin{array}{l}\text { OGFOR_IMP } \\
\text { OGINIT_IMP }\end{array}$ & DISRT & dise & Discount rate & Fraction & Canada & $\begin{array}{l}\text { Office of Integrated Analysis and } \\
\text { Forecasting }\end{array}$ \\
\hline $\begin{array}{l}\text { OGCOST_AK } \\
\text { OGINIT_AK }\end{array}$ & DRILLLAK & DAILL & $\begin{array}{l}\text { Alaska drilling cost (not including new. } \\
\text { field wildcats) }\end{array}$ & 1990\$/well & $\begin{array}{l}\text { Class (exploratory, } \\
\text { developmental); } \\
3 \text { Alaska regions; } \\
\text { Fuel (oil, gas) }\end{array}$ & $\begin{array}{l}\text { Office of Integrated Analysis and } \\
\text { Forecasting }\end{array}$ \\
\hline $\begin{array}{l}\text { OGFOR_IMP } \\
\text { OGINIT_IMP }\end{array}$ & DRILLCAN & DAILL & Canadian initial drilling costs & $1987 \$$ & Canada; Fuel (oll, gas) & $\begin{array}{l}\text { Office of Integrated Analysis and } \\
\text { Forecasting }\end{array}$ \\
\hline $\begin{array}{l}\text { OGALL_OFF } \\
\text { OGFOR_OFF } \\
\text { OGINIT_OFF }\end{array}$ & DRILLOFF & DRILL & Offshore drilling cost & $1987 \$$ & $\begin{array}{l}8 \text { Lower } 48 \text { olfshore } \\
\text { subregions }\end{array}$ & Mineral Management Service \\
\hline $\begin{array}{l}\text { OGCOST_AK } \\
\text { OGINIT_AK }\end{array}$ & DRLNFWATK & - & Alaska drilling cost of a new field wildeat & $1990 \$ /$ well & $\begin{array}{l}3 \text { Alaska regions; } \\
\text { Fuel (oil, gas) }\end{array}$ & $\begin{array}{l}\text { Office of Integrated Analysis and } \\
\text { Forecasting }\end{array}$ \\
\hline
\end{tabular}




\begin{tabular}{|c|c|c|c|c|c|c|}
\hline \multirow{3}{*}{ Subroutine } & \multicolumn{5}{|c|}{ Data } & \multirow{3}{*}{ Source } \\
\hline & \multicolumn{2}{|c|}{ Varlable Name } & \multirow{2}{*}{$\begin{array}{l}\text { Description } \\
\therefore . \\
\end{array}$} & \multirow{2}{*}{ Unlt } & \multirow{2}{*}{ Classiffcatlon } & \\
\hline & Code & Text & & & & \\
\hline $\begin{array}{l}\text { OGDCF_AK } \\
\text { OGDEV_AK } \\
\text { OGINIT_AK } \\
\text { OGNEW_AK }\end{array}$ & DAYAK & DAY & Alaska dry hole cost & 1990\$/hole & $\begin{array}{l}\text { Class (exploratory, } \\
\text { developmental); } \\
3 \text { Alaska regions; } \\
\text { Fuel (oil, gas) } \\
\end{array}$ & $\begin{array}{l}\text { Office of Integrated Analysis and } \\
\text { Forecasting }\end{array}$ \\
\hline $\begin{array}{l}\text { OGFOR_IMP } \\
\text { OGINIT_IMP }\end{array}$ & DRYCAN & DRY & Canadian dry hole cost & $1987 \$$ & $\begin{array}{l}\text { Class (exploratory, } \\
\text { developmental) }\end{array}$ & $\begin{array}{l}\text { Office of Integrated Analysis and } \\
\text { Forecasting }\end{array}$ \\
\hline $\begin{array}{l}\text { OGALL_OFF } \\
\text { OGEXP_CALC } \\
\text { OGFOR_OFF } \\
\text { OGINIT_OFF }\end{array}$ & DRYOFF & DRY & Oftshore dry hole cost & $1987 \$$ & $\begin{array}{l}\text { Class (exploratory: } \\
\text { developmental); } \\
8 \text { Lower } 4 \mathrm{~B} \text { olfshore } \\
\text { subregions } \\
\end{array}$ & Minerals Management Service \\
\hline $\begin{array}{l}\text { OGFOR_OFF } \\
\text { OGINIT_OFF }\end{array}$ & DVWELLOFF & - & $\begin{array}{l}\text { Offshore development project drilling } \\
\text { schedules }\end{array}$ & wells per year & $\begin{array}{l}8 \text { Lower } 48 \text { offshore } \\
\text { subregions: } \\
\text { Fuel (oil, gas) }\end{array}$ & Minerals Management Service \\
\hline $\begin{array}{l}\text { OGFOR_L48 } \\
\text { OGINIT_L48 }\end{array}$ & DVWLCBML48 & 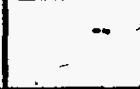 & $\begin{array}{l}\text { Lower } 48 \text { development project drilling } \\
\text { schedules for coalbed methane }\end{array}$ & wells per year & $\begin{array}{l}6 \text { Lower } 48 \text { onshore } \\
\text { regions. }\end{array}$ & $\begin{array}{l}\text { Office of Integrated Analysis and } \\
\text { Forecasting }\end{array}$ \\
\hline $\begin{array}{l}\text { OGFOR_L48 } \\
\text { OGINIT_L48 }\end{array}$ & DVWLDGSL48 & - & $\begin{array}{l}\text { Lower } 4 B \text { development project drilling } \\
\text { sctiedules for doep gas : }\end{array}$ & wells per year & $\begin{array}{l}6 \text { Lower } 48 \text { onshore } \\
\text { regions }\end{array}$ & $\begin{array}{l}\text { Office of Integrated Analysis and } \\
\text { Forecasting }\end{array}$ \\
\hline $\begin{array}{l}\text { OGFOR_L48 } \\
\text { OGINIT_L48 }\end{array}$ & DVWLDVSL48 & - & $\begin{array}{l}\text { Lower } 48 \text { development project drilling } \\
\text { schedules for dovonian shale }\end{array}$ & wells per year & $\begin{array}{l}6 \text { Lower } 48 \text { onshore- } \\
\text { regions }\end{array}$ & $\begin{array}{l}\text { Office of Integrated Analysis and } \\
\text { Forecasting }\end{array}$ \\
\hline $\begin{array}{l}\text { OGFOR_IMP } \\
\text { OGINIT_IMP }\end{array}$ & DWWLGASCAN & - & $\begin{array}{l}\text { Canadian development gas drilling. } \\
\text { schiedule }\end{array}$ & $\begin{array}{l}\text { wells per } \\
\text { project per } \\
\text { year }\end{array}$ & Canada & Not Used \\
\hline $\begin{array}{l}\text { OGFOR_IMP } \\
\text { OGINIT_IMP }\end{array}$ & DVWLOILCAN & . $\cdot-$ & $\begin{array}{l}\text { Canadian development oil drilling } \\
\text { schedule }\end{array}$ & $\begin{array}{l}\text { wells per } \\
\text { project per } \\
\text { year }\end{array}$ & Canada & Not Used \\
\hline $\begin{array}{l}\text { OGFOR_L48 } \\
\text { OGINIT_L48 }\end{array}$ & DVWLOILL48 &. & $\begin{array}{l}\text { Lower } 48 \text { development project drilling } \\
\text { schedules for oil }\end{array}$ & wells per year & $\begin{array}{l}6 \text { Lower. } 48 \text { onshore } \\
\text { regions }\end{array}$ & $\begin{array}{l}\text { Office of Integrated Analysis and } \\
\text { Forecasting }\end{array}$ \\
\hline $\begin{array}{l}\text { OGFOR_L48 } \\
\text { OGINIT_L48 }\end{array}$ & DVWLSGSL48 & .. & $\begin{array}{l}\text { Lower } 48 \text { development project drilling } \\
\text { schedules for shallow gas }\end{array}$ & wells per year & $\begin{array}{l}6 \text { Lower } 48 \text { onshore } \\
\text { regions }\end{array}$ & $\begin{array}{l}\text { Office of Integrated Analysis and } \\
\text { Forecasting }\end{array}$ \\
\hline $\begin{array}{l}\text { OGFOR_L48 } \\
\text { OGINIT_L48 }\end{array}$ & DVWLTSGL48 & $\cdots$ & $\begin{array}{l}\text { Development project drilling schedules } \\
\text { for tight gas }\end{array}$ & wells per year & $\begin{array}{l}6 \text { Lower } 48 \text { onshore } \\
\text { regions }\end{array}$ & $\begin{array}{l}\text { Office of Integrated Analysis and } \\
\text { Forecasting }\end{array}$ \\
\hline
\end{tabular}




\begin{tabular}{|c|c|c|c|c|c|c|}
\hline \multicolumn{7}{|c|}{ Data } \\
\hline \multirow{2}{*}{ Subroutlne } & \multicolumn{2}{|c|}{ Variable Name } & \multirow{2}{*}{ Description } & \multirow{2}{*}{ Unit } & \multirow{2}{*}{ Classiffcation } & \multirow{2}{*}{ Source } \\
\hline & Code & Text & & & & \\
\hline $\begin{array}{l}\text { OGINIT_L48 } \\
\text { OGINIT_RES } \\
\text { OGOUT_L48 }\end{array}$ & ELÁSTL48 & - & $\begin{array}{l}\text { Lower } 48 \text { onshore production elasticity } \\
\text { values }\end{array}$ & Fraction & $\begin{array}{l}6 \text { OGSm Lower } 48 \\
\text { onshore regions }\end{array}$ & $\begin{array}{l}\text { Olfice of Integrated Analysis and } \\
\text { Forecasting }\end{array}$ \\
\hline $\begin{array}{l}\text { OGINIT_OFF } \\
\text { OGINIT_RES } \\
\text { OGOUT_OFF }\end{array}$ & ELASTOFF & - & Ofishore production elasticity values & Fraction & $\begin{array}{l}8 \text { Lower } 48 \text { offshore } \\
\text { subregions }\end{array}$ & $\begin{array}{l}\text { Office of Integrated Analysis and } \\
\text { Forecasting }\end{array}$ \\
\hline $\begin{array}{l}\text { OGCOMP_EMIS } \\
\text { OGINIT_EMIS }\end{array}$ & EMCO & -- & Emission factors for crude oil production & Fraction & Census regions & $\begin{array}{l}\text { EPA - Energy Technology } \\
\text { Characterizations Handbook }\end{array}$ \\
\hline $\begin{array}{l}\text { OGCOMP_EMIS } \\
\text { OGINIT_EMIS }\end{array}$ & EMFACT & -- & Emission factors & $\begin{array}{l}\text { MMB } \\
\text { MMCF }\end{array}$ & Census regions & $\begin{array}{l}\text { EPA - Energy Technology } \\
\text { Characterizations Handbook }\end{array}$ \\
\hline $\begin{array}{l}\text { OGCOMP_EMIS } \\
\text { OGINIT_EMIS }\end{array}$ & EMNG & - & $\begin{array}{l}\text { Emission factors for natural gas } \\
\text { production }\end{array}$ & Fraction & Census regions & $\begin{array}{l}\text { EPA - Energy Technology } \\
\text { Characlerizations Handbook }\end{array}$ \\
\hline $\begin{array}{l}\text { OGCOST_AK } \\
\text { OGINIT_AK }\end{array}$ & EQUIPAK & EQUIP & Alaska lease equipment cost & $1990 \$ /$ well & $\begin{array}{l}\text { Class (exploralory, } \\
\text { developmental); } 3 \\
\text { Alaska regions; Fuel (oil, } \\
\text { gas) }\end{array}$ & U.S. Geological Survey \\
\hline $\begin{array}{l}\text { OGEXP_CALC } \\
\text { OGINIT_BFW }\end{array}$ & EXOFFRGNLAG & -. & $\begin{array}{l}\text { Offshore exploration \& development } \\
\text { regional expenditure (1989) }\end{array}$ & $1987 \$$ & $\begin{array}{l}\text { Class (exploralory, } \\
\text { developmental); } \\
8 \text { Lower } 48 \text { oflshore } \\
\text { subregions }\end{array}$ & $\begin{array}{l}\text { Office of Integrated Analysis and } \\
\text { Forecasting }\end{array}$ \\
\hline $\begin{array}{l}\text { OGDEV_AK } \\
\text { OGINIT_AK } \\
\text { OGSUP_AK } \\
\end{array}$ & EXP_AK & -. & $\begin{array}{l}\text { Alaska drilling schedule for other } \\
\text { exploratory wells }\end{array}$ & wells per year & 3 Alaska regions & $\begin{array}{l}\text { Office of Integrated Analysis and } \\
\text { Forecasting }\end{array}$ \\
\hline $\begin{array}{l}\text { OGCAN_DCF } \\
\text { OGFOR_IMP } \\
\text { OGINIT_IMP } \\
\end{array}$ & EXPENSE & EXP & Fraction of drill costs that are expensed & fraction & $\begin{array}{l}\text { Class (exploratory, } \\
\text { developmental) }\end{array}$ & Canadian Tax Code \\
\hline $\begin{array}{l}\text { OGFOR_OFF } \\
\text { OGINIT_OFF }\end{array}$ & EXWELLOFF & - & $\begin{array}{l}\text { Olfshore exploratory project drilling } \\
\text { schedules }\end{array}$ & wells per year & $\begin{array}{l}8 \text { Lower } 48 \text { offshore } \\
\text { subregions }\end{array}$ & Minerals Management Service \\
\hline $\begin{array}{l}\text { OGFOR_L48 } \\
\text { OGINIT_L48 }\end{array}$ & EXWLCBML48 & -. & $\begin{array}{l}\text { Lower } 48 \text { exploratory project dilling } \\
\text { schedules for coalbed methane }\end{array}$ & wells per year & $\begin{array}{l}6 \text { Lower } 48 \text { onshore } \\
\text { regions }\end{array}$ & $\begin{array}{l}\text { Office of Integrated Analysis and } \\
\text { Forecasting }\end{array}$ \\
\hline $\begin{array}{l}\text { OGFOR_L48 } \\
\text { OGINIT_L48 }\end{array}$ & EXWLDGSL48 & - & $\begin{array}{l}\text { Lower } 48 \text { exploratory and developmental } \\
\text { project drilling schedules for deep gas }\end{array}$ & wells per year & $\begin{array}{l}6 \text { Lower } 48 \text { onshore } \\
\text { regions }\end{array}$ & $\begin{array}{l}\text { Office of Integrated Analysis and } \\
\text { Forecasting }\end{array}$ \\
\hline
\end{tabular}




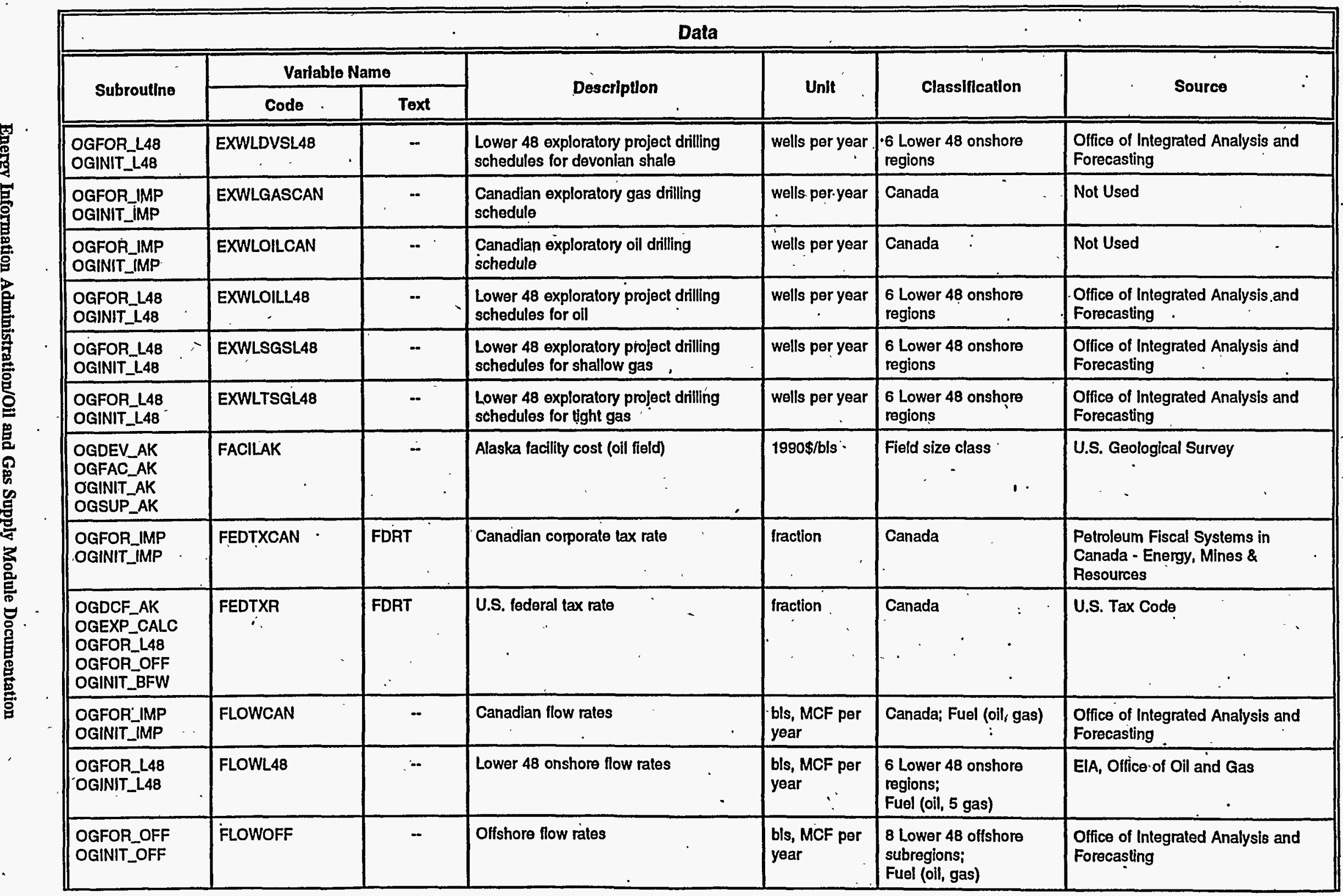




\begin{tabular}{|c|c|c|c|c|c|c|}
\hline & $\cdot$ & & Data & & & \\
\hline \multirow{2}{*}{ Subroutlne } & \multicolumn{2}{|c|}{ Varlable Name } & \multirow{2}{*}{ Description } & \multirow{2}{*}{ Unit } & \multirow{2}{*}{ Classification } & \multirow{2}{*}{ Source } \\
\hline & Code & Text & & & & \\
\hline $\begin{array}{l}\text { OGINIT_LNG } \\
\text { OGPROF_LNG }\end{array}$ & FPRDCST & -- & Foreign production costs & $\begin{array}{l}1991 \$ / M C F \\
\text { per year }\end{array}$ & LNG Source Country & National Petroleum Council \\
\hline $\begin{array}{l}\text { OGINIT_IMP } \\
\text { OGOUT_IMP }\end{array}$ & FRCAN & FR & Canädian initial linding rate & $\begin{array}{l}\text { MMB } \\
\text { BCF } \\
\text { per well }\end{array}$ & Canada & $\begin{array}{l}\text { Office of Integrated Analysis and } \\
\text { Forecasting }\end{array}$ \\
\hline $\begin{array}{l}\text { OGINIT_IMP } \\
\text { OGOUT_IMP }\end{array}$ & FRMINCAN & FRMIN & $\begin{array}{l}\text { Canadian minimum economic finding } \\
\text { rate }\end{array}$ & $\begin{array}{l}\text { MMB } \\
\text { BCF } \\
\text { per well }\end{array}$ & Canada & $\begin{array}{l}\text { Office of Integrated Analysis and } \\
\text { Forecasting }\end{array}$ \\
\hline $\begin{array}{l}\text { OGINIT_L48 } \\
\text { OGOUT_L48 }\end{array}$ & FRMINL48 & FRMIN & $\begin{array}{l}\text { Lower } 48 \text { onshore minimum exploratory } \\
\text { well finding rate }\end{array}$ & $\begin{array}{l}\text { MMB } \\
\text { BCF } \\
\text { per well }\end{array}$ & $\begin{array}{l}6 \text { Lower } 48 \text { onshore } \\
\text { regions; } \\
\text { Fuel (oil, } 5 \text { gas) }\end{array}$ & $\begin{array}{l}\text { Office of Integrated Analysis and } \\
\text { Forecasting }\end{array}$ \\
\hline $\begin{array}{l}\text { OGINIT_OFF } \\
\text { OGOUT_OFF }\end{array}$ & FRMINOFF & FRMIN & $\begin{array}{l}\text { Offshore minimum exploratory wẹll } \\
\text { finding rate }\end{array}$ & $\begin{array}{l}\text { MMB } \\
\text { BCF } \\
\text { per well }\end{array}$ & $\begin{array}{l}8 \text { Lower } 48 \text { offshore } \\
\text { subregions; } \\
\text { Fuel (oil, gas) }\end{array}$ & $\begin{array}{l}\text { Office of Integrated Analysis and } \\
\text { Forecasting }\end{array}$ \\
\hline $\begin{array}{l}\text { OGINIT_L48 } \\
\text { OGOUT_L48 }\end{array}$ & FRIL48 & FRI & $\begin{array}{l}\text { Lower } 48 \text { onshore new field wildcat well } \\
\text { finding rate }\end{array}$ & $\begin{array}{l}\text { MMB } \\
\text { BCF } \\
\text { per well }\end{array}$ & $\begin{array}{l}6 \text { Lower } 48 \text { onshore } \\
\text { regions; } \\
\text { Fuel (oil, } 5 \text { gas) } \\
\end{array}$ & $\begin{array}{l}\text { Office of Integrated Analysis and } \\
\text { Forecasting }\end{array}$ \\
\hline $\begin{array}{l}\text { OGINIT_OFF } \\
\text { OGOUT_OFF }\end{array}$ & $\begin{array}{c}\text { FR1OFF } \\
\text {. }\end{array}$ & FRI & $\begin{array}{l}\text { Ofishore new field wildcat well finding } \\
\text { rate }\end{array}$ & $\begin{array}{l}\text { MMB } \\
\text { BCF } \\
\text { per well }\end{array}$ & $\begin{array}{l}8 \text { Lower } 48 \text { offshore } \\
\text { subregions; } \\
\text { Fuel (oil, gas) }\end{array}$ & $\begin{array}{l}\text { Office of Integrated Analysis and } \\
\text { Forecaisting }\end{array}$ \\
\hline $\begin{array}{l}\text { OGINIT_L48 } \\
\text { OGOUT_L48 }\end{array}$ & FR2L48 & FR3 & $\begin{array}{l}\text { Lower } 48 \text { onshore developmental well. } \\
\text { finding rate }\end{array}$ & $\begin{array}{l}\text { MMB } \\
\text { BCF } \\
\text { per well }\end{array}$ & $\begin{array}{l}6 \text { Lower } 48 \text { onshore } \\
\text { regions; } \\
\text { Fuel (oil, } 5 \text { gaś) }\end{array}$ & $\begin{array}{l}\text { Office of Integrated Analysis and } \\
\text { Forecasting }\end{array}$ \\
\hline $\begin{array}{l}\text { OGINIT_OFF } \\
\text { OGOUT_OFF }\end{array}$ & -FR2OFF & FA3 & Offshore developmental well finding rate & $\begin{array}{l}\mathrm{MMB} \\
\mathrm{BCF} \\
\text { per well }\end{array}$ & $\begin{array}{l}8 \text { Lower } 48 \text { olfshore } \\
\text { subregions; } \\
\text { Fuel (oil, gas) }\end{array}$ & $\begin{array}{l}\text { Office of Integrated Arialysis and } \\
\text { Forecasting }\end{array}$ \\
\hline $\begin{array}{l}\text { OGINIT_L48 } \\
\text { OGOUT_L48 }\end{array}$ & FR3L48 & FR2 & $\begin{array}{l}\text { Lower } 48 \text { other exploratory well finding } \\
\text { rate }\end{array}$ & $\begin{array}{l}\text { MMB } \\
\text { BCF } \\
\text { per well }\end{array}$ & $\begin{array}{l}\text { 6. Lower } 48 \text { onshore } \\
\text { regions; } \\
\text { Fuel (oil, } 5 \text { gas) }\end{array}$ & $\begin{array}{l}\text { Office of Integrated Analysis and } \\
\text { Forecasting }\end{array}$ \\
\hline $\begin{array}{l}\text { OGINIT_OFF } \\
\text { OGOUT_OFF }\end{array}$ & FR3OFF & FR2 & $\begin{array}{l}\text { Offshore other exploratory well finding } \\
\text { rate }\end{array}$ & $\begin{array}{l}\text { MMB } \\
\text { BCF. } \\
\text { per woll }\end{array}$ & $\begin{array}{l}8 \text { Lower } 48 \text { offshore } \\
\text { subregions; } \\
\text { Fuel (oil, gas) }\end{array}$ & $\begin{array}{l}\text { Office of Inlegrated Analysis and } \\
\text { Forecasting }\end{array}$ \\
\hline
\end{tabular}




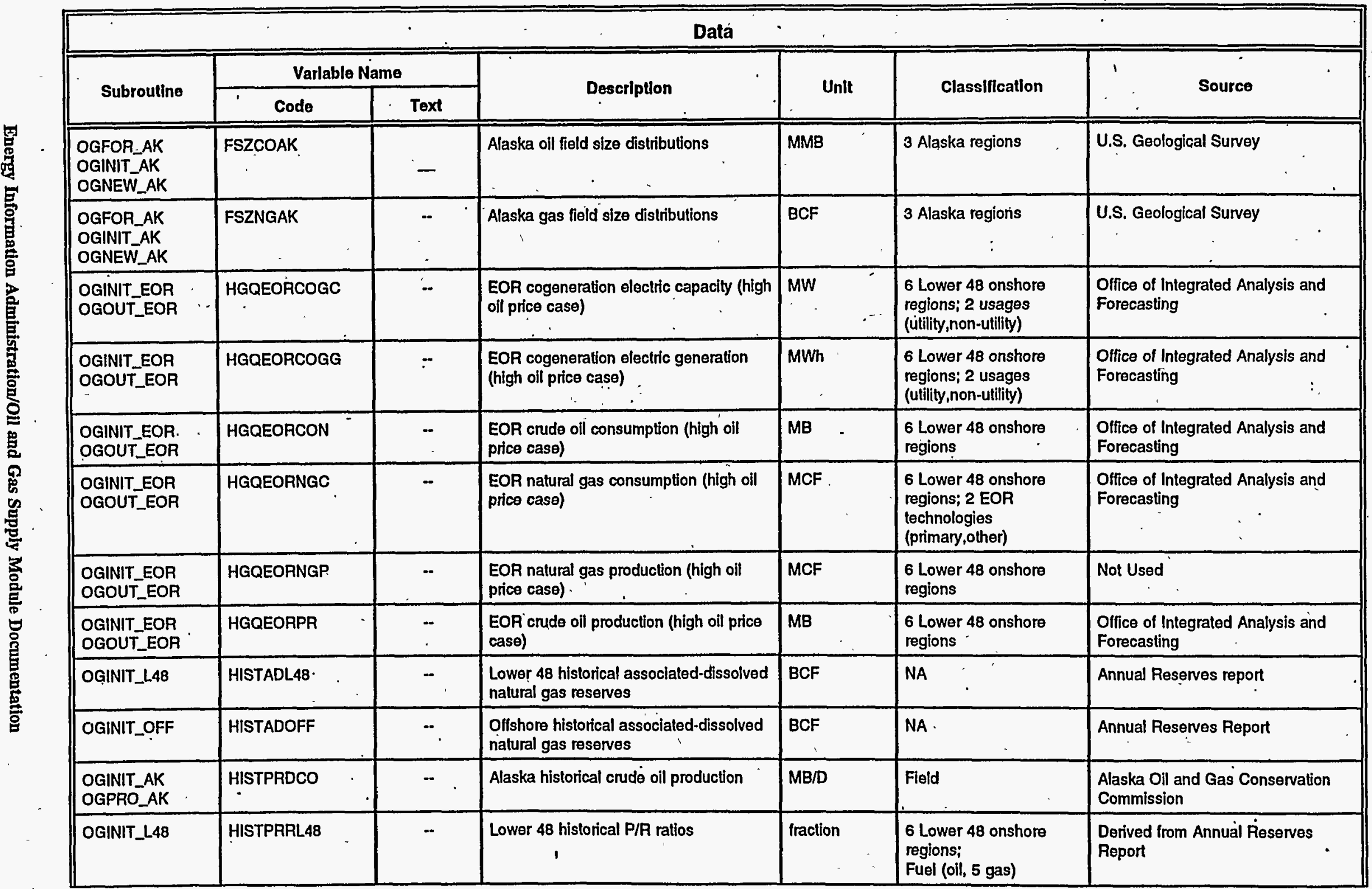




\begin{tabular}{|c|c|c|c|c|c|c|}
\hline \multirow{3}{*}{ Subroutlne } & \multicolumn{5}{|c|}{ Data } & \multirow{3}{*}{ Source } \\
\hline & \multicolumn{2}{|c|}{ Varlable Name } & \multirow{2}{*}{ Description } & \multirow{2}{*}{ Unit } & \multirow{2}{*}{ Classiffcation } & \\
\hline & Code & Text & & & & \\
\hline OGINIT_OFF & HISTPRROFF & -- & Offshore historical P/R ratios & fraction & $\begin{array}{l}8 \text { Lower } 48 \text { offshore } \\
\text { subregions; } \\
\text { Fuel (oil, gas) }\end{array}$ & $\begin{array}{l}\text { Derived from Annual Resorves } \\
\text { Report }\end{array}$ \\
\hline OGINIT_L48 & HISTPRRTDM & - & $\begin{array}{l}\text { Lower } 48 \text { onshore historical P/R ratios at } \\
\text { the NGTDM lovel }\end{array}$ & fraction & $\begin{array}{l}17 \text { OGSM/NGTDM } \\
\text { regions; Fuel (oil, } 5 \text { gas) }\end{array}$ & $\begin{array}{l}\text { Otfice of Integrated Analysis and } \\
\text { Forecasting }\end{array}$ \\
\hline OGINIT_L48 & HISTRESL48 & $\cdots$ & $\begin{array}{l}\text { Lower } 48 \text { onshore historical beginning- } \\
\text { of-year reserves }\end{array}$ & $\begin{array}{l}\text { MMB } \\
\text { BCF }\end{array}$ & $\begin{array}{l}6 \text { Lower } 48 \text { onshore } \\
\text { regions; Fuel (oil, } 5 \\
\text { gas) }\end{array}$ & Annual Reserves Report \\
\hline OGINIT_OFF & HISTRESOFF & - & $\begin{array}{l}\text { Offshore historical beginning-of-year } \\
\text { reserves }\end{array}$ & $\begin{array}{l}\text { MMB } \\
\text { BCF }\end{array}$ & $\begin{array}{l}8 \text { Lower } 48 \text { offshore } \\
\text { subregions; } \\
\text { Fuel (oil, gas) }\end{array}$ & Annual Reserves Report \\
\hline OGINIT_L48 & HISTRESTDM & -- & $\begin{array}{l}\text { Lower } 48 \text { onshore historical beginning- } \\
\text { of-year reserves atthe NGTDM level }\end{array}$ & $\begin{array}{l}\text { MMB } \\
\text { BCF }\end{array}$ & $\begin{array}{l}17 \text { OGSM/NGTDM } \\
\text { reglans; Fuel (oil, } 5 \text { gas) }\end{array}$ & Annual Reserves Report \\
\hline $\begin{array}{l}\text { OGDCF_AK } \\
\text { OGFOR_L48 } \\
\text { OGFOR_OFF } \\
\text { OGINIT_BFW }\end{array}$ & INFL & infi & U.S. inflation rate & fraction & National & $\begin{array}{l}\text { Office of Integrated Analysis and } \\
\text { Forecasting }\end{array}$ \\
\hline $\begin{array}{l}\text { OGINIT_L48 } \\
\text { OGOUT_L48 }\end{array}$ & INFRSVL48 & 1 & Lower 48 onshore inferred reserves & $\begin{array}{l}\text { MMB } \\
\text { BCF }\end{array}$ & $\begin{array}{l}6 \text { Lower } 48 \text { onshore } \\
\text { regions; } \\
\text { Fuel (oil, } 5 \text { gas) }\end{array}$ & $\begin{array}{l}\text { Office of Integrated Analysis and } \\
\text { Forecasting }\end{array}$ \\
\hline $\begin{array}{l}\text { OGINIT_OFF } \\
\text { OGOUT_OFF }\end{array}$ & INFRSVOFF & 1, & Offshore inferred resẹves & $\begin{array}{l}\text { MMB } \\
\text { BCF }\end{array}$ & $\begin{array}{l}8 \text { Lower } 48 \text { offshore } \\
\text { subregions; } \\
\text { Fuel (oil, gas) }\end{array}$ & $\begin{array}{l}\text { Office of Integrated Analysis and } \\
\text { Forecasting }\end{array}$ \\
\hline $\begin{array}{l}\text { OGFOR_IMP } \\
\text { OGINIT_IMP }\end{array}$ & INFRT & inff & Canadian inflation rate & fraction & Canada & $\begin{array}{l}\text { Olfice of Integrated Analysis and } \\
\text { Forecasting }\end{array}$ \\
\hline $\begin{array}{l}\text { OGFOR_IMP } \\
\text { OGINIT_IMP }\end{array}$ & INVESTRT & INVESTCR & Canadian investment tax credit & fraction & Canada & Not Used \\
\hline $\begin{array}{l}\text { OGDCF_AK } \\
\text { OGINIT_AK }\end{array}$ & KAPFRCAK & EXKAP & $\begin{array}{l}\text { Alaska drill costs that are tangible } \\
\text { must be depreciated }\end{array}$ & fraction & Alaska & U.S. Tax Code \\
\hline $\begin{array}{l}\text { OGFOR_L48 } \\
\text { OGINIT_L48 }\end{array}$ & KAPFRCL48 & EXKAP & $\begin{array}{l}\text { Lower } 48 \text { onshore drill costs that are } \\
\text { tangible \& must be depreciated }\end{array}$ & fraction & $\begin{array}{l}\text { Class (exploratory, } \\
\text { developmental) }\end{array}$ & U.S. Tax Code \\
\hline
\end{tabular}




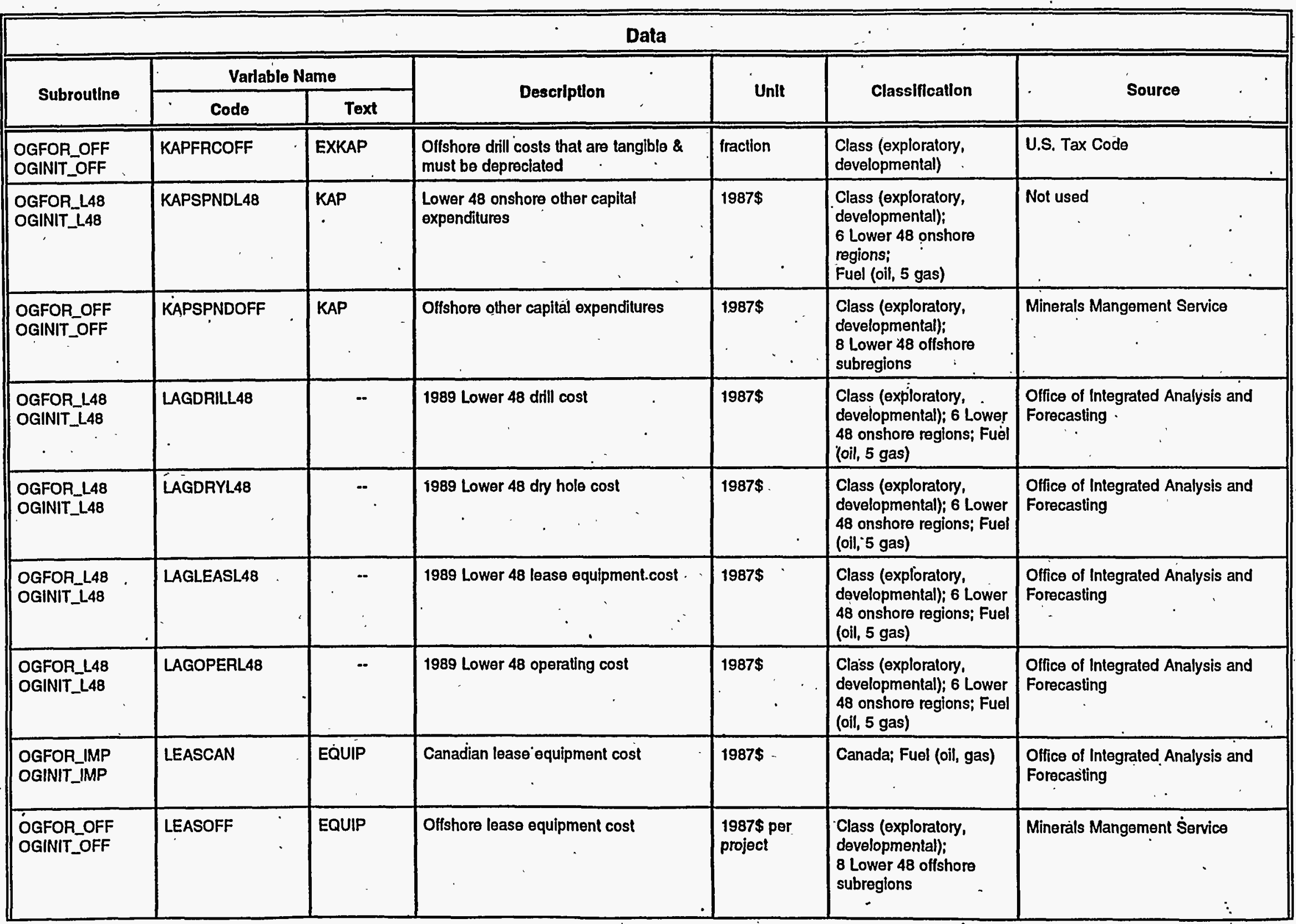




\begin{tabular}{|c|c|c|c|c|c|c|}
\hline & & & Data & & & \\
\hline \multirow{2}{*}{ Subroutine } & \multicolumn{2}{|c|}{ - Varlable Name } & \multirow{2}{*}{ Description } & \multirow{2}{*}{ Unit } & \multirow{2}{*}{ Classification } & \multirow{2}{*}{ Source } \\
\hline & Codo & Text & & & & \\
\hline $\begin{array}{l}\text { OGINIT_EOR } \\
\text { OGOUT_EOR }\end{array}$ & LGQEORCOGC & -- & Electric cogeneration capacity from EOR & MW & $\begin{array}{l}6 \text { Lower } 48 \text { onshore } \\
\text { regions; } 2 \text { usages } \\
\text { (utility,non-utility) }\end{array}$ & $\begin{array}{l}\text { Office of Integrated Analysis and } \\
\text { Forecasting }\end{array}$ \\
\hline $\begin{array}{l}\text { OGINIT_EOR } \\
\text { OGOUT_EOR }\end{array}$ & $\begin{array}{c}\text { LGQEORCOGG } \\
\text {. }\end{array}$ & - & Electric cogeneration volumes from. EOR & MWh & $\begin{array}{l}6 \text { Lower } 48 \text { onshore } \\
\text { regions; } 2 \text { usages } \\
\text { (utility,non-utility) }\end{array}$ & $\begin{array}{l}\text { Office of Integrated Analysis and } \\
\text { Forecasting. }\end{array}$ \\
\hline $\begin{array}{l}\text { OGINIT_EOR } \\
\text { OGOUT_EOR }\end{array}$ & LGQEORCON & -. & EOR crude oil consumption & MB & $\begin{array}{l}6 \text { Lower } 48 \text { onshore } \\
\text { regions }\end{array}$ & Not Used \\
\hline $\begin{array}{l}\text { OGINIT_EOR } \\
\text { OGOUT_EOR }\end{array}$ & LGQEORNGC & -. & EOR natural gas consumption & MCF & $\begin{array}{l}6 \text { Lower } 48 \text { onshore } \\
\text { regions; } 2 \text { EOR } \\
\text { technologies } \\
\text { (primary,other) }\end{array}$ & $\begin{array}{l}\text { Office of Inlegrated Analysis and } \\
\text { Forecasting }\end{array}$ \\
\hline $\begin{array}{l}\text { OGINIT_EOR } \\
\text { OGOUT_EOR }\end{array}$ & LGQEORNGP & -. & EOR natural gas production & MCF & $\begin{array}{l}6 \text { Lower } 48 \text { onshore } \\
\text { regions }\end{array}$ & $\begin{array}{l}\text { Office of integrated Analysis and } \\
\text { Forecasting }\end{array}$ \\
\hline $\begin{array}{l}\text { OGINIT_EOR } \\
\text { OGOUT_EOR }\end{array}$ & LGQEORPA & -. & EOR crude oll production & MB & $\begin{array}{l}6 \text { Lower } 48 \text { onshore } \\
\text { regions }\end{array}$ & $\begin{array}{l}\text { Office of Integrated Analysis and } \\
\text { Forecasting }\end{array}$ \\
\hline $\begin{array}{l}\text { OGEXPAND_LNG } \\
\text { OGINIT_LNG }\end{array}$ & LIQCAP & -. & Liquefaction capacity & BCF & LNG Source Country & National Petroleum Council \\
\hline $\begin{array}{l}\text { OGINIT_LNG } \\
\text { OGPROF_LNG }\end{array}$ & LLQCST & - & Liquefaction costs & 1991\$/MCF & LNG Source Counlry & National Pelroleun Council \\
\hline $\begin{array}{l}\text { OGEXPAND_LNG } \\
\text { OGPROF_LNG }\end{array}$ & LIQSTAGE & -- & Liquefaction stage & NA & NA & National Pelroleum Council \\
\hline $\begin{array}{l}\text { OGFOR_AK } \\
\text { OGINIT_AK } \\
\text { OGPRO_AK } \\
\end{array}$ & MAXPRO & -- & Alaska maximum crude oil production & $M B / D$ & Field & Announced Plans \\
\hline $\begin{array}{l}\text { OGINIT_IMP } \\
\text { OGOUT_MEX }\end{array}$ & MEXEXP & -- & Exports from Mexico & $B C F$ & $\begin{array}{l}\text { 3 USMexican border } \\
\text { crossing }\end{array}$ & $\begin{array}{l}\text { Office of Integrated Analysis and } \\
\text { Forecasting }\end{array}$ \\
\hline $\begin{array}{l}\text { OGINIT_IMP } \\
\text { OGOUT_MEX }\end{array}$ & MEXIMP & -- & Imports from Mexico & BCF & $\begin{array}{l}\text { 3 USMexican Border } \\
\text { crosssing }\end{array}$ & $\begin{array}{l}\text { Office of Integrated Analysis and } \\
\text { Forecasting }\end{array}$ \\
\hline $\begin{array}{l}\text { OGINIT_AK } \\
\text { OGNEW_AK }\end{array}$ & NFW_AK & - & $\begin{array}{l}\text { Alaska drilling schedule for new field } \\
\text { wildeats }\end{array}$ & wolls & NA & $\begin{array}{l}\text { Office of Integraled Analysis and } \\
\text { Forecasting }\end{array}$ \\
\hline
\end{tabular}




\begin{tabular}{|c|c|c|c|c|c|c|}
\hline & & & Data & & & \\
\hline \multirow{2}{*}{ Subroutine } & \multicolumn{2}{|c|}{ Varlable Name } & \multirow{2}{*}{ Description } & \multirow{2}{*}{ Unit } & \multirow{2}{*}{ Classification } & \multirow{2}{*}{ Source } \\
\hline & Code & Text & & & & \\
\hline $\begin{array}{l}\text { OGFOR_OFF } \\
\text { OGINIT_OFF }\end{array}$ & NFWCOSTOFF & COSTEXP & Offshore new field wildcal cost & $1987 \$$ & $\begin{array}{l}\text { Class (exploratory, } \\
\text { developmental); } \\
8 \text { Lower } 48 \text { offshore } \\
\text { subregions }\end{array}$ & Minerals Management Service. \\
\hline $\begin{array}{l}\text { OGFOR_OFF } \\
\text { OGINIT_OFF }\end{array}$ & NFWELLOPFF & .- & $\begin{array}{l}\text { Offshore exploratory and developmental } \\
\text { project drilling schedules }\end{array}$ & $\begin{array}{l}\text { wells per } \\
\text { project per } \\
\text { year }\end{array}$ & $\begin{array}{l}\text { Class (exploratory, } \\
\text { developmental); } \\
r=1 \text {. }\end{array}$ & Minerals Management Service \\
\hline $\begin{array}{l}\text { OGINIT_L48 } \\
\text { OGINIT_RES } \\
\text { OGOUT_L48 }\end{array}$ & NGTDMMAP & , - & $\begin{array}{l}\text { Mapping of NGTDM regions to OGSM } \\
\text { regions }\end{array}$ & NA. & $\begin{array}{l}17 \text { OGSM/NGTDM } \\
\text { regions }\end{array}$ & $\begin{array}{l}\text { Office of Integrated Analysis and } \\
\text { Forecasting }\end{array}$ \\
\hline OGINIT_IMP & OGCNBLOSS & - & Gas lost in transit to border & $B C F$ & $\begin{array}{l}6 \text { US/Canadian border } \\
\text { crossings }\end{array}$ & Not Used \\
\hline OGINIT_IMP & OGCNCAPB & -- & $\begin{array}{l}\text { Canadian capacities at borders - base } \\
\text { case }\end{array}$ & BCF & $\begin{array}{l}6 \text { US/Canadian border } \\
\text { crossing }\end{array}$ & Denived from Natural Gas Annual \\
\hline OGINIT_IMP & OGCNCAPH. & -- & $\begin{array}{l}\text { Canadian capacities at borders - high } \\
\text { WOP case }\end{array}$ & BCF & $\begin{array}{l}6 \text { US/Canadian border } \\
\text { crossing }\end{array}$ & Derived from Natural Gas Annual \\
\hline OGINIT_IMP & OGCNCAPL & -. & $\begin{array}{l}\text { Canadian capacities at borders - low } \\
\text { WOP case }\end{array}$ & BCF & $\begin{array}{l}6 \text { US/Canadian border } \\
\text { crossing }\end{array}$ & Derived from Natural Gas Annual \\
\hline $\begin{array}{l}\text { OGINIT_IMP } \\
\text { OGOUT_IMP }\end{array}$ & OGCNCON & .. & Canadian gas consumption. & BCF & Canada; Fuel (oil, gas) & $\begin{array}{l}\text { Office of Integrated Analysis and } \\
\text { Forecasting }\end{array}$ \\
\hline OGINIT_IMP & OGCNDEM & -. & $\begin{array}{l}\text { Canadian demand calculation } \\
\text { parameters }\end{array}$ & NA & NA & Not Used \\
\hline OGINIT_IMP & OGCNDMLOSS & $\therefore$ & $\begin{array}{l}\text { Gas lost Irom wellhead to Canadian } \\
\text { demand }\end{array}$ & BCF & Canada & $\begin{array}{l}\text { Office of Integrated Analysis and } \\
\text { Forecasting }\end{array}$ \\
\hline OGINIT_IMP & OGCNEXLOSS & $\cdots$ & $\begin{array}{l}\text { Gas lost from US export to Canadian } \\
\text { demand }\end{array}$ & BCF & Canada & $\begin{array}{l}\text { Office of Integrated Analysis and } \\
\text { Forecasting }\end{array}$ \\
\hline OGINIT_IMP & OGCNFLW & -- & 1989 flow volumes by border crossing & BCF & $\begin{array}{l}6 \text { US/Canadian border } \\
\text { crossings }\end{array}$ & $\begin{array}{l}\text { Office of Integrated Ánalysis and } \\
\text { Forecasting }\end{array}$ \\
\hline OGINIT_IMP & OGCNPARM1 & -. & Actual gas allocation lactor. & fraction & Canada & $\begin{array}{l}\text { Olfice of Integrated Analysis and } \\
\text { Forecasting }\end{array}$ \\
\hline OGINIT_IMP & OGCNPARM2 & -. & $\begin{array}{l}\text { Responsiveness of flow to different } \\
\text { border prices }\end{array}$ & fraction & Canada & $\begin{array}{l}\text { Office of Integrated Analysis and } \\
\text { Forecasting }\end{array}$ \\
\hline
\end{tabular}




\begin{tabular}{|c|c|c|c|c|c|c|}
\hline \multicolumn{7}{|c|}{ Data } \\
\hline \multirow{2}{*}{ Subroutlne } & \multicolumn{2}{|c|}{ Varlable Name } & \multirow{2}{*}{ Descriptlon } & \multirow{2}{*}{ Unit } & \multirow{2}{*}{ Classification } & \multirow{2}{*}{ Source } \\
\hline & Code & Text & & & & \\
\hline OGINIT_PRICE & OGCNPPRD & -- & Canadian price of oil and gas & $\begin{array}{l}\text { oil: } 87 \$ s / B \\
\text { gas: } 87 \$ s / m c f\end{array}$ & Canada & NGTDM \\
\hline $\begin{array}{l}\text { OGPIP_AK } \\
\text { OGPROF_LNG }\end{array}$ & $\begin{array}{c}\text { OGPNGIMP } \\
\text {, }\end{array}$ & -- & Nalural gas import price & $87 \$ s / m c f$ & $\begin{array}{l}\text { US/Canadian \& } \\
\text { USMexican border } \\
\text { crossings and LNG } \\
\text { destination points }\end{array}$ & NGTDM \\
\hline $\begin{array}{l}\text { OGFOR_IMP } \\
\text { OGINIT_IMP }\end{array}$ & OPERCAN & OPCOST & Canadian operating cost & $\$ 1987$ & Canada; Fuel (oil, gas) & $\begin{array}{l}\text { Office of Integrated Analysis and } \\
\text { Forecasting }\end{array}$ \\
\hline $\begin{array}{l}\text { OGFOR_OFF } \\
\text { OGINIT_OFF }\end{array}$ & OPEAOFF & OPCOST & . & $\begin{array}{l}1987 \$ \text { per } \\
\text { well per year }\end{array}$ & $\begin{array}{l}\text { Class (exploratory, } \\
\text { developmenlal); } \\
8 \text { Lower } 48 \text { offshore } \\
\text { subregions }\end{array}$ & Mineral Management Service \\
\hline $\begin{array}{l}\text { OGDCF_AK } \\
\text { OGINIT_AK }\end{array}$ & PRJAK & $n$. & Alaska oil project lile & Years & Fuel (oil, gas) & $\begin{array}{l}\text { Office of Integrated Analysis and } \\
\text { Forecasting }\end{array}$ \\
\hline $\begin{array}{l}\text { OGFOR_L48 } \\
\text { OGINIT_L48 }\end{array}$ & PRJL48 & $n$ & Lower $\mathbf{4 8}$ project lile & Years & Fuel (oil, gas) & $\begin{array}{l}\text { Office of Integrated Analysis and } \\
\text { Forecasting }\end{array}$ \\
\hline $\begin{array}{l}\text { OGFOR_OFF } \\
\text { OGINIT_OFF }\end{array}$ & PRJOFF & $\mathbf{n}$ & Olfshore project life & Years & Fuel (oil, gas) & $\begin{array}{l}\text { Office of Integrated Analysis and } \\
\text { Forecasting }\end{array}$ \\
\hline $\begin{array}{l}\text { OGFOR_IMP } \\
\text { OGINIT_IMP }\end{array}$ & PAOVTXCAN & $\begin{array}{c}\text { PROVRT } \\
\text {. }\end{array}$ & Canadian provincial corporale tax rates & traction & Canada & $\begin{array}{l}\text { Petroleum Fiscal Systems in } \\
\text { Canada - Energy, Mines \& } \\
\text { Resources }\end{array}$ \\
\hline $\begin{array}{l}\text { OGFÖ_AK } \\
\text { OGINIT_AK } \\
\text { OGPRO_AK }\end{array}$ & PROYR & - & Start year for known fields in Alaska & Year & Field & Announced Plans \\
\hline $\begin{array}{l}\text { OGEXPAND_LNG } \\
\text { OGINIT_LNG } \\
\text { OGLNG_OUT }\end{array}$ & QLNG & 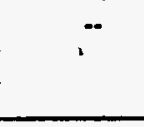 & LNG operating flow capacity & $B C F$ & LNG destination points & National Petroleum Council \\
\hline $\begin{array}{l}\text { OGEXPAND_LNG } \\
\text { OGINIT_LNG } \\
\text { OGLNG_OUT }\end{array}$ & QLNGMAX & - & LNG maximum capacity & BCF & LNG destination Points & $\begin{array}{c}\text { National Pelroleum Council } \\
\cdot\end{array}$ \\
\hline $\begin{array}{l}\text { OGDCF_AK } \\
\text { OGINIT_AK }\end{array}$ & RCPADAK & $m$ & $\begin{array}{l}\text { Alaska recovery period of intangible \& } \\
\text { tangible drill cost }\end{array}$ & Years & Alaska & U.S. Tax Code \\
\hline
\end{tabular}




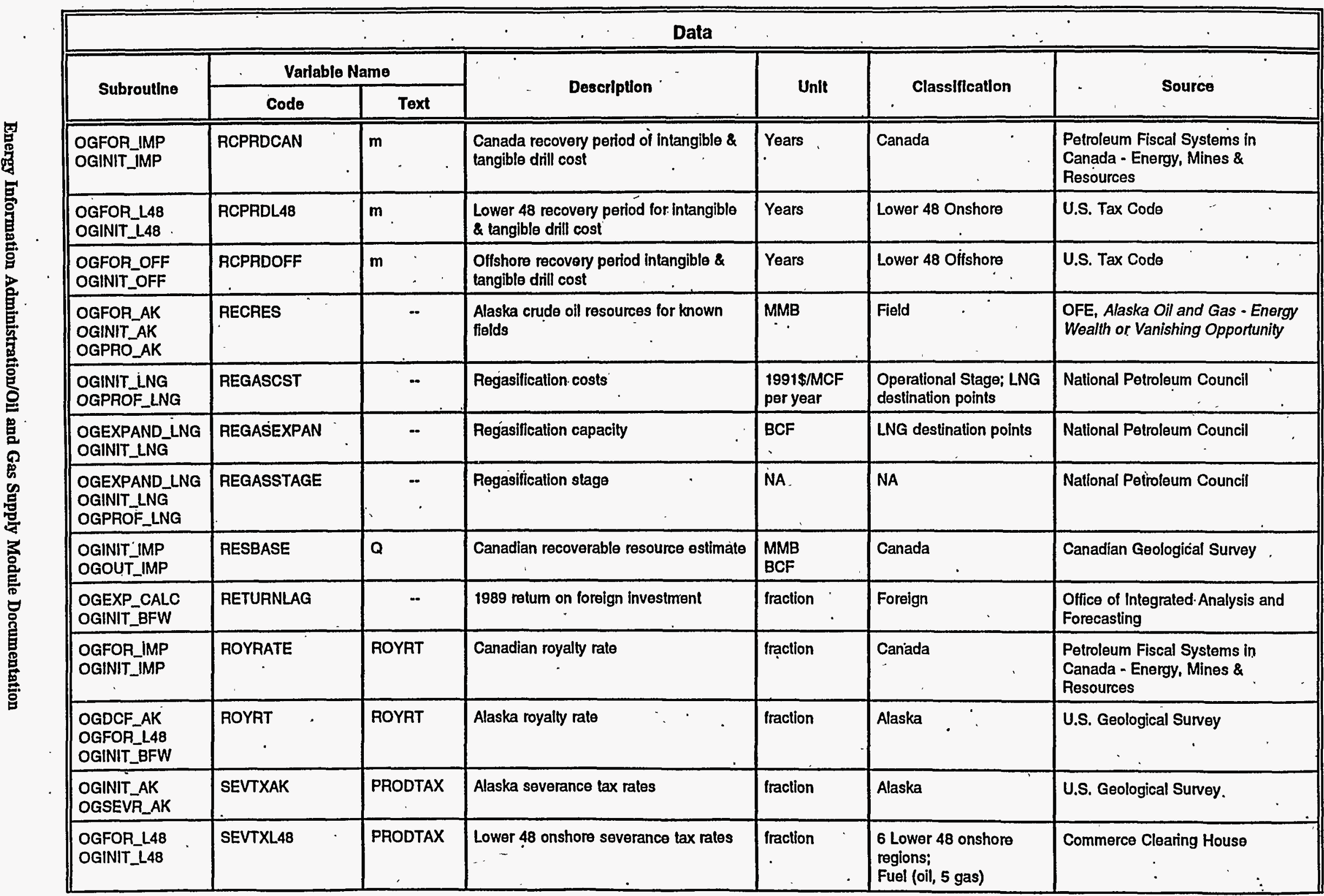




\begin{tabular}{|c|c|c|c|c|c|c|}
\hline \multicolumn{7}{|c|}{ Data } \\
\hline \multirow{2}{*}{ Subroutlne } & \multicolumn{2}{|c|}{ Varlable Name } & \multirow{2}{*}{ Description } & \multirow{2}{*}{ Unit } & \multirow{2}{*}{ Classiffcation } & \multirow{2}{*}{ Source } \\
\hline & Code & Text & & & & \\
\hline $\begin{array}{l}\text { OGFOR_OFF } \\
\text { OGINIT_OFF }\end{array}$ & SEVTXOFF & PAODTAX & Offishore severance tax rates & fraction & $\begin{array}{l}8 \text { Lower } 48 \text { offshore } \\
\text { subregions; } \\
\text { Fuel (oil, gas) } \\
\end{array}$ & Commerce Clearing House \\
\hline $\begin{array}{l}\text { OGEXP_CALC } \\
\text { OGINIT_BFW }\end{array}$ & SKEWEDP & SKP & Skewed price & fraction & NA & $\begin{array}{l}\text { Office of Integrated Analysis and } \\
\text { Forecasting }\end{array}$ \\
\hline $\begin{array}{l}\text { OGEXP_CALC } \\
\text { OGINIT_BFW }\end{array}$ & SKEWEDPLAG & -- & $\begin{array}{c}1989 \text { Skewed price } \\
. .\end{array}$ & fraction & NA & $\begin{array}{l}\text { Office of Integrated Analysis and } \\
\text { Forecasting }\end{array}$ \\
\hline $\begin{array}{l}\text { OGEXP_CALC } \\
\text { OGINIT_BFW }\end{array}$ & SPENDIRKLAG & -- & $\begin{array}{l}1989 \text { Lower } 48 \text { exploration \& } \\
\text { development expenditures }\end{array}$ & $1987 \$$ & $\begin{array}{l}\text { Class (exploratory, } \\
\text { developmental) }\end{array}$ & $\begin{array}{l}\text { Office of Integrated Analysis and } \\
\text { Forecasting }\end{array}$ \\
\hline $\begin{array}{l}\text { OGEXP_CALC } \\
\text { OGINIT_BFW }\end{array}$ & SPENDLAGL48 & -. & $\begin{array}{l}1989 \text { Lower } 48 \text { onshore exploration \& } \\
\text { development expenditures }\end{array}$ & $1987 \$$ & $\begin{array}{l}\text { Class (exploratory, } \\
\text { developmental)i } \\
6 \text { Lower } 48 \text { onshore } \\
\text { regions; } \\
\text { Fuel (oil, } 5 \text { gas) } \\
\end{array}$ & $\begin{array}{l}\text { Office of Integrated Analysis and } \\
\text { Forecasting }\end{array}$ \\
\hline $\begin{array}{l}\text { OGEXP_CALC } \\
\text { OGINIT_BFW }\end{array}$ & SPENDLAGOFF & - & $\begin{array}{l}1989 \text { offshore exploration \& } \\
\text { development expenditures } \\
\therefore\end{array}$ & $1987 \$$ & $\begin{array}{l}\text { Class (exploratory, } \\
\text { developmental); } \\
8 \text { Lower } 48 \text { offshore } \\
\text { subregions; } \\
\text { Fuel (oil, } 5 \text { gas) } \\
\end{array}$ & $\begin{array}{l}\text { Office of Integrated Analysis and } \\
\text { Forecasting }\end{array}$ \\
\hline $\begin{array}{l}\text { OGEXP_CALC } \\
\text { OGINIT_BFW }\end{array}$ & SPENDRGNLAG & -. & $\begin{array}{l}1989 \text { Lower } 48 \text { exploration \& } \\
\text { development regional expenditures }\end{array}$ & $1987 \$$ & $\begin{array}{l}\text { Class (exploratory, } \\
\text { developmental); } \\
6 \text { Lower } 48 \text { onshore } \\
\text { regions }\end{array}$ & $\begin{array}{l}\text { Office of Integrated Analysis and } \\
\text { Forecasting }\end{array}$ \\
\hline $\begin{array}{l}\text { OGEXP_CALC } \\
\text { OGINIT_BFW }\end{array}$ & SPEXLAGL4B & -. & $\begin{array}{l}1988 \text { Lower } 48 \text { onshore exploration } \\
\text { expenditures }\end{array}$ & $1987 \$$ & Lówer 48 & $\begin{array}{l}\text { Office of Integrated Analysis and } \\
\text { Forecasting }\end{array}$ \\
\hline $\begin{array}{l}\text { OGEXP_CALC } \\
\text { OGINIT_BFW }\end{array}$ & SPEXLAGOFF2 & $\cdots$ & 1988 offshore exploration expenditures & $1987 \$$ & Lower 48 & $\begin{array}{l}\text { Office of Integrated Analysis and } \\
\text { Forecasling }\end{array}$ \\
\hline $\begin{array}{l}\text { OGEXP_CALC } \\
\text { OGINIT_BFW }\end{array}$ & SPEXOFFIRKLAG & $\cdot \cdot$ & $\begin{array}{c}1989 \text { offshore exploration \& } \\
\text { development expenditures } \\
1 \\
.\end{array}$ & $1987 \$$ & $\begin{array}{l}\text { Class (exploratory, } \\
\text { developmental): } \\
8 \text { Lower } 48 \text { offshore } \\
\text { subregions; } \\
\text { Fuel (oil, gas) } \\
\end{array}$ & $\begin{array}{l}\text { Office of Integrated Analysis and } \\
\text { Forecasting }\end{array}$ \\
\hline
\end{tabular}




\begin{tabular}{|c|c|c|c|c|c|c|}
\hline \multicolumn{7}{|c|}{ Data } \\
\hline \multirow{2}{*}{ Subroutine } & \multicolumn{2}{|c|}{ Varlable Name } & \multirow{2}{*}{ Description } & \multirow{2}{*}{ Unit } & \multirow{2}{*}{ Classiffcation } & \multirow{2}{*}{ Source } \\
\hline & Code & Text & & & & \\
\hline $\begin{array}{l}\text { OGDCF_AK } \\
\text { OGDEV_AK } \\
\text { OGINIT_AK } \\
\text { OGNEW_AK } \\
\end{array}$ & SRAK & SR & Alaska drilling success rates & fraction. & Alaska & Office of Oil and Gas \\
\hline $\begin{array}{l}\text { OGFOR_IMP } \\
\text { OGINIT_IMP } \\
\text { OGFOR_IMP } \\
\end{array}$ & SACAN & SR & Canada drilling success rates & fraction & Canada & $\begin{array}{l}\text { Office of Integrated Analysis and } \\
\text { Forecasting }\end{array}$ \\
\hline $\begin{array}{l}\text { OGEXP_CALC } \\
\text { OGEXP_FIX } \\
\text { OGFOR_L48 } \\
\text { OGINIT_L48 } \\
\text { OGOUT_L48 } \\
\end{array}$ & SRL48 & SR & Lower $\mathbf{4 8}$ drilling succoss rates & fraction & $\begin{array}{l}\text { Class (exploratory, } \\
\text { developmental); } \\
6 \text { Lower } 48 \text { onshore } \\
\text { reglonsi } \\
\text { Fuel (oil, } 5 \text { gas) } \\
\end{array}$ & $\begin{array}{l}\text { Office of Integrated Analysis and } \\
\text { Forecasting } \\
\end{array}$ \\
\hline $\begin{array}{l}\text { OGALL_OFF } \\
\text { OGFOR_OFF } \\
\text { OGINIT_OFF } \\
\text { OGOUT_OFF }\end{array}$ & SROFF & SR & Offishore drilling success rates & fraction & $\begin{array}{l}\text { Class (exploratory, } \\
\text { developmental): } \\
8 \text { Lower } 48 \text { offshore } \\
\text { subreglons; : } \\
\text { Fuel (oil, gas) } \\
\end{array}$ & Minerals Management Service \\
\hline $\begin{array}{l}\text { OGEXPAND_LNG } \\
\text { OGINIT_LNG } \\
\end{array}$ & STARTLAG & $\therefore$. & $\begin{array}{l}\text { Number of year between stages } \\
\text { (regasification and liquefaction) }\end{array}$ & years & NA & $\begin{array}{l}\text { Office of Integrated Analysis and } \\
\text { Forecasting }\end{array}$ \\
\hline $\begin{array}{l}\text { OGDCF_AK } \\
\text { OGINIT_AK } \\
\end{array}$ & STTXAK & STAT & Alaska stale tax rate & fraction & Alaska & U.S. Geological Survey \\
\hline $\begin{array}{l}\text { OGEXP_CALC } \\
\text { OGFOR_L48 } \\
\text { OGINIT_L48 } \\
\end{array}$ & STTXL48 & STAT & State tax rates & fraction & $\begin{array}{l}6 \text { Lower } 48 \text { onshore } \\
\text { regions }\end{array}$ & Commerce Clearing House \\
\hline $\begin{array}{l}\text { OGEXP_CALC } \\
\text { OGFOR_OFF } \\
\text { OGINIT_L48 } \\
\end{array}$ & STTXOFF & STRT & State tax rates & fraction & $\begin{array}{l}8 \text { Lower } 48 \text { offshore } \\
\text { subreglons }\end{array}$ & Commerce Clearing House \\
\hline $\begin{array}{l}\text { OGCOST_AK } \\
\text { OGINIT_AK }\end{array}$ & TECHAK & TECH & Alaska lechnology factors & fraction & Alaska & $\begin{array}{l}\text { Office of Integrated Analysis and } \\
\text { Forecasting. }\end{array}$ \\
\hline $\begin{array}{l}\text { OGFOR_IMP } \\
\text { OGINIT_IMP }\end{array}$ & TECHCAN & TECH & $\begin{array}{l}\text { Canada technology factors applied to } \\
\text { costs }\end{array}$ & fraction & Canada & $\begin{array}{l}\text { Office of Integrated Analysis and } \\
\text { Forecasting }\end{array}$ \\
\hline $\begin{array}{l}\text { OGFOR_IMP } \\
\text { OGINIT_IMP }\end{array}$ & TECHL48 & TECH & $\begin{array}{l}\text { Lower } 48 \text { onshore technology factors } \\
\text { applied to costs }\end{array}$ & fraclion & Lower 48 Onshore & $\begin{array}{l}\text { Office of Integrated Analysis and } \\
\text { Forecasting }\end{array}$ \\
\hline
\end{tabular}




\begin{tabular}{|c|c|c|c|c|c|c|}
\hline \multicolumn{7}{|c|}{ Data } \\
\hline \multirow{2}{*}{ Subroutine } & \multicolumn{2}{|c|}{ Variable Name } & \multirow{2}{*}{ Description } & \multirow{2}{*}{ Unit } & \multirow{2}{*}{ Classification } & \multirow{2}{*}{ Source } \\
\hline & Code & Text & & & & \\
\hline $\begin{array}{l}\text { OGFOR_OFF } \\
\text { OGINIT_OFF } \\
\end{array}$ & TECHOFF & TECH & $\begin{array}{l}\text { Offshore technology factors applied to } \\
\text { costs }\end{array}$ & fraction & Lower 48 Offshore & $\begin{array}{l}\text { Office of Inlegrated Analysis and } \\
\text { Forecasting }\end{array}$ \\
\hline $\begin{array}{l}\text { OGINIT_LNG } \\
\text { OGPROF_LNG } \\
\end{array}$ & TRANCST & -- & LNG transporation costs & 1990MCF & NA & National Petroleum Council \\
\hline $\begin{array}{l}\text { OGDCF_AK } \\
\text { OGINIT_AK }\end{array}$ & TRANSAK & TRANS & Alaska Iransportation cost & $1990 \$$ & $\begin{array}{l}3 \text { Alaska regions; } \\
\text { Fuel (oil, gas) }\end{array}$ & $\begin{array}{l}\text { Office of Integrated Analysis and } \\
\text { Forecasting }\end{array}$ \\
\hline $\begin{array}{l}\text { OGFOR_L48 } \\
\text { OGINIT_L48 }\end{array}$ & TRANSL48 & TRANS . & $\begin{array}{l}\text { Lower } 48 \text { onshore expected } \\
\text { transportation costs } \\
\end{array}$ & NA & $\begin{array}{l}6 \text { Lower } 48 \text { onshore } \\
\text { regions; Fuel (oil, } 5 \text { gas) }\end{array}$ & Not Used \\
\hline $\begin{array}{l}\text { OGFOR_OFF } \\
\text { OGINIT_OFF }\end{array}$ & TRANSOFF & TRANS & Offshore expected transportation costs & NA & $\begin{array}{l}8 \text { Lower } 48 \text { offshore } \\
\text { subregions; Fuel (oil, } \\
\text { gas)' }\end{array}$ & Not Used \\
\hline $\begin{array}{l}\text { OGINIT_OFF } \\
\text { OGOUT_OFF }\end{array}$ & UNRESOFF & $\mathbf{a}$ & Offshore undiscovered resources & $\begin{array}{l}\text { MMB } \\
\text { BCF }\end{array}$ & $\begin{array}{l}8 \text { Lower } 48 \text { offshore } \\
\text { subregions; } \\
\text { Fuel (oil, gas) }\end{array}$ & $\begin{array}{l}\text { Office of Integrated Analysis and } \\
\text { Forecasting }\end{array}$ \\
\hline $\begin{array}{l}\text { OGINIT_L48 } \\
\text { OGOUT_L48 } \\
\end{array}$ & URRCRDL48 & $\mathbf{Q}$ & $\begin{array}{l}\text { Lower } 48 \text { onshore undiscovered } \\
\text { recoverable crude oil resources }\end{array}$ & MMB & $\begin{array}{l}6 \text { Lower } 48 \text { onshore } \\
\text { regions. }\end{array}$ & $\begin{array}{l}\text { Office of Integrated Analysis and } \\
\text { Forecasting }\end{array}$ \\
\hline $\begin{array}{l}\text { OGINIT_L48 } \\
\text { OGOUT_L48 }\end{array}$ & URRTDM & -. & $\begin{array}{l}\text { Lower } 48 \text { onshore undiscovered } \\
\text { recoverable natural gas resources }\end{array}$ & TCF . & $\begin{array}{l}6 \text { Lower } 48 \text { onshore } \\
\text { regions }\end{array}$ & $\begin{array}{l}\text { Office of Integrated Analysis and } \\
\text { Forecasting }\end{array}$ \\
\hline $\begin{array}{l}\text { OGEXP_CALC } \\
\text { OGINIT_BFW }\end{array}$ & VARPOIL & VARPOIL & Variance in the Price of Oil & fraction & National & $\begin{array}{l}\text { Office of Integrated Analysis and } \\
\text { Forecasting }\end{array}$ \\
\hline $\begin{array}{l}\text { OGEXP_CALC } \\
\text { OGINIT_BFW } \\
\end{array}$ & VARPOILLAG & $\therefore$ & 1989 Variance in the Price of Oil & fraction & National & $\begin{array}{l}\text { Office of Integrated Analysis and } \\
\text { Forecasting }\end{array}$ \\
\hline $\begin{array}{l}\text { OGEXP_CALC } \\
\text { OGINIT_BFW }\end{array}$ & WDCFIRKLAG & .. & $\begin{array}{l}1989 \text { Lower } 48 \text { exploration \& } \\
\text { development weighted DCFs }\end{array}$ & $1987 \$$ & $\begin{array}{l}\text { Class (exploratory, } \\
\text { developmental); } \\
6 \text { Lower } 48 \text { onshore } \\
\text { regions; } \\
\text { Fuel (oil, } 5 \text { gas) } \\
\end{array}$ & $\begin{array}{l}\text { Office of Integrated Analysis and } \\
\text { Forecasting }\end{array}$ \\
\hline $\begin{array}{l}\text { OGEXP_CALC } \\
\text { OGINIT_BFW }\end{array}$ & WDCFIRLAG & .. & $\begin{array}{l}1989 \text { Lower } 48 \text { regional exploration \& } \\
\text { development weighted DCFs }\end{array}$ & $1987 \$$ & $\begin{array}{l}\text { Class (exploratory, } \\
\text { developmental); } \\
6 \text { Lower } 48 \text { onshore } \\
\text { regions; }\end{array}$ & $\begin{array}{l}\text { Office of Integrated Analysis and } \\
\text { Forecasting }\end{array}$ \\
\hline
\end{tabular}




\begin{tabular}{|c|c|c|c|c|c|c|}
\hline \multicolumn{7}{|c|}{ Data } \\
\hline \multirow{2}{*}{ Subroutine } & \multicolumn{2}{|c|}{ Varlable Name } & \multirow{2}{*}{ Description } & \multirow{2}{*}{ Unit. } & \multirow{2}{*}{ Classiflcation } & \multirow{2}{*}{ Source } \\
\hline & Code & Text & & & & \\
\hline $\begin{array}{l}\text { OGEXP_CALC } \\
\text { OGINIT_BFW }\end{array}$ & WDCFL4BLAG & -. & $\begin{array}{l}1989 \text { Lower } 48 \text { onshore exploration \& } \\
\text { development weighted DCFs }\end{array}$ & $1987 \$$ & $\begin{array}{l}\text { Class (exploratory, } \\
\text { developmental) }\end{array}$ & $\begin{array}{l}\text { Office of Integrated Analysis and } \\
\text { Forecasting }\end{array}$ \\
\hline $\begin{array}{l}\text { OGEXP_CALC } \\
\text { OGINIT_BFW }\end{array}$ & WDCFOFFIRKLAG & - & $\begin{array}{l}1989 \text { offishore exploration \& } \\
\text { development weighted DCFs }\end{array}$ & $1987 \$$ & $\begin{array}{l}\text { Class (exploratory, } \\
\text { developmental); } \\
8 \text { Lower } 48 \text { offshore } \\
\text { subregions; } \\
\text { Fuel (oil, gas) }\end{array}$ & $\begin{array}{l}\text { Office of Integrated Analysis and } \\
\text { Forecasting }\end{array}$ \\
\hline $\begin{array}{l}\text { OGEXP_CALC } \\
\text { OGINIT_BFW }\end{array}$ & WDCFOFFIRLAG & -- & $\begin{array}{l}1989 \text { offshore regional exploration \& } \\
\text { development weighted DCFs }\end{array}$ & $1987 \$$ & $\begin{array}{l}\text { Class (exploratory, } \\
\text { developmental); } \\
8 \text { Lower } 48 \text { offshore } \\
\text { subregions; }\end{array}$ & $\begin{array}{l}\text { Office of Integraled Analysis and } \\
\text { Forecasting }\end{array}$ \\
\hline $\begin{array}{l}\text { OGEXP_CALC } \\
\text { OGINIT_BFW }\end{array}$ & WDCFOFFLAG & -. & $\begin{array}{l}1989 \text { offshore exploration \& } \\
\text { development weighted DCFs }\end{array}$ & $1987 \$$ & $\begin{array}{l}\text { Class (exploratory, } \\
\text { developmental) }\end{array}$ & $\begin{array}{l}\text { Office of integrated Analysis and } \\
\text { Forecasting }\end{array}$ \\
\hline $\begin{array}{l}\text { OGINIT_IMP } \\
\text { OGOUT_IMP }\end{array}$ & WELLAGCAN & WELLS & 1989 wells drilled in Canada & $\begin{array}{l}\text { Wells per } \\
\text { year }\end{array}$ & Fuel (oil, gas) & Canadian Petroleum Association \\
\hline $\begin{array}{l}\text { OGEXP_CALC } \\
\text { OGEXP_FIX. } \\
\text { OGINIT_L48 }\end{array}$ & WELLAGL48 & WELLSON & 1989 Lower 48 wells drilled & $\begin{array}{l}\text { Wells per } \\
\text { year }\end{array}$ & $\begin{array}{l}\text { Class (exploratory, } \\
\text { developmental); } \\
6 \text { Lower } 48 \text { onshore } \\
\text { regions; } \\
\text { Fuel (oil, } 5 \text { gas) }\end{array}$ & Office of Oil \& Gas \\
\hline $\begin{array}{l}\text { OGALL_OFF } \\
\text { OGEXP_CALC } \\
\text { OGINIT_OFF }\end{array}$ & WELLLAGOFF & $\begin{array}{c}\text { WELLSOFF } \\
-\end{array}$ & 1989 oflshöre wells drilled & $\begin{array}{l}\text { Wells per } \\
\text { year }\end{array}$ & $\begin{array}{l}\text { Class (exploratory, } \\
\text { developmental); } \\
8 \text { Lower } 48 \text { affshore } \\
\text { subregions; } \\
\text { Fuel (oil, gas) }\end{array}$ & Olfice of Oil \& Gas \\
\hline $\begin{array}{l}\text { OGCANDCF } \\
\text { OGFOR_IMP } \\
\text { OGINIT_IMP }\end{array}$ & WELLLIFE & $n$ & Canadian project life & Years & Canada & $\begin{array}{l}\text { Olfice of Integrated Analysis and } \\
\text { Forecasting }\end{array}$ \\
\hline $\begin{array}{l}\text { OGDCF_AK } \\
\text { OGINIT_AK }\end{array}$ & XDCKAPAK. & XDCKAP & $\begin{array}{l}\text { Alaska intangible drill costs that must be } \\
\text { depreciated }\end{array}$ & fraction & Alaska & U.S. Tax Code \\
\hline $\begin{array}{l}\text { OGFOR_L48 } \\
\text { OGINIT_L48 }\end{array}$ & XDCKAPL48 & XDCKAP & $\begin{array}{l}\text { Lower } 48 \text { intangible drill costs that must } \\
\text { be depreciated }\end{array}$ & fraction & NA & U.S. Tax Code \\
\hline $\begin{array}{l}\text { OGFOR_OFF } \\
\text { OGINIT_OFF }\end{array}$ & XDCKAPOFF & XDCKAP & $\begin{array}{l}\text { Olfshore intangible drill costs that must } \\
\text { be depreciated }\end{array}$ & fraction & NA & U.S. Tax Code \\
\hline
\end{tabular}




\begin{tabular}{|c|c|c|c|c|c|}
\hline \multicolumn{6}{|c|}{ Parameters } \\
\hline \multirow{2}{*}{$\begin{array}{c}\text { Appendlx B } \\
\text { Equation - } \\
\text { Number }\end{array}$} & \multirow{2}{*}{ Subroutine } & \multicolumn{2}{|c|}{ Parameter Name } & \multirow[t]{2}{*}{ Assoclated Varlable } & \multirow[t]{2}{*}{ Classification } \\
\hline & & Code & Text & & \\
\hline 23 & OGEXP_CALC & ACASH(1) & 80 & Constant coefficient ' & NA \\
\hline 23 & OGEXP_CALC & ACASH(2) & e1 & World oil price coefficient & NA \\
\hline 23 & OGEXP_CALC. & ACASH(3) & e2 & Lagged cashflow & NA \\
\hline 23 & OGEXP_CALC & $\mathrm{ACASH}(4)$ & e3 & Lagged world oil price coefficient & NA \\
\hline 24 & OGEXP_CALC & ARETURN(i) & 10 & Constant coefficient & NA \\
\hline 24 & OGEXP_CALC & ARETURN(2) & 11 & World oil price coefficient & NA \\
\hline 24 & OGEXP_CALC & ARETURN(3) & 12 & Lagged retum on foreign operations & NA \\
\hline 24 & OGEXP_CALC & ARETURN(4) & 13 & Lagged world oil price coefficient & NA \\
\hline 30 & OGEXP_CALC & BXPENDON(1) & bo & Constant & NA \\
\hline 30 & OGEXP_CALC & BXPEND́N(2) & b1 & Onshore development DCF & NA \\
\hline 30 & OGEXP_CALC & BXPENDON(3) & b2 & Cashflow & NA \\
\hline 30 & OGEXP_CALC & BXPENDON(4) & b3 & Dummy constant & NA \\
\hline 30 & OGEXP_CALC & BXPENDON(5) & b4 & Relum on foreign operations & NA \\
\hline 30 & OGEXP_CALC & BXPENDON(6) & b5 & SKEWEDP & NA \\
\hline 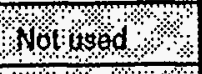 & ४ै..\%. & Expenoporit? & 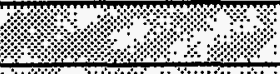 & ये. & ?.? \\
\hline Notissods. & \%... . . & OXPENDONG: & 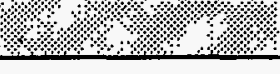 & $4.4 \%$ (4) & (1): \\
\hline 29 & OGEXP_CALC & AXPENDON(1) & ao & Constant & NA \\
\hline 29 & OGEXP_CALC & AXPENDON(2) & a1 & Onshore exploratory DCF & NA \\
\hline 29 & OGEXP_CALC & AXPENDON(3) & a2 & Cashllow & NA \\
\hline 29. & OGEXP_CALC & AXPENDON(4). & a3 & Dummy constant & NA \\
\hline 29 & OGEXP_CALC & AXPENDON(5) & a4 & Retum on foreign operations & NA \\
\hline Not ised $\%$ & ও৷? & $A x p$ ENOGN(6): & 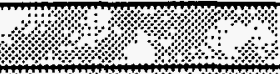 & 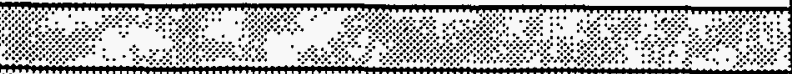 & ४. \\
\hline No used:? & $1 \%$ & 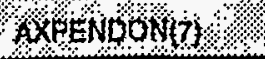 & :ং & \% & ४४: \\
\hline
\end{tabular}




\begin{tabular}{|c|c|c|c|c|c|}
\hline \multirow{3}{*}{$\begin{array}{c}\text { Appendlx } \mathrm{B} \\
\text { Equation } \\
\text { Number }\end{array}$} & & 1 & & Parameters & . \\
\hline & \multirow{2}{*}{ Subroutine } & \multicolumn{2}{|c|}{ Parameter Name } & \multirow[t]{2}{*}{ Assoclated Varlable } & \multirow[t]{2}{*}{ Classification } \\
\hline & & Code & Text & & \\
\hline rorised. & 9.1 .9$. & 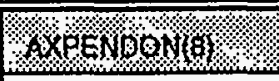 & 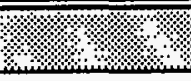 & (1:- & 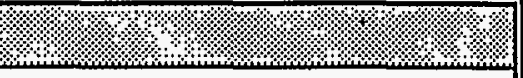 \\
\hline $\begin{array}{l}31 \\
32 \\
33 \\
34 \\
35 \\
36 \\
\end{array}$ & 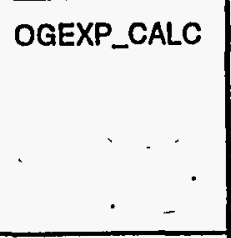 & $\operatorname{ASPENDRGN}(1, r)$ & $\begin{array}{l}j 0 \\
j 0 \\
j 0 \\
j 0 \\
j 0^{1 \cdot p} \\
j^{1 \cdot p}\end{array}$ & $\begin{array}{lll}\text { Constant coefficient } & \\
& \\
& \end{array}$ & $\begin{array}{l}\text { onshore region }=1 \\
\text { onshore.region }=2 \\
\text { onshore region }=3 \\
\text { onshore region }=4 \\
\text { onshore region }=5 \\
\text { onshore region }=6 \\
\end{array}$ \\
\hline $\begin{array}{l}31 \\
32 \\
33 \\
34 \\
35 \\
36 \\
\end{array}$ & OGEXP_CALC & $\begin{array}{c}\text { ASPENDRGN }(2, r) \\
-\end{array}$ & $\begin{array}{l}j 1 \\
j 1 \\
j 1 . \\
j 1 \\
-p * j 1 \\
-p * j 1\end{array}$ & $\begin{array}{l}\text { National expenditure coefficient } \\
\text {. }\end{array}$ & $\begin{array}{l}\text { onshore region }=1 \\
\text { onshore region }=2 \\
\text { onshore region }=3 \\
\text { onshore region }=4 \\
\text { onshore region }=5 \\
\text { onshore region }=6\end{array}$ \\
\hline $\begin{array}{l}31 \\
32 \\
33 \\
34 \\
35 \\
36 \\
36\end{array}$ & OGEXP_CALC & $\begin{array}{l}\text { ASPENDRGN }(3, r) \\
\cdot\end{array}$ & 12 & $\begin{array}{c}\text { Relative DCF coefficient } \\
\qquad\end{array}$ & $\begin{array}{l}\text { onshore region }=1 \\
\text { onshore region }=2 \\
\text { onshore region }=3 \\
\text { onshore region }=4 \\
\text { onshore region }=5 \\
\text { onshore region }=6\end{array}$ \\
\hline $\begin{array}{l}31 \\
33 \\
34 \\
35 \\
\end{array}$ & OGEXP_CALC & ASPENDRGN $(4,1)$ & $\begin{array}{l}j 3 \\
j 3 \\
j 3 \\
-p \cdot j 3 \\
\end{array}$ & Coefficient of variation & $\begin{array}{l}\text { onshore region }=1 \\
\text { onshore region }=3 \\
\text { onshore region }=4 \\
\text { onshore region }=5 \\
\end{array}$ \\
\hline $\begin{array}{l}35 \\
36 \\
\end{array}$ & OGEXP_CALC & ASPENDRGN(5,r) & $\rho$ & Lag exploralory expenditure coefficient & $\begin{array}{l}\text { onshiore region }=5 \\
\text { onshore region }=6\end{array}$ \\
\hline 33 & OGEXP_CALC & ASPENDRGN $(6, r)$ & $\stackrel{14}{-p \cdot j 4}$ & Estimated autocorrelation (Rho) & $\begin{array}{l}\text { onshore region }=3 \\
\text { onshore region }=5\end{array}$ \\
\hline Not.ista & $4+2,1$ & Astenopartros & 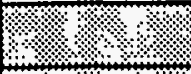 & 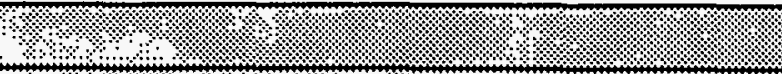 & (4. \\
\hline Nowked? & 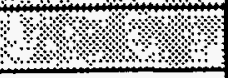 & 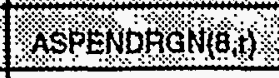 & 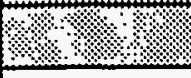 & 48 (1) & 4.1 .1 .1 .4 .8$. \\
\hline 37 & OGEXP_CALC & $\operatorname{BSPENDRGN}(1, r)$ & jo & Constant coofficient & $r=$ onshore region $=1, \ldots, 5$ \\
\hline 37 & OGEXP_CALC & BSPENDFGN(2,r) & j1 & National expenditure coefficient . & $r=$ onshore region $=1, \ldots, 5$ \\
\hline
\end{tabular}




\begin{tabular}{|c|c|c|c|c|c|}
\hline & & & . & Parameters & \\
\hline \multirow{2}{*}{$\begin{array}{l}\text { Appendlx } B \\
\text { Equation } \\
\text { Number }\end{array}$} & \multirow{2}{*}{ Subroutlne } & \multicolumn{2}{|c|}{ Parameter Name } & \multirow[t]{2}{*}{ Assoclated Varlable } & \multirow[t]{2}{*}{ Classiffication } \\
\hline & & Code & Text & & \\
\hline 37 & OGEXP_CALC & BSPENDRGN $(0, r)$ & $\mathrm{j} 2$ & Relative DCF coefficient & $r=$ onshore region $=1, \ldots, 5$ \\
\hline 37 & OGEXP_CALC & BSPENDRGN $(4, r)$ & j3 & National onshore DCF & $r=$ onshore region $=1, \ldots, 5$ \\
\hline Notised & $4+2+1$ & BSpANDNGNG, & 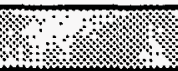 & 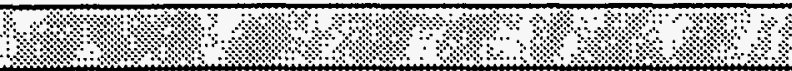 & ४ \\
\hline Nolotsed & 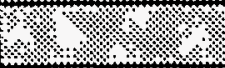 & 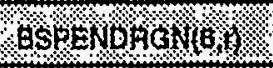 & 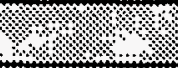 & 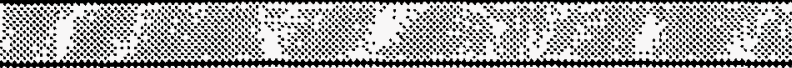 & ২. \\
\hline Hol used & 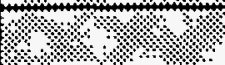 & 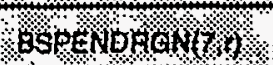 & \% & ২. & 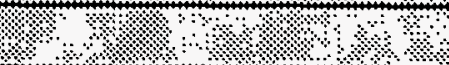 \\
\hline notusdo & 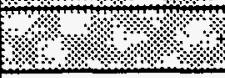 & 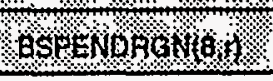 & $3.1 \%$ & ४ & (3. \\
\hline $\begin{array}{l}38 \\
38 \\
39 \\
40 \\
41 \\
42 \\
43 \\
44 \\
45 \\
46 \\
47 \\
48 \\
49\end{array}$ & OGEXP_CALC & $\begin{array}{l}\text { ASPENDIRK }(1,1, k) \\
\text { ASPENDIRK }(1,2, k) \\
\text { ASPENDIRK }(1,3,1) \\
\text { ASPENDIRK }(1,3,2) \\
\text { ASPENDIRK }(1,3,3) \\
\text { ASPENDIRK }(1,4,1) \\
\text { ASPENDIRK }(1,4,2) \\
\text { ASPENDIRK }(1,4,3) \\
\text { ASPENDIRK }(1,5,1) \\
\text { ASPENDIRK }(1,5,2) \\
\text { ASPENDIRK }(1,5,3) \\
\text { ASPENDIRK }(1,5,4) \\
\text { ASPENDIRK }(1,6,3)\end{array}$ & $\begin{array}{l}m o \\
m o \\
m o \\
m 0^{1 \cdot p} \\
m o \\
m 0^{1 \cdot p} \\
m 0^{1 \cdot p} \\
m o \\
m o \\
m 0^{1 \cdot p} \\
m 0^{1 \cdot p} \\
m 0^{1 \cdot p} \\
m o\end{array}$ & Constant coefficient & 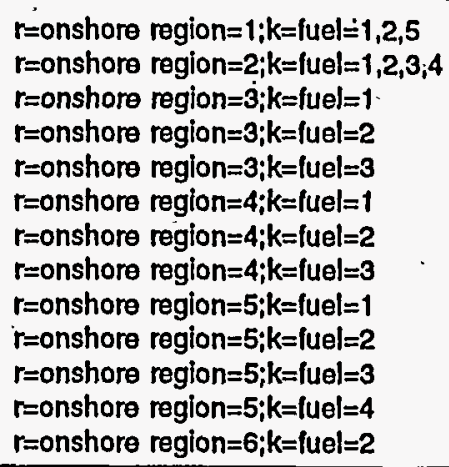 \\
\hline $\begin{array}{l}38 \\
38 \\
39 \\
40 \\
41 \\
42 \\
43 \\
44 \\
45 \\
46 \\
47 \\
48 \\
49\end{array}$ & OGEXP_CALC & $\begin{array}{l}\text { ASPENDIRK }(2,1, k) \\
\text { ASPENDIRK }(2,2, k) \\
\text { ASPENDIRK }(2,3,1) \\
\text { ASPENDIRK }(2,3,2) \\
\text { ASPENDIRK }(2,3,3) \\
\text { ASPENDIRK }(2,4,1) \\
\text { ASPENDIRK }(2,4,2) \\
\text { ASPENDIRK }(2,4,3) \\
\text { ASPENDIRK }(2,5,1) \\
\text { ASPENDIRK }(2,5,2) \\
\text { ASPENDIRK }(2,5,3) \\
\text { ASPENDIRK }(2,5,4) \\
\text { ASPENDIRK }(2,6,3) .\end{array}$ & $\begin{array}{l}m 1 \\
m 1 \\
m 1 \\
m 1^{1-p} \\
m 1 \\
m 1^{1-p} \\
m 1^{1-p} \\
m 1 \\
m 1 \\
m 1^{1-p} \\
m 1^{1-p} \\
m 1^{1-p} \\
m 1^{1}\end{array}$ & $\begin{array}{c}\text { Regional expenditure coeficient } \\
.\end{array}$ & 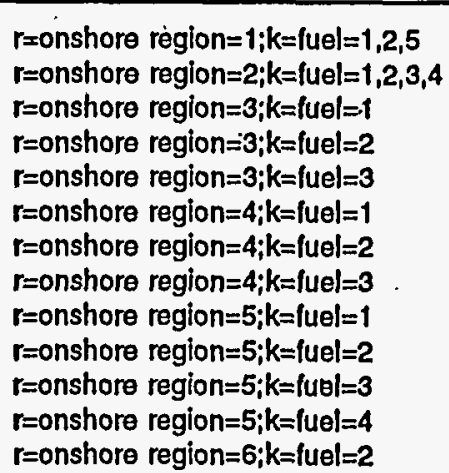 \\
\hline
\end{tabular}




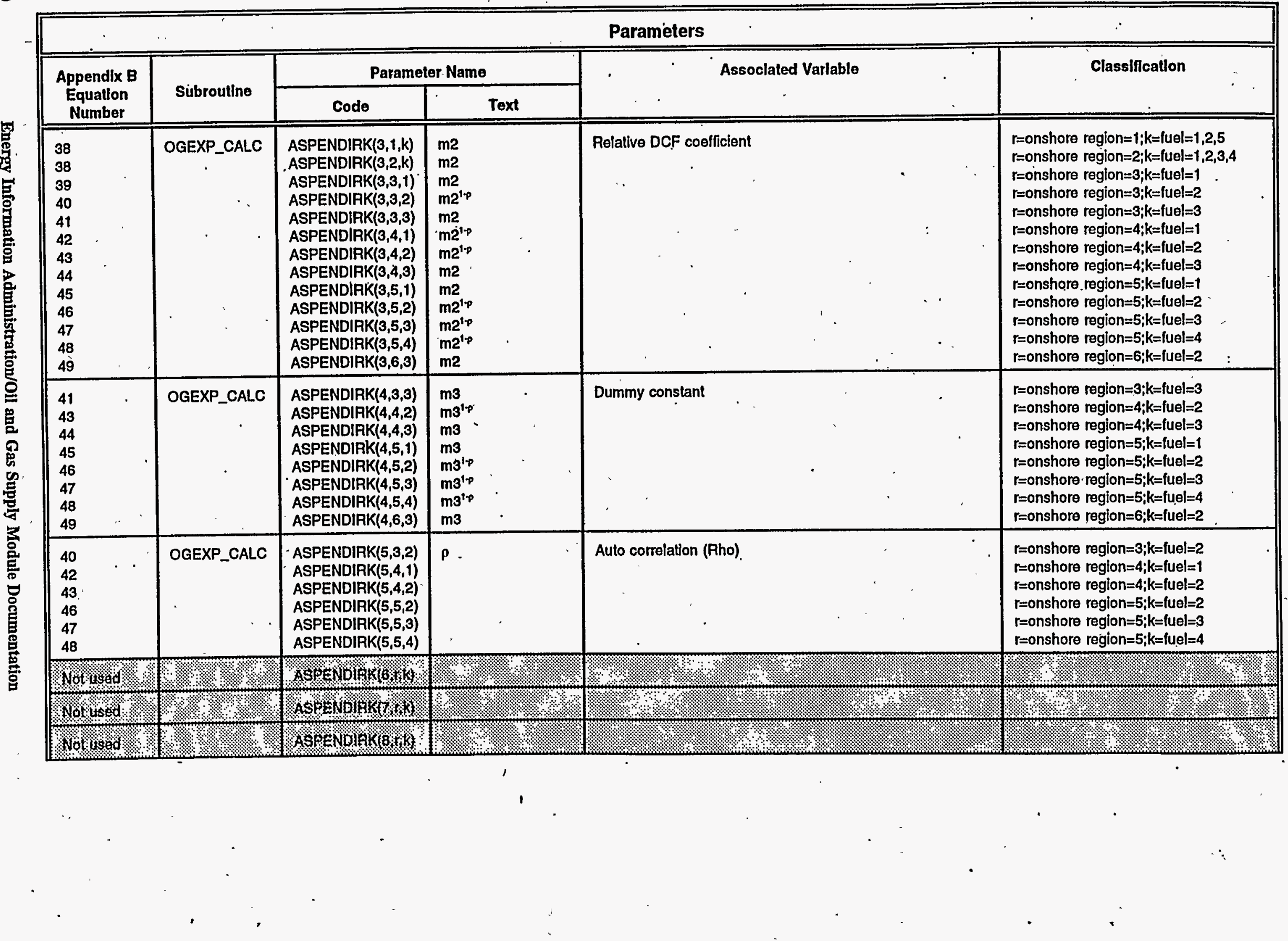




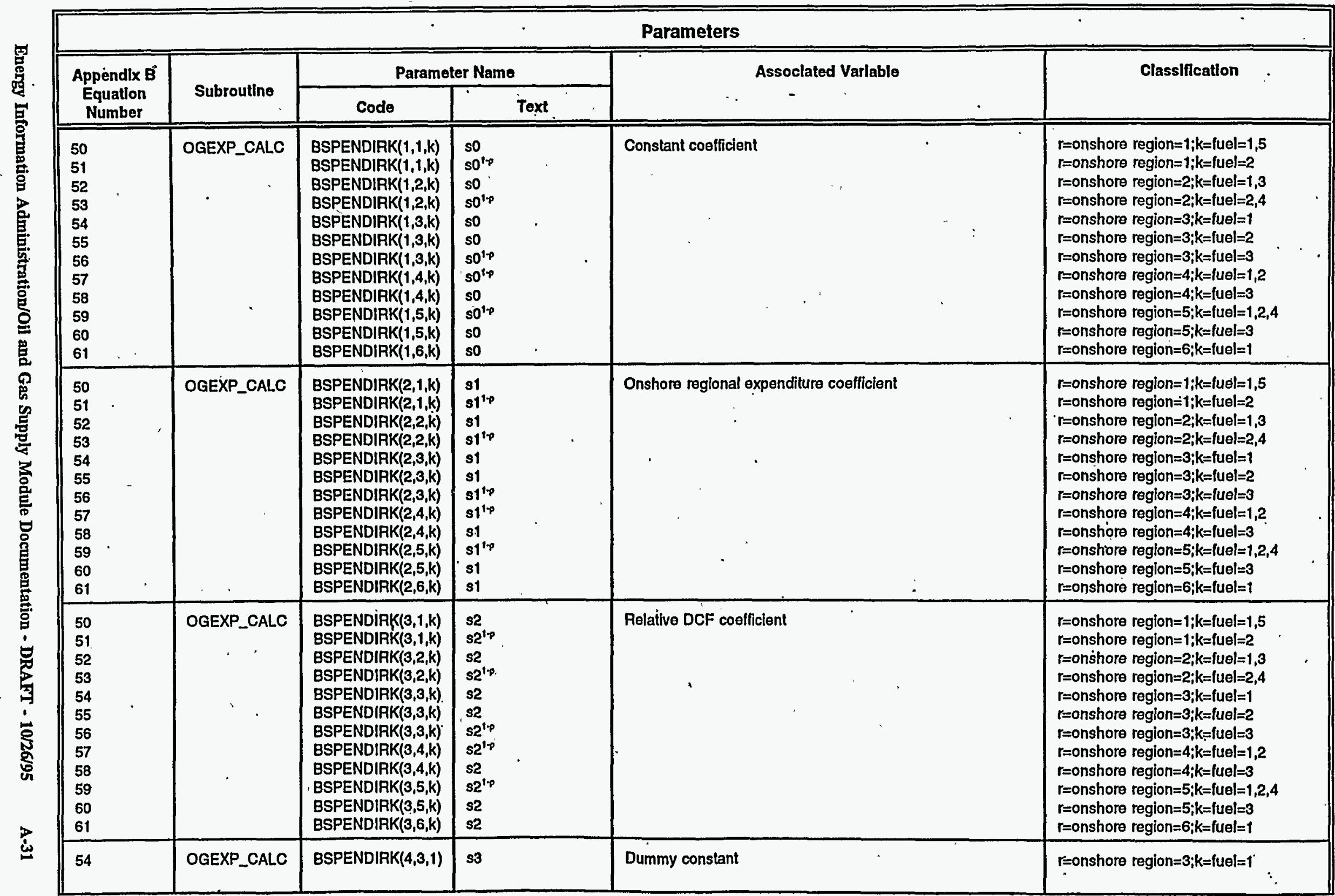




\begin{tabular}{|c|c|c|c|c|c|}
\hline \multicolumn{6}{|c|}{ Parameters } \\
\hline \multirow{2}{*}{$\begin{array}{l}\text { Appendlx B } \\
\text { Equation } \\
\text { Number }\end{array}$} & \multirow{2}{*}{ Subroutlne } & \multicolumn{2}{|c|}{ Parameter Name } & \multirow[t]{2}{*}{ Assoclated Varlable. } & \multirow[t]{2}{*}{ Classification } \\
\hline & & Code & Text & & \\
\hline $\begin{array}{l}51 \\
53 \\
56 \\
57 \\
59\end{array}$ & $\begin{array}{c}\text { OGEXP_CALC } \\
\therefore\end{array}$ & $\begin{array}{l}\text { BSPENDIRK }(5,1,2) \\
\text { BSPENDIRK }(5,2, k) \\
\text { BSPENDIRK }(5,3,3) . \\
\text { BSPENDIRK }(5,4, k) \\
\text { BSPENDIRK }(5,5, k)\end{array}$ & $\rho$ & Aulo correlation (Rho) & $\begin{array}{l}r=\text { onshore region }=1 ; k=\text { fuel }=2 \\
r=\text { onshore region }=2 ; k=\text { fuel }=2,4 \\
r=\text { onshore region }=3 ; k=\text { fuel }=3 \\
r=\text { onshore region }=4 ; k=\text { fuel }=1,2 \\
r=\text { onshore region }=5 ; k=\text { fuel }=1,2,4\end{array}$ \\
\hline 1.1045ed ? & (4. & 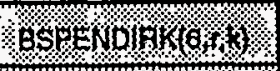 & 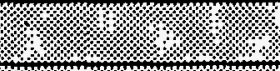 & (4), & \%. \\
\hline 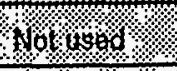 & $4 . \% . \%$ & 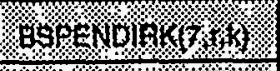 & 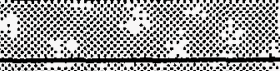 & 7. & 2.1 .1 .4$. \\
\hline 1.4. & 19.1 .4$. & 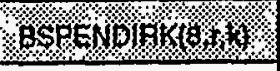 & 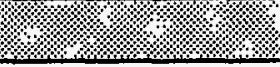 & 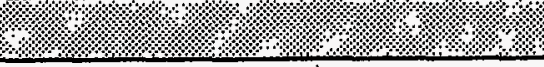 & 1. \\
\hline 69 & OGEXP_CALC & AXPENDOFF(1) & $\infty 0^{\prime p}$ & Constant & NA \\
\hline 69 & OGEXP_CALC & AXPENDOFF(2) & $-\rho . .61$ & Offshore exploratory DCF & NA \\
\hline 69 & OGEXP_CALC & AXPENDOFF(3) & $-p * c 2$ & VARPOIL & NA \\
\hline 69 & OGEXP_CALC & AXPENDOFF(4) & $-p+c 3$ & Cashilow & NA \\
\hline 69 & OGEXP_CALC & AXPENDOFF(5) & $-p * c 4$ & 1989 dummy constant & NA \\
\hline 69 & OGEXP_CALC & AXPENDOFF(6) & $-\rho * c 5$ & TIME constant & NA \\
\hline 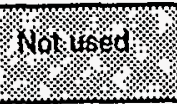 & 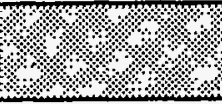 & 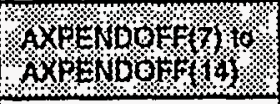 & ?.4. & (4) & ?:। \\
\hline 70 & OGEXP_CALC & BXPENDOFF(1) & do & Constant & NA \\
\hline 70 & OGEXP_CALC & BXPENDOFF(2) & di & Olfshore development DCF & NA \\
\hline 70 & OGEXP_CALC & BXPENDOFF(3) & d2. & Dummy constant & NA \\
\hline Nof wasto & 4.8 .1 .4 & 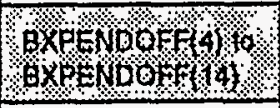 & (4. & ? & (4. \\
\hline $\begin{array}{l}71 \\
72 \\
73 \\
74\end{array}$ & OGEXP_CALC & $\operatorname{CSPENDRGN}(1, r)$ & $\begin{array}{l}\text { ko } \\
\text { k0'p } \\
\text { k0 } \\
\text { k0 }\end{array}$ & Constant & $\begin{array}{l}\text { offshore region }=2 \\
\text { ofishore region }=3 \\
\text { offshore region }=5 \\
\text { oflshore region }=6\end{array}$ \\
\hline
\end{tabular}




\begin{tabular}{|c|c|c|c|c|c|}
\hline \multicolumn{6}{|c|}{ Parameters } \\
\hline \multirow{2}{*}{$\begin{array}{c}\text { Appendix B } \\
\text { Equation } \\
\text { Number } \\
\end{array}$} & \multirow{2}{*}{ Subroutine } & \multicolumn{2}{|c|}{ Parameter Name } & \multirow[t]{2}{*}{ - Assoclated Varlable } & \multirow[t]{2}{*}{ Classiffication } \\
\hline & & Code & Text & & \\
\hline $\begin{array}{l}71 \\
72 \\
73 \\
74 \\
\end{array}$ & OGEXP_CALC & CSPENDRGN $(2, \pi)$ & $\begin{array}{l}k 1 \\
k 1 \\
k 1^{1 p p} \\
k 1 \\
k 1\end{array}$ & Total offshore exploratory expenditure & $\begin{array}{l}\text { offshore region=2 } \\
\text { offshore region }=3 \\
\text { offshore region=5 } \\
\text { offshore region=6 }\end{array}$ \\
\hline $\begin{array}{l}72 \\
74\end{array}$ & OGEXP_CALC & CSPENDPGN $(3, r)$ & $\begin{array}{l}\mathrm{k} 2^{1 p} \\
\mathrm{k} 2\end{array}$ & Relative DCF & $\begin{array}{l}\text { offshore region }=3 \\
\text { offshore region }=6\end{array}$ \\
\hline $\begin{array}{l}71 \\
72 \\
74\end{array}$ & OGEXP_CALC & CSPENDRGN $(4, r)$ & $\begin{array}{l}k 3 \\
k 3^{1 \cdot p} \\
k 3\end{array}$ & Dummy constant & $\begin{array}{l}\text { offshore region }=2 \\
\text { offshore region }=3 \\
\text { offshore region }=6\end{array}$ \\
\hline 72 & OGEXP_CALC & CSPENDRGN $(5, r)$ & $p$ & Auto correlation (Rho) & offshore region $=3$ \\
\hline Magsed, & 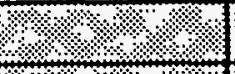 & espandang 60 & 1. & (1) & 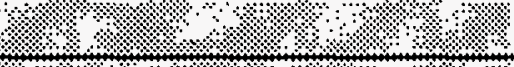 \\
\hline Not & 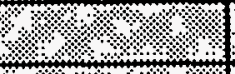 & 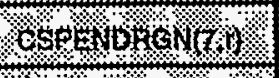 & 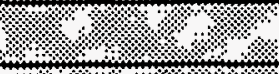 & $4+\%$ & 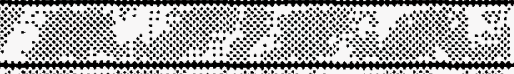 \\
\hline Norigseds? & 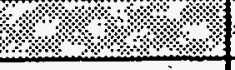 & ostenogorvo, & (1., & $3.13 \%$ & 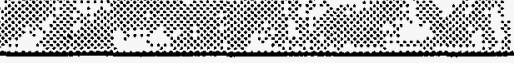 \\
\hline $\begin{array}{l}75 \\
76 \\
77 \\
\end{array}$ & OGEXP_CALC & DSPENDRGN $(1, r)$ & $\begin{array}{l}\mathrm{kO} \\
\mathrm{kO} 0^{1 \cdot p} \\
\mathrm{kO}\end{array}$ & Constant & $\begin{array}{l}r=\text { offshore region=2,5 } \\
\text { offshore region=3 } \\
\text { offshore region=6 }\end{array}$ \\
\hline $\begin{array}{l}75 \\
76 \\
77 \\
\end{array}$ & OGEXP_CALC & DSPENDRGN(2,r) & $\begin{array}{l}\mathbf{k} 1^{1+p} \\
\mathbf{k} 1^{1-p} \\
\mathbf{k 1}\end{array}$ & National offshore spending & $\begin{array}{l}r=\text { offshore region }=2,5 \\
\text { offshore region=3 } \\
\text { offshore region }=6\end{array}$ \\
\hline 76 & OGEXP_CALC & DSPENDRGN $(3, r)$ & k3 & Relative DCF & offshore region $=3$ \\
\hline 76 & OGEXP_CALC & DSPENDRGN(4,r) & $\mathbf{k 4}$ & VARPOIL & offshore region $=3$ \\
\hline 76 & OGEXP_CALC & DSPENDRGN $(5, r)$ & $k 5$ & SKEWEDP & offshore region $=3$ \\
\hline $\begin{array}{l}75 \\
76 \\
\end{array}$ & OGEXP_CALC & DSPENDRGN $(6, r)$ & $\mathbf{p}$ & Auto correlation (Pho) & $\begin{array}{l}r=0 f f s h o r e \text { region }=2,5 \\
\text { olfshore region }=3\end{array}$ \\
\hline 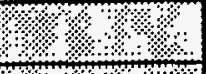 & $4 \%$ & 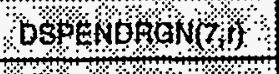 & 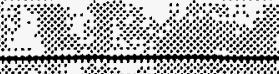 & $4014.4 .1 \%$ ? & (1:) \\
\hline 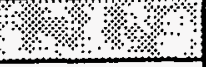 & ४. & ospENonGN(g) & ४. \% : & $4.4 \%$ & 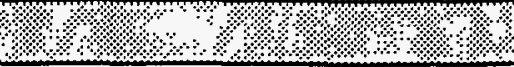 \\
\hline 82 & OGEXP_CALC & DSPENDIRK $(1, r, k)$ & $\alpha 0$ & Constant coelficient & $r=$ offshore region $=2,3,5,6 ; k=f u e l=1,2$ \\
\hline
\end{tabular}




\begin{tabular}{|c|c|c|c|c|c|}
\hline \multirow{3}{*}{$\begin{array}{l}\text { Appendlx } \mathbf{B} \\
\text { Equatlon } \\
\text { Number }\end{array}$} & \multirow{3}{*}{ Subroutlne - } & \multicolumn{3}{|r|}{ Parameters } & \multirow{3}{*}{ Classiflcation } \\
\hline & & \multicolumn{2}{|c|}{ Parameter Name } & \multirow[t]{2}{*}{ Assoclated Varlable } & \\
\hline & & Code & Text & & \\
\hline 82 & OGEXP_CALC & DSPENDIRK $(2, r, k)$ & $-\rho * \alpha 1$ & Regional oftshore expenditure & $r=$ offshore reglon $=2,3,5,6 ; k=|u \theta|=1,2$ \\
\hline Notysogr. & (1. & 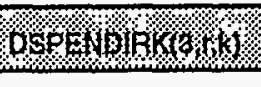 & ২. & \% & / \\
\hline 82 & OGEXP_CALC & DSPENDIRK $(4, r, k)$ & $\rho$ & Auto correlation (Rho) & $r=$ offshore region $=2,3,5,6 ; \mathrm{k}=\{\mathrm{fue} \mid=1,2$ \\
\hline $\begin{array}{l}80 \\
81\end{array}$ & OĠEXP_CALC & CSPENDIRK $(1, r, k)$ & $\alpha 0$ & Constant coefficient & $r=0$ fishore region $=3,5 ; k=f u e l=1$ \\
\hline $\begin{array}{l}80 \\
81\end{array}$ & OGEXP_CALC & CSPENDIPK $(2, r, k)$ & $\alpha 1$ & Regional offshore expenditure & $r=$ offshore region $=3 ; 5 ; k=f u e l=1$ \\
\hline 81: & OGEXP_CALC & CSPENDIRK $(3, r, k)$ & $\alpha 2$ & Relative DCF coefficient & $r=$ offshore region $=5 ; \mathrm{k}=$ fuel $=1$ \\
\hline 80 & OGEXP_CALC & CSPENDIRK $(4, r, k)$ & $\rho$ & Coefficient of variance & $r=0$ ffshore region $=3 ; k=f$ uel $=1$ \\
\hline 125 & OGOUT_IMP & AWELLS1 & $-\rho$ * BO & Exploratory constant coefficient & NA \\
\hline 125 & OGOUT_IMP & BWĖLLS1 & $-\rho * \beta 1$ & Exploratory oil DCF coefficient & NA \\
\hline 125 & OGOUT_IMP & CWELLS1 & $-p * \beta 2$ & Exploratory dummy constant & NA \\
\hline 125 & OGOUT_IMP & AWELLS2 & $-\rho$ * $\beta 0$ & Developmental constant coefficient & NA \\
\hline 125 & OGOUT_IMP & BWELLS2 & $-\rho * \beta 1$ & Developmental oll DCF coefficient & NA \\
\hline 125 & OGOUT_IMP & CWELLS2 & $-\rho * \beta 2$ & Developmental dummy constant & NA \\
\hline 125 & OGOUT_IMP & RHOCAN(1) & $\rho$ & Exploratory auto correlation (Rho) & NA \\
\hline 125 & OGOUT_IMP & RHOCAN(2) & $\rho$ & Developmental auto correlation (Rho) & NA \\
\hline
\end{tabular}




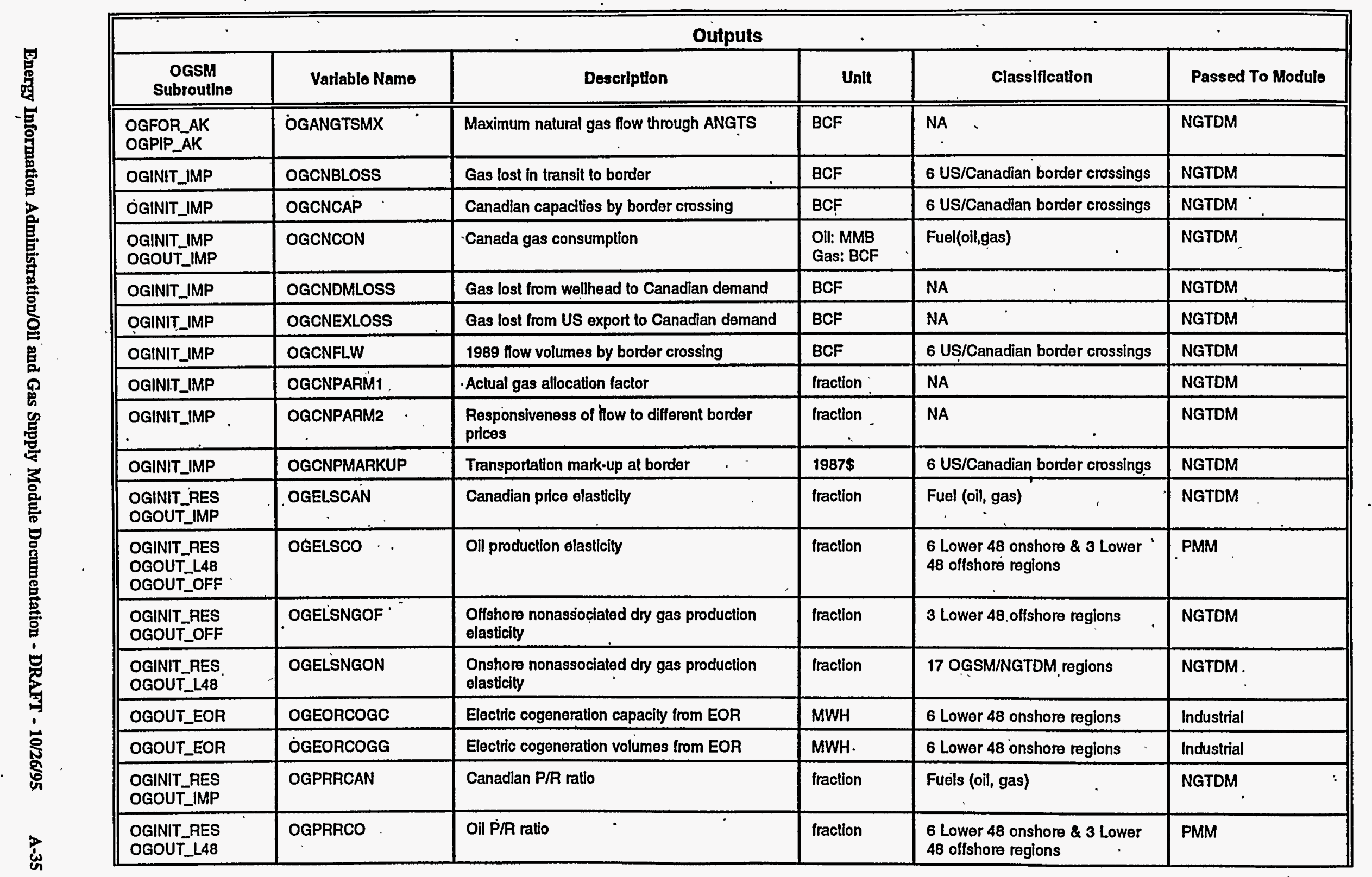




\begin{tabular}{|c|c|c|c|c|c|}
\hline \multicolumn{6}{|c|}{ Outputs } \\
\hline $\begin{array}{l}\text { OGSM } \\
\text { Subroutine }\end{array}$ & Varlable Name & Description & Unit & Classification & Passed To Modulo \\
\hline $\begin{array}{l}\text { OGFOR_AK } \\
\text { OGPIP_AK }\end{array}$ & OGANGTSMX & Maximum natural gas flow through ANGTS & $\mathrm{BCF}$ & NA & NGTDM \\
\hline $\begin{array}{l}\text { OGINIT_RES } \\
\text { OGOUT_OFF }\end{array}$ & OGPRRNGOF & Olfshore nonassociated dry gas P/R ratio & fraction & 3 Lower 48 offshore regions & NGTDM \\
\hline $\begin{array}{l}\text { OGINIT_RES } \\
\text { OGOUT_L48 }\end{array}$ & OGPRANGON & Onshore nonassociated dry gas $P / R$ ratio & fraction & $\begin{array}{c}17 \text { OGSM/NGTDM regions } \\
:\end{array}$ & NGTDM \\
\hline $\begin{array}{l}\text { OGFOR_AK } \\
\text { OGPIP_AK } \\
\text { OGPRO_AK }\end{array}$ & OGQANGTS & Gas flow at U.S. border from ANGTS & $\mathrm{BCF}$ & NA & NGTDM \\
\hline $\begin{array}{l}\text { OGCOMP_EMIS } \\
\text { OGOUT_EOR }\end{array}$ & OGQEORPR & Oll supply from EOR & MB & $\begin{array}{r}6 \text { Lower } 48 \text { onshore regions } \\
\quad \cdot\end{array}$ & PMM \\
\hline $\begin{array}{l}\text { OGINIT_IMP } \\
\text { OGOUT_IMP } \\
\text { OGOUT_MEX }\end{array}$ & OGQNGEXP & Natural gas exports & BCF & $\begin{array}{l}6 \text { US/Canada \& } 3 \\
\text { USMexico border crossings }\end{array}$ & NGTDM \\
\hline $\begin{array}{l}\text { OGLNG_OUT. } \\
\text { OGOUT_IMP. } \\
\text { OGOUT_MEX }\end{array}$ & OGQNGIMP & Natural gas imports & BCF & $\begin{array}{l}3 \text { USMexico border crossings; } 4 \\
\text { LNG terminals }\end{array}$ & NGTDM \\
\hline $\begin{array}{l}\text { OGINIT_RES } \\
\text { OGOUT_IMP }\end{array}$ & OGRESCAN & Canadlan end-of-year reserves & $\begin{array}{l}\text { oil: MMB } \\
\text { gas: BCF }\end{array}$ & Fuel (oil, gas) & NGTDM \\
\hline $\begin{array}{l}\text { OGINIT_RES } \\
\text { OGOUT_L48 } \\
\text { OGOUT_OFF }\end{array}$ & OGRESCO & $\begin{array}{c}\text { Oll reserves } \\
\cdots\end{array}$ & MMB & $\begin{array}{l}6 \text { Lower } 48 \text { onshore \& } 3 \text { Lower } \\
48 \text { olfshore regions }\end{array}$ & PMM \\
\hline $\begin{array}{l}\text { OGINIT_RES } \\
\text { OGOUT_OFF }\end{array}$ & OGRESINGOF & Offishore nonassocialed dry gas reserves & BCF & 3 Lower 48 offshore regions & NGTDM \\
\hline $\begin{array}{l}\text { OGINIT_RES } \\
\text { OGOUT_L48. }\end{array}$ & OGRESNGGON & Onshore nonassocialed diy gas reserves & BCF & 17 OGSM/NGTDM regions & NGTDM \\
\hline
\end{tabular}


Appendix B. Mathematical Description 



\section{Calculation of Costs}

Drilling costs

Successful

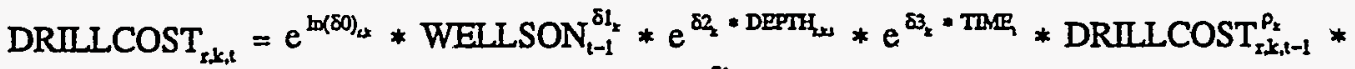

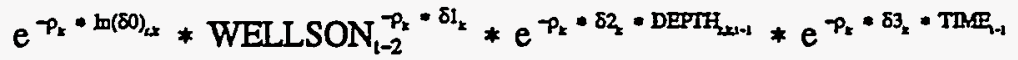

$$
\begin{aligned}
& \text { for } I=2 \text { through } 5 ; k=1,2,3 \\
& \text { for } I=1,6 ; k=1,2
\end{aligned}
$$

Dry

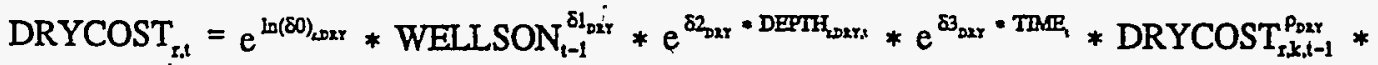

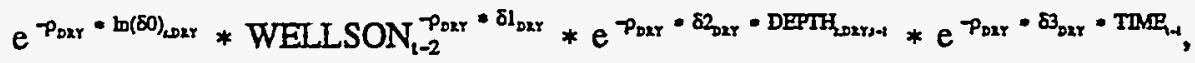

$$
\begin{aligned}
& \text { for } I=1 \text { through } 6
\end{aligned}
$$

Lease equipment costs

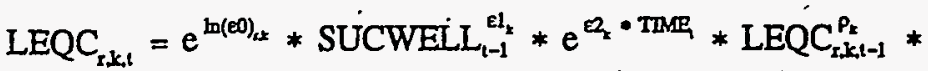

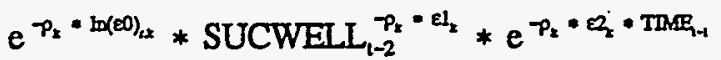

$$
\begin{aligned}
& \text { for } I=2 \text { through } 5 ; k=1,2,3 \\
& \text { - for } \mathrm{r}=1,6 ; k=1,2
\end{aligned}
$$

\section{Operating Costs}

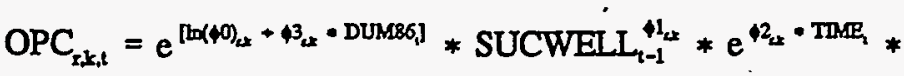

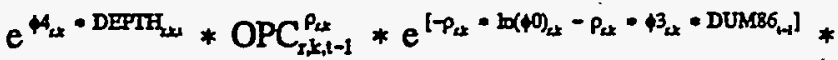

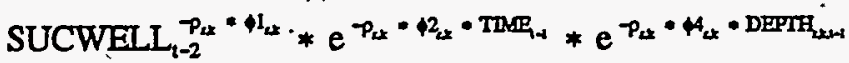

$$
\begin{aligned}
& \text { for } \mathrm{I}=2 \text { through } 5 ; \mathrm{k}=1,2,3 \text {, for } \mathrm{I}=1,6, k=1,2
\end{aligned}
$$

\section{Discounted Cash Flow Algorithm}

Net cash flow

$$
\begin{aligned}
\mathrm{NCF}_{\mathrm{i}, \mathrm{x}, \mathrm{T} T \mathrm{~T}}= & (\text { REV - ROY - PRODTAX - DRIILCOST - EQUIPCOST - } \\
& \text { OPERCOST - DRYCOST - STATETAX - FEDTAX })_{\text {is, }, \mathrm{T} T}
\end{aligned}
$$

Expected discounted cash flow

$$
\begin{aligned}
& \text { PROJDCF }_{i, s, t, l}=\text { (PVREV - PVROY - PVPRODTAX - PVDRILLCOST - PVEQUIP - } \\
&\text { PVKAP - PVOPERCOST - PVABANDON - PVSIT - PVFIT })_{i, s, t}
\end{aligned}
$$

Present value of expected revenues 
PVREV $_{i, i, k, t}=\sum_{T=1}^{t+n}\left[Q_{t, k T} * \lambda *\left(P_{x, L T}-\right.\right.$ TRANS $\left.\left._{x, k}\right) *\left[\frac{1}{1+d i s c}\right]^{t-T}\right], \lambda=\left\{\begin{array}{cl}1 & \text { if primary fuel } \\ \text { COPRD if secondary fuel }\end{array}\right.$

Present value of expected royalty payments

$$
\text { PVROY }_{i, s, j, t}^{\prime *}=\text { ROYRT }^{\prime} \text { PVREV }_{i, r, j, i}
$$

Present value of expected production taxes

$$
\text { PVPRODTAX }_{i, x \leq 1,}=\text { PVREV }_{i, i, k, t} *\left(1-\text { ROYRT } * \text { PRODTAX }_{i, k}\right.
$$

Present value of expected costs

Drilling costs

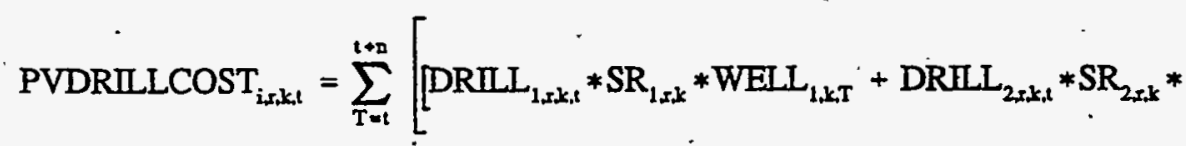

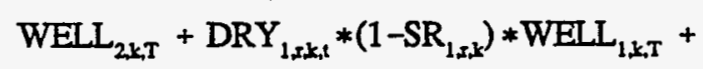

$$
\begin{aligned}
& \left.\left.\mathrm{DRY}_{2, \mathrm{r}, \mathrm{t}, \mathrm{t}} *\left(1-\mathrm{SR}_{2 \neq 1, \mathrm{k}}\right) * \mathrm{WELI}_{2, \mathrm{~T}, \mathrm{~T}}\right] *\left(\frac{1}{1+\text { disc }}\right)^{\mathrm{T}-\mathrm{t}}\right]
\end{aligned}
$$

Lease equipment costs

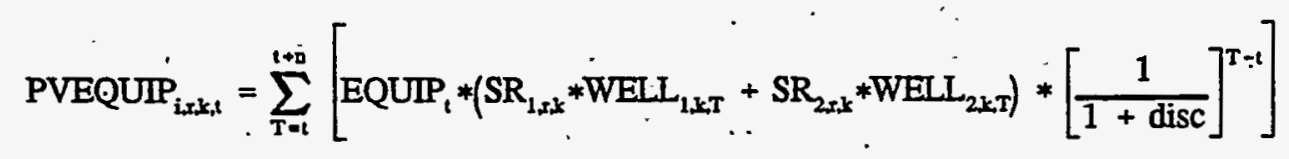

Capital costs

$$
\operatorname{PVKAP}_{\text {iskt }}=\sum_{T=t}^{t+n}\left[\operatorname{KAP}_{i, r, k, T} *\left[\frac{1}{1+\text { disc }}\right]^{T-t}\right]
$$

Operating costs

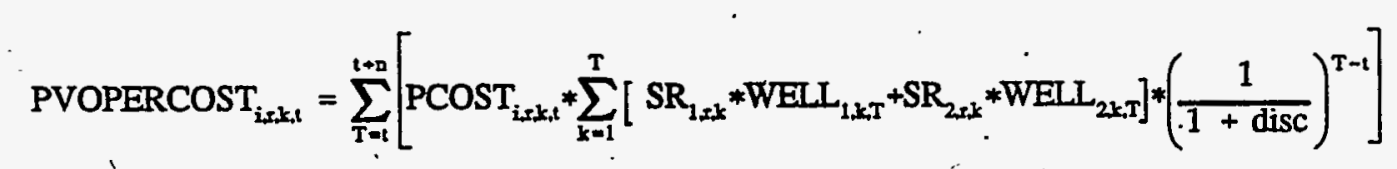

Abandonment costs

$$
\text { PVABANDON }_{i, x, 1,1}=\sum_{T=1}^{i+n}\left[\operatorname{COSTABN}_{i x, k} *\left[\frac{1}{1+\text { disc }}\right]^{T-1}\right]
$$

Present value of expected tax base 


$$
\begin{aligned}
& \text { PVTAXBASE }_{i, x, k, t}=\sum_{T=1}^{\iota+\infty}[(\text { REV -ROY -PRODTAX -OPERCOST-ABANDON -XIDC - } \\
& \text { DEPREC } \left.-\mathrm{DHC})_{\text {is } \& \mathrm{t}} *\left(\frac{1}{1+\text { disc }}\right)^{\mathrm{T}-\mathrm{t}}\right]
\end{aligned}
$$

Expected expensed costs

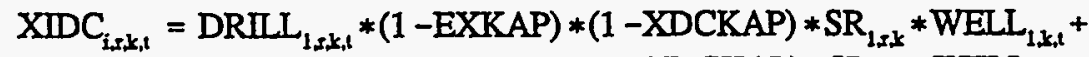

$$
\begin{aligned}
& \mathrm{DRIIL}_{2 \pi x, 1} *(1-\mathrm{DVKAP}) *(1-\mathrm{XDCKAP}) * \mathrm{SR}_{2, \mathrm{x}} * \mathrm{WELL}_{2 \mathrm{kt} \text { t }}
\end{aligned}
$$

Expected dry hole costs

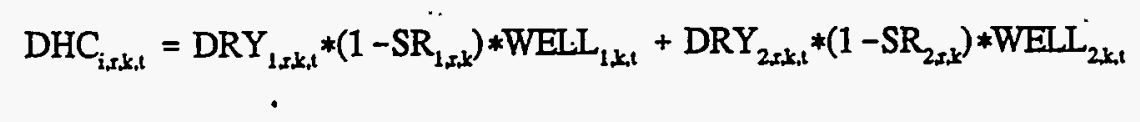

Expected depreciable costs

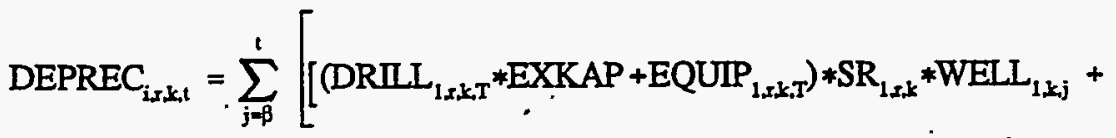

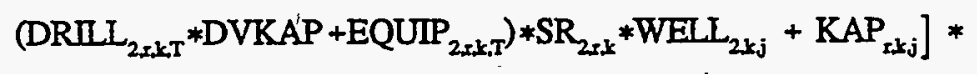

$$
\begin{aligned}
& \left.\mathrm{DEP}_{\mathrm{i} j+1} *\left(\frac{1}{1+\text { infl }}\right)^{t-j} *\left(\frac{1}{1+\text { disc }}\right)^{t-\mathrm{j}}\right] \text {, } \\
& \beta=\left\{\begin{array}{l}
T \text { for } t \leq T+m-1 \\
t-m+1 \text { for } t>T+m-1
\end{array}\right.
\end{aligned}
$$

Present value of expected state income taxes

$$
\operatorname{PVSIT}_{i x, \mathbf{x}, t}=\text { PVTAXBASE }_{i x, i, t} * \text { STRT . }
$$

Present value of expected federal income taxes

$$
\text { PVFTT }_{i, r, i, t}=\text { PVTAXBASE } E_{i, r, t, t} *(1-S T R T) * \text { FDRT. }
$$

Discounted cash flow for a representative developmental well

$$
\mathrm{DCF}_{2 x, k, t}=\mathrm{PROJDCF}_{2, x, k,} * \mathrm{SR}_{2, x, k}
$$

Discounted cash flow for a representative exploratory well 


$$
\mathrm{DCF}_{1, x, 1, t}=\mathrm{PROJDCF}_{1, x, k, t} * \mathrm{SR}_{1, x, k}
$$

Industry Cash Flow.

$$
\mathrm{CF}_{t-1}=\mathrm{e} 0 * \mathrm{WOP}_{t-1}^{\mathrm{el}} * \dot{\mathrm{CF}}_{t=2}^{p} * \mathrm{WOP}_{t-2}^{-p} * \mathrm{cl}
$$

Return on Foreign Operations

$$
\mathrm{RF}_{\mathrm{t}}=\mathrm{fO} * \mathrm{WOP}_{\mathrm{t}}^{\mathrm{n}} * \mathrm{RF}_{\mathrm{t}-1}^{\mathrm{P}} * \mathrm{WOP}_{\mathrm{t}-1}^{-p} \text { * f1 }
$$

\section{Lower 48 Onshore Expenditures and Well Determination}

Share of total wells at the class, region, fuel level

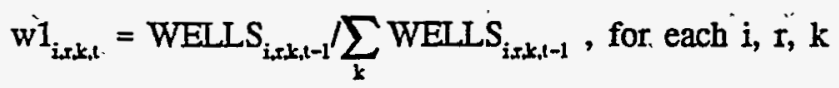

Regional onshore DCF

$$
\text { - } \operatorname{RDCFON}_{i, t, t}=\sum_{k} w 1_{i x, t, t} * \operatorname{DCFON}_{i, r, k, t} \text { for } i=1,2, \tau=\text { onshore regions, } k=1, \ldots, 6
$$

Share of total wells at the class, region level

$$
\dot{w} 2_{i x, t}=\text { WELLS } S_{i s, t-1} / \sum_{T} \text { WELLS }_{i s, i-1,1} \text {, for each } i, r
$$

National onshore DCF

$$
\operatorname{NDCFON}_{i, t}=\sum_{x} w 2_{i x, t} * \operatorname{RDCFON}_{i, x, t^{*}} \text { for } \mathrm{i}=1,2, \mathrm{r}=\text { onshore regions }
$$

National onshore exploratory expenditures

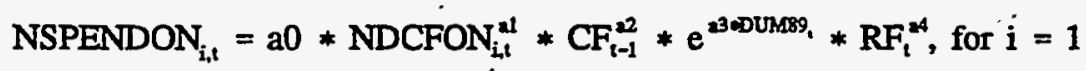

National onshore developmental expenditures

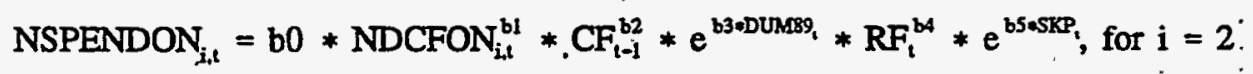

Regional onshore exploration expenditures

Region1

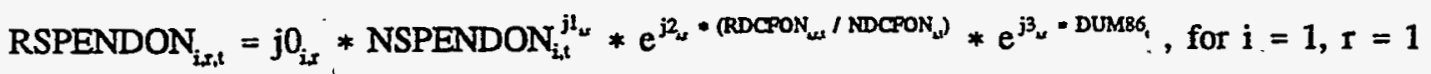

\section{Region 2}

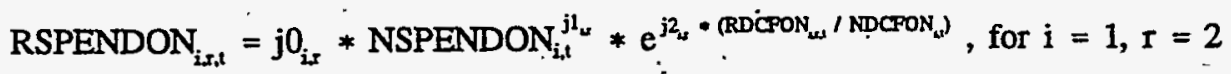


Region 3

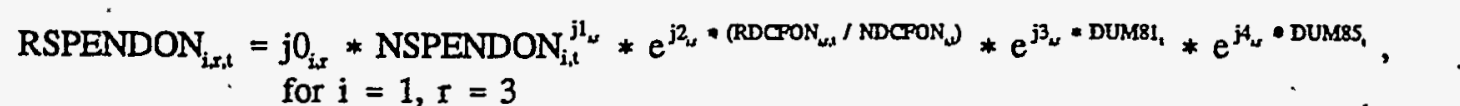

Region 4

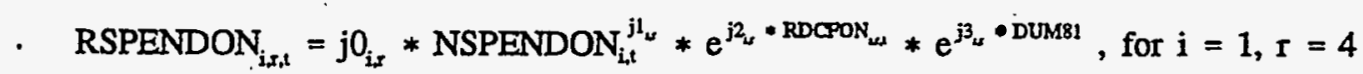

\section{Region 5}

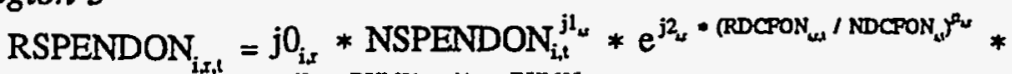

$$
\begin{aligned}
& \mathrm{e}^{\mathrm{j} 3^{4} \cdot D U M 81_{1}+\mathrm{j}_{4} \cdot D U M 8 S_{1}}
\end{aligned}
$$

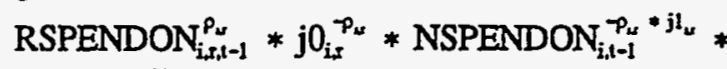

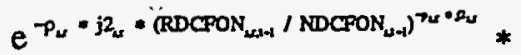

$$
\begin{aligned}
& e^{-P_{x}=j 3_{s} \cdot D U M B 1_{1-1}-P_{x} \cdot j 4^{4} \cdot D U M B S_{1-4}} \text {, } \\
& \text { for } i=1, r=5
\end{aligned}
$$

Region 6

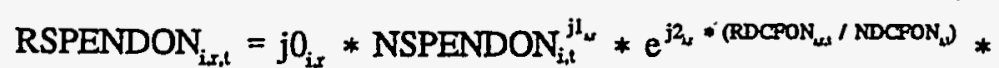

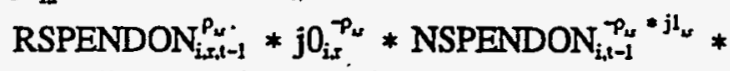

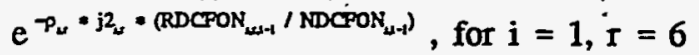

Regional onshore development expenditures

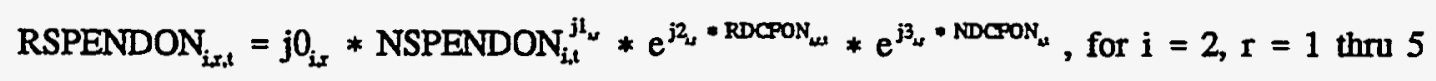

Onshore regional exploration expenditures by fuel type

Regions $I$ and 2

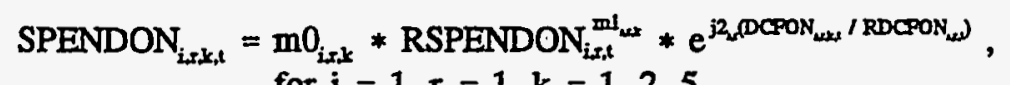

$$
\begin{aligned}
& \text { for } i=1, r=1, k=1,2,5 \\
& \text { for } \mathrm{i}=1, \mathrm{r}=2, \mathrm{k}=1,2,3,4
\end{aligned}
$$

Region 3

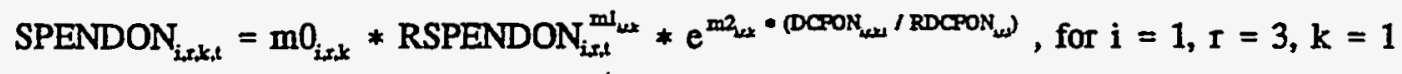

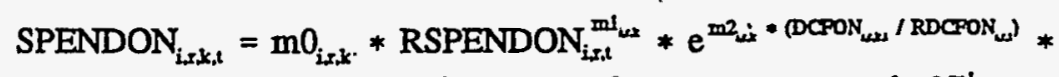

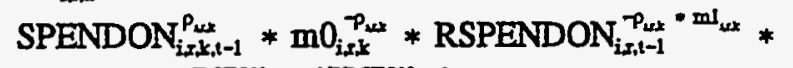

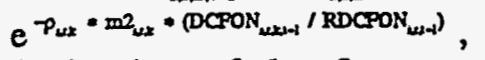

$$
\begin{aligned}
& \text { for } \mathrm{i}=1, \mathrm{r}=3, \mathrm{k}=2
\end{aligned}
$$

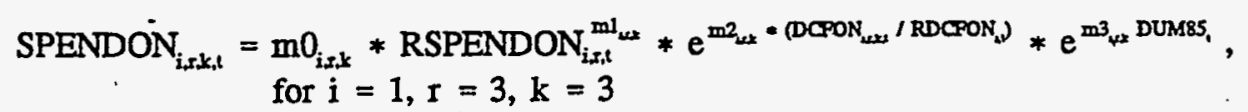


Region 4

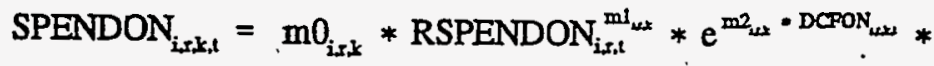

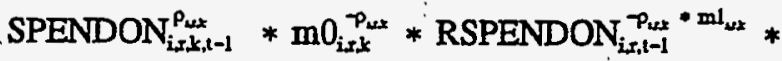

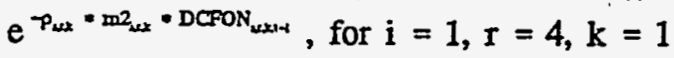

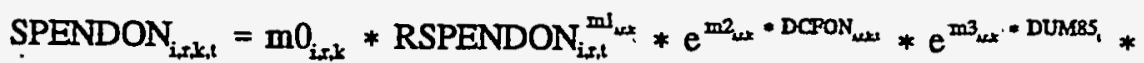

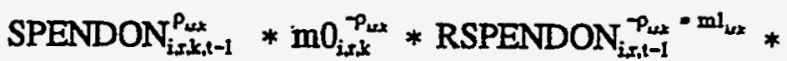

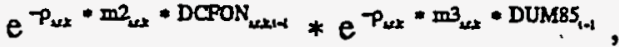

$$
\begin{aligned}
& \text { for } i=1, r=4, k \doteq 2
\end{aligned}
$$

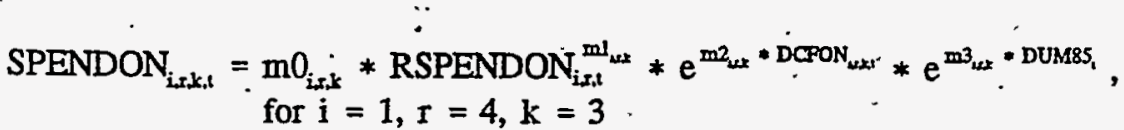

\section{Region 5}

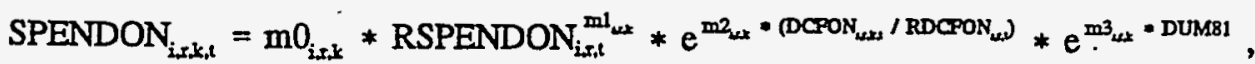

$$
\begin{aligned}
& \text { for } i=1 ; x:=5, k=1
\end{aligned}
$$

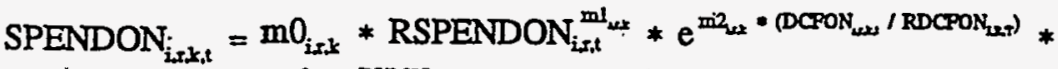

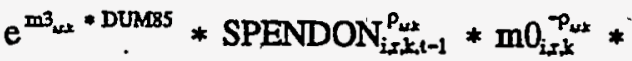

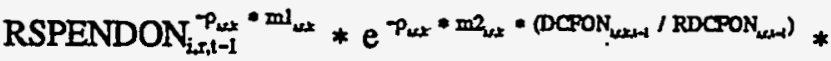

$$
\begin{aligned}
& e^{P_{W x} \cdot m 3_{U 2} \cdot D U M B S_{1}}, \text { for } i=1, r=5, k=2
\end{aligned}
$$

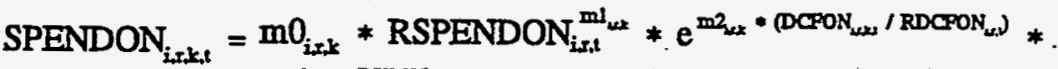

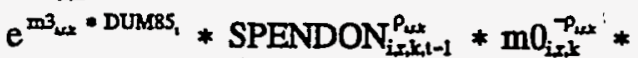

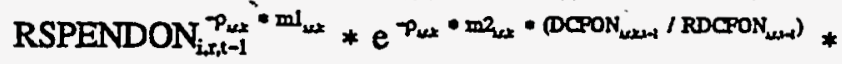

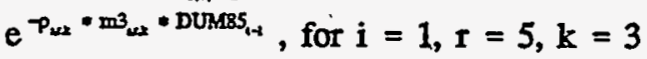

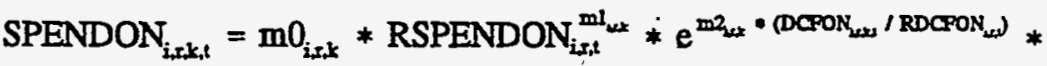

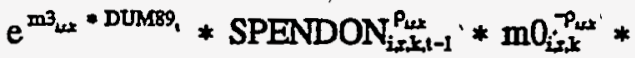

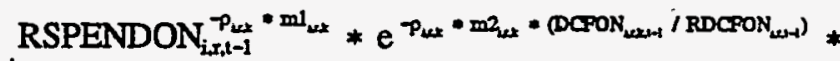

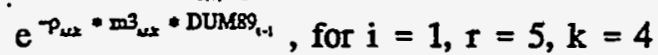

Region 6

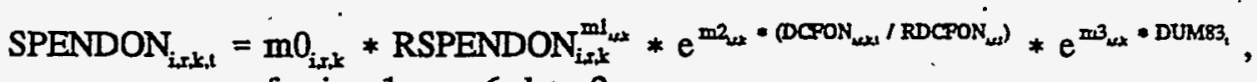

$$
\begin{aligned}
& \text { for } i=1, r=6, k=2
\end{aligned}
$$

Onshore regional development expenditures by fuel type 


\section{Region 1}

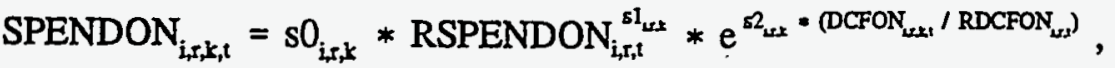

$$
\begin{aligned}
& \text { for } \mathrm{i}=2, \mathrm{r}=1, \mathrm{k}=1,5
\end{aligned}
$$

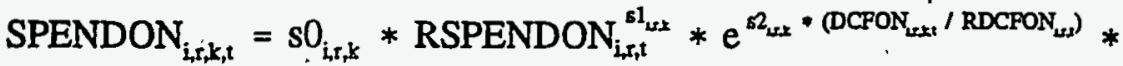

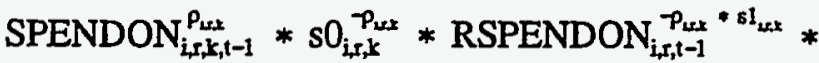

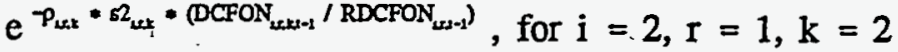

Region 2

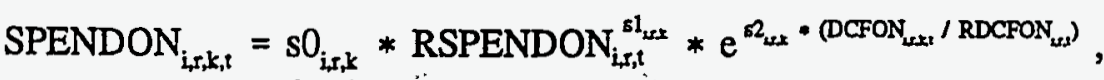

$$
\begin{aligned}
& \text { for } i=2, r=2, k=1,3
\end{aligned}
$$

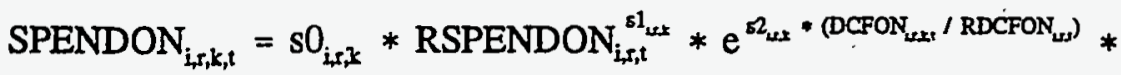

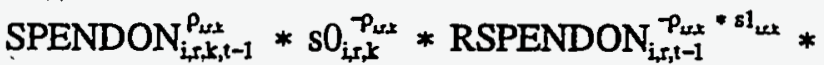

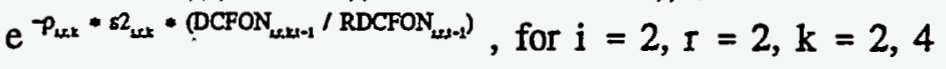

Region 3

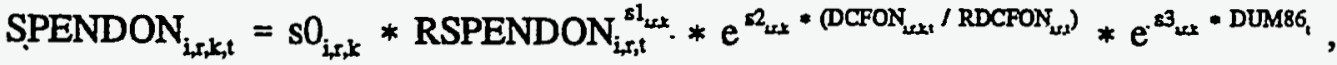

$$
\begin{aligned}
& \text { for } \mathrm{i}=2, \mathrm{r}=3, \mathrm{k}=1
\end{aligned}
$$

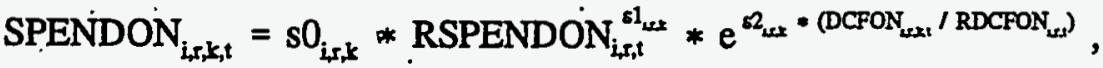

$$
\begin{aligned}
& \text { for } i=2, r=3, k=2
\end{aligned}
$$

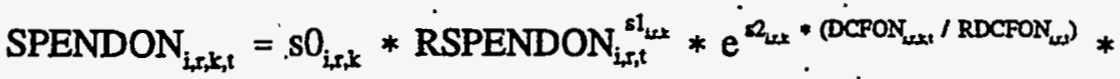

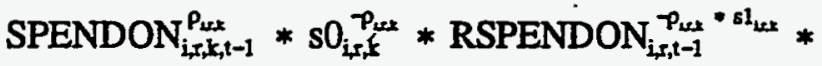

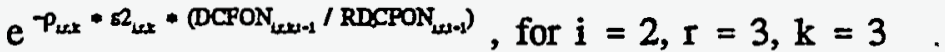

Region 4

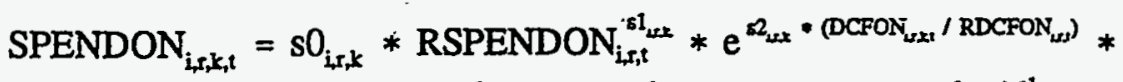

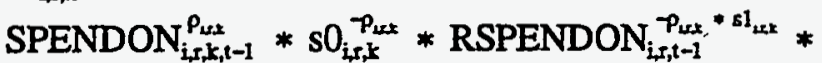

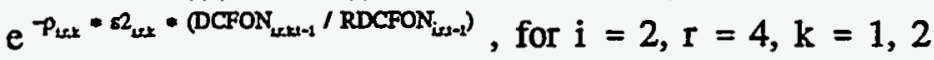

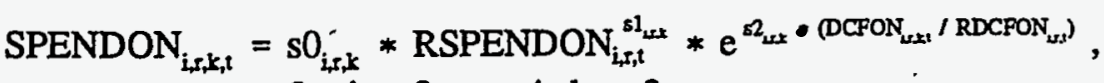

$$
\begin{aligned}
& \text { for } i=2, r=4, k=3
\end{aligned}
$$


Region 5

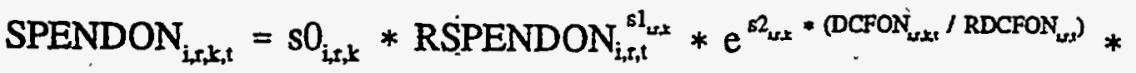

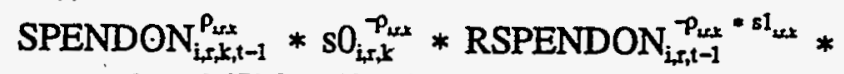

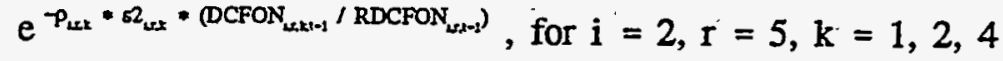

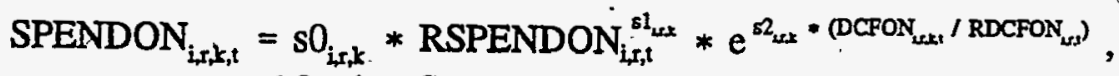

$$
\begin{aligned}
& \text { for } i=2, I=5, k=3
\end{aligned}
$$

Region 6

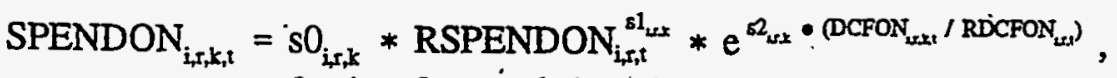

$$
\begin{aligned}
& \text { for } i=2, r=6, k=1
\end{aligned}
$$

Calculation of total onshore wells

$$
\begin{array}{r}
\text { WELLSON }_{i, r, k, t}=\frac{\text { SPENDON }_{i, r, k, t}}{\operatorname{DRMLL}_{i, r, k, t} * \operatorname{SR}_{i, r, 1}+\operatorname{DRY}_{i, r, k, t} *\left(1-\operatorname{SR}_{i, r, k}\right)}, \\
\text { for } i=1,2, r=\text { onshore regions, } k=1 \text { thru } 6
\end{array}
$$

Calculation of successful onshore wells

$$
\begin{aligned}
\text { SUCWELSON }_{i, r, k, t}= & \text { WELLSON }_{i, r, k, t} * \operatorname{SR}_{L, r, k}, \text { for } i=1,2, r=\text { onshore regions, } \\
& k=1 \text { thru } 6
\end{aligned}
$$

Calculation of onshore dry holes

$$
\begin{gathered}
\text { DRYWELON }_{i, k, t}=\text { WELLSON }_{i, r, t,}-\text { SUCWELSON }_{i, r, k, t} \text { for } i=1,2, \\
\quad r=\text { onshore regions, } k=1 \text { thru } 6
\end{gathered}
$$

\section{Lower 48 Offshore Expenditures and Well Determination}

Share of total offishore wells at the class, region, fuel level

$$
w 3_{i, r, k, t}=W E L I S_{i, r, k,-1} / \sum_{k} W E L L S_{i, r, k,-1} \text {, for each } i, r, k
$$

Regional offshore DCF

$$
\operatorname{RDCFOFF}_{\mathrm{i}, \mathrm{r}, \mathrm{t}}=\sum_{\mathbf{k}} \mathrm{w}_{\mathrm{i}, \mathrm{r}, \mathrm{k}, \mathrm{t}} * \mathrm{DCFOFF}_{\mathrm{i}, \mathrm{r}, \mathrm{k}, \mathrm{t}} \text { for } \mathrm{i}=1,2, \mathrm{r}=\text { offshore regions, } \mathrm{k}=1,2
$$

Share of total offshore wells at the class, region level 
$w 4_{i, r, t}=W E L L S_{i, r, t-1} / \sum_{s}$ WELLS $_{i, r, t-1}$, for each $i, r$

National offshore DCF

NDCFOFF $_{i, t}=\sum_{r} w_{i, r, t} * R$ RCFOFF $_{i, r, t}$ for $i=1,2, r=$ offshore regions

National offshore exploratory expenditures

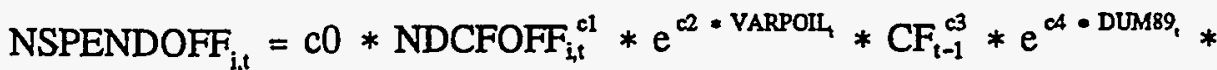

$$
\begin{aligned}
& \mathrm{e}^{\mathrm{c5} * \mathrm{TMM}} * \mathrm{NSPENDOFF} \mathrm{i}_{\mathrm{i}, 1-1}^{\mathrm{T}} * \mathrm{c0}^{-p} * \mathrm{NDCFOFF}_{\mathrm{i}, t-1}^{-p} * \mathrm{c1} *
\end{aligned}
$$

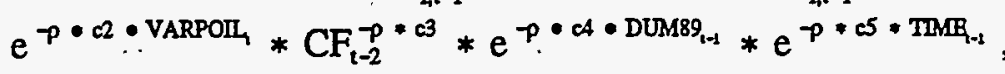

$$
\begin{aligned}
& \text { for } i=1
\end{aligned}
$$

National offshore developmental expenditures

$$
\operatorname{NSPENDOFF}_{i, t}=d 0 * \operatorname{NDCFOFF}_{i, t}^{d 1} * \mathrm{e}^{\mathrm{d} \cdot \text { DUM89, }_{\mathrm{i}}}, \text { for } \mathrm{i}=2
$$

Regional offshore exploration expenditures

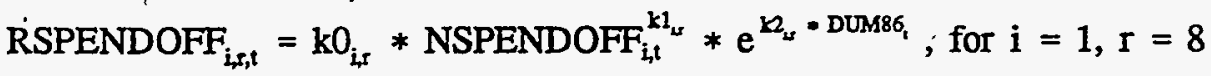

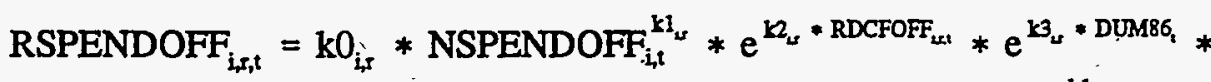

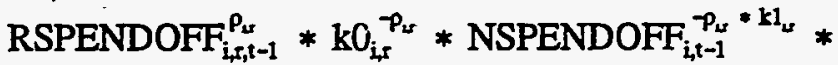

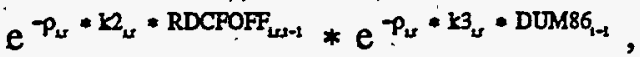

$$
\begin{aligned}
& \text { for } i=1, r=9 \\
& \text { RSPENDOFF }_{i, r, i}=k_{i, r} * \text { NSPENDOFF }_{i, t}^{k 1_{i,}} \text {, for } \mathrm{i}=1, \mathrm{r}=10
\end{aligned}
$$

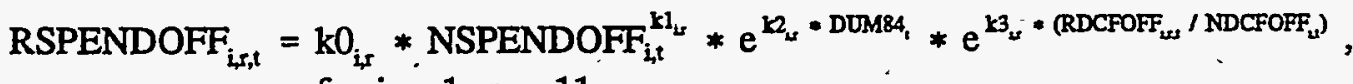

$$
\begin{aligned}
& \text { for } i=1, r=11
\end{aligned}
$$

Regional offshore development expenditures

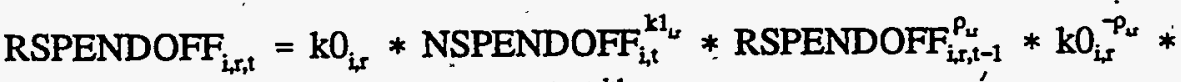

$$
\begin{aligned}
& \mathrm{NSPENDOFF}_{i, r, 1-1}^{-P_{s} * k 1_{s s}} \text {, for } \mathrm{i}=2, \dot{r}=8,10
\end{aligned}
$$

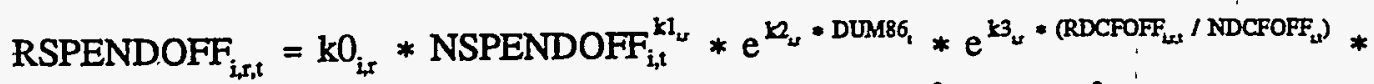

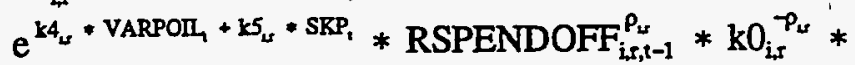

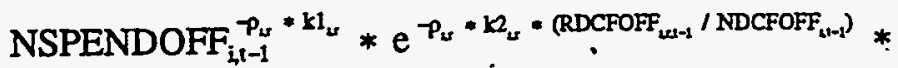

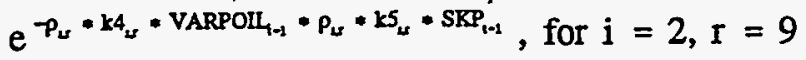

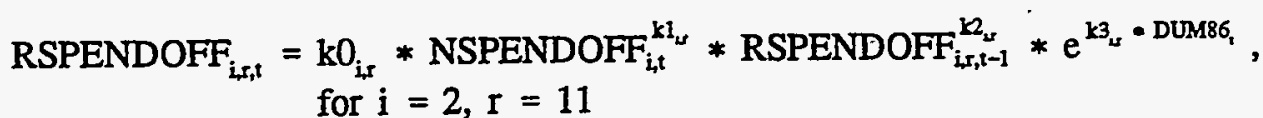


Offshore regional exploration expenditures by fuel type

$$
\text { SPENDOFF }_{i, k, t, t}=\text { RSPENDOFF }_{i, r, t} \text {, for } \mathrm{i}=1, \mathrm{r}=8,11, \mathrm{k}=1
$$

$$
\text { SPENDOFF }_{i, r, k, t}=0, \text { for } \cdot \mathrm{i}=1, \mathrm{r}=8,11, \mathrm{k}=2
$$

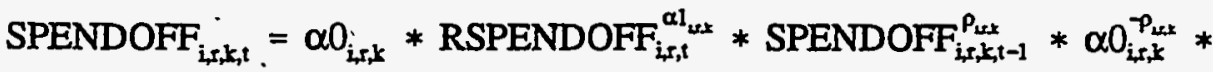

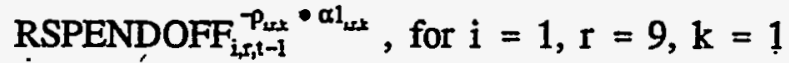

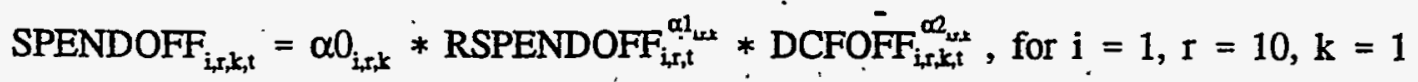

Offshore regional development expenditures by fuel type

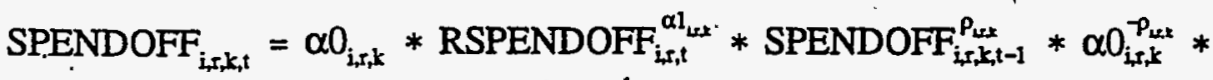

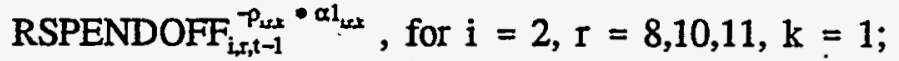

$$
\begin{aligned}
& \text { for } i=2, r=9, k=2
\end{aligned}
$$

Calculation of total offshore wells

$$
\begin{aligned}
& \text { WELLSOFF }_{i, r, t, t}=\frac{\text { SPENDOFF }_{i, r, t, t}}{\operatorname{DRILL}_{i, r, k, t} * \operatorname{SR}_{i, r, k}+\operatorname{DRY}_{\mathrm{i}, \mathrm{r}, \mathrm{k}, \mathrm{t}} *\left(1-\mathrm{SR}_{\mathrm{i}, \mathrm{r}, \mathrm{k}}\right)} \text {, } \\
& \text { for } \mathrm{i}=1,2, \mathrm{I}=\text { offshore regions, } \mathrm{k}=1,2
\end{aligned}
$$

Calculation of successful offshore wells

$$
\begin{aligned}
\text { SUCWELSOFF }_{i, r, k, t}= & \text { WELLSOFF }_{i, r, k, t} * \text { SR }_{i, r, k} \\
& \text { for } i=1,2, r=\text { offshore regions, } k=1,2
\end{aligned}
$$

Calculation of offshore dry holes

$$
\begin{aligned}
\text { DRYWELOFF }_{i, r, k, t}= & \text { WELLSOFF } \\
& r=\text { offshore regions, } k=1,2
\end{aligned}
$$

\section{Lower 48 Onshore \& Offshore Resërve Additions}

New reserve discoveries 


$$
\begin{aligned}
& F R 1_{x, k, t}=F R 1_{x, k, t-1} * e^{-\delta 1_{x x t} * S W 1_{k x t}}
\end{aligned}
$$

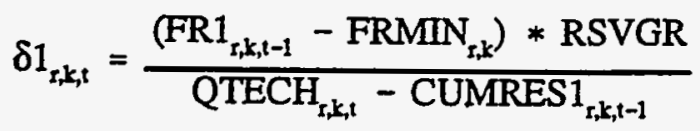

$$
\begin{aligned}
& \text { CUMRES1 }_{x, k, t}=\sum_{T=1}^{t}\left(\mathrm{NRD}_{\mathrm{r}, \mathrm{T}, \mathrm{T}} * \mathrm{RSVGR}\right) \\
& \mathrm{NDR}_{\mathrm{r}, \mathrm{k}, \mathrm{t}}=\frac{\mathrm{FR} 1_{r, \mathrm{k}, \mathrm{t}-1}}{\delta 1_{\mathrm{r}, \mathrm{k}, \mathrm{t}}} *\left(1-\mathrm{e}^{-\delta 1_{\mathrm{t} \mathrm{t} t} \cdot \mathrm{SW} /}\right)
\end{aligned}
$$

Inferred reserves

$$
I_{t, k, t}=N R_{r, k, t} *(R S V G R-1)
$$

\section{Reserve revisions}

$$
\begin{aligned}
& F R 2_{r, k, t}=F R 2_{x, k, t-1} * e^{-\delta 2_{2 s t} * S W 2_{2 e t}}
\end{aligned}
$$

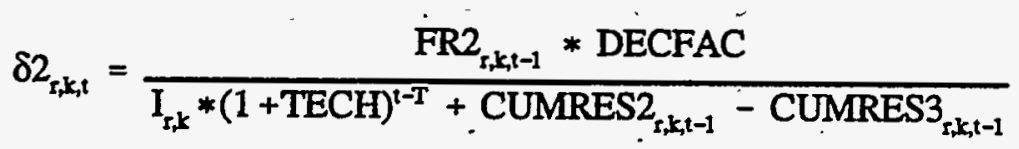

$$
\begin{aligned}
& \mathrm{REV}_{\mathrm{x}, \mathrm{k}, \mathrm{t}}=\frac{\mathrm{FR} 2_{\mathrm{r}, \mathrm{t},-1}}{\delta 2_{\mathrm{r}, \mathrm{k}, \mathrm{t}}} *\left(1-\mathrm{e}^{-\delta 2_{\mathrm{set}} \cdot \mathrm{sW}}\right)
\end{aligned}
$$


Reserve exfensions

$$
\begin{aligned}
& F R 3_{r, k, t}=F R 3_{r, k, t-1} * e^{-\delta 3_{2 x} * S W 3_{2 x t}} \\
& \delta 3_{\mathrm{r}, \mathrm{k}, \mathrm{t}}=\frac{\mathrm{FR}_{\mathrm{r}, \mathrm{k}, \mathrm{t}-1} * \text { DECFAC }}{\mathrm{I}_{\mathrm{r}, \mathrm{k}} *(1+\mathrm{TECH})^{1-\mathrm{T}}+\mathrm{CUMRES}_{\mathrm{r}, \mathrm{k}, \mathrm{t}-1}-\mathrm{CUMRES}_{\mathrm{r}, \mathrm{k}, \mathrm{t}-1}} \\
& \operatorname{CUMRES3}_{\mathrm{r}, \mathrm{k}, \mathrm{t}}=\sum_{\mathrm{T}=1}^{1}\left(\mathrm{EXT}_{\mathrm{r}, \mathrm{k}, \mathrm{T}, \mathrm{T}}+\mathrm{REV}_{\mathrm{r}, \mathrm{k}, \mathrm{T}, \mathrm{T}}\right) \\
& \operatorname{EXT}_{r, k, t}=\frac{F R 3_{r, k, t-1}}{\delta 3_{r, k, t}} *\left(1-\mathrm{e}^{-\delta 3_{k x s} * \mathrm{sw}^{\prime} 3}\right)
\end{aligned}
$$

Total reserve additions

$$
R A_{r, k, t}=N R D_{r, k, t}+R E V_{t, k, t}+E X T_{r, k, t}
$$

End-of-year reserves

$$
R_{t, k, t}=R_{r, k, t-1}-Q_{r, k, t}+R A_{r, k, t}
$$

\section{Lower 48 Onshore \& Offshore Production to Reserves Ratio}

$$
\mathrm{PR}_{\mathrm{t}+1 .}=\frac{\mathrm{R}_{\mathrm{t}-1} * \mathrm{PR}_{\mathrm{t}} *\left(1-\mathrm{PR}_{\mathrm{t}}\right)+\mathrm{PRNEW} * \mathrm{RA}_{\mathrm{t}} *(1-\mathrm{PRNEW} / 2)}{\ddots}
$$

\section{Alaska Expenditure Determination}

Developmental expenditures

$$
\operatorname{SPENDDV}_{f, t}=(\mathrm{NDEV} *(\mathrm{DEVCOST}+\mathrm{EQUIP})+\mathrm{NDRYDEV} * \mathrm{DRYDEVCOST})_{\mathrm{f}, \mathrm{t}}
$$

Exploratory expenditures 


\section{Tariff Routine}

$$
\begin{aligned}
& \text { TRR }_{t}=\text { OPERCOST }_{t}+\text { DRR }_{t}+\text { TOTDEP }_{t}+\text { MARGIN }_{t}+\text { DEFRETREC }_{t}+\text { TXALLW }_{t} \\
& \text { TRR }_{t}=\text { NONTRANSREV }_{t}+\text { CARRYOVER }_{t} \\
& \operatorname{TOTDEP}_{t}=\text { DEP }_{t} *\left(\text { DEPPROP }_{t-2}+\text { ADDS }_{t-1}-\text { PROCEEDS }_{t-1}-\text { TOTDEP }_{t-1}\right) \\
& \text { MARGIN }_{t}=\text { ALLOW }_{t} * \text { THRUPUT }_{t}+0.064 * \\
& \left(\text { DEPPROP }_{\mathrm{NBW}, \mathrm{t}}^{\prime \prime}+\mathrm{DEFRET}_{\mathrm{NBW,i}}-\mathrm{DEFTAX}_{\mathrm{NBW,}, \mathrm{t}}\right) \\
& \text { DEFRETREC }_{t}=\text { DEP }_{!} *\left(\text { DEFRET }_{t-2}+\text { INFLADJ }_{t-1}+\text { AFUDC }_{t-1}-\text { DEFRETREC }_{t-1}\right) \\
& \text { TXALLW }_{1}=\operatorname{TXRATE}^{*}\left(\text { MARGIN }_{t}+\text { DEFRETREC }_{t}\right)
\end{aligned}
$$

\section{Canadian Gas Trade}

Net cash flow

$$
\begin{aligned}
\mathrm{NCF}_{\mathbf{i k}, \mathbf{T}}= & (\text { REV - ROY - DRILICOST - EQUIPCOST - } \\
& \text { OPERCOST - DRYCOST - PROVTAX - FEDTAX })_{i \mathbf{K}, \mathrm{T}}
\end{aligned}
$$

Expected discounted cash flow

$$
\text { PROJDCF }_{\mathrm{i}, \mathrm{k}, \mathrm{t}}=\sum_{\mathrm{T}=\mathrm{t}}^{\mathrm{t} \text { th }}\left[\mathrm{NCF}_{\mathrm{i}, \mathrm{k}, \mathrm{T}} *\left[\frac{1}{1+\text { disc }}\right]^{\mathrm{T}-\mathrm{t}}\right]
$$

Expected revenues

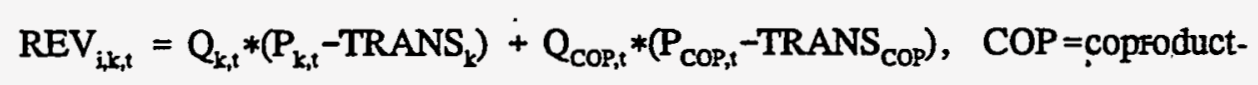

Expected royalty payments

$$
\mathrm{ROY}_{\mathrm{i}, \mathrm{k}, \mathrm{t}}=\mathrm{ROYRT} * \mathrm{REV}_{\mathrm{i} \mathbf{k}, \mathrm{t}}
$$

Expected costs

Successful drilling costs

$$
\operatorname{DRILCOST}_{i \mathbf{k}, \mathrm{t}}=\mathrm{DRILL}_{1, k, \mathrm{t}} * \mathrm{SR}_{1, k} * \mathrm{WELL}_{1, k, \mathrm{~T}}+\mathrm{DRIII}_{2, \mathrm{k}, \mathrm{t}} * \mathrm{SR}_{2, \mathrm{k}} * \mathrm{WELI}_{2 \mathrm{k}, \mathrm{T}}
$$


Dry hole costs

$$
\operatorname{DRYCOST}_{1, k, t}=\mathrm{DRY}_{1, \mathbf{k}, \mathrm{t}} *\left(1-\mathrm{SR}_{1, \mathrm{k}}\right) * \mathrm{WELL}_{1, \mathbf{k}, \mathrm{T}}+\mathrm{DRY}_{2, \mathrm{k}, \mathrm{t}} *\left(1-\mathrm{SR}_{2, \mathrm{k}}\right) * \mathrm{WELL}_{2, \mathbf{k}, \mathrm{T}} \quad \cdot
$$

Lease equipment costs

$$
\mathrm{EQUIP}_{\mathrm{i,k,t}}=\mathrm{EQUIP}_{\imath} *\left(\mathrm{SR}_{1, \mathrm{k}} * \mathrm{WELL}_{1, \mathrm{k}, \mathrm{T}}+\mathrm{SR}_{2, \mathrm{k}} * \mathrm{WELL}_{2, \mathrm{k}, \mathrm{T}}\right)
$$

Operating costs

$$
\operatorname{OPERCOST}_{\mathrm{i}, \mathrm{k}, \mathrm{t}}=\operatorname{OPCOST}_{\mathrm{i}, \mathrm{k}, \mathrm{t}} * \sum_{\mathbf{k}=1}^{\mathrm{T}}\left[\mathrm{SR}_{1, \mathrm{k}} * \mathrm{WELL}_{1, \mathbf{k}, \mathrm{T}}+\mathrm{SR}_{2, \mathrm{k}} * \mathrm{WELL}_{2, \mathbf{k}, \mathrm{T}}\right]
$$

Expected federal tax base

$$
\mathrm{FIT}_{\mathrm{i}, \mathrm{k}, \mathrm{R}}=(\mathrm{REV}-\mathrm{OPERCOST}-\mathrm{XIDC}-\mathrm{DEPREC}-\mathrm{RA}-\mathrm{DA}-\mathrm{DRYCOST})_{\mathrm{ik,t}, \mathrm{f}}
$$

Expected expensed costs

$$
\mathrm{XIDC}_{\mathrm{i}, \mathrm{k}, \mathrm{t}}=\dot{\mathrm{DRIL}}_{1, \mathrm{k}, \mathrm{t}} * \mathrm{EXP}_{1} * \mathrm{SR}_{1, \mathrm{k}} * \mathrm{WELL}_{1, k, \mathrm{t}}+\mathrm{DR} \mathrm{LL}_{2, \mathrm{k}, \mathrm{t}} * \mathrm{EXP}_{2} * \mathrm{SR}_{2, \mathrm{k}} * \mathrm{WELL}_{2, \mathrm{k}, \mathrm{t}}
$$

Expected depreciable costs

$$
\begin{aligned}
& \text { DEPREC }_{i, k, t}=\sum_{j=\beta}^{t}\left[\left[\left(\operatorname{DRILL}_{1, k, T} *\left(1-\mathrm{EXP}_{1}\right)+\mathrm{EQUIP}_{1, k, \mathrm{~T}}\right) * \mathrm{SR}_{1, k} * \dot{\mathrm{WELL}} \mathrm{L}_{1, k, \mathrm{j}}+.\right.\right. \\
& \left.\left(\mathrm{DRILL}_{2, \mathrm{k}, \mathrm{T}} *\left(1-\mathrm{EXP}_{2}\right)+\mathrm{EQUIP}_{2, \mathrm{k}, \mathrm{T}}\right) * \mathrm{SR}_{2, \mathrm{k}} * \mathrm{WELL}_{2, \mathrm{k}, \mathrm{j}}\right] \text { * } \\
& \left.\operatorname{DEP}_{t-j+1} *\left(\frac{1}{1+\text { infl }}\right)^{t-j} *\left(\frac{1}{1+\text { disc }}\right)^{t-j}\right] \text {, } \\
& \beta=\left\{\begin{array}{l}
T \cdot \text { for } t \leq T+m-1 \\
t-m+1 \cdot \text { for } t>T+m-1
\end{array}\right.
\end{aligned}
$$

Expected resource allowance

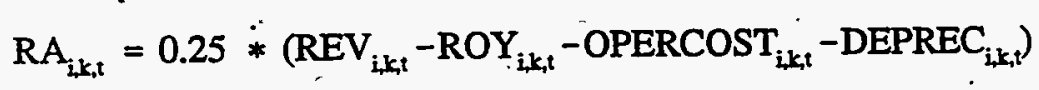

Expected depletion allowance

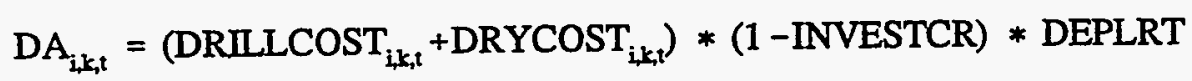


Expected provincial tax base

$$
\mathrm{PTI}_{i, k, t}=\mathrm{FTI}_{\mathrm{i}, \mathrm{k}, \mathrm{t}}-\mathrm{ROY}_{\mathrm{i}, \mathrm{k}, \mathrm{t}}-\mathrm{RA}_{\mathrm{i}, \mathrm{k}, \mathrm{t}}-\mathrm{DRYCOST}_{\mathrm{i}, \mathrm{k}, \mathrm{t}}
$$

Expected provincial income taxes

$$
\text { PROVTAX }_{i, k, t}=\mathrm{FTI}_{i, k, t} * \text { PROVRT }
$$

Expected federal income taxes

$$
\text { FEDTAX }_{\mathrm{i}, \mathrm{k}, \mathrm{t}}=\mathrm{FTI}_{\mathrm{i}, \mathrm{k}, \mathrm{t}} \text { * FDRT }
$$

Calculation of successful Canadian wells

$$
\begin{aligned}
\text { WELLS }_{k, 1}= & \beta 0_{k}+\beta 1_{k} * \operatorname{DCF}_{k, t}+\beta 2_{k} * \operatorname{DUM}+\rho_{t} * \rho_{k} * \text { WELS }_{k, t-1}-\rho_{k} * \\
& \beta 0_{k}-\rho_{k} * \beta 1_{k} * \operatorname{DCF}_{k, t-1}-\rho_{k} * \beta 2_{k} *{\operatorname{DUM} 83_{t-1},} \\
& \text { for } \mathrm{k}=\text { oil, gas }
\end{aligned}
$$

Reserve additions

$$
\begin{aligned}
& \mathrm{FR}_{\mathrm{t}, \mathrm{l}}=\mathrm{FR}_{\mathrm{t}, \mathrm{t}-1} * \mathrm{e}^{-\delta_{\mathrm{z}}} \cdot \text { WHLLS }_{\mathrm{xt}} \\
& \delta_{k, t}=\frac{\left(\mathrm{FR}_{\mathrm{k}, \mathrm{t}-1}-\mathrm{FRMIN}_{\mathrm{k}}\right) * \mathrm{RSVGR}^{\mathrm{T}}}{\mathrm{Q}_{\mathrm{k}} *(1.0+\mathrm{TECH})^{\mathrm{t}-\mathrm{T}}-\text { CUMRES }_{\mathrm{k}, \mathrm{t}-1}} \\
& \mathrm{RA}_{\mathrm{k}, t}=\frac{\mathrm{FR}_{\mathrm{k}, t-1}}{\delta_{\mathrm{k}, \mathrm{t}}} *\left(1-\mathrm{e}^{-\delta_{\mathrm{kt}} \cdot \mathrm{WBILS}_{\mathrm{v}}}\right) \\
& \text { CUMRES }_{k, t}=\sum_{T=1}^{t} R_{t, T}
\end{aligned}
$$

End-of-year reserves

$$
R_{k, t}=R_{t, t-1}+R A_{t, t}-Q_{k, t}
$$

Production to reserves ratio

$$
\mathrm{PR}_{\mathrm{t}, \mathrm{t}+1}=\frac{\mathrm{Q}_{\mathrm{k}, \mathrm{t}} *\left(1-\mathrm{PR}_{\mathrm{t}, \mathrm{t}}\right)+\mathrm{PRNEW} * \mathrm{RA}_{\mathrm{k}, \mathrm{t}}}{\mathrm{R}_{\mathrm{k}, \mathrm{t}}}
$$





\section{Appendix C. Bibliography}



Aerospace Corporation. 1976. Alaska Natural Gas Transportation Systems Economic and Risk Analysis. "

Argonne National Laboratory, Environmental Assessment and Information Sciences Division. June 7, 1991 (revised draft). National Energy Strategy Environmental Analysis Model (NESEAM): Documentation and Findings, prepared for the DOE Office of Policy, Planning, and Analysis under contract W-31-109-Eng-38.

Arps, J.J. and T.G. Roberts. 1958. "Economics of Drilling for Cretaceous Oil on East Flank of Denver-Julesburg Basin," Bulletin of American Association of Petroleum Geologists, Vol. 42, No. 11 (November) pp. 2549-2567.

Attanasi, E.D., L.J. Drew, and D.H. Root. 1981. "Physical Variables and the Petroleum Discovery Process" in James Ramsey, ed., The Economics of Exploration for Energy Resources (Greenwich: JAI Press).

Baker, R.A., Gehman, H.M., James, W.R., and White, D.A. 1984. "Geologic Field Number and Size. Assessments of Oil and Gas Plays," The American Association of Petroleum Geologists Bulletin, Vol 68, No. 4 , pages $426-437$.

Beach, C. and MacKimnon, J. 1978. "A Maximum Likelihood Procedure for Regression with Autocorrelated Errors," Econometrica, Vol. 46, pages 51-58.

Beltramo, M., Manne a., Weyant J., The Energy Journal, 7 (July 1986), pp.15-32.

Bird, K.J. 1986. "A Comparison of the Play Analysis Techniques as Applies in Hydrocarbon Resource Assessments of the National Petroleum Reserve in Alaska and the Arctic National Wildlife Refuge," in Rice, D.D., ed., Oil and Gas Assessment, Methods and Applications, American Association of Petroleum Geologists Studies in Geology, No. 21, Tulsa.

Bowers, B., Kutney, R., "Trends in Crude Oil and Natural Gas Reserves Additions Rates and Marginal Supply Costs for Western Canada," Journal of Canadian Petroleum Technology, May-June 1989, vol 28 \#3, pp. 88-94.

Brown, Kevin, J., "Towards A Continental Natural Gas. Market: Historical Perspectives And Long-Term Outlook," Canadian Energy Research Institute, Ștudy No. 26, March 1988.

Canadian Energy Research Institute, Continental Natural Gas Market: Canadian Export Capacity in the 90s, Study No. 32, October 1989.

Cazalet, E.G. 1977. Generalized Equilibrium Modeling: The Methodology of the SRI-Gulf Energy Model, Decision Focus Incorporated, Palo Alto, CA and Stanford Research Institute, Menlo Park, CA.

Cherniavsky, E.A., and Juang, L.L. October 1979. Resource Submodels of the Long-Range Energy Analysis Program: Documentation, Report to the Division of Long-range Analysis, Energy Information Administration, Washington.

Cherniavsky, E.A. May 1982. "Oil/Gas Supply Modeling Considerations in Long-range Forecasting," in Gass, S.I., Oil and Gas Supply Modeling, Proceedings of a Symposium held at the Department of Commerce, Washington, D.C., June 18-20, 1980, U.S. Department of Commerce, NBS Special Publication 631. 
Cox, J., and Wright, A. 1976. "The Determinants of Investment in Petroleum Reserves and Their Implications for Public Policy," American Economic Review, Vol. 66, No. 1, pages 153-167.

Davis, J.C., and Harbaugh, J.W. 1981: "A Simulation Model for Oil Exploration Policy on Federal Lands of the U.S. Outer Continental Shelf," in Ramsey, J., ed., The Economics of Exploration for Energy Resources, JAI Press, Greenwich.

Deacon, R., et al. 1983. The Proposed California Crude Oil Severance Tax: An Economic Analysis, The Economics Group, Inc:, Santa Barbara.

Department of Revenue, State of Alaska. 1989, 1990, and 1991. Petroleum Production Revenue Forecast. Alaska.

Drew, L.J., Schuenemeyer, J.H., and Bawiec, W.J. 1982. Estimation of the Future Rate of Oil and Gas Discovery in the Gulf of Mexico, U.S. Geologic Survey Professional Paper, No. 252, Reston, VA.

DRI/McGraw-Hill, Energy Review: Natural Gas Market Focus, Standard \& Poor's Corporation, Lexington, Massachusetts, 1990.

Eckbo, P.L., Jacoby, H.D., and Smith, J.L. 1978. "Oil Supply Forecasting: A Disaggregated Process Approach," Bell Joumal of Economics, Vol. 9, No. 1, pages 218-235.

Energy and Environmental Anaiysis Inc., Costs for LNG Imports Into the United States, prepared for Gas Research Institute, GRI Contract \#5087-800-1474, August 1988.

Energy and Environmental Analysis Inc. 1991. "Import and Supplemental Gas Supply," prepared for the Source and Supply Task Group of the National Petroleum Council Natural Gas Study.

Energy Research Associates, The Reemergence of LNG - A Global Perspective, Volume I, 1989.

Epple, D. 1975. Petroleum Discoveries and Government Policy: An Econometric Study of. Supply, Ballinger Publishing Company, Cambridge, Mass.

Epple, D. 1985. "The Econometrics of Exhaustible Resource Supply: A Theory and an Application," in Sargent, T.J., ed., Energy Foresight and Strategy, Resources for the Future, Washington.

Erickson, E.W., and Spann, R.M. 1971. "Supply Response in a Regulated Industry: The Case of Naturar Gas," The Bell Journal of Economics and Management Science, Vol. 2, No: 1, pages 94-121.

Erickson, E.W., Millsaps, S.W., and Spann, R.M. 1974. "Oil Supply and Tax Incentives," Brookings Papers on Economic Activity, Vol. 2, pages 449-493.

Executive Office of the President. 1977. Decision and Report to Congress on the Alaska Natural Gas Transportation System. Energy Policy and Planning.

Eyssell, J.H. "The Supply Response of Crude Petroleum: New and Optimistic Results," Business Economics, Vol. 13, No. 3, pages 15-28.

Farmer, Richard D., Harris, Carl M., Murphy, Frederic H., and Damuth, Robert J. 1984. "The Outer continental Shelf Oil and gas Supply model of the Energy Information Administration," North-Holland European Journal Of Operation Research, 18.

C-2 
Fisher, F.M. 1964. Supply and Costs in the United States Petroleum Industry, Johns Hopkins University Press for Resources for the Futures, Baltimore.

Fisher, W.L., et al, 1988, An Assessment of the Natural Gas Resource Base of the United States, Bureau of Economic Geology, University of Texas at Austin, Austin, Texas.

Gas Research Institute, Baseline Projection Data Book: The 1989 GRI Baseline Projection of U.S. Energy Supply and Demand to 2010, Strategic Planning and Analysis Division, Washington, DC, 1990.

Gas Research Institute, "The Long-Term Trends in U.S. Gas Supply and Prices: The 1989 GRI Baseline Projection of U.S. Energy Supply and Demand to 2010," as published in Gas Research İnsights, Strategic Planning and Analysis Division, Washington, DC, 1990.

Gas Research Institute (GRI). 1990. Guide to the Hydrocarbon Supply Model, prepared for the Gas Research Institute by Energy and Environmental Analysis, Inc., Washington, DC.

Goerold, W.T. 1987. Environmental and Petroleum Resource Conflicts: A Simulation Model to Determine the Benefits of Petroleum Production in the Arctic National Wildlife Refuge, Alaska. Materials and Society II(3).

Goerold, W.T. 1988. A Simulation Model to Determine the Probability of Finding Economically Producible Petroleum in the Arctic National Wildlife Refuge, Alaska, Proceedings Tenth Annual North American Conference. International Association for Energy Economics. Houston TX.

Griffin, James M., and Moroney., John R., Texas Severance Tax Model - The Economic Impact of Severance Taxes: Results from an Econometric Model of the Texas Oil and Gas Industry, 1985. Report to the Texas Mid Continent Oil and Gas Association.

Hansen, J.J. and Kombrath, R.W. 1986. Resource Appraisal Simulation for Petroleum in the Arctic. National Wildlife Refuge, Alaska. State of Alaska, Department of Natural Resources, Division of Geological and Geophysical Surveys, Professional Report 90.

Helfat, Constance E. September 1989. Investment in Offshore Oil by Diversified Petroleum Companies, Journal of Industrial Economics, Volume XXXVIII.

Hendricks, K. Novales, A. 1987. Estimation of Dynamic Investment Functions in Oil Exploration, Draft Manuscript.

Herron, E. Hunter. June 1982. Unconventional-Gas Production Model, Final Report prepared for the Brookhaven National Laboratory Associated Universities, Inc. by Gruy Federal Inc.

Huntington, H.G., Schuler, Glen E., et al., "North American Natural Gas Markets,". Energy Modeling Forum Stanford University, February. 1989.

Huntington, H.G., Schuler, Glen E., et al., "North American Natural Gas Markets: Selected Technical Studies," Energy Modeling Forum Stanford University, April 1989.

Huntington, H.G., Lyon, Thomas P., "Responses To Modeler Questionnaires, EMF 9: North American Natural Gas Markets," Energy Modeling Forum Stanford University, May 1987. 
International Petroleum Encyclopedia, PennWell Publishing Co., Tulsa, OK, 1989.

Kalter, R.J., Tyner, W.E., and Hughes, D.W. 1975. Alternative Energy Leasing Strategies and Schedules for the Outer Continental Shelf, Comell University, Department of Agricultural Economics, A.E.RES. 7533, Ithaca, N.Y.

Kaufman, G.M., and Barouch, E. 1978. "The Interface Between Geostatistical Modeling of Oil and Gas Discovery and Economics," Mathematical Geology; 10(5).

Kaufman, G.M., Runggaldier, W., and Livne, Z. 1981. "Predicting the Time Rate of Supply from a Petroleum Play," in Ramsey, J., ed., The Economics of Exploration for Energy Resources, JAI Press, Greenwich.

Khazzoom, D.J. "The FPC Staff's Econometric Model of Natural Gas Supply in the United States," The Bell Journal of Economics and Managements Science, Vol. 2, No. 1, pages 51-93.

LNG Digest, Volume 15, Number 11, "News Briefs," Energy Research Associates, New York, November 1989.

MacAvoy, P.W. and Pindyck, R.S. "Alternative Regulatory Policies for Dealing with the Natural Gas Shortage," The Bell Journal of Economics and Management Science, Vol. 4, No. 2, pages 454-498.

Mansvelt Beck, F.W., and Wiig, K.M. 1977. The Economics of Offshore Oil and Gas Supplies, Lexington Books, Lexington, Mass.

Megill, R.E. 1988. Exploration Economics.

Moritis, Guntis. April 20, 1992. "EOR Increases 24\% Worldwide; Claims 10\% of U.S. production" [Biennial EOR Production Report], Oil and Gas Journal, page 51 and following.

Moritis, Guntis. June 29, 1992. "More Enhanced Oil Recovery Project Information Obtained," Oil and Gas Journal, page 70 and following pages.

Murphy, Frederic H. and William Trapmann. 1982. An Evaluation of the Alaskan Hydrocarbon Supply Model," Oil and Gas Supply Modeling, published by the National Bureau of Standards. Washington, DC.

National Energy Board, Canadian Energy: Supply and Demand 1987-2005, Minister of Supply and Services Canada, Ottawa, Canada, 1988.

National Energy Boaid, 1989 Annual Report, Minister of Supply and Services Canada, Ottawa, Canada, 1989.

National Petroleum Council. 1981. U.S. Arctic Oil and Gas. Energy and Environmental Analysis, Inc. Arlington, VA.

National Petroleum Council. December 1980. Unconventional Gas Sources, Vols 14.

National Petroleum Council. 1994. Enhanced Oil Recovery, Washington, D.C.

National Petroleum Council. 1991. Field Development Assumptions and Costs in the Hydrocarbon Supply Model, Energy and Environmental Analysis, Inc., Arlington, VA.

C-4 : Energy Information Administration/Oil and Gas Supply Model Documentation 
National Petroleum Council. 1992. The Potential for Natural Gas in the United States, Washington, DC.

National Research Council. 1992. The National Energy Modeling System, Committee on the National Energy Modeling System, Washington, DC.

Natural Gas Week, "DOẸ OKs Gas Import/Export with Mexico," June 12, 1989

Nesbitt, D., and Phillips, R. September 1980. Financial Statements and Producer Behavior in Generalized Equilibrium Models Such as LEAP, Decision Focus Incorporated Report.

Nesbitt, D.M. 1988. Methodology of the GRI North American Regional Gas Supply-Demand Model, Appendix A, Decision Focus Incorporated, Los Altos, CA.

Nesbitt, D.M. 1991. Insights from the North American Regional Gas (NARG) Supply-Demand Model, Presentation to the Imports and Alaska Working Group of the National Petroleum Council Natural Gas Study.

Newendorp, Paul, D. 1975. Decision Analysis for Petroleum Exploration, The Petroleum Publishing Company, Tulsa, OK.

Pautz, James F., et al. 1992. Enhanced Oil Recovery Projects Data Base, NIPER-583, National Institute for Petroleum and Energy Research, Bartlesville, Oklahoma.

Petroleum Economist, Volume LVI, Number 12, "Gas Set for 1990s Growth," Euromoney Publications pic, London, UK, December 1989.

Petroleum Economist, Volume LVI, Number 12, "Liquefied Natural Gas: Continued Market Expansion," Euromoney Publications pic, London, UK, December 1989.

Petroleum Intelligence Weekly, Special Supplement Issue, "World LNG Trade Entering New Growth Phase," Petroleum \& Energy Intelligence Weekly, Inc., November 13, 1989.

Platt's Oilgram News, Volume 68, Number 54, "MARAD Rebuff's Cabot's \$45-Million Attempt to Buy 3 LNG Tankers at Center of Dispute," McGraw-Hill, New York, March 19, 1990.

Platt's Oilgram News, Volume 68, Number 201, "LNG Ship Deal Jeopardized by New Lawsuit," McGraw-Hill, New York, October 16, 1990.

Potential Gas Committee. 1988a. Potential Supply of Natural Gas in the United States, Potential Gas Agency, Colorado School of Mines, Golden, Colorado.

Powell, Stephen G. September 1990. Arctic National Wildlife Refuge - Höw Much Oil Can We Expect?. Resources Policy.

Powell, Stephen G. 1990. A Risk Analysis of Oil Development in the Arctic National Wildlife Refuge. The Energy Journal, Volume 12, Number 3.

Prato, A.A., and Miller, R.R. 1981. "Evaluating the Energy Production Potential of the United States Outer Continental Shelf," Land Economics, Vol. 57, No. 1, pages 77-90. 
Riva, Joseph P., Jr. November 19, 1992. The Domestic Oil Status and a Projection of Future Production, CRS Report for Congress, 92-826 SPR, Congressional'Research Service, Washington, D.C.

Riva, Joseph P., Jr. October 5, 1992. Domestic Oil Production, CRS Issue Brief, Order Code IB87068, Congressional Research Service, Washington, D.C.

Rowse, J. "Allocation of Canadian Natural Gas to Domestic and Export Markets," Canadian Journal of Economics, 19 (August 1986), pp. 417-442.

Rowse, J. "Canadian Natural Gas Exports, Domestic Gas Prices and Future Gas Supply Costs", The Energy Journal, 8.(April 1987), pp. 43-62.

Roy, K.J. 1975. "Hydrocarbon Assessment Using Subjective Probability and Monte Carlo Methods," in First IIASA Conference on Methods and Models for Assessing Energy Resources Conference, Honolulu.

Roy, K.J., Procter, R.M., and McCrossam, R.G. 1975. "Hydrocarbon Assessment Using Subjective Probability," in Davis, J.C., Doveton, J.H., and Harbaugh, J.W., conveners, Probability Methods in Oil Exploration: American Association of Petroleum Geologists Research Symposium Notes, Stanford, - University, pages 56-60.

Samuelson, P., "Spatial Price Equilibrium and Linear Programming," American Economic Review, 42, 1952.

Sproule Associates Ltd., "The Future Natural Gas Supply Capability Of The Western Canada Sedimentary Basin", Report to Transcariada Pipelines Ltd., January 1990.

Trapmann, William. 1991. "Relating Natural Gas Resource Estimates to the Outlook for the Market," paper presented at the 14th Annual International Conference of the International Association for Energy Economists.

U.S. Congress. Office of Technology Assessment. 1989. Oil Production in the Arctic National Wildlife Refuge: The Technology and the Alaskan Oil Context. OTA-E-394. Washington, D.C.

U.S. Department of Energy. 1991. Recommended Design for the National Energy Modeling System, Energy Information Administration, NEMS Project Office, Washington, DC.

U.S. Department of Energy. 1978. Midterm Oil and Gas Supply Modeling System Methodology Description, DOE/EIA-0103/17 Energy Information Administration, Washington, DC.

U.S. Department of Energy. December 1982. Outer Continental Shelf (OCS) Oil and Gas Supply Model, Volume 1, Model Summary and Methodology Description, DOE/EIA-0372/1 Energy Information Administration, Washington, DC.

U.S. Department of Energy. 1982. Outer Continental Shelf (OCS) Oil and Gas Supply Model, Volume 1, Model Summary and Methodology Description, DOE/EIA-0372/1, Energy. Information Administration, Washington, DC.

U.S. Department of Energy, The Petroleum Resources of Mexico, DOE/EIA-0423, Energy Information Administration, Washington, DC, 1983. 
U.S. Department of Energy. 1986. An Economic Analysis of Natural Gas Resources and Supply, DOE/EIA-0481, Energy Information Administration, Washington, DC.

U.S. Department of Energy. 1987. Potential Oil Production from the Coastal Plain of the Arctic National Wildlife Refuge. SR/RNGD/87-01. Energy Information Administration. Washington, DC.

U.S. Department of Energy, 1988, An Assessment of the Natural Gas Resource Base of the United States, DOE/W/31109-H1, Office of Policy, Planning \& Analysis, Washington, DC.

U.S. Department of Energy, International Energy Annual 1988, DOE/EIA-0219(88), Energy Information Administration, Washington, DC, 1988a.

U.S. Department of Energy, Natural Gas Annual 1988, DOE/EIA-0131(88), Energy Information Administration, Washington, DC, 1988a.

U.S. Department of Energy, Assessment of Costs and Benefits of Flexible and Alternative Fuel Use in the U.S. Transportation Sector; Technical Report Three: Methanol Production and Transportation Costs, DOE/PE-0093 Office of Policy Planning and Analysis, November 1989.

U.S. Department Of Energy. 1989. Abandonment Rates of the Known Domestic Oil Resource, DOE/BC--89/6/SP, Bartlesville Project Office, Bartlesville, Oklahoma.

U.S. Department of Energy. 1989. An Examination of Domestic Natural Gas Resource Estimates, SR/RNGD/89-01, Energy Information Administration, Washington, DC.

U.S. Department of Energy. 1989. Federal Oil Research: A Strategy for Maximizing the Producibility of Known U.S. Oil, DOE/FE-0139, Office of Fossil Energy, Washington, D.C.

U.S. Department of Energy. 1989a. Annual Energy Review, DOE/EIA-0384(89), Energy Information Administration, Washington, DC.

U.S. Department of Energy. 1990. The Domestic Oil and Gas Recoverable Resource Base: Supporting Analysis for the National Energy Strategy, SR/NES/90-05, Energy Information Administration, Washington, DC.

U.S. Department of Energy. 1990. United States Crude Oil, Natural Gas, and Natural Gas Liquids Reserves. DOE/EIA-0216(90). Energy Information Administration. Washington, DC.

U.S. Department of Energy, Development Costs of Undeveloped Non-associated Gas Reserves in Selected Countries, Office of Policy Planning and Analysis, 1990.

U.S. Department of Energy, Quarterly Sales and Prices Report, Office of Fossil Energy, Office of Fuels Programs, various issues, 1990.

U.S. Department of Energy. 1990a. United States Crude Oil, Natural Gas, and Natural Gas Liquids Reserves, DOE/EIA-0216(90), Energy Information Administration, Washington, DC.

U.S. Department of Energy. May 1991. Intermediate Future Forecasting System: Executive Summary, DOE/EIA-M023(91) Energy Information Administration, Washington, DC. 
U.S. Department of Energy. 1991. Alaska Oil and Gas Energy Wealth or Vanishing Opportunity?. DOE/ID/01570-H1. Office of Fossil Energy. Washington, DC.

U.S. Department of Energy. 1991. The Outlook for Natural Gas Imports: Supporting Analysis for the National Energy Strategy, SR/NES/90-06, Energy Information Administration, Washington, DC.

U.S. Department of Energy. April 1992. Model Methodology and Data Description of the Production of Onshore Lower 48 Oil and Gas Model, Energy Information Administration, Office of Oil and Gas, Washington, DC.

U.S. Department of Energy. 1994. Documentation of the Oil and Gas Supply Module (OGSM), DOE/EIA-M063, Energy Information Administration, Washington, DC.

U.S. Department of Energy: 1994. Documentation of the Oil and Gas Supply Module (OGSM), Appendix: Model Developers Report, Energy Information Administration, Washington, DC.

U.S. Department of Energy. 1992. Component Design Report - Basic Framework \&.Onshore Lower 48 Conventional Oil and Gas Supply. Energy Information Administration. Washington, DC.

U.S. Department of Energy. 1992. Model Methodology and Data Description of the Production of Onshore Lower 48 Oil and Gas Model, Draft Report, Energy Information Administration, Washington, DC.

U.S. Department of the Interior, 1981, Estimates of Undiscovered Recoverable Conventional Resources of Oil and Gas in the United States, United States Geological Survey Circular 860, United States Geological Survey, Reston, Virginia.

U.S. Department of the Interior, 1987, Economics of Dil and Gas Production from ANWR for the Determination of Minimum Economic Field Size, PT-87-015-3120-985, Bureau of Land Management, Division of Mineral Resources, Alaska State Office.

U.S. Department of the Interior, 1988, National Assessment of Undiscovered Conventional Oil and Gas Resources, USGS-MMS Working Paper, Open File Report 88-373, United States Geological Survey and Minerals Management Service, Reston, Virginia.

U.S. Department of the Interior, 1989, Estimates of Undiscovered Conventional Oil and Gas Resources in the United States - A Part of the Nation's Energy Endowment, United States Geological Survey and Minerals Management Service, Denver, Colorado.

U.S. Department of the Interior, Federal Offshore Statistics 1990, Minerals Management Service (MMS).

U.S. Department of the Interior, Estimates of Undiscovered, Economically Recoverable Oil \& Gas Resources: for the Outer Continental Shelf, Revised as of January 1990, Minerals Management Service.

Van Poolten, H.K and Associates, Inc. 1978. Documentation of Input Variables: Northern Alaska Hydrocarbon Model.

Walls, M.A. 1989. Forecasting Oil Market Behavior: Rational Expectations Analysis of Price Shocks, Resources for the Future Discussion Paper EM87-03. Washington.

C-8 Energy Information Administration/On and Gas Supply Model Documentation 
Walls, Margaret A. October 1990. Analyzing the Determinants of Offshore Oil and Gas Supply: A Factual and Methodological Assessment, Final Report Prepared for the Reserves and Natural Gas Division of the " Energy Information Administration under ORNL Subcontract No. 90X-SE635V.

Walls, Margaret A. 1990. A Survey of Oil and Gas Supply Models, Draft Report, Resources for the Future, Washington, DC.

Wharton Econometric Forecasting Associates, July 1988, Canadian Energy Analysis Quartérly, The WEFA Group, Toronto, Canada .

White, D.A., and Gehman, H.M. 1979. "Methods of Estimating Oil'and Gas Resources," The American Association of Petroleum Geologists Bulletin, Vol. 63, pages 2183-2192.

White, D.A. 1980. "Assessing Oil and Gas Plays in Facies-Cycle Wedges," The American Association of - Petroleum Geologists Bulletin, Vol 64, pages 1158-1178.

White, D.A. 1981. "A Play Approach to Hydrocarbon Resource Assessment and Evaluation," in Ramsey, J., ed., The Economics of Exploration for Energy Resources, JAI Press, Greenwich.

Young, J.S. and Hauser, W.S. 1986. Economics of Oil and Gas for ANWR for the Determination of Minimum Economic Field Size. Bureau of Land Management. Division of Mineral Resource. Alaska State Office. 

Appendix D. Model Abstract 

1. Model Name

Oil and Gas Supply Module

2. Acronym

OGSM

3. Description

OGSM projects the following aspects of the crude oil and natural gas supply industry:

- production

- reserves.

- drilling activity

- natural gas imports and exports

4. Purpose

OGSM is used by the Oil and Gas Analysis Branch in the Office of Integrated Analysis and Forecasting as an analytic aid to support preparation of projections of reserves and production of crude oil and natural gas at the regional and national level. The annual projections and associated analyses appear in the Annual Energy Outlook (DOE/EIA-0383) of the Energy Information Administration. The projections also are provided as a service to other branches of the U.S. Department of Energy, the Federal Government, and non-Federal public and private institutions . concerned with the crude oil and natural gas industry.

5. Date of Last Update

1994

6. Part of Another Model

National Energy Modeling System (NEMS)

7. Model Interface References

Coal Module

Electricity Module

Industrial Module

International Module

Natural Gas Transportation and Distribution Model (NGTDM)

Macroeconomic Module

Petroleum Market Module (PMM)

8. Official Model Representative

- Office: Integrating Analysis and Forecasting

- Division: Energy Supply and Conversion

- Branch: Oil and Gas Analysis

- Model Contact: Ted McCallister

- Telephone: (202) 586-4820

9. Documentation Reference

U.S. Department of Energy. 1994. Documentation of the Oil and Gas Supply Module (OGSM), DOE/EIA-M063, Energy Information Administration, Washington, DC.

U.S. Department of Energy. 1994. Documentation of the Oil and Gas Supply Module (OGSM), Appendix: Model Developers Report, Energy Information Administration, Washington, DC. 
10. Archive Media and Installation Manual NEMS95

11. Energy Systems Described

The OGSM forecasts oil and natural gas production activities for six onshore and three offshore regions as well as three Alaskan regions. Exploratory and developmental drilling are treated separately, with exploratory drilling further differentiated as new field wildcats or other exploratory wells. New field wildcats are those wells drilled for a new field on a structure or in an environment never before productive. Other exploratory wells are those drilled in already productive locations. Development wells are primarily.within or near proven areas and can result in extensions or revisions. Exploration yields new additions to the stock of reserves and development determines the rate of production from the stock of known reserves.

The OGSM also projects natural gas trade via pipeline with Canada and Mexico, as well as liquefied natural gas (LNG) trade. U.S. natural gas trade with Canada is represented by six entry/exit points and trade with Mexico by three entry/exit points. Four LNG receiving terminals are represented.

12. Coverage

- Geographic: Six Lower 48 onshore supply regions, three Lower 48 offshore regions, and three Alaskan regions.

- Time Units/Frequency: Annually 1990 through 2010

- Product(s): Crude oil and natural gas

- Economic Sector(s): Oil and gas field production activities and foreign natural gas trade

13. Model Features

- Model Structure: Modular, containing five major components

- Lower 48 Onshore Supply Submodule

- Lower 48 Offshore Supply.Submodule

- Foreign Natural Gas Supply Submodule

- Enhanced Oil Recovery Submodule

- Alaska Oil and Gas Supply Submodule

- Modeling Technique: The OGSM is a hybrid econometric/discovery process model. Drilling activities in the United States and Canada are determined by the discounted cash flow that measures the expected present value profits for the proposed effort and other key economic variables. LNG imports are projected on the basis of unit supply costs for gas delivered into the Lower 48 pipeline network.

- Special Features: Can run stand-alone or within the NEMS. Integrated NEMS runs employ short term supply functions for efficient market equilibration.

14. Non-DOE Input. Data

- Alaskan Oil and Gas Field Size Distributions - U.S. Geological Survey

- Alaska Facility Cost By Oil Field Size - U.S. Geological Survey

- Alaska Operating cost - U.S. Geological Survey

- State Corporate Tax Rate - Commerce Clearing House, Inc. State Tax Guide

- State Severance Tax Rate - Commerce Clearing House, Inc. State Tax Guide 
- Federal Corporate Tax Rate, Royalty Rate - U.S. Tax Code

- Onshore Drilling Costs - American Petroleum Institute. Joint Association Survey of Drilling Costs (1970-1990), Washington, D.C.

- Offshore Drilling Costs - Department of Interior. Minerals Management Service (Correspondence from Gulf of Mexico and Pacific OCS regional offices)

- Offshore Platform Costs - Department of Interior. Minerals Manägement Service (Correspondence from, Gulf of Mexico and Pacific OCS regional offices)

- Offshore Lease Equipment and Operating Costs - Department of Interior. Minerals Management Service (Comespondence from Gulf of Mexico and Pacific OCS regional offices)

- Offshore Wells Drilled per Project - Department of Interior. Minerals Management Service (Correspondence from Gulf of Mexico and Pacific OCS regional offices)

- Offshore Expected Recovery of Oil and Gas - Department of Interior. Minerals Management Service (Correspondence from Gulf of Mexico and Pacific OCS regional offices)

- Canadian Royalty Rate, Corporate Tax Rate, Provincial Corporate Tax Rate- Energy Mines and Resources Canada. Petroleum Fiscal Systems in Canada, (Third Edition - 1988)

- Canadian Wells drilled - Canadian Petroleum Association. Statistical Handbook, (1976-1990)

- Canadian Lease Equipment and Operating Costs - Sproule Associates Limited. The Future Natural Gas Supply Capability of the Western Canadian Sedimentary Basin (Report Prepared for Transcanada Pipelines Limited, January 1990)

- Ċanadian Recoverable Resource Base - National Energy Board. Canadian Energy Supply and Demand 1990 - 2010, June 1991

- Canadian Reserves - Canadian Petroleum Association. Statistical Handbook, (1976-1990)

15. DOE Input Data

- Onshore Lease Equipment Cost - Energy Information Administration. Costs and Indexes for Domestic Oil and Gas Field Equipment and Production Operations (1980 - 1991), DOE/EIA-0815(80-91)

- Onshore Operating Cost - Energy Information Administration. Costs and Indexes for Domestic Oil and Gas Field Equipment and Production Operations (1980 - 1991),

- DOE/EIA-0815(80-91)

- Emissions Factors - Energy Information Administration.

- Canadian Gas Imports Border Crossing Point Capacities - Energy Information Administration. Capacity and Service on the Interstate Natural Gas Pipeline System 1990, DOE/EIA-0556 
- Oil and Gas Well Initial Flow Rates - Energy. Information Administration. Office of Oil and Gas

- Wells Drilled - Energy Information Administration. Office of Oil and Gas

- Expected Recovery of Oil and Gas Per Well - Énergy Information Administration. Office of Oil and Gas

- Undiscovered Recoverable Resource Base - Energy Information Administration. The Domestic Oil and Gas Recoverable Resource Base: Supporting Analysis for the National Energy strategy, SR/NES/90-05

- Oil and Gas Reserves - Energy Information Administration. U.S. Crude Oil, Natural Gas, $\because$ and Natural Gas Liquids Reserves, (1977-1992), DOE/EIA-0216(77-92)

16. Computing Environment

- Hardware Used: IBM3084QX

- Operating System: MVS/XA

- Language/Software Used: VS FORTRAN

- Memory Requirement: $5000 \mathrm{~K}$

- Storage Requirement: 10 tracks for input data storage; 97 tracks for output storage; 26

- tracks for code storage; and 22 tracks for compiled code storage

- Estimated Run Time: 8 seconds

17. Reviews conducted

Independent Expert Reviews (ongoing)

18. Status of Evaluation Efforts

- Not Applicable

19. Bibliography

See Appendix $C$ of this document. 


\section{Appendix E. Parameter Estimation}





\section{Introduction}

The major portion of the lower 48 oil and gas supply component of the OGSM consists of a system of 119 equations with 311 parameters that are used to forecast national, regional, and intraregional exploratory and developmental drilling expenditures. The equations are grouped in a sequence of logically occurring blocks. Industry financial variables are determined in the first block, national expenditures in the second, regional expenditures in the third, and so on. This sequential structure yields a recursive-type system of equations. Specifically, equations within a block may include as explanatory variables the dependent variables of equations from only the previous block. Additionally, in some instances, equations within each block may include as explanatory variables the dependent variables from the previous equations in the same block. The error terms across blocks are assumed to be uncorrelated so that consistent parameter estimates can be obtained by estimating each block separately using an appropriate technique.

The sections below document the equations, the estimation techniques, and the statistical results. Documentation is also provided for the estimation of the drilling, lease equipment, and operating cost equations as well as the Canadian oil and gas wells equations. Finally, the appendix documents the estimation of oil and gas supply price elasticities that are passed to the PMM and the NGTDM for (possible) use in their short run supply functions. The econometric software package, TSP, was used for all estimations.

\section{Industry Financial Variables}

Both industry cash flow and return on foreign operations were hypothesized to be simple log-linear functions of the world oil price. The equations were estimated separately using a maximum likelihood iterative technique developed by Beach and MacKinnon (1978) to correct for first order serial correlation.

$$
\mathrm{LCF}_{\mathrm{t}}=\ln (\mathrm{e} 0)+\mathrm{e} 1 * \mathrm{LWOP}_{\mathrm{t}}+\rho * \mathrm{LCF}_{\mathrm{t}-1}-\rho *\left(\ln (\mathrm{e} 0)+\mathrm{e} 1 * \mathrm{LWOP} \mathrm{t}_{-1}\right)
$$

where,

$$
\begin{aligned}
\text { LCF } & =\text { natural logarithm of industry cash flow from oil and gas operations } \\
\text { LWOP } & =\text { natural logarithm of world oil price } \\
\ln (\mathrm{e} 0), \mathrm{e} 1 & =\text { estimated parameters } \\
\rho & =\text { autocorrelation parameter } \\
\mathrm{t} & =\text { year. }
\end{aligned}
$$




\section{Results}

\begin{tabular}{||l|l|}
\hline Parameter,$\ldots$ & $\begin{array}{l}\text { Estimate } \\
\text { (t-statistic) }\end{array}$ \\
\hline $\ln (e 0)$ & $\begin{array}{l}-3.416 \\
(11.292)\end{array}$ \\
\hline$e 1$ & $\begin{array}{l}0.408 \\
(4.412)\end{array}$ \\
\hline$\rho$ & $\begin{array}{l}0.564 \\
(2.589)\end{array}$ \\
\hline
\end{tabular}

NUMBER OF OBSERVATIONS $=14$.

Dependent variable: $\mathrm{LCF}$

(Statistics based on transformed data)

Mean of dependent; variable =

Std. dev. of dependent var.'

Sum of squared residuals

Variance of residuals

Std. error of regression

R-squared

$\begin{array}{lll}\text { Adjusted R-squared } \quad & =867199\end{array}$

Durbin-Watson statistic $\quad=\quad 1.57665$

F-statistic (zero slopes) $\quad=\quad 85.6165$

Log of likelihood function $=14.2164$

(Statistics based on original data)

Mean of dependent variable $=-2.09785$

Std. dev. of dependent var. $=.203543$

Sum of squared residuals $=.104787$

Variance of residuals $\quad-\quad=\quad .873227 \mathrm{E}-02$

Std. enror of regression $\cdot=\quad .093447$

$\begin{array}{lll}\text { R-squared } & = & .814569\end{array}$

Adjusted R-squared $\quad=.799116$

Durbin-Watson statistic $\quad .=1.57306$

$L R F_{t}=\ln (f 0)+f 1 * L W O P_{t}+\rho * L R F_{t-1}-\rho *\left(\ln (f 0)+f 1 * L W O P_{t-1}\right)$

where,

$$
\begin{aligned}
\text { LRF } & =\text { natural logarithm of industry return on foreign operations } \\
\text { LWOP } & =\text { natural logarithm of world oil price } \\
\ln (\mathrm{f0}), \mathrm{f1} & =\text { estimated parameters } \\
\rho & =\text { autocorrelation paramieter } \\
\mathrm{t} & =\text { year. }
\end{aligned}
$$


Results

\begin{tabular}{||l|l|}
\hline Parameter & $\begin{array}{l}\text { Estimate } \\
\text { (f-statistic) }\end{array}$ \\
\hline $\ln (\mathrm{f0})$ & $\begin{array}{l}-4.74047 \\
(-7.38272)\end{array}$ \\
\hline $\mathrm{f} 1$ & $\begin{array}{l}1.27479 \\
(6.73943)\end{array}$ \\
\hline$\rho$ & .844722 \\
\hline
\end{tabular}

NUMBER OF OBSERVATIONS $=15$.

Dependent variable: $L R F$

(Statistics based on transformed data)

Mean of dependent variable $=$

Std. dev. of dependent var. =

Sum of squared residuals

Variance of residuals =

Std. error of regression

R-squared $=$

Adjusted R-squared

Durbin-Watson statistic

F-statistic (zero slopes)

Log of likelihood function $=4.93309$

(Statistics based on original data)

Mean of dependent variable $=\quad-.669015$

Std. dev. of dependent var. ' $=.611996$

Sum of squared residuals $=\quad .544894$

Variance of residuals $=.041915$

Std. enror of regression $=.204731$

R-squared $\quad=\quad .900454$

Adjusted R-squared $\quad=\quad 892797$

Durbin-Watson statistic $\quad \cdot=1.01843$

\section{National Exploration and Developmental Drilling Expenditures}

National exploratory and developmental drilling expenditures for the onshore lower 48 and offshore lower 48 were regressed on their corresponding DCF's, industry financial variables, measures of risk, and a dummy variable to capture structural change.

Two measures of risk were included as explanatory variables. The first, the variance in the price of oil (VARPOIL), was included to capture the impact of oil price volatility on drilling expenditures. The second, the coefficient of skewness in the price of oil (SKP), was employed to capture the effect of asymmetric movements in the price of oil. 
The four equation system was estimated in log-linear form using Zellner's seemingly unrelated regression ' (SURE) technique. Where appropriate, the equations were estimated in generalized difference form to " correct for first-order serial correlation. The specification of the final. estimating equations and the estimation results are provided below.

$$
\begin{aligned}
& \text { LNSPENDON }_{i, t}=\ln (a 0)+a 1 * \mathrm{LNDCFON}_{i, t}+\mathrm{a} 2 * \mathrm{LCF}_{\mathrm{t}}+23 * \mathrm{DUM}_{\mathrm{M}} 89_{\mathrm{t}}+\mathrm{a} 4 * \mathrm{LRF}, \text { for } \mathrm{i}=1 \\
& \text { LNSPENDON }_{i, t}=\ln (\mathrm{b} 0)+b 1 * \mathrm{LNDCFON}_{\mathrm{i}, \mathrm{t}}+\mathrm{b} 2 * \mathrm{LCF}_{\mathrm{t}-1}+\mathrm{b} 3 * \mathrm{DUM} \mathrm{g}_{\mathrm{t}}+\mathrm{b} 4 * \mathrm{LRF}_{\mathrm{t}} \\
& +\mathrm{b} 5 * \mathrm{SKP}_{\mathrm{t}} ; \text { for } \mathrm{i}=2 \\
& \mathrm{LNSPENDOFF}_{\mathrm{i}, \mathrm{t}}=\ln (\mathrm{c} 0)+\mathrm{c} 1 * \mathrm{LNDCFOFF}_{\mathrm{i}, t}+\mathrm{c} 2 * \mathrm{VARPOIL}_{\mathrm{t}}+\mathrm{c} 3 * \mathrm{LCF}_{\mathrm{t}-1}+ \\
& \mathrm{c} 4 * \text { DUM } 89_{\mathrm{t}}+\mathrm{c5} * \mathrm{TIME}_{\mathrm{t}}+\rho * \mathrm{LNSPENDOFF}_{1, \mathrm{t}-1} \\
& -p\left(\ln (\mathrm{c} 0)+\mathrm{c} 1 * \mathrm{LNDCFOFF}_{\mathrm{i} t-1}+\mathrm{c} 2 * \mathrm{VARPOIL}_{\mathrm{t}-1}\right. \\
& \left.+c 3 * \mathrm{LCF}_{\mathrm{t}-2}+\mathrm{c} 4 * \mathrm{DUM} 89_{\mathrm{t}-1}+\mathrm{c} 5 * \mathrm{TMME}_{\mathrm{t}-1}\right) ; \text { for } \mathrm{i}=2
\end{aligned}
$$

\begin{tabular}{|c|c|c|}
\hline LNSPENDON & $=$ & natural logarithm of national onshore drilling expenditures by well type \\
\hline LNSPENDOFF & $=$ & natural logarithm of national offshore drilling expenditures by well type \\
\hline LNDCFON & $=$ & natural logarithm of the national onshore discounted cash flow \\
\hline LNDCFOFF & $=$ & natural logarithm of the national offshore discounted cash flow \\
\hline LCF & $=$ & natural-logarithm of industry cash flow from oil and gas operations \\
\hline DUM89 & $=$ & 1 of $t>1988,0$ otherwise. \\
\hline VARPOIL & $=$ & $\begin{array}{l}\text { variance in monthly oil prices within a given year. The value of this variable } \\
\text { is held constant over the forecast. }\end{array}$ \\
\hline SKP & $=$ & $\begin{array}{l}\text { Measure of price skewness within a year. This variable is the third moment } \\
\text { of the distribution of monthly oil prices in any given year. The value of this } \\
\text { variable is held constant over the forecast. }\end{array}$ \\
\hline $\ln (a 0), a 1, a 2, a 3$ & $=$ & estimated parameters \\
\hline $\ln (\mathrm{b} 0), \mathrm{b} 1, \mathrm{~b} 2, \mathrm{~b} 3$ & $=$ & estimated parameters \\
\hline $\ln (\mathrm{c} 0), \mathrm{c} 1, \mathrm{c} 2, \mathrm{c} 3$ & $=$ & estimated parameters \\
\hline $\ln (\mathrm{d} 0), \mathrm{d} 1, \mathrm{~d} 2$ & $=$ & estimated parameters \\
\hline$\rho$ & $=$ & autocorrelation parameter \\
\hline & $=$ & well type, 1 for exploratory, 2 for development \\
\hline & & \\
\hline
\end{tabular}

where; 


\section{Results}

\begin{tabular}{||l|l||}
\hline Parameter & $\begin{array}{l}\text { Estimate } \\
\text { (t-statistic) }\end{array}$ \\
\hline $\ln (\mathrm{a} 0)$ & $11.6027749 \quad(4.49416721)$ \\
\hline $\mathrm{a} 1$ & $.964306387 \quad(5.65904450)$ \\
\hline $\mathrm{a} 2$ & $1.92120822 \quad(12.5918788)$ \\
\hline $\mathrm{a} 3$ & $\begin{array}{l}-.508585758 \\
(-9.28429323)\end{array}$ \\
\hline $\mathrm{a} 4$ & $\begin{array}{l}-.508268610 \\
(-2.63493564)\end{array}$ \\
\hline
\end{tabular}

\begin{tabular}{||l|l|}
\hline Parameter & $\begin{array}{l}\text { Estimate } \\
\text { (t-statistic) }\end{array}$ \\
\hline $\ln (\mathrm{b} 0)$ & $14.6762124 \quad(8.85336834)$ \\
\hline $\mathrm{b} 1$ & $.952594392 \quad(6.57475684)$ \\
\hline $\mathrm{b} 2$ & $1.58719092 \quad(7.50568795)$ \\
\hline $\mathrm{b} 3$ & -.632178744 \\
$(-10.4296984)$ \\
\hline $\mathrm{b} 4$ & -.350053915 \\
\hline & $(-2.22116134)$ \\
\hline $\mathrm{b} 5$ & $\begin{array}{l}-.065329407 \\
(-5.94947796)\end{array}$ \\
\hline
\end{tabular}




\begin{tabular}{||l|l|}
\hline Parameter & $\begin{array}{l}\text { Estimate } \\
(1-\text { statistic) }\end{array}$ \\
\hline $\ln (\mathrm{c} 0)$ & $\begin{array}{l}-307.261297 \\
(-19.0581727)\end{array}$ \\
\hline$c 1$ & $\begin{array}{l}.204933097 \\
(8.64164041)\end{array}$ \\
\hline$c 2$ & $\begin{array}{l}-.016565197 \\
(-13.1778503)\end{array}$ \\
\hline$c 3$ & $1.31884655(11.6710343)$ \\
\hline$c 4$ & $\begin{array}{l}-.734577836 \\
(-16.4281472)\end{array}$ \\
\hline$c 5$ & $\begin{array}{l}.165312403 \\
(19.6872229)\end{array}$ \\
\hline$\rho$ & -.464234813 \\
\hline & $(-7.44723228)$ \\
\hline
\end{tabular}

\begin{tabular}{||l|ll|}
\hline Parameter & $\begin{array}{l}\text { Estimate } \\
\text { (t-statistic) }\end{array}$ \\
\hline $\ln (\mathrm{d} 0)$ & 5.38507858 & $(288610181)$ \\
\hline $\mathrm{d} 1$ & 1.01884198 & $(8.61922714)$ \\
\hline $\mathrm{d} 2$ & & $\begin{array}{l}-.168195306 \\
(-2.99804144)\end{array}$ \\
\hline
\end{tabular}

Standard Errors computed from heteroscedastic-consistent matrix (Robust-White)

\section{NUMBER OF OBSERVATIONS $=11$}

Dependent variable: LNSSPENDON, i=1 (exploration)

Mean of dependent variable $=22.0275423$

Std. dev. of dependent var. $=.801840419$

Sum of squared residuals $=.093579666$

Variance of residuals $\quad=\quad .850724236 \mathrm{E}-02$

Std. error of regression $\quad \doteq .092234713$

$\mathrm{R}$-squared $\quad=\quad .985503382$

Durbin-Watson statistic $\quad=\quad \mathbf{1 . 5 4 9 8 6 2 6 4}$

Dependent variable: LNSPENDON, $\mathrm{i}=2$ (development)

Mean of dependent variable $=23.3186742$

Std. dev. of dependent var. $=.686599561$

Sum of squared residuals $=.102554160$

Variance of residuals $\quad=\quad .932310549 \mathrm{E}-02$

. Std. error of regression $=\quad .096556230$

R-squared $\quad=.978339736$

Durbin-Watson statistic $\quad=\quad 2.27714418$ 
Dependent variable: LNSPENDOFF, $\mathrm{i}=1$ (exploration)

Mean of dependent variable $=21.1420496$

Std. dev. of dependent var. $=.275329520$

Sum of squared residuals $\quad=\quad .071835981$

Variance of residuals $=.653054371 \mathrm{E}-02$

Std. error of regression $=.080811780$

R-squared $\quad=\quad .910828054$

Durbin-Watson statistic . $\quad=2.67119705$

Dependent variable: LNSPENDOFF, $\mathrm{i}=2$ (development)

Mean of dependent variable . $=$. 21.2907810

Std. dev. of dependent var. $=.355020740$

Sum of squared residuals $=.119229441$

Variance of residuals.. $\quad=.010839040$

Std. error of regression $=. .104110711$

R-squared $\quad=\quad .905536420$

Durbin-Watson statistic $\quad=2.58545823$

\section{Onshore Regional and Intraregional Exploratory Expenditure} Equations

For each of the six onshore lower 48 regions, a block of equations consisting of a regional exploratory . expenditure equation along with the intraregional exploratory expenditure equations by fuel type was estimated using SURE. Where indicated, equations were estimated in generalized difference form to correct for first order serial correlation.

Generally, regional exploratory expenditures are a function of national exploratory expenditures and the relative profitability of exploratory drilling in the region (measured as the ratio of the regional exploratory DCF to the national exploratory DCF). Similarly, intraregional exploratory expenditures by fuel type are a function of the regional exploratory expenditure level and the relative profitability of exploratory drilling for the fuel type within the region (measured as the ratio of the intraregional fuel type exploratory DCF to the regional exploratory DCF). In some instances, dummy variables are included to account for structural shifts.

\section{Onshore Exploration (Region 1)}

Equations are estimated for onshore region 1 and fuel type oil, gas, and gas from Devonian shale. The forms of the equations are:

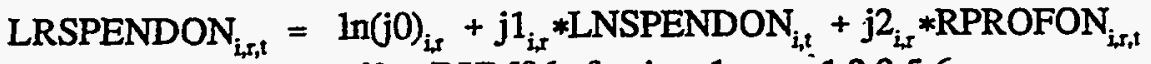

$$
\begin{aligned}
& +\mathrm{j}_{\mathrm{i}, *} * \mathrm{DUM} 86, \text { for } \mathrm{i}=1, \mathrm{r}=1,2,3,5,6
\end{aligned}
$$

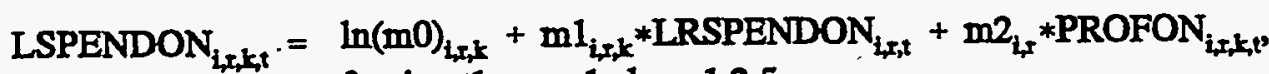

$$
\begin{aligned}
& \text { for } i=1, x=1, k=1 ; 2,5
\end{aligned}
$$

where, 


$$
\begin{aligned}
\text { LRSPENDON } & =\begin{array}{l}
\text { natural logarithm of regional }: \text { lower } 48 \text { onshore exploration drilling } \\
\text { expenditures }
\end{array} \\
\text { LNSPENDON } & =\text { natural logarithm of national onshore exploration drilling expenditures } \\
\text { RPROFON } & =\text { regional lower } 48 \text { onshore exploration profitability } \\
\text { DUM86 } & =1 \text { if } t>1985,0 \text { otherwise } \\
\text { LSPENDON } & =\text { natural logarithm of regional exploration drilling expenditures by fuel type } \\
\text { PROFON } & =\text { regional lower } 48 \text { onshore profitability by fuel type, region, and well type } \\
\ln (\mathrm{m} 0), \mathrm{m} 1, \mathrm{~m} 2 & =\text { estimated parameters } \\
\ln (\mathrm{j} 0), \mathrm{j} 1, \mathrm{j} 2, \mathrm{j} 3 & =\text { estimated parameters } \\
\mathrm{i} & =\text { well type, } 1 \text { for exploratory } \\
\mathrm{r} & =\text { OGSM region } 1-\text { lower } 48 \text { onshore } \\
\mathrm{k} & =\text { fuel type, } 1 \text { for oil, } 2 \text { for shallow gas, } 5 \text { for devonian shale gas } \\
\mathrm{t} & =\text { year. }
\end{aligned}
$$

Results

\begin{tabular}{||l|l|}
\hline Parameter & Region 1 \\
\hline $\ln (j 0)$ & $\begin{array}{l}3.81407 \\
(2.36805\end{array}$ \\
\hline $\mathrm{j} 1$ & $\begin{array}{l}0.69316 \\
(9.68695)\end{array}$ \\
\hline $\mathrm{j} 2$ & $\begin{array}{l}0.163403 \\
(5.59565)\end{array}$ \\
\hline $\mathrm{j} 3$ & -0.319006 \\
$(-3.21339)$ \\
\hline
\end{tabular}

\begin{tabular}{|l|l|l|l|}
\hline Parameter & Oil & Shallow Gas & Devonian shale \\
\hline $\ln (\mathrm{m} 0)$ & $\begin{array}{l}-3.40738 \\
(-1.76613)\end{array}$ & $\begin{array}{l}4.70862 \\
(3.65506)\end{array}$ & $\begin{array}{l}-16.4655 \\
(-5.53374)\end{array}$ \\
\hline $\mathrm{m} 1$ & $\begin{array}{l}1.11552 \\
(11.0142)\end{array}$ & $\begin{array}{l}0.70708 \\
(10.4891)\end{array}$ & $\begin{array}{l}1.67118 \\
(10.5814)\end{array}$ \\
\hline $\mathrm{m} 2$ & $\begin{array}{l}.163403 \\
(5.05824)\end{array}$ & $\begin{array}{l}.163403 \\
(5.05824)\end{array}$ & $\begin{array}{l}.163403 \\
(5.05824)\end{array}$ \\
\hline
\end{tabular}

NUMBER OF OBSERVATIONS $=12$.

Stanđard Errors computed from quadratic form of analytic first derivatives (Gauss)

Dependent variable: LRSPENDON $(r=1)$

Mean of dependent variable $=$

Std. dev. of dependent var. $=.706942$

Sum of squared residuals $=.167723$

Variance of residuals $\quad=\quad .013977$

Std. error of regression $\quad=\quad .118224$

R-squared $\quad=\quad .969494$

Durbin-Watson statistic $\quad=\quad 1.78689$ 
Dependent variable: LSPENDON ( $r=1, k=1)$

Mean of dependent variable $=18.0092$

Std. dev. of dependent var. $=\quad .837135$

Sum of squared residuals $\quad=\quad .676868$

Variance of residuals $\quad=\quad .056406$

Std. error of regression $=.237499$

R-squared $\quad=\quad .912375$

Durbin-Watson statistic . $=1.33860$

Dependent variable: LSPENDON ( $r=1, k=2)$

Mean of dependent variable $=18.3274$

Std. dev, of dependent var. $=.500615$

Sum of squared residuals $=.296740$

Variance of residuals .. $=.024728$

Std. error of regression $\quad \doteq .157252$

R-squared $\quad=\quad .892383$

Durbin-Watson statistic $\quad=1.61613$

Dependent variable: LSPENDON $(r=1, k=5)$

Mean of dependent variable $=15.5256$

Std. dev. of dependent var. $=1.38967$

Sum of squared residuals $\quad=\quad 1.58574$

Variance of residuals $\quad=\quad .132145$

Std. error of regression $=.363517$

R-squared $\quad=.925816$

Durbin-Watson statistic $\quad=\quad 1.33662$

\section{Onshore Exploration (Region 2)}

Equations are estimated for onshore region 2 and fuel type oil, gas, deep gas, and gas from tight sands. Coalbed methane is the residual. The forms of the equations are:

$$
\begin{aligned}
& \text { LRSPENDON }_{\mathrm{i}, \mathrm{r}, \mathrm{t}}= \ln (\mathrm{j} 0)_{\mathrm{i}, \mathrm{r}}+\mathrm{j} 1_{\mathrm{i}, \mathrm{r}} * \mathrm{LNSPENDON}_{\mathrm{i}, \mathrm{t}}+\mathrm{j} 2_{\mathrm{i}, \mathrm{r}} * \mathrm{RPROFON}_{\mathrm{irr}, \mathrm{t}} \\
& \text { for } \mathrm{i}=1, \mathrm{r}=2
\end{aligned}
$$

$$
\begin{aligned}
\text { LSPENDON }_{i, r, k, t}= & \ln (m 0)_{i, r, k}+m 1_{i, r, x} * \operatorname{LRSPENDON}_{i, r, t}+m 2_{i, r} * \text { PROFON }_{i, r, k, t}, \\
& \text { for } \mathrm{i}=1, \mathrm{r}=2, \mathrm{k}=1,2,3,4
\end{aligned}
$$

where,

$$
\begin{aligned}
& \text { LRSPENDON = natural logarithm of regional lower } 48 \text { onshore exploration drilling } \\
& \text { expenditures } \\
& \text { LNSPENDON }=\text { natural lagarithm of national onshore exploration drilling expenditures } \\
& \text { RPROFON }=\text { regional lower } 48 \text { onshore exploration profitability } \\
& \text { LSPENDON = natural logarithm of regional exploration drilling expenditures by fuel type } \\
& \text { PROFON }=\text { regional lower } 48 \text { onshore profitability by fuel type, region, and well type } \\
& \ln (\mathrm{m} 0), \mathrm{m} 1, \mathrm{~m} 2=\text { estimated parameters }
\end{aligned}
$$




$$
\begin{aligned}
\ln (\mathrm{j} 0), \mathrm{j} 1, \mathrm{j} 2 & =\text { estimated parameters } \\
\mathrm{i} & =\text { well type, } 1 \text { for exploratory } \\
\mathrm{I} & =\text { OGSM region } 2-\text { lower } 48 \text { onshore } \\
\mathrm{k} & =\text { fuel type, } 1 \text { for oil, } 2 \text { for shallow gas, } 3 \text { for deep gas, } 4 \text { for tight sands gas } \\
\mathrm{t} & =\text { year. }
\end{aligned}
$$

\section{Results}

\begin{tabular}{||l|l|}
\hline Parameter & Region 2 \\
\hline $\ln (j 0)$ & $\begin{array}{l}0.767012 \\
(1.0238)\end{array}$ \\
\hline $\mathrm{j} 1$ & $\begin{array}{l}0.921341 \\
(27.6019)\end{array}$ \\
\hline $\mathrm{j} 2$ & $\begin{array}{l}0.097049 \\
(2.68313)\end{array}$ \\
\hline
\end{tabular}

\begin{tabular}{||l|l|l|l|l|}
\hline Parameter & Oil & Shallow Gas & $\begin{array}{l}\text { Deep } \\
\text { Gas }\end{array}$ & Tight Sands Gas \\
\hline $\ln (\mathrm{m} 0)$ & $\begin{array}{l}-0.489236, \\
(-0.235955)\end{array}$ & $\begin{array}{l}-0.807742 \\
(-1.16427)\end{array}$ & $\begin{array}{l}0.645916 \\
(-0.410401)\end{array}$ & $\begin{array}{l}-12.4199 \\
(-2.66486)\end{array}$ \\
\hline $\mathrm{m} 1$ & $\begin{array}{l}0.920601 \\
(9.46363)\end{array}$ & $\begin{array}{l}1.01104 \\
(31.0589)\end{array}$ & $\begin{array}{l}0.965671 \\
(13.057)\end{array}$ & $\begin{array}{l}1.38756 \\
(6.34473)\end{array}$ \\
\hline $\mathrm{m} 2$ & $\begin{array}{l}0.017998 \\
(3.14252)\end{array}$ & $\begin{array}{l}0.017998 \\
(3.14252)\end{array}$ & $\begin{array}{l}0.017998 \\
(3.14252)\end{array}$ & $\begin{array}{l}0.017998 \\
(3.14252)\end{array}$ \\
\hline
\end{tabular}

\section{NUMBER OF OBSERVATIONS = 12}

Standard Errors computed from quadratic form of analytic first derivatives (Gauss)

Dependent variable: LRSPENDON $(r=2)$

$\begin{array}{lll}\text { Mean of dependent variable } & =21.3025 \\ \text { Std. dev. of dependent var. } & = & .714818 \\ \text { Sum of squared residuals } & = & .093124 \\ \text { Variance of residuals } & = & .776030 \mathrm{E}-02 \\ \text { Std. error of regression } & = & .088093 \\ \text { R-squared } & =.983432 \\ \text { Durbin-Watson statistic } & = & 1.10103\end{array}$

Dependent variable: LSPENDON $(\mathrm{r}=2, \mathrm{k}=1)$

Mean of dependent variable $=19.1297$

Std. dev. of dependent var. $=.713615$

Sum of squared residuals $\cdot=.645909$

Variance of residuals $\quad=.053826$

Std. error of regression $=.232004$

R-squared $\quad=\quad .885019$

Durbin-Watson statistic $\quad=\quad 1.26895$ 
Dependent variable: LSPENDON $(\mathrm{r}=2, \mathrm{k}=2)$..

Mean of dependent variable $=20.7413$

Std. dev. of dependent var. $=.724166$

Sum of squared residuals $=.071770$

Variance of residuals $\quad=\quad .598080 \mathrm{E}-02$

Std. error of regression $=.077336$

R-squared $\quad=.987569$

Durbin-Watson statistic $\quad=1.31390$

Dependent variable: LSPENDON ( $\mathrm{r}=2, \mathrm{k}=3$ )

Mean of dependent variable $=20.0448$

Std. dev. of dependent var. $=.726640$

Sum of squared residuals $=.366793$

Variance of residuals ... $=.030566$

Std. error of regression $=.174832$

R-squared $\quad=\quad .936848$

Durbin-Watson statistic $\quad=\quad 2.03077$

Dependent variable: LSPENDON $(r=2, k=4)$

Mean of dependent variable $=17.3020$

Std. dev. of dependent var. $=1.06899$

Sum of squared residuals $=3.29644$

Variance of residuals $=.274703$

Std. error of regression $=.524121$

R-squared $\quad=.740624$

Durbin-Watson statistic $\quad=\quad 2.03241$

\section{Onshore Exploration (Region 3)}

Equations are estimated for onshore region 3 and fuel type oil, gas, and deep gas. Gas from tight_sands is the residual. The form of the equations are:

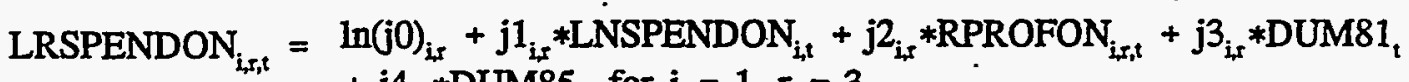

$$
\begin{aligned}
& +\mathrm{j} 4_{i, r} * \text { DUM85, for } \mathrm{i}=1, \mathrm{r}=3 \\
& \text { LSPENDON }_{i, r, k, t}=\ln (m 0)_{i, r, k}+m 1_{i, r, i} * \operatorname{LRSPENDON~}_{\mathrm{i}, \mathrm{r}, \mathrm{t}}+\mathrm{m} 2_{\mathrm{i}, \mathrm{r}} * \mathrm{PROFON}_{\mathrm{i}, \mathrm{k}, \mathrm{t}, \mathrm{t}} .
\end{aligned}
$$

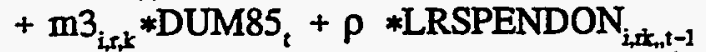

$$
\begin{aligned}
& -\rho *\left(\ln (m 0)_{i, r, \mathrm{k}}+\mathrm{m} 1_{\mathrm{i}, \mathrm{r}, \mathrm{k}} * \mathrm{LRSPENDON}_{\mathrm{i}, \mathrm{i}, \mathrm{i}-1}+\mathrm{m} 2_{\mathrm{i}, \mathrm{s}} * \text { PROFON }_{\mathrm{i}, \mathrm{r}, \mathrm{k}, \mathrm{t}-1}\right. \text {. } \\
& +m 3_{i, r, k} * D U M 85_{t-1} \text { ), for } i=1, r=3, k=1,2,3
\end{aligned}
$$

where,

$$
\begin{aligned}
\text { LRSPENDON } & =\begin{array}{l}
\text { natural logarithm of regional lower } 48 \text { onshore exploration drilling } \\
\text { expenditures }
\end{array} \\
\text { LNSPENDON } & =\text { natural logarithm of national onshore exploration drilling expenditures } \\
\text { RPROFON } & =\text { regional lower } 48 \text { onshore exploration profitability } \\
\text { LSPENDON } & =\text { natural logarithm of regional exploration drilling expenditures by fuel type }
\end{aligned}
$$


PROFON $=$ regional lower 48 onshore profitability by fuel type, region, and well type

DUM81 = 1 if $t>1980,0$ otherwise

DUM85 $=1$ if $\mathrm{t}>1984,0$ otherwise

$\ln (\mathrm{m} 0), \mathrm{m} 1, \mathrm{~m} 2, \mathrm{~m} 3=$ estimated parameters

$\ln (\mathrm{j} 0), \mathrm{j} 1, \mathrm{j} 2, \mathrm{j} 3, \mathrm{j} 4=$ estimated parameters

$\mathrm{i}=$ well type, 1 for exploratory

$r .=$ OGSM region 3 - lower 48 onshore

$\mathrm{k}^{*}=$ fuel type, 1 for oil, 2 for shallow gas, 3 for deep gas

$\mathrm{t}=$ year.

\section{Results}

\begin{tabular}{|c|c|}
\hline Parameter & Region 3 \\
\hline $\ln (j 0)$ & $\begin{array}{l}2.34293 \\
(1.86363)\end{array}$ \\
\hline j1 & $\begin{array}{l}0.795285 \\
(14.2917)\end{array}$ \\
\hline j2 & $\begin{array}{l}0.371542 \\
(2.25755)\end{array}$ \\
\hline j3 & $\begin{array}{l}0.306503 \\
(3.14782)\end{array}$ \\
\hline j4 & $\begin{array}{l}-0.3924 \\
(-4.47467)\end{array}$ \\
\hline
\end{tabular}

\begin{tabular}{|c|l|l|l||}
\hline Parameter & Oil & Shallow Gas & $\begin{array}{l}\text { Deep } \\
\text { Gas }\end{array}$ \\
\hline $\ln (\mathrm{m} 0)^{\circ}$ & $\begin{array}{l}2.6345 \\
(1.63611)\end{array}$ & $\begin{array}{l}9.59281 \\
(3.29023)\end{array}$ & $\begin{array}{l}-19.0403 \\
(-3.05085)\end{array}$ \\
\hline $\mathrm{m} 1$ & $\begin{array}{l}0.829685 \\
(10.3928)\end{array}$ & $\begin{array}{l}0.459266 \\
(3.03701)\end{array}$ & $\begin{array}{l}1.83544 \\
(6.08952)\end{array}$ \\
\hline $\mathrm{m} 2$ & $\begin{array}{l}0.016053 \\
(2.17509)\end{array}$ & $\begin{array}{l}0.016053 \\
(2.17509)\end{array}$ & $\begin{array}{l}0.016053 \\
(2.17509)\end{array}$ \\
\hline $\mathrm{m} 3$ & 0 & 0 & $\begin{array}{l}-0.603976 \\
(-1.34795)\end{array}$ \\
\hline$\rho$ & 0 & $\begin{array}{l}0.749598 \\
(3.70912)\end{array}$ & 0 \\
\hline
\end{tabular}

NUMBER OF OBSERVATIONS $=12$

Standard Errors computed from quadratic form of analytic first derivatives (Gauss)

Dependent variable: $L$ RSPENDON $(r=3)$

Mean of dependent variable $=20.1471$

Std. dev. of dependent var. $=.804846$

Sum of squared residuals $\quad=\quad .222834$ 
$\begin{array}{llll}\text { Variance of residuals } & = & \cdot & .018569 \\ \text { Std. error of regression } & = & .136270 \\ \text { R-squared } & = & .968859 \\ \text { Durbin-Watson statistic } & = & 2.35184\end{array}$

Dependent variable: LSPENDON $(r=3, k=1)$

Mean of dependent variable $=19.3645$

Std. dev. of dependent var. $=.706064$

Sum of squared residuals $=.725393$

Variance of residuals $=\quad .060449$

Std. error of regression $=.245865$

R-squared $\quad=\quad .867768$

Durbin-Watson statistic $\quad=\quad 1.82562$

Dependent variable: LSPENDON ( $\mathrm{r}=3, \mathrm{k}=2)$

Mean of dependent variable $=18.9470$

Std. dev. of dependent var. $=.551977$

Sum of squared residuals $=.168640$

Variance of residuals $\quad=\quad .014053$

Std. error of regression $=.118547$

R-squared $\quad=.950344$

Durbin-Watson statistic $\quad=1.58436$

Dependent variable: LSPENDON $(r=3, k=3)$

Mean of dependent variable $=18.1127$

Std. dev. of dependent var. $=1.84034$

Sum of squared residuals $. \quad=\quad 2.00930$

Variance of residuals $=.167442$

Std. error of regression $=.409196$

R-squared $\quad \cdot=.946386$

Durbin-Watson statistic $\quad=\quad 2.60760$

\section{Onshore Exploration (Region 4)}

Equations are estimated for onshore region 4 and fuel type oil, gas, and deep gas. Gas from tight sands is the residual. The forms of the equations are:

$$
\begin{aligned}
& \text { LRSPENDON }_{i, r, t}=\ln (j 0)_{i, r}+j 1_{i, s} * \text { LNSPENDON }_{i, t}+j 2_{i, r} * \text { RDCFON }_{i, r, t} \\
& +j 3_{i, r} * D U M 81_{\mathfrak{t}} \text {, for } \mathrm{i}=1, \mathrm{r}=4 \\
& \text { LSPENDON }_{i, r, k, t}=\ln (m 0)_{i, r, k}+m 1_{i, r, k} * \operatorname{LRSPENDON~}_{i, r, t}+m 2_{i, r} * \text { DCFON }_{i, r, k, t}
\end{aligned}
$$

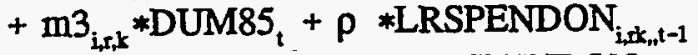

$$
\begin{aligned}
& \text { - } \rho *\left(\ln (\mathrm{m} 0)_{\mathrm{i}, \mathrm{r}, \mathrm{k}}+\mathrm{m} 1_{\mathrm{i}, \mathrm{r}, \mathrm{k}} * \mathrm{LRSPENDON}_{\mathrm{i}, \mathrm{r}, \mathrm{l}-\mathrm{i}}+\mathrm{m} 2_{\mathrm{i}, \mathrm{i}} * \mathrm{DCFON}_{\mathrm{i}, \mathrm{r}, \mathrm{k}, \mathrm{l}-1}\right. \\
& \left.+\mathrm{m}_{\mathrm{i}, \mathrm{s}, \mathrm{L}} * \mathrm{DUM}_{\mathrm{i}} \mathrm{i-1}\right) \text {, for } \mathrm{i}=1, \mathrm{r}=4, \mathrm{k}=1,2,3
\end{aligned}
$$

where,

$$
\text { LRSPENDON }=\begin{aligned}
& \text { natural logarithm } \\
& \text { expenditures }
\end{aligned}
$$


LNSPENDON = natural logarithm of national onshore exploration drilling expenditures

RDCFON $=$ regional lower 48 onshore exploration discounted cash flow

LSPENDON $=$ natural logarithm of regional exploration drilling expenditures by fuel type

DCFON $=$ regional lower 48 onshore discounted cash flow by fuel type, region, and well type

DUM81 = 1 if $t>1980,0$ otherwise

DUM85 = 1 'if $t>1984,0$ otherwise

$\ln (\mathrm{m} 0), \mathrm{m} 1, \mathrm{~m} 2, \mathrm{~m}^{\circ}=$ estimated parameters

$\ln (\mathrm{j} 0), \mathrm{j} 1, \mathrm{j} 2, \mathrm{j} 3=$ estimated parameters

$i=$ well type, 1 for exploratory

$r=$ OGSM region 4 - lower 48 onshore

$\mathrm{k} \cdot$ : fuel type, 1 for oil, 2 for shallow gas, 3 for deep gas

$\mathrm{t}=$ year.

Results

\begin{tabular}{|l|l|}
\hline Parameter & Region 4 \\
\hline $\ln (0)$. & $\begin{array}{l}-1.45810 \\
(-1.48729)\end{array}$ \\
\hline $\mathrm{j} 1$ & $\begin{array}{l}0.945157 \\
(21.0086)\end{array}$ \\
\hline $\mathrm{j} 2$ & $\begin{array}{l}-123032 \mathrm{E}-06 \\
(7.60599)\end{array}$ \\
\hline $\mathrm{j} 3$ & $\begin{array}{l}0.252528 \\
(7.65593)\end{array}$ \\
\hline
\end{tabular}

\begin{tabular}{||l|l|l|l|}
\hline Parameter & Oil & Shallow Gas & $\begin{array}{l}\text { Deep } \\
\text { Gas }\end{array}$ \\
\hline $\ln (\mathrm{m} 0)$ & $\begin{array}{l}3.41611 \\
(3.08093)\end{array}$ & $\begin{array}{l}3.33533 \\
(0.395282)\end{array}$ & $\begin{array}{l}0.654032 \\
(0.230051)\end{array}$ \\
\hline $\mathrm{m} 1$ & $\begin{array}{l}0.801938 \\
(13.7213)\end{array}$ & $\begin{array}{l}0.605145 \\
(8.69175)\end{array}$ & $\begin{array}{l}0.792526 \\
(5.45035)\end{array}$ \\
\hline $\mathrm{m} 2$ & $\begin{array}{l}0.961670 \mathrm{E}-08 \\
(8.20276)\end{array}$ & $\begin{array}{l}0.961670 \mathrm{E}-08 \\
(8.20276)\end{array}$ & $\begin{array}{l}0.961670 \mathrm{E}-08 \\
(8.20276)\end{array}$ \\
\hline $\mathrm{m} 3$ & 0 & 0 & $\begin{array}{l}-0.805161 \\
(-7.15158)\end{array}$ \\
\hline$\dot{p}$ & 0.725806 & $\begin{array}{l}0.966799 \\
(11.9838)\end{array}$ & 0 \\
\hline
\end{tabular}

NUMBER OF OBSERVATIONS $=12$

Standard Errors computed from quadratic form of analytic first derivatives (Gauss)

Dependent variable: LRSPENDON $(r=4)$

Mean of dependent variable $=19.8426$

Std. dev. of dependent var. $=.891531$ 


$\begin{array}{lll}\text { Sum of squared residuals } & = & .169969 \\ \text { Variance of residuals } & = & .014164 \\ \text { Std. error of regression } & = & .119013 \\ \text { R-squared } & = & .980632 \\ \text { Durbin-Watson statistic } & = & 1.43017 .\end{array}$

Dependent variable: LSPENDON ( $r=4, k=1)$

Mean of dependent variable $=19.2357$

Std. dev. of dependent var. $=.703305$

Sum of squared residuals $=.071847$

Variance of residuals $\quad=\quad .598725 \mathrm{E}-02$

Std. error of regression $=.077377$

R-squared . $\cdot \quad=.988573$

Durbin-Watson statistic $\quad=\quad 2.28567$

Dependent variable: LSPENDON ( $r=4, k=2)$

Mean of dependent variable $=.18 .6145$

Std. dev. of dependent var. $=1.02953$

Sum of squared residuals $=.421928$

Variance of residuals $\quad=\quad .035161$

Std. error of regression $=.187512$

R-squared $\quad=\quad .963812$

Durbin-Watson statistic . $=2.09314$

Dependent variable: LSPENDON $(r=4, k=3)$.

- Mean of dependent variable $=17.5208$

Std. dev. of dependent var. $=1.68658$

Sum of squared residuals $=3.32057$

Variance of residuals $=.276714$

Std. error of regression $\quad=\quad .526036$

R-squared : $\quad=.899212$

Durbin-Watson statistic = $\quad 1.76114$

\section{Onshore Exploration (Region 5)}

Equations are estimated for onshore region 5 and fuel type oil, gas, and deep gas. Gas from tight sands is the residual. The forms of the equations are:

$$
\begin{aligned}
& \begin{aligned}
\text { LRSPENDON }_{\mathrm{i}, \mathrm{r}, \mathrm{t}}= & \ln (\mathrm{j} 0)_{\mathrm{i}, \mathrm{r}}+\mathrm{j} 1_{\mathrm{i}, \mathrm{r}} * \mathrm{LNSPENDON}_{\mathrm{i}, \mathrm{t}}+\mathrm{j} 2_{\mathrm{i}, \mathrm{r}} * \mathrm{RDCFON}_{\mathrm{i}, \mathrm{r}, \mathrm{t}} \\
& +\mathrm{j} 3_{\mathrm{i}, \mathrm{r}} * \mathrm{DUM} 81_{\mathrm{t}} \text {, for } \mathrm{i}=1, \mathrm{r}=4
\end{aligned}
\end{aligned}
$$

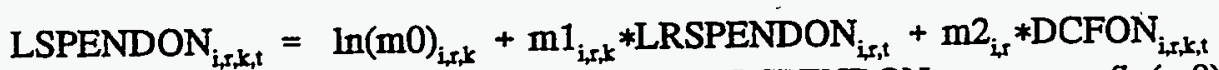

$$
\begin{aligned}
& +m 3_{i, r, t} * \text { DUM85, }+\rho * \text { LRSPENDON }_{i, r, t, t-1}-\rho *\left(\ln (\mathrm{m} 0)_{i, r, k}\right.
\end{aligned}
$$

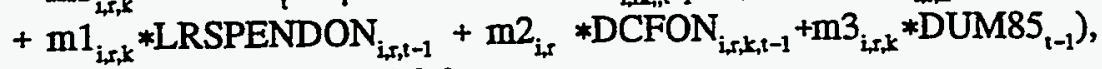

$$
\begin{aligned}
& \text { for } \mathrm{i}=1, \mathrm{r}=4, \mathrm{k}=1,2,3
\end{aligned}
$$

where, 


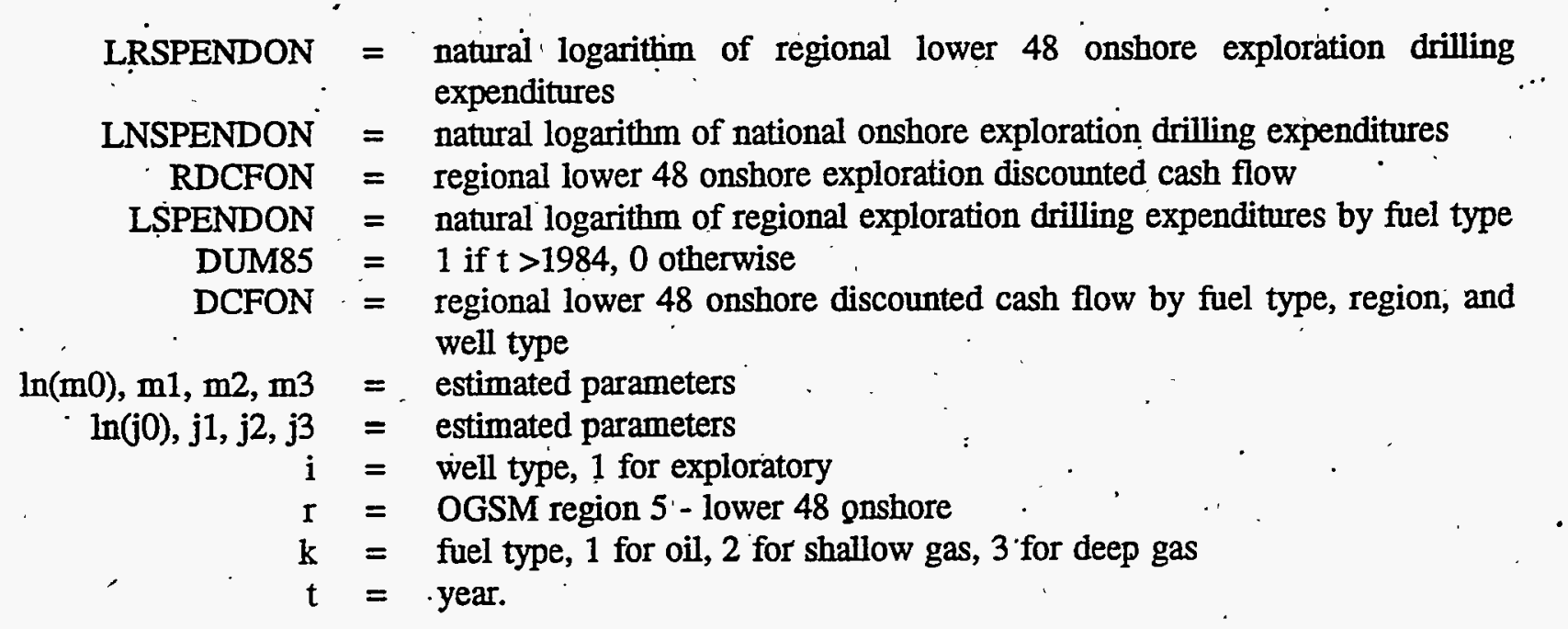

Results

\begin{tabular}{||l|l|}
\hline Parameter & Region 5 \\
\hline $\ln (\mathrm{j0})$ & $\begin{array}{l}-4.95312 \\
(-3.56009)\end{array}$ \\
\hline $\mathrm{j} 1$ & $\begin{array}{l}1.13564 \\
(18.6951)\end{array}$ \\
\hline $\mathrm{j} 2$ & $\begin{array}{l}0.218768 \\
(2.62479)\end{array}$ \\
\hline$\rho$ & 0.288272 \\
& $(1.23667)$ \\
\hline
\end{tabular}

\begin{tabular}{|c|c|c|c|c|}
\hline Parameter & Oil & Shallow Gas & $\begin{array}{l}\text { Deep } \\
\text { Gas }\end{array}$ & $\begin{array}{l}\text { Tight } \\
\text { Sands Gas }\end{array}$ \\
\hline $\ln (m 0)$ & $\begin{array}{l}-1.5552 \\
(-1.99924)\end{array}$ & $\begin{array}{l}-2.63902 \\
(-0.704541)\end{array}$ & $\begin{array}{l}4.42696 \\
(0.683096)\end{array}$ & $\begin{array}{l}-32.3394 \\
(-4.55217)\end{array}$ \\
\hline $\mathrm{m} 1$ & $\begin{array}{l}1.05225 \\
(27.5546)\end{array}$ & $1.03206(5.6106)$ & $\begin{array}{l}0.63925 \\
(2.12698)\end{array}$ & $\begin{array}{l}2.36706 \\
(6.90103)\end{array}$ \\
\hline $\mathrm{m} 2$ & $\begin{array}{l}0.00814 \\
(4.70887)\end{array}$ & $\begin{array}{l}0.00814 \\
(4.70887)\end{array}$ & $\begin{array}{c}-0.00814 \\
(4.70887)\end{array}$ & $\begin{array}{l}0.00814 \\
(4.70887)\end{array}$ \\
\hline $\mathrm{m} 3$ & 0 & 0 & $\begin{array}{l}0.568265 \\
(8.86446)\end{array}$ & 0 \\
\hline $\mathrm{m4}$ & 0 & 0 & 0 & $\begin{array}{l}1.24453 \\
(3.50624)\end{array}$ \\
\hline$\rho$ & 0 . & $\begin{array}{l}0.711064 \\
(4.66985)\end{array}$ & $\begin{array}{l}0.714691 \\
(9.32235)\end{array}$ & $\begin{array}{l}0.254105 \\
(2.01547)\end{array}$ \\
\hline
\end{tabular}

\section{NUMBER OF OBSERVATIONS $=12$}

Standard Errors computed from quadratic form of analytic first derivatives (Gauss) 
Dependent variable: LRSPENDON $(r=5)$

Mean of dependent variable $=20.3989$

Std. dev. of dependent var. $={ }^{\cdot} .925430$

Sum of squared residuals $=.251044$

Variance of residuals $=.020920$

Std. error of regression $=.144638$

R-squared $=.978652$

Durbin-Watson statistic $\quad=\quad 1.36313$

Dependent variable: LSPENDON $(r=5, \vec{k}=1)$

Mean of dependent variable $=19.9141$

Std. dev. of dependent var. $=.858486$

Sum of squared residuals $\quad=\quad .396987$

Variance of residuals .. $=.033082$

Std. error of regression $=.181885$

R-squared $\quad=.973290$

Durbin-Watson statistic $\quad=1.09339$

Dependent variable: LSPENDON $(r=5, k=2)$

Mean of dependent variable $=\quad 18.5807$

Std. dev. of dependent var. $=1.06612$

Sum of squared residuals $=.838736$

Variance of residuals $\quad=\quad .069895$

Std. error of regression $=\quad .264376$

R-squared $\quad=\quad .945438$

Durbin-Watson statistic $\quad=\quad 1.67465$

Dependent variable: LSPENDON $(r=5, k=3)$

Mean of dependent variable $=18.3465$

Std. dev. of dependent var. $=1.53439$

Sum of squared residuals $=-8.32229$

Variance of residuals $=.693524$

Std. enror of regression $\quad=\quad .832781$

$\begin{array}{lll}\text { R-squared } \quad & =.748819\end{array}$

Durbin-Watson statistic $\quad=\quad .855119$

Dependent variable: LSPENDON ( $\mathrm{r}=5, \mathrm{k}=4)$

Mean of dependent variable $=16.2087$

Std. dev. of dependent var. $=\quad 1.71344$

Sum of squared residuals $=\mathbf{8 . 0 7 3 1 3}$

Variance of residuals $=.672761$

Std. error of regression $=\quad .820220$

R-squared $\quad=\quad .757474$

Durbin-Watson statistic $\quad=\quad 1.74222$

\section{Onshore Exploration (Region 6)}

Equations are estimated for onshore region 6 and fuel type gas. Oil is the residual. The forms of the equations are: 
LRSPENDON $_{i, r, i}=\ln (j 0)_{i, r}+j 1_{i, r} *$ LNSPENDON $_{i, t}+j 2_{i, r} *$ PROFON $_{i, s, t}$ for $i=1, r=4$

$$
\begin{aligned}
& \text { LSPENDON }_{\mathrm{i}, r, \mathrm{k}, \mathrm{t}}=\ln (\mathrm{m} 0)_{\mathrm{i}, \mathrm{r}, \mathrm{k}}+\mathrm{m} 1_{\mathrm{i}, \mathrm{r}, \mathrm{k}} * \mathrm{LRSPENDON}_{\mathrm{i}, \mathrm{r}, \mathrm{t}}+\mathrm{m} 2_{\mathrm{ir}, \mathrm{PROFON}} * \mathrm{PRO}_{\mathrm{i}, \mathrm{k}, \mathrm{r}, \mathrm{r}} \\
& +\mathrm{m}_{\mathrm{i}, \mathrm{k}} * \mathrm{DUM} 85_{\mathrm{r}}+\rho * \mathrm{LRSPENDON}_{\mathrm{i}, \mathrm{k} k, \mathrm{t}-1}-\rho *\left(\ln (\mathrm{m} 0)_{\mathrm{i}, \mathrm{r}, \mathrm{k}}\right. \\
& \left.+\mathrm{m}_{\mathrm{i}, \mathrm{r}, \mathrm{L}} * \mathrm{LRSPENDON}_{\mathrm{i}, \mathrm{i}-1}+\mathrm{m} 2_{\mathrm{i}, \mathrm{r}} * \mathrm{PROFON}_{\mathrm{i}, \mathrm{r}, \mathrm{k}, \mathrm{t}-1}+\mathrm{m} 3_{\mathrm{i}, \mathrm{r}, \mathrm{k}} * \mathrm{DUM} 85_{\mathrm{t}-1}\right) \text {, } \\
& \text { for } \mathrm{i}=1, \mathrm{r}=4, \mathrm{k}=1,2,3
\end{aligned}
$$

where,

$$
\begin{aligned}
\text { LRSPENDON } & =\begin{array}{l}
\text { natural logarithm of regional lower } 48 \text { onshore exploration drilling } \\
\text { expenditures }
\end{array} \\
\text { LNSPENDON } & =\text { natural logarithm of national onshore exploration drilling expenditures } \\
\text { RPROFON } & =\text { regional lower } 48 \text { onshore exploration relative profitability } \\
\text { LSPENDON } & =\text { natural logarithm of regional exploration drilling expenditures by fuel type } \\
\text { PROFON } & =\text { regional lower } 48 \text { onshore relative profitability by fuel type, region, and well } \\
1 \text { DUM85 } & =1 \text { if } \mathrm{t}>1984,0 \text { otherwise } \\
\ln (\mathrm{m} 0), \mathrm{m} 1, \mathrm{~m} 2, \mathrm{~m} 3 & =\text { estimated parameters } \\
\ln (\mathrm{j} 0), \mathrm{j} 1, \mathrm{j} 2, \mathrm{j} 3 & =\text { estimated parameters } \\
\mathrm{i} & =\text { well type, } 1 \text { for exploratory } \\
\mathrm{I} & =\text { OGSM region } 4-\text { lower } 48 \text { onshore } \\
\mathrm{k} & =\text { fuel type, } 1 \text { for oil, } 2 \text { for shallow gas, } 3 \text { for deep gas } \\
\mathrm{t} & =\text { year. }
\end{aligned}
$$

\section{Results}

\begin{tabular}{||l|l|}
\hline Parametei & Region 6 \\
\hline $\ln (\mathrm{j} 0)$ & $\begin{array}{l}-3.49089 \\
(-1.37169)\end{array}$ \\
\hline $\mathrm{j} 1$ & $\begin{array}{l}0.978141 \\
(9.27303)\end{array}$ \\
\hline $\mathrm{j} 2$ & $\begin{array}{l}0.591528 \\
(1.16399)\end{array}$ \\
\hline
\end{tabular}

\begin{tabular}{||l|l|}
\hline Parameter & Shallow Gas \\
\hline $\ln (\mathrm{m} 0)$ & $\begin{array}{l}-2.04086 \\
(-2.61989)\end{array}$ \\
\hline $\mathrm{ml}$ & $\begin{array}{l}1.07123 \\
(26.8055)\end{array}$ \\
\hline $\mathrm{m} 2$ & $\begin{array}{l}0.089420 \\
(3.41456)\end{array}$ \\
\hline $\mathrm{m} 3$ & $\begin{array}{l}0.488085 \\
(9.36964)\end{array}$ \\
\hline
\end{tabular}


NUMBER OF OBSERVATIONS $=12$

Standard Errors computed from quadratic form of analytic first derivatives (Gauss)

Dependent variable: LRSPENDON $(\mathrm{r}=6)$

Mean of dependent variable $=\quad 18.5937$

Std. dev. of dependent var. $=.767280$

Sum of squared residuals $\quad=\quad .718589$

Variance of residuals $\quad=\quad 059882$

Std. error of regression $\quad=.244709$

R-squared $\quad=.889036$

Durbin-Watson statistic $\quad=\quad 2.22591$

Dependent variable: LSPENDON $(r=6, k=2)$

Mean of dependent variable $=18.2553$

Std. dev. of dependent var. $=.582301$

Sum of squared residuals $=.022529$

Variance of residuals $\quad=. \quad .187738 \mathrm{E}-02$

Std. error of regression $=.043329$

R-squared $\quad=\quad .993960$

Durbin-Watson statistic $\quad=\quad 2.29105$

\section{Onshore Regional Development Expenditure Equations}

Regional development expenditure equations for onshore regions 1 through 5 were estimated using SURE. The generalized difference form was used where problems with first order serial correlation were indicated. Development expenditures for onshore region 6 are estimated as the residual.

Regional development expenditures are hypothesized to be a function of the level of national development expenditures, the regional development drilling DCF, and the national development drilling DCF: Dummy variables are included to capture the effects of structural change.

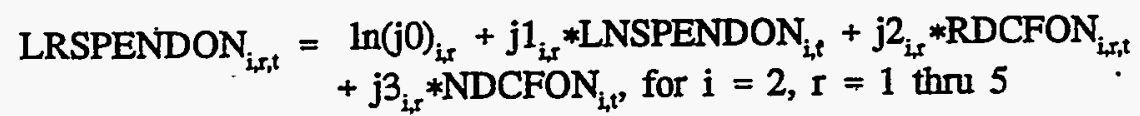

where,

$$
\begin{aligned}
\text { LRSPENDON } & =\begin{array}{l}
\text { natural logarithm of regional lower } 48 \text { onshore development drilling } \\
\text { expenditures }
\end{array} \\
\text { LNSPENDON } & =\text { natural logarithm of national onshore development drilling expenditures } \\
\text { RDCFON } & =\text { regional lower } 48 \text { onshore discounted cash flow } \\
\text { NDCFON } & =\text { national lower } 48 \text { onshore discounted cash flow } \\
\ln (\mathrm{j} 0), \mathrm{j} 1, \mathrm{j} 2, \mathrm{j} 3, \mathrm{j} 4, \mathrm{j} 5 & =\text { estimated parameters } \\
\rho & =\text { autocorrelation parameter } \\
\mathrm{i} & =\text { well type, } 2 \text { for development } \\
\mathrm{r} & =\text { OGSM regions, } 1, \ldots ., 5 \text { for lower } 48 \text { onshore } \\
\mathrm{t} & =\text { year. }
\end{aligned}
$$


Results

\begin{tabular}{||l|l|l|l|l|l|}
\hline Parameter & Region 1 & Region 2 & Region 3 & Region 4. & Region 5 \\
\hline $\ln (0)$. & $\begin{array}{l}-0.328993 \\
(-0.260500)\end{array}$ & $\begin{array}{l}2.00109 \\
(2.68494)\end{array}$ & $\begin{array}{l}-6.89848 \\
(-6.95171)\end{array}$ & $\begin{array}{l}-1.83753 \\
(-1.83484)\end{array}$ & $\begin{array}{l}-7.03343 \\
(-6.07903)\end{array}$ \\
\hline$j 1$ & $\begin{array}{l}0.924889 \\
(17.0591)\end{array}$ & $\begin{array}{l}0.866073 \\
(26.7563)\end{array}$ & $\begin{array}{l}1.23527 \\
(28.9375)\end{array}$ & $\begin{array}{l}1.00379 \\
(23.3128)\end{array}$ & $\begin{array}{l}1.20832 \\
(24.3657)\end{array}$ \\
\hline$j 2$ & $\begin{array}{l}0.205175 \mathrm{E}-06 \\
(2.69556)\end{array}$ & $\begin{array}{l}0.205175 \mathrm{E}-06 \\
(2.69556)\end{array}$ & $\begin{array}{l}0.205175 \mathrm{E}-06 \\
(2.69556)\end{array}$ & $\begin{array}{l}0.205175 \mathrm{E}-06 \\
(2.69556)\end{array}$ & $\begin{array}{l}0.205175 \mathrm{E}-06 \\
(2.69556)\end{array}$ \\
\hline$j 3$ & $\begin{array}{l}-0.368489 \mathrm{E}-06 \\
(-3.46031)\end{array}$ & $\begin{array}{l}-0.368489 \mathrm{E}-06 \\
(-3.46031)\end{array}$ & $\begin{array}{l}-0.368489 \mathrm{E}-06 \\
(-3.46031)\end{array}$ & $\begin{array}{l}-0.368489 \mathrm{E}-06 \\
(-3.46031)\end{array}$ & $\begin{array}{l}-0.368489 \mathrm{E}-06 \\
(-3.46031)\end{array}$ \\
\hline
\end{tabular}

NUMBER OF OBSERVATIONS $=16$

Dependent variable: LRSPENDON $_{\mathrm{is,t}}(\mathrm{i}=2$, development, $\mathrm{r}=1$ )

Mean of dependent variable $=21.1896$

Std. dev. of dependent var. $\quad=.596760$

Sum of squared residuals $=.162495$

Variance of residuals $\quad=\quad .013541$

Std. error of regression $=-.116367$

R-squared $\quad=.958519$

、 Durbin-Watson statistic $\quad=\quad 1.43127$

Dependent variable: LRSPENDON $_{\mathrm{ix,t}}(\mathrm{i}=2$, development, $\mathrm{x}=2$ )

Mean of dependent variable $=22.2359$

Std. dev. of dependent var. $=\mathbf{5 8 9 0 7 4}$

Sum of squared residuals $\quad=\quad .045061$

Variance of residuals $\quad=\quad .375511 \mathrm{E}-02$

Std. error of regression $=\quad .061279$

R-squared $\quad=.988196$

Durbin-Watson statistic - $\quad=\quad 1.31307$

Dependent variable: LRSPENDON $_{\mathrm{i}, \mathrm{r}, \mathrm{t}}(\mathrm{i}=2$, development, $\mathrm{r}=3$ )

Mean of dependent variable $=21.8572$

Std. dev. of dependent var. $=.791100$

Sum of squared residuals $\quad=.097615$

Variance of residuals $=.813458 \mathrm{E}-02$

Std. error of regression $=.090192$

R-squared $\quad=\quad .985821$

Durbin-Watson statistic $\quad=\quad 1.50440$

Dependent variable: , LRSPENDON $\mathrm{i}_{\mathrm{i}, \mathrm{t}}(\mathrm{i}=2$, development, $\mathrm{r}=4)$

Mean of dependent variable $=21.5138$

Std. dev. of dependent var. $=.643659$

Sum of squared residuals $=.101132$.

Variance of residuals $\quad=\quad .842766 \mathrm{E}-02$

Std. enror of regression $=\quad .091802$.

R-squared $\quad=.977809$

Durbin-Watson statistic $\quad=.601830$.

E-20 Energy Information AdministrationJOIl and Gas Supply Module Documentation 
Dependent variable: LRSPENDON $_{\mathrm{i}, \mathrm{si}}(\mathrm{i}=2$, development, $\mathrm{r}=5$ )

Mean of dependent variable $=21.1521$

Std. dev. of dependent var. $=.790516$

Sum of squared residuals $=.138403$

Variance of residuals $\quad=\quad .011534$

Std. error of regression $\quad=\quad .107394$

R-squared $\quad=\quad .979870$

Durbin-Watson statistic ${ }^{\prime}=1.13682$

\section{Intraregional Development Expenditure Equations by Fuel Type}

For each of the six onshore regions, a block of development expenditure equations, by fuel type, was estimated using SURE. Where first order serial correlation was indicated to be a potential problem, equations were estimated in generalized difference form. In each region, development expenditures for one fuel type were estimated as the residual.

Generally, intraregional development expenditures by fuel are a function of regional development expenditures and the relative profitability of development drilling by fuel type (measured as the ratio of the intraregional development drilling $\mathrm{DCF}$ for the fuel type to the regional development drilling $\mathrm{DCF}$ ). In specific instances, dummy variables are also included.

\section{Region 1}

Development expenditures for tight sands are calculated as a residual. The form of the equation is:

$$
\begin{aligned}
& \text { LSPENDON }_{i, r, k, t}=\ln (s 0)_{i, r, k}+s 1_{i, r, k} * \operatorname{LRSPENDON}_{i, r, t}+s 2_{i, r} * \text { PROFON }_{i, r, k, t}
\end{aligned}
$$

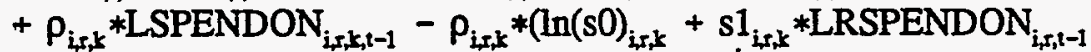

$$
\begin{aligned}
& +s 2_{i, r} * P_{R O F O N} N_{i, k, t-1} \text { ) for } i=2, r=1, k=1,2,5
\end{aligned}
$$

where,

$\begin{aligned} \text { LSPENDON } & =\text { natural logarithm of regional development drilling expenditures by fuel type } \\ \text { LRSPENDON } & =\text { natural logarithm of regional development drilling expenditures } \\ \text { PROFON } & =\text { regional lower } 48 \text { onshore profitability by fuel type; region, and well type } \\ \ln (\mathrm{s} 0), \mathrm{s} 1, \mathrm{~s} 2 & =\text { estimated parameters } \\ \mathrm{P} & =\text { autocorrelation parameter } \\ \mathrm{i} & =\text { well type, } 2 \text { for development } \\ \mathrm{r} & =\text { OGSM region } 1 \text { for lower } 48 \text { onshore } \\ \mathrm{k} & =\text { fuel type, } 1 \text { for oil, } 2 \text { for shallow gas, } 5 \text { for } \text { devonian shale gas } \\ \mathrm{t} & =\text { year. }\end{aligned}$




\section{Results}

\begin{tabular}{|c|c|c|c|}
\hline Parameter & Shallow Oil & Shallow Gas & Devonian Shale \\
\hline $\operatorname{In}(s 0)$ & $\begin{array}{l}-3.85074 \\
(-1.95987)\end{array}$ & $\begin{array}{l}14.3975 \\
(3.00266) \\
\end{array}$ & $\begin{array}{l}3.67775 \\
(1.24357)\end{array}$ \\
\hline$s 1$ & $\begin{array}{l}1.11260 \\
(12.0915)\end{array}$ & $\begin{array}{l}0.207589 \\
(.883234)\end{array}$ & $\begin{array}{l}0.727338 \\
(5.16832)\end{array}$ \\
\hline$\dot{s} 2$ & $\begin{array}{l}0.206063 \\
(2.11223)\end{array}$ & $\begin{array}{l}0.206063 \\
(2.11223)\end{array}$ & $\begin{array}{l}0.206063 . \\
(2.11223)\end{array}$ \\
\hline$p$ & 0 & $\begin{array}{l}0.749494 \\
(6.99264)\end{array}$ & 0 \\
\hline
\end{tabular}

\section{NUMBER OF OBSERVATIONS $=12$}

Standard Errors computed from heteroscedastic-consistent matrix (Robust-White)

Dependent variable: LSPENDON ( $\mathrm{i}=2, \mathrm{r}=1, \mathrm{k}=1$ - oil)

$\begin{array}{lll}\text { Mean of dependent variable } & = & 19.9828 \\ \text { Std. dev. of dependent var. } & = & .728414 \\ \text { Sum of squared residuals } & = & .526223 \\ \text { Variance of residuals } & = & .043852 \\ \text { Std. error of regression } & = & .209408 \\ \text { R-squared- } & = & .912655 \\ \text { Durbin-Watson statistic } & = & 1.86756\end{array}$

Dependent variable: LSPENDON ( $\mathrm{i}=2, \mathrm{r}=1, \mathrm{k}=2$ - shallow gas)
Mean of dependent variable $=19.3857$
Std. dev. of dependent var. $=.460686$
Sum of squared residuals $\cdot=.547551$
Variance of resiđuals $=.045629$
Std. error of regression $=.213610$
R-squared $\quad \therefore \quad=.771214$
Durbin-Watson statistic $\quad=\quad 1.40108$

Dependent variable: LSPENDON ( $\mathrm{i}=2, \mathrm{r}=1, \mathrm{k}=5$ - devonian shale)

Mean of dependent variable $=19.1834$

Std. dev. of dependent var. ${ }^{\prime}=\quad .547122$.

Sum of squared residuals $\quad=\quad .851866$

Variance of residuals $\quad=\quad .070989$

Std. error of regression $=.266437$

R-squared $\quad=.756550$

Durbin-Watson statistic $\quad \cdot=1.36594$ 


\section{Region 2}

Development expenditures for coalbed methane are calculated as a residual. The form of the equation is:

$$
\begin{aligned}
& \text { LSPENDON }_{\mathrm{i}, \mathrm{r}, \mathrm{k}, \mathrm{t}}=\ln (\mathrm{s} 0)_{\mathrm{i}, \mathrm{r}, \mathrm{k}}+s 1_{\mathrm{i}, \mathrm{k}, \mathrm{k}} * \mathrm{LRSPENDON}_{\mathrm{i}, \mathrm{r}, \mathrm{t}}+s 2_{\mathrm{i}, \mathrm{r}} * \mathrm{PROFON}_{\mathrm{i}, \mathrm{k}, \mathrm{k}, \mathrm{f}} \\
& +\rho_{i, r, k} * \operatorname{LSPENDON}_{i, r, \mathrm{k}, \mathrm{t}-1}-\rho_{\mathrm{i}, \mathrm{r}, \mathrm{k}} *\left(\ln (\mathrm{s} 0)_{\mathrm{i}, \mathrm{r}, \mathrm{k}}+\mathrm{s} 1_{\mathrm{i}, \mathrm{r}, \mathrm{k}} * \mathrm{LRSPENDON}_{\mathrm{i}, \mathrm{r}, \mathrm{l}-1}\right. \\
& +s 2_{i, r} * P_{R O F O N}{ }_{i, r, k, t-1} \text { ) for } \mathrm{i}=2, \mathrm{r}=2, \mathrm{k}=1,2,3,4
\end{aligned}
$$

where,

$$
\begin{aligned}
\text { LSPENDON } & =\text { natural logarithm of regional exploration drilling expenditures by fuel type } \\
\text { LRSPENDON } & =\text { natural logarithm of regional exploration drilling expenditures } \\
\text { PROFON } & =\text { regional lower } 48 \text { onshore profitability by fuel type, region, and well type } \\
\ln (\mathrm{s} 0), \mathrm{s} 1, \mathrm{~s} 2 & =\text { estimated parameters } \\
\mathrm{\rho} & =\text { autocorrelation parameter } \\
\mathrm{i} & =\text { well type, } 2 \text { for development } \\
\mathrm{r} & =\text { OGSM region } 1 \text { for lower } 48 \text { onshore } \\
\mathrm{k} & =\text { fuel type, } 1 \text { for oil, } 2 \text { for shallow gas, } 4 \text { for deep gas, } 4 \text { for tight sands gas } \\
\mathrm{t} & =\text { year. }
\end{aligned}
$$

\section{Results}

\begin{tabular}{||l|l|l|l|l||}
\hline Parameter & Shallow Oil & Shallow Gas & Deep Gas & Tight Sands \\
\hline $\ln (s 0)$ & $\begin{array}{l}-4.89929 \\
(-2.64373)\end{array}$ & $\begin{array}{l}0.617139 \\
(0.353505)\end{array}$ & $\begin{array}{l}1.49006 \\
(0.691671)\end{array}$ & $\begin{array}{l}-6.12426 \\
(-1.52784)\end{array}$ \\
\hline$s 1$ & $\begin{array}{l}1.17351 \\
(14.0801)\end{array}$ & $0.924058(11.7571)$ & $\begin{array}{l}0.837339 \\
(8.61441)\end{array}$ & $1.16258(6.44739)$ \\
\hline$s 2$ & $\begin{array}{l}0.032426 \\
(4.30165)\end{array}$ & $0.032426(4.30165)$ & $\begin{array}{l}0.032426 \\
(4.30165)\end{array}$ & $\begin{array}{l}0.032426 \\
(4.30165)\end{array}$ \\
\hline$\rho$ & & $0.370986(3.48406)$ & & $\begin{array}{l}0.396205 \\
(6.22141)\end{array}$ \\
\hline
\end{tabular}

Standard Errors computed from quadratic form of analytic first derivatives (Gauss)

\section{NUMBER OF OBSERVATIONS $=12$}

Dependent variable: LSPENDON ( $\mathrm{i}=2, \mathrm{r}=2, \mathrm{k}=1$ - oil)

$\begin{array}{lll}\text { Mean of dependent variable. } & = & 21.2108 \\ \text { Std. dev. of dependent var. } & = & .705888 \\ \text { Sum of squared residuals } & = & .381309 \\ \text { Variance of residuals } & = & .031776 \\ \text { Std. error of regression } & = & .178257 \\ \text { R-squared } & = & .930757 \\ \text { Durbin-Watson statistic } & = & 1.94394\end{array}$

Dependent variable: LSPENDON ( $\mathrm{i}=2, \mathrm{r}=2, \mathrm{k}=2$ - shallow gas)

Mean of dependent variable $=.21 .2300$

Std. dev. of dependent var. $=.603890$ 
Sum of squared residuals

Variance of resicuals

Std. error of regression

R-squared

Durbin-Watson statistic

$$
\begin{array}{ll}
= & .199042 \\
= & .016587 \\
= & .128790 \\
= & .952539 \\
= & 1.47665
\end{array}
$$

Dependent variable: LSPENDON ( $\mathrm{i}=2, \mathrm{r}=2, \mathrm{k}=3$ - deep gas)

Mean of dependent variable $=20.4024$

Std. dev. of dependent var. $=.535672$

Sum of squared residuals $\doteq .435335$

Variance of residuals $\quad=.036278$

Std. error of regression $\quad \cdot=\quad .190468$

- R-squared $=.864097$

Durbin-Watson statistic. $\quad=\quad 1.58031$

Dependent variable: LSPENDON ( $\mathrm{i}=2, \mathrm{r}=2, \mathrm{k}=4$ - tight sands)

$\begin{array}{lll}\text { Mean of dependent variable } & = & 19.7497 \\ \text { Std. dev. of dependent var. } & = & .693022 \\ \text { Sum of squared residuals } & = & .746214 \\ \text { Variance of residuals } & = & .062184 \\ \text { Std. error of regression } & = & .249368 \\ \text { R-squared } & = & .861798 \\ \text { Durbin-Watson statistic } & = & 2.71700\end{array}$

\section{Region 3}

Development expenditures for tight sands are calculated as a residual. The form of the equation is:

$$
\begin{aligned}
& \text { LSPENDON }_{i, r, k, t}=\ln (s 0)_{i, r, k}+s 1_{i, r, t} * \text { LRSPENDON }_{i, r, t}+s 2_{i, r} * \text { PROFON }_{i, r, k, t}+ \\
& s 3_{i, s} * \text { DUM86 } 6_{t}+\rho_{i, r, k} * L_{S P E N D O N} N_{i, r, k, t-1}-\rho\left(\ln (s 0)_{i, r, k}+\right.
\end{aligned}
$$

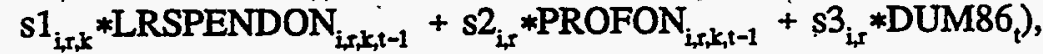

$$
\begin{aligned}
& \text { for } i=2, r=3, k=1,2,3
\end{aligned}
$$

where,

$$
\begin{aligned}
\text { LSPENDON } & =\text { natural logarithm of regional exploration drilling expenditures by fuel type } \\
\text { LRSPENDON } & =\text { natural logarithm of regional exploration drilling expenditures } \\
\text { PROFON } & =\text { regional lower } 48 \text { onshore profitability by fuel type, region, and well type } \\
\text { DUM86 } & =1 \text { if } t>1985,0 \text { otherwise } \\
\ln (\mathrm{s} 0), \mathrm{s} 1, \mathrm{~s} 2, \mathrm{~s} 3 & =\text { estimated parameters } \\
P & =\text { autocorrelation parameter } \\
\mathrm{i} & =\text { well type, } 2 \text { for development } \\
\mathrm{r} & =\text { OGSM region } 3 \text { for lower } 48 \text { onshore } \\
\mathrm{k} & =\text { fuel type, } 1 \text { for oil, } 2 \text { for shallow gas, } 3 \text { for deep gas } \\
\mathrm{t} & =\text { year. }
\end{aligned}
$$


Results

\begin{tabular}{||l|l|l|l|}
\hline Parameter & Shallow Oil & Shallow Gas & Deep Gas \\
\hline $\ln (s 0)$ & $\begin{array}{l}-0.708510 \\
(-0.574379)\end{array}$ & $5.61624(5.80465)$ & $\begin{array}{l}-3.99265 \\
(-1.64270)\end{array}$ \\
\hline$s 1$ & $\begin{array}{l}1.00088 \\
(17.8069)\end{array}$ & $\begin{array}{l}0.697418 \\
(15.7642)\end{array}$ & $\begin{array}{l}1.07062 \\
(9.62371)\end{array}$ \\
\hline$s 2$ & $\begin{array}{l}0.022772 \\
(5.28440)\end{array}$ & $\begin{array}{l}0.022772 \\
(5.28440)\end{array}$ & $\begin{array}{l}0.022772 \\
(5.28440)\end{array}$ \\
\hline$s 3$ & -0.265819 & 0 & 0 \\
\hline$\rho$ & $(-7.62331)$ & 0 & $\begin{array}{l}-0.151707 \\
(-4.62471)\end{array}$ \\
\hline
\end{tabular}

NUMBER OF OBSERVATIONS $=12$

Standard Errors computed from quadratic form of analytic first derivatives (Gauss)

Dependent variable: LSPENDON ( $\mathrm{i}=2, \mathrm{r}=3, \mathrm{k}=1$ - oil)

Mean of dependent variable $=21.0844$

Std. dev. of dependent var. $=.936056$

Sum of squared residuals $=.227780$

Variance of residuals $\quad=\quad .018982$

Std. error of regression $\quad=\quad .137774$

R-squared $\quad=\quad .976474$

Durbin-Watson statistic $\quad=\quad 1.35144$

Dependent variable: LSPENDON ( $\mathrm{i}=2, \mathrm{r}=3, \mathrm{k}=2$ - shallow gas)

Mean of dependent variable $=20.8622$

Std. dev. of dependent var. $=.569288$

Sum of squared residuals $=.165604$

Variance of residuals $=.013800$

Std. error of regression $=.117475$

R-squared $\quad=.953621$

Durbin-Watson statistic $\quad . \quad=\quad: 789851$

Dependent variable: LSPENDON ( $\mathrm{i}=2, \mathrm{r}=3, \mathrm{k}=3$ - deep gas)

Mean of dependent variable $=19.8428$

Std. dev. of dependent var. $=1.00238$

Sum of squared residuals $=1.65488$

Variance of residuals $=.137906$

Std. èrror of regression $=.371357$

R-squared $\quad=\quad .857343$

Durbin-Watson statistic $\quad=\quad 1.42433$ 


\section{Regions 4, 5, and 6}

The form of the equation is:

$$
\begin{aligned}
& \text { LSPENDON }_{i, r, k, t}=\ln (s 0)_{i, r, k}+s 1_{i, r, k} * \text { LRSPENDON }_{i, r, 1}+s 2_{i, r} * \text { PROFON }_{i, r, k, t} \\
& +\rho * \operatorname{LSPENDON}_{i, r, k, t-1}-\rho\left(\ln (\mathrm{s} 0)_{i, r, k}+s 1_{i, r, k} * \operatorname{LRSPENDON}_{\mathrm{i}, \mathrm{r}, \mathrm{k}, \mathrm{t}-1}\right. \\
& \left.+s 2_{i, r} * \text { PROFON } N_{i, r, k, t-1}\right) \text {, . } \\
& \text { for } i=2, r=4, k=1,2,3 \\
& \text { for } \mathrm{i}=2, \mathrm{r}=5, \mathrm{k}=1,2,3,4 \\
& \text { for } i=2, r=6, k=1
\end{aligned}
$$

where,

$$
\begin{aligned}
\text { LSPENDON } & =\text { natural logarithm of regionial exploration drilling expenditures by fuel type } \\
\text { LRSPENDON } & =\text { natural logarithm of regional exploration drilling expenditures } \\
\text { PROFON } & =\text { natural logarithm of regional lower } 48 \text { onshore profitability by fuel type, } \\
\ln (\mathrm{s} 0), \mathrm{s} 1, \mathrm{~s} 2 & =\text { estimated well type } \\
\rho & =\text { autocorrelation parameter } \\
\mathbf{i} & =\text { well type, } 2 \text { for development } \\
\mathbf{r} & =\text { OGSM region } 4,5,6 \text { for lower } 48 \text { onshore } \\
\mathbf{k} & =\text { fuel type, } 1 \text { for oil, } 2 \text { for shallow gas, } 3 \text { for deep gas, } 4 \text { for tight sands } \\
\mathrm{t} & =\text { year. }
\end{aligned}
$$

Region 4.

\section{Results}

Development expenditures for tight sands are calculated as a residual.

\begin{tabular}{||l|l|l|l|}
\hline Parameter & Shallow Oil & Shallow Gas & Deep Gas \\
\hline $\ln (\mathrm{s} 0)$ & $\begin{array}{l}0.835522 \\
(1.03313)\end{array}$ & $\begin{array}{l}-4.33310 \\
(-1.74492)\end{array}$ & $\begin{array}{l}-19.4201 \\
(-11.3779)\end{array}$ \\
\hline$s 1$ & $\begin{array}{l}0.950451 \\
(25.1256)\end{array}$ & $1.09309(9.33345)$ & $\begin{array}{l}1.73221 \\
(21.9237)\end{array}$ \\
\hline$s 2$ & $\begin{array}{l}0.675520 \mathrm{E}-03 \\
(3.59397)\end{array}$ & $\begin{array}{l}0.675520 \mathrm{E}-03 \\
(3.59397)\end{array}$ & $\begin{array}{l}0.675520 \mathrm{E}-03 \\
(3.59397)\end{array}$ \\
\hline$\rho$ & $\begin{array}{l}0.570503 \\
(3.75241)\end{array}$ & $\begin{array}{l}0.638942 \\
(7.17799)\end{array}$ & 0 \\
\hline
\end{tabular}

\section{NUMBER OF OBSERVATIONS $=12$}

Standard Errors computed from heteroscedastic-consistent matrix (Robust-White)

Dependent variable: LSPENDON ( $\mathrm{i}=2, \mathrm{r}=4, \mathrm{k}=1$ - oil)
Mean of dependent variable $=21.2740$
Std. dev. of dependent var. $=.620067$
Sum of squared residuals,$=.028778$ 
Variance of residuals

Std. error of regression

R-squared

Durbin-Watson statistic $=\quad .239818 \mathrm{E}-02$

$=.048971$

$=.994224$

$=1.33640$

Dependent variable: LSPENDON ( $\mathrm{i}=2, \mathrm{r}=4, \mathrm{k}=2$ - shallow gas)

Mean of dependent variable $=19.3308$

Std. dev. of dependent var. $=.821221$

Sum of squared residuals $=.260793$

Variance of residuals $\quad=\quad .021733$

Std. error of regression $\cdot=\quad .147420$

R-squared $\quad=.965882$

Durbin-Watson statistic $\quad=\quad 1.68114$

Dependent variable: LSPENDON ( $\mathrm{i}=2, \mathrm{r}=4, \mathrm{k}=3$ - deep gas)

Mean of dependent variable $=17.9658$

Std. dev. of dependent var. $=1.04054$

Sum of squared residuals $=.448589$

Variance of residuals $=.037382$

- Std. error of regression $=.193345$

R-squared $\quad=.964899$

Durbin-Watson statistic $\quad=\quad 1.44713$

\section{Region 5}

\section{Results}

Development expenditures for coalbed methane are calculated as a residual.

\begin{tabular}{||c|l|l|l|l||}
\hline Parameter & Shallow Oil & Shallow Gas & Deep Gas & Tight Sands \\
\hline $\ln (s 0)$ & $\begin{array}{l}-2.37330 \\
(-1.24871)\end{array}$ & $\begin{array}{l}2.80549 \\
(0.837460)\end{array}$ & $\begin{array}{l}-4.53525 \\
(-.792133)\end{array}$ & $\begin{array}{l}-6.98719 \\
(-2.45288)\end{array}$ \\
\hline$s 1$ & $\begin{array}{l}1.07958 \\
(12.0244)\end{array}$ & $\begin{array}{l}0.797515 \\
(4.96830)\end{array}$ & $\begin{array}{l}1.00079 \\
(3.56158)\end{array}$ & $\begin{array}{l}1.23426 \\
(9.09203)\end{array}$ \\
\hline$s 2$ & $\begin{array}{l}0.030321 \\
(2.93588)\end{array}$ & $\begin{array}{l}0.030321 \\
(2.93588)\end{array}$ & $\begin{array}{l}0.030321 \\
(2.93588)\end{array}$ & $\begin{array}{l}0.030321 \\
(2.93588)\end{array}$ \\
\hline$p$ & $\begin{array}{l}0.447507 \\
(2.07870)\end{array}$ & $\begin{array}{l}0.714744 \\
(4.47690)\end{array}$ & 0 & $\begin{array}{l}0.441813 \\
(6.12788)\end{array}$ \\
\hline
\end{tabular}

\section{NUMBER OF OBSERVATIONS $=12$}

Standard Errors computed from quadratic form of analytic first derivatives (Gauss)

Deperident variable: LSPENDON ( $\mathrm{i}=2, \mathrm{r}=5, \mathrm{k}=1$ - oil)

Mean of dependent variable $=20.5079$

Std. dev. of dependent var. $\quad=\quad .906731$

Sum of squared residuals $=.287053$.

Variance of residuals $\quad=\quad .023921$

Std. error of regression, $=\quad .154664$ 
R-squared

Durbin-Watson statistic
$=.971186$

$=1.09353$

Dependent variable: LSPENDON ( $\mathrm{i}=2, \mathrm{r}=5, \mathrm{k}=2$ - shallow gas).

Mean of dependent variable $=19.7460$

Std. dev. of dependent var. $=.732388$

Sum of squared residuals $=.448722$

Variance of residuals $\quad=.037393$

Std. error of regression $\quad \doteqdot \quad .193374$

R-squared $\quad=.931741$

Durbin-Watson statistic $\quad=\quad 1.33837$

Dependent variable: LSPENDON ( $\mathrm{i}=2, \mathrm{r}=5, \mathrm{k}=3$ - deep gas)

Mean of dependent variable $=17.9687$

Std. dev. of dependent var. $=1.38316$

Sum of squared residuals $\quad=\quad 5.01660$

Variance of resicuals $=.418050$

Std. error of regression $\cdot=.646568$

R-squared $\quad=\quad .761662$

Durbin-Watson statistic $\quad=\quad 1.12902$

Dependent variable: 'LSPENDON ( $\mathrm{i}=2, \mathrm{r}=5 ; \mathrm{k}=4$ - tight sands)

Mean of dependent variable $=18.9259$

Std. dev. of dependent var. $=.1 .01821$

Sum of squared residuals $=.621766$

Variance of residuais $\cdot \cdot=.051814$

Std. error of regression $\quad=.227627$

R-squared $\quad=\quad .947670$

Durbin-Watson statistic $=2.25358$

\section{Region 6}

Results

Development expenditures for shallow gas are:calculated as a residual. Equation is estimated using maximum likelihood iterative technique.

\begin{tabular}{|l|l|}
\hline Parameter & Shallow Oil \\
\hline $\operatorname{In}(\mathrm{s} 0)$ & $\begin{array}{l}1.21832 \\
(1.23894)\end{array}$ \\
\hline$s 1$ & $\begin{array}{l}0.917142 \\
(16.9893)\end{array}$ \\
\hline$\rho$ & 0.357290 \\
\hline
\end{tabular}

NUMBER OF OBSERVATIONS $=12$

Dependent variable: $L$ SPENDON $(\mathrm{i}=2, \mathrm{r}=6, \mathrm{k}=1$ - oil)

(Statistics based on transformed data) 


$$
\begin{array}{lll}
\text { Mean of dependent variable } & =5.34089 \\
\text { Std. dev. of dependent var. } & =2.36353 \\
\text { Sum of squared residuals } & = & .014458 \\
\text { Variance of residuals } & =.160649 \mathrm{E}-02 \\
\text { Std. enror of regression } & =.040081 \\
\text { R-squared } & =.999797 \\
\text { Adjusted R-squared } & =.999751 \\
\text { Durbin-Watson statistic } & =1.05520 \\
\text { Rho (autocorrelation coef.) } & =.764479 \\
\text { Standard error of rho } & =.184605 \\
\text { t-statistic for rho } & =4.14115 \\
\text { F-statistic (zero siopes) } & =19120.7 \\
\text { Log of likelihood function } & =22.8620 \\
& \\
\text { (Statistics based on original data) } & \\
\text { Mean of dependent variable } & =19.8877 \\
\text { Std. dev. of dependent var. } & =.442015 \\
\text { Sum of squared residuals } & =.016108 \\
\text { Variance of residuals } & =.178976 \mathrm{E}-02 \\
\text { Std. error of regression } & =.042306 \\
\text { R-squared } & =.992696 \\
\text { Adjusted R-squared } & =.991073 \\
\text { Durbin-Watson statistic } & =.986890 \\
&
\end{array}
$$

\section{Offshore Regional and Intraregional Exploration Expenditure Equations}

$\begin{array}{lll}\text { Adjusted R-squared } & = & .991073 \\ \text { Durbin-Watson statistic } & = & .986890\end{array}$

For offshore regions 8 and 11, regional exploration expenditures were estimated as a function of national offshore exploration expenditures and a dummy variable using nonlinear least squares. Since all exploration expenditures for these regions were assumed to be allocated to oil, no intraregional equations were estimated.

For offshore regions 9 and 10, regional and intraregional expenditures were estimated using SURE. - Generally, regional expenditures were estimated as a function of national offshore exploratory expenditures and the relative profitability of exploratory drilling in the region. Correspondingly, intraregional expenditures were a function of the regional expenditures and a measure of the fuel-specific profitability. In many instances, measures of profitability were not statistically significant and were not included in the final forms of the equations. Dummy variables were also.included where appropriate.

\section{Offshore Exploration (Region 8)}

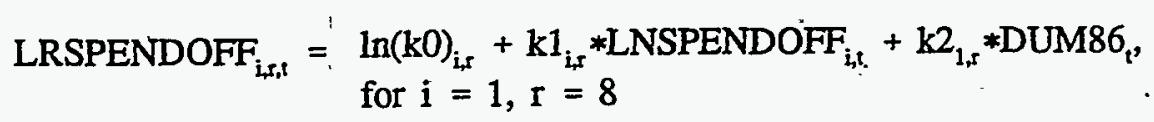

where,

$$
\text { LRSPENDOFF }=\begin{aligned}
& \text { natural logarithm of regional lower } 48 \text { offshore exploration drilling } \\
& \text { expenditures }
\end{aligned}
$$




$$
\begin{aligned}
\text { LNSPENDOFF } & =\text { natural logarithm of national offshore exploration drilling expenditures } \\
\text { DUM86 } & =1 \text { if } t>1985,0 \text { otherwise } \\
\ln (\mathrm{k} 0), \mathrm{k} 1, \mathrm{k} 2 & =\text { estimated parameters } \\
\mathrm{i} & =\text { well type, } 1 \text { for exploratory } \\
\mathrm{p} & =\text { autocorrelation parameter } \\
\mathrm{r} & =\text { OGSM regions } 8 \text { and } 11 \text { for the lower } 48 \text { offshore } \\
\mathrm{t} & =\text { year. }
\end{aligned}
$$

Results

\begin{tabular}{||l|l|}
\hline Parameter & $\begin{array}{l}\text { Region 8 } \\
\text { Pacific }\end{array}$ \\
\hline in(k0) & $\begin{array}{l}-9.87048 \quad \cdots \\
(-.592930)\end{array}$ \\
\hline $\mathrm{k} 1$ & $\begin{array}{l}1.35128 \\
(1.72376)\end{array}$ \\
\hline $\mathrm{k} 2$ & $\begin{array}{l}-0.891962 \\
(-2.13778)\end{array}$ \\
\hline
\end{tabular}

Standard Errors computed from quadratic form of analytic first derivatives (Gauss)

NUMBER OF OBSERVATIONS $=10$

Dependent yariable: LRSPENDOFF $_{\mathrm{i}, \mathrm{r}, \mathrm{t}}(\mathrm{i}=1$, exploration, $\mathrm{r}=8)$

$\begin{array}{lll}\text { Mean of dependent variable. } & \stackrel{1}{=} & 18.3776 \\ \text { Std. dev. of dependent var. } & = & .865412 \\ \text { Sum of squared residuals } & = & 2.65566 \\ \text { Variance of residuals } & = & .379380 \\ \text { Std. error of regression } & = & .615938 \\ \text { R-squared } & = & .606011 \\ \text { Adjusted R-squared } & = & .493443 \\ \text { Durbin-Watson statistic } & = & 1.77375\end{array}$

\section{Offshore Exploration (Region 9)}

$$
\begin{aligned}
& \text { LRSPENDOFF }_{\mathrm{i}, r, t}=\ln (\mathrm{k} 0)_{\mathrm{i}, \mathrm{s}}+\mathrm{k} 1_{\mathrm{i}, \mathrm{r}} * \mathrm{LNSPENDOFF}_{\mathrm{i}, \mathrm{t}}+\mathrm{k} 2_{\mathrm{i}, \mathrm{r}} * \mathrm{RPROFON}_{\mathrm{t}} \\
& \text { for } i=1, r=9
\end{aligned}
$$

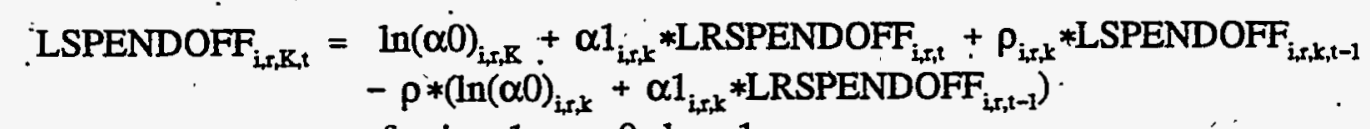

$$
\begin{aligned}
& \text { for } \mathrm{i}=1, \mathrm{r}=9, \mathrm{k}=1 \text {. }
\end{aligned}
$$

where,

LRSPENDOFF = natural logarithm of regional lower 48 offshore exploration drilling expenditures

LNSPENDOFF = natural logarithm of national offshore exploration drilling expenditures 


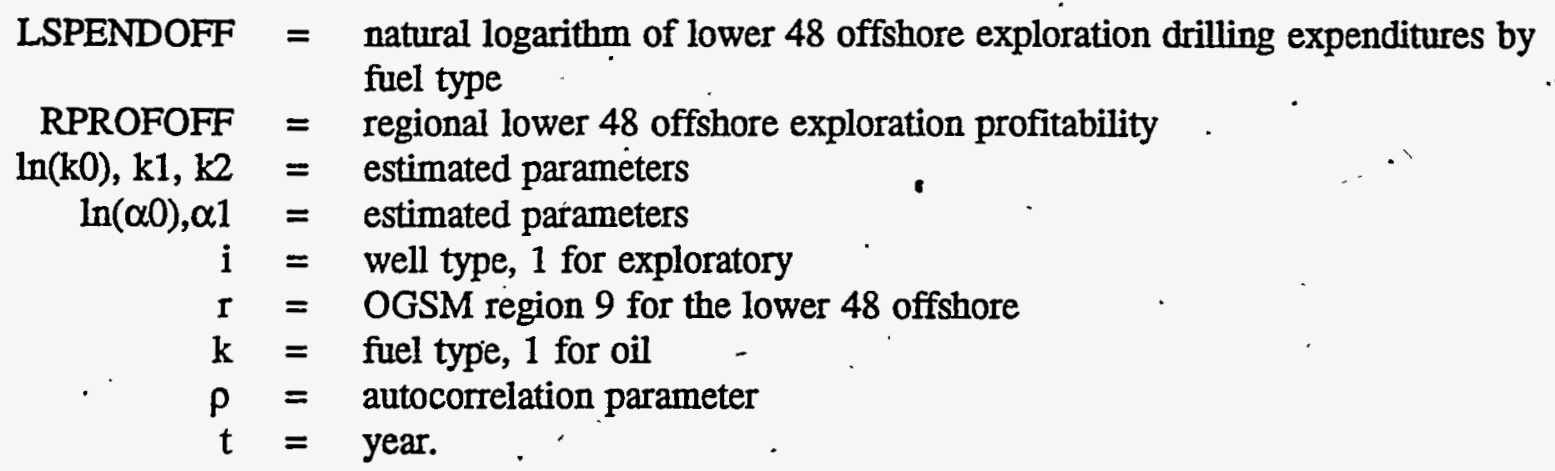

Results

\begin{tabular}{|l|l|}
\hline Parameter & $\begin{array}{l}\text { Region 9 } \\
\text { WGOM }\end{array}$ \\
\hline $\ln (\mathrm{k} 0)$ & $\begin{array}{l}-8.72775 \\
(-1.23192)\end{array}$ \\
\hline$k 1$ & $\begin{array}{l}1.31843 \\
(3.93793)\end{array}$ \\
\hline$k 2$ & $\begin{array}{l}0.462887 \mathrm{E}-07 \\
(2.63772)\end{array}$ \\
\hline
\end{tabular}

\begin{tabular}{||l|l|}
\hline Parameter & Oil \\
\hline $\ln (\alpha 0)$ & $\begin{array}{l}-24.7885 \\
(-4.13552)\end{array}$ \\
\hline$\alpha 1$ & 2.26865 \\
& $(7.41669)$ \\
\hline$\rho$ & 0.676053 \\
& $(2.70699)$ \\
\hline
\end{tabular}

Standard Errors computed from quadratic form of analytic first derivatives (Gauss)

\section{NUMBER OF OBSERVATIONS $=7$}

Dependent variable: LRSPENDOFF $_{\mathrm{i}, \mathrm{s}}(\mathrm{i}=1$ exploration, $\mathrm{r}=9$ )

Mean of dependent variable $=19.4073$

Std. dev. of dependent var. $=.489979$

Sum of squared residuals $=.344523$

Variance of residuals $\quad=\quad .049218$

Std. error of regression $=.221850$

R-squared $\quad=\quad .762718$

Durbin-Watson statistic $\quad=1.43539$

Dependent variable: LSPENDOFF $_{\mathrm{is}, \mathrm{k}}(\mathrm{i}=1$ exploration, $\mathrm{r}=9, \mathrm{k}=1$ )

Mean of dependent variable $=18.9900$

Std. dev. of dependent var. $=.877553$

Sum of squared residuals $=.939155$

Variance of residuals $\quad=.134165$ 
Std. error of regression

R-squared

Durbin-Watson statistic
$=.366286$

$=.874484$

$=2.41585$

\section{Offshore Exploration (Region 10)}

$$
\begin{aligned}
\text { LRSPENDOFF }_{\mathrm{i}, \mathrm{r}, \mathrm{t}}= & \ln (\mathrm{k} 0)_{\mathrm{i}, \mathrm{r}}+\mathrm{k} 1_{\mathrm{i}, \mathrm{r}} * \mathrm{LNSPENDOFF}_{\mathrm{i}, t} \\
& \text { for } \mathrm{i}=1, \mathrm{r}=10
\end{aligned}
$$

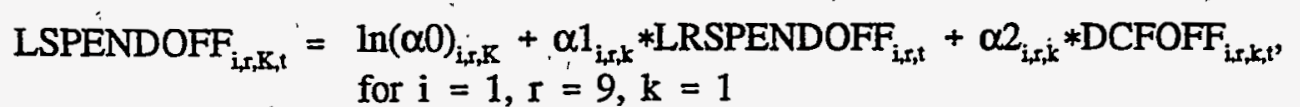

where,

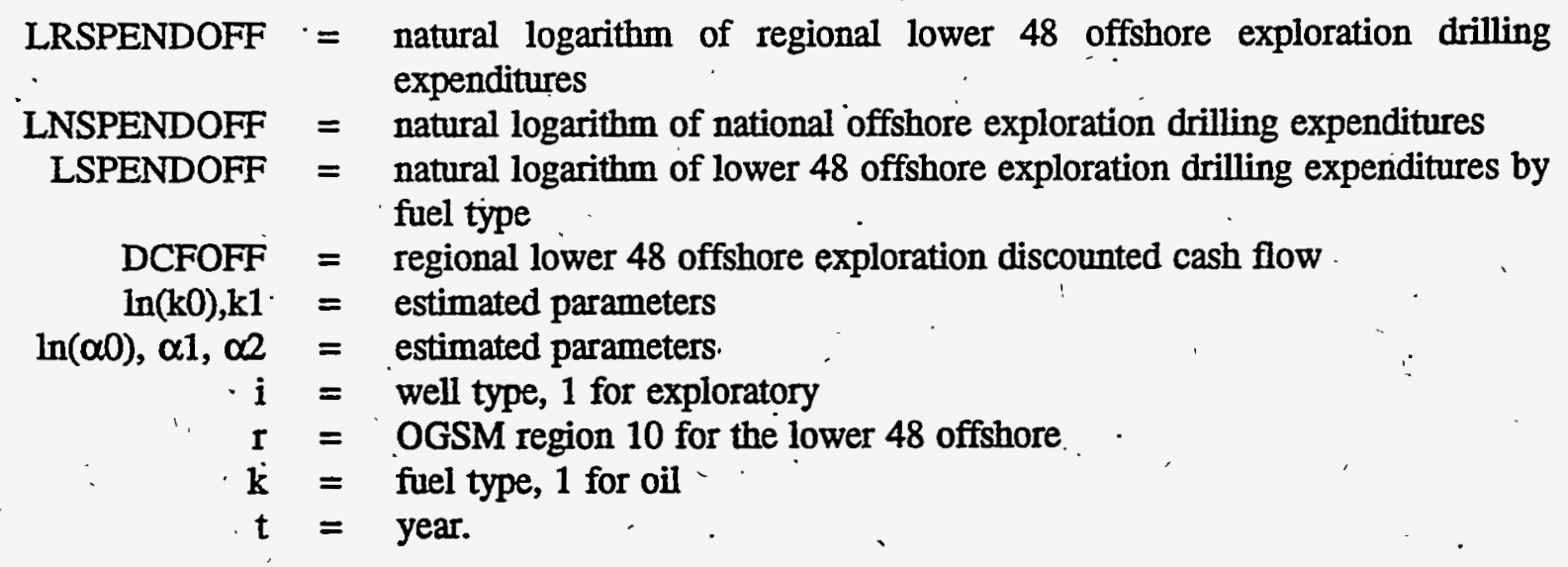

\section{Results}

\begin{tabular}{||l|l|}
\hline Parameter & $\begin{array}{l}\text { Region 10 } \\
\text { CGOM }\end{array}$ \\
\hline $\ln (\mathrm{k} 0)$ & $\begin{array}{l}-5.02615 \\
(-1.14373)\end{array}$ \\
\hline $\mathrm{k} 1$ & $\begin{array}{l}1.19191 \\
(5.74941)\end{array}$ \\
\hline
\end{tabular}

\begin{tabular}{||l|l|}
\hline Parameter $\cdots$ & Oil \\
\hline $\ln (\alpha 0)$ & $\begin{array}{l}1.32156 \\
(0.168476)\end{array}$ \\
\hline$\alpha 1$ & $\begin{array}{l}0.843216 \\
(2.15652)\end{array}$ \\
\hline$\alpha 2$ & $\begin{array}{l}0.127953 \mathrm{E}-06 \\
(5.80712)\end{array}$ \\
\hline
\end{tabular}

Standard Errors computed from quadratic form of analytic first derivatives (Gauss) 
NUMBER OF OBSERVATIONS $=10$

Dependent variable: LRSPENDOFF $_{\mathrm{i}, \mathrm{r}}$ ( $\mathrm{i}=1$ exploration, $\left.\mathrm{r}=10\right)^{\circ}$

Mean of dependent variable $=.20 .2386$

Std. dev. of dependent var. $\quad=\quad .296224$

Sum of squared residuals $=.183429$

Variance of residuals $\quad=\quad .018343$

Std. error of regression $=.135436$

R-squared $\quad=\quad .767735$

Durbin-Watson statistic $\quad=\quad 1.65378$

Dependent variable: LSPENDOFF $_{\mathrm{i}, \mathrm{r}, \mathrm{k}}(\mathrm{i}=1$ exploration, $\mathrm{r}=10, \mathrm{k}=1)$

Mean of dependent variable $=19.0721$

Std. dev. of dependent var. $=\quad \mathbf{8 9 6 1 3 3}$

Sum of squared residuals $\quad=\quad .778134$

Variance of residuals $\quad=\quad .077813$

Std. error of regression $=.278950$

R-squared $\quad=\quad .892338$

Durbin-Watson statistic $\quad=\quad 2.13938$

\section{Offshore Exploration (Region 11)}

$$
\begin{aligned}
\text { LRSPENDOFF }_{\mathrm{i}, \mathrm{t}, \mathrm{t}}= & \ln (\mathrm{k} 0)_{\mathrm{i}, \mathrm{r}}+\mathrm{k} 1_{\mathrm{i}, \mathrm{r}} * \mathrm{LNSPENDOFF}_{\mathrm{i}, \mathrm{t}}+\mathrm{k} 2_{1, \mathrm{r}} * \mathrm{DUM} 84_{\mathrm{t},} \\
& \text { for } \mathrm{i}=1, \mathrm{r}=11
\end{aligned}
$$

where,

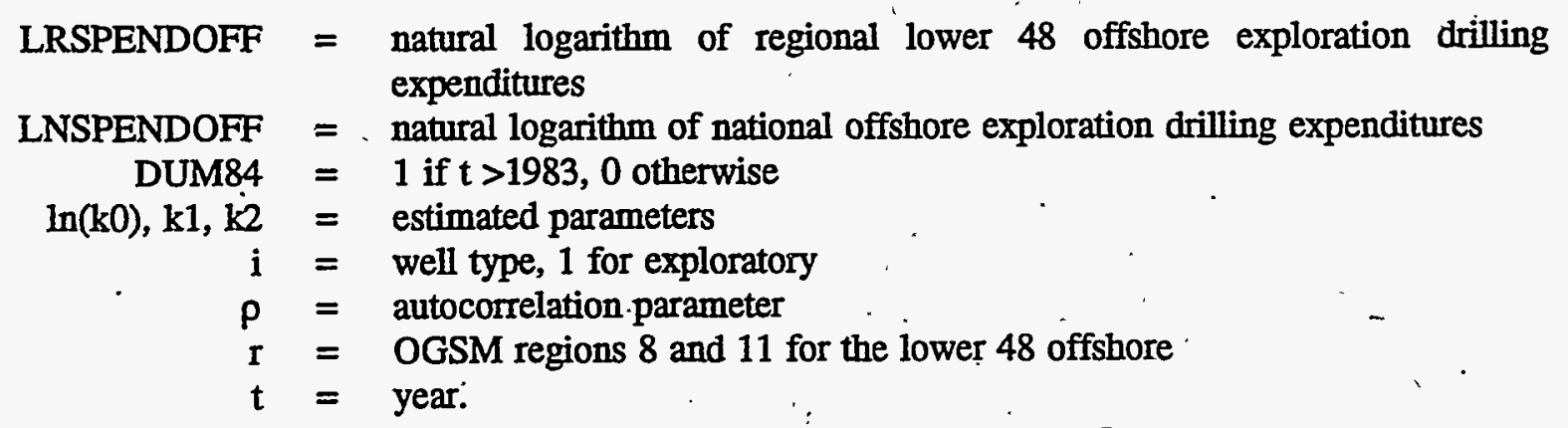




\section{Results}

\begin{tabular}{||l|l|}
\hline Parameter & $\begin{array}{l}\text { Region 11 } \\
\text { Deep GOM }\end{array}$ \\
\hline $\ln (\mathrm{k} 0)$ & $\begin{array}{l}11.7034 \\
(1.17)\end{array}$ \\
\hline $\mathrm{k} 1$ & $\begin{array}{l}0.3286 \\
(0.701)\end{array}$ \\
\hline $\mathrm{k} 2$ & $\begin{array}{l}1.536 \\
(6.374)\end{array}$ \\
\hline
\end{tabular}

Standard Errors computed from quadratic form of analytic first derivatives (Gauss)

\section{NUMBER OF OBSERVATIONS $=10$}

Dependent variable: LRSPENDOFF $F_{i, r, t}(i=1$, exploration, $r=11)$.

$\begin{array}{lll}\text { Mean of dependent variable } & = & 19.8591 \\ \text { Std. dev. of dependent var. } & = & .705128 \\ \text { Sum of squared residuals } & = & .496692 \\ \text { Variance of residuals } & = & .082782 \\ \text { Std. error of regression } & = & .287718 \\ \text { R-squared } & = & .875129 \\ \text { Durbin-Watson statistic } & = & 1.87498\end{array}$

\section{Offshore Regional and Intraregional Development Expenditure Equations}

For each of the offshore regions, a regional development expenditure equation along with the intraregional fuel type equations were estimated using SURE, in generalized difference form when necessary. In all cases, regional development expenditures were estimated as a function of national offshore development expenditures while intraregional development expenditures by fuel were estimated as a function of the level of regional development expenditures.

\section{Offshore Development (Region 8)}

$$
\begin{aligned}
& \begin{aligned}
\text { LRSPENDOFF }_{\mathrm{i}, \mathrm{r}, \mathrm{t}}= & \ln (\mathrm{k} 0)_{\mathrm{i}, \mathrm{r}}+\mathrm{k1}_{\mathrm{i}, \mathrm{r}} * \mathrm{LNSPENDOFF}_{\mathrm{i}, \mathrm{r}}+\rho_{\mathrm{i}, \mathrm{r}} * \mathrm{LRSPENDOFF}_{\mathrm{i}, \mathrm{r}, \mathrm{t}-1,}, \\
& -\rho *\left(\mathrm{LN}(\mathrm{K} 0)_{\mathrm{i}, \mathrm{r}}+\mathrm{k1}_{\mathrm{i}, \mathrm{r}} * \mathrm{LNSPENDOFF}_{\mathrm{i}, \mathrm{l}-1}\right),
\end{aligned} \\
& \text { for } i=2, r=8
\end{aligned}
$$

$$
\text { LSPENDOFF }_{i, r, k, t}=\ln (\alpha 0)_{i, r, k}+\alpha 1_{i, r, k} * \operatorname{LRSPENDOFF}_{i, r, t}
$$

where, 


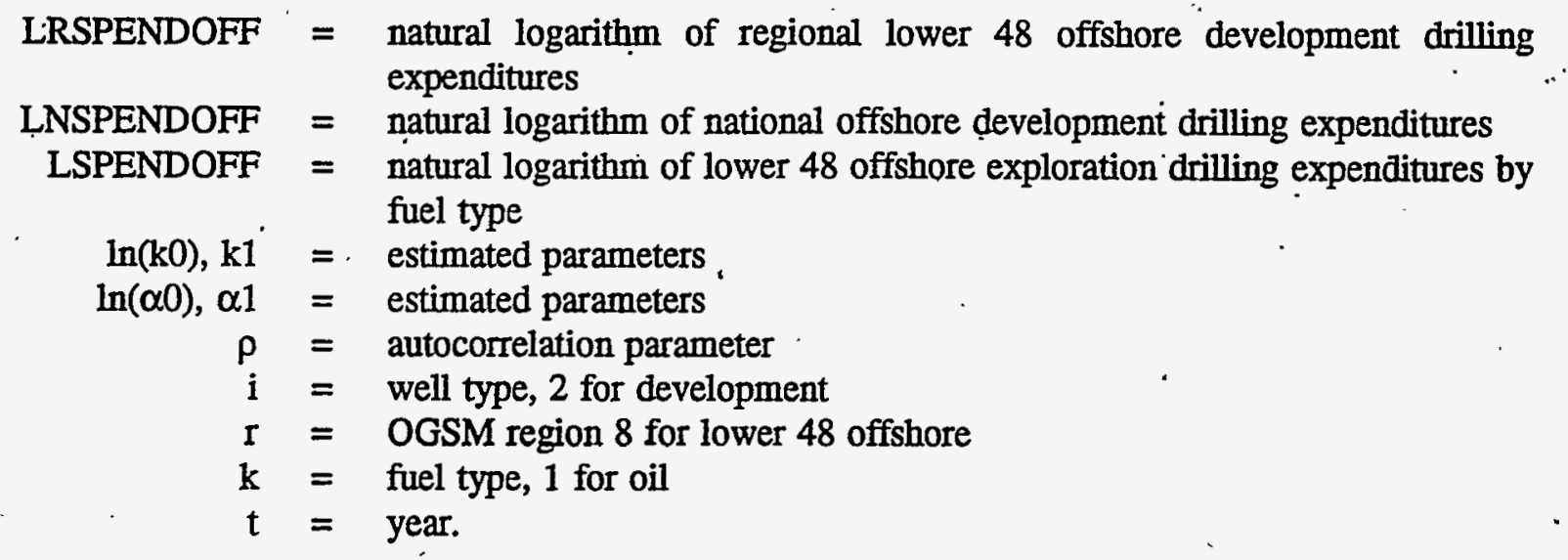

\section{Results}

\begin{tabular}{||l|l|}
\hline Parameter & $\begin{array}{l}\text { Region 8 } \\
\text { Pacific }\end{array}$ \\
\hline $\ln (k 0)$ & $\begin{array}{l}-9.07119 \\
(-1.00949)\end{array}$ \\
\hline$k 1$ & $\begin{array}{l}1.29061 \\
(2.92335)\end{array}$ \\
\hline$\rho$ & $\begin{array}{l}0.857258 \\
(2.76314)\end{array}$ \\
\hline
\end{tabular}

\begin{tabular}{||l|l|}
\hline Parameter & Oil \\
\hline $\ln (\alpha 0)$ & $\begin{array}{l}-0.455868 \\
(-1.54499)\end{array}$ \\
\hline$\alpha 1$ & $\begin{array}{l}1.02255 \\
(65.6681)\end{array}$ \\
\hline
\end{tabular}

Standard Errors computed from quadratic form of analytic first derivatives (Gauss)

\section{NUMBER OF OBSERVATIONS $=11$}

Dependent variable: LRSPENDOFF $_{\mathrm{i}, \mathrm{r}}(\mathrm{i}=2$ development; $\mathrm{r}=8)$

$\begin{array}{lll}\text { Mean of dependent variable } & = & 18.9340 \\ \text { Std. dev. of dependent var. } & = & .765588 \\ \text { Sum of squared residuals } & = & 1.08020 \\ \text { Variance of residuals } & = & .098200 \\ \text { Std. error of regression } & = & .313369 \\ \text { R-squared } & =.817878 \\ \text { Durbin-Watson statistic } & = & 1.29144\end{array}$

Dependent variable: LSPENDOFF $_{\mathrm{i}, \mathrm{r}, \mathrm{k}}(\hat{\mathrm{i}=2}$ development, $\mathrm{r}=8, \mathrm{k}=1)$

Mean of dependent variable $=18.9052$

Std. dev. of dependent var. $=.790763$

Sum of squared residuals $=.016906$

Variance of residuals $-\quad=\quad .153695 E-02$ 
Std. error of regression

R-squared

Durbin-Watson statistic

$$
\begin{array}{ll}
= & .039204 \\
= & .997372 \\
= & 1.77376
\end{array} .
$$

\section{Offshore Development (Region 9)}

$$
\begin{aligned}
\text { LRSPENDOFF }_{\mathrm{i}, \mathrm{i}}= & \ln (\mathrm{k} 0)_{\mathrm{i}, \mathrm{r}}+\mathrm{k} 1_{\mathrm{i}, \mathrm{r}} * \mathrm{LNSPENDOFF}_{\mathrm{i}, \mathrm{t}}+\mathrm{k} 2_{\mathrm{i}, \mathrm{r}} * \text { foUM86, } \\
& \text { for } \mathrm{i}=2, \mathrm{r}=9
\end{aligned}
$$

$$
\begin{aligned}
\text { LSPENDOFF }_{\mathrm{i}, \mathrm{k}, \mathrm{t}, \mathrm{t}}= & \ln (\alpha 0)_{\mathrm{i}, \mathrm{r}, \mathrm{k}}+\alpha 1_{\mathrm{i}, \mathrm{r}, \mathrm{k}} * \mathrm{LRSPENDOFF}_{\mathrm{i}, \mathrm{r}, \mathrm{t}} \\
& \text { for } \mathrm{i}=2, \mathrm{r}=9, \mathrm{k}=2
\end{aligned}
$$

where,

$$
\begin{aligned}
\text { LRSPENDOFF } & =\begin{array}{l}
\text { natural logarithm of regional lower } 48 \text { offshore development drilling } \\
\text { expenditures }
\end{array} \\
\text { LNSPENDOFF } & =\text { natural logarithm of national offshore development drilling expenditures } \\
\text { LSPENDOFF } & =\text { natural logarithm of lower } 48 \text { offshore exploration drilling expenditures by } \\
\text { fuel type } & 1 \text { if } t>1985,0 \text { otherwise } \\
\operatorname{DUM86} & =\text { estimated parameters } \\
\ln (\mathrm{k} 0), \mathrm{k} 1 & =\text { estimated parameters } \\
\mathrm{ln}(\alpha 0), \alpha 1 & =\text { well type, } 2 \text { for development } \\
\mathrm{r} & =\text { OGSM region } 9 \text { for lower } 48 \text { offshore } \\
\mathbf{k} & =\text { fuel type, } 2 \text { for oil } \\
\mathrm{t} & =\text { year. }
\end{aligned}
$$

\section{Results}

\begin{tabular}{||l|l|}
\hline Parameter & $\begin{array}{l}\text { Region 8 } \\
\text { Pacific }\end{array}$ \\
\hline $\ln (\mathrm{k} 0)$ & $\begin{array}{l}-9.07119 \\
(-1.00949)\end{array}$ \\
\hline $\mathrm{k} 1$ & $\begin{array}{l}1.29061 \\
(2.92335)\end{array}$ \\
\hline$\rho$ & $\begin{array}{l}0.857258 \\
(2.76314)\end{array}$ \\
\hline
\end{tabular}

\begin{tabular}{||l|l|}
\hline Parameter & Oil \\
\hline $\operatorname{In}(\alpha 0)$ & $\begin{array}{l}-0.455868 \\
(-1.54499)\end{array}$ \\
\hline$\alpha 1$ & $\begin{array}{l}1.02255 \\
(65.6681)\end{array}$ \\
\hline
\end{tabular}

Standard Errors computed from quadratic form of analytic first derivatives (Gauss) 
NUMBER OF OBSERVATIONS $=11$

Dependent variable: LRSPENDOFF $_{\mathrm{i}, \mathrm{r}}(\mathrm{i}=2$ development, $\mathrm{r}=9$ )

Dependent variable: LSPENDOFF $_{i, r, k}(\mathrm{i}=2$ development, $r=9, k=2)$

\section{Offshore Development (Region 10)}

$$
\begin{aligned}
\text { LRSPENDOFF }_{\mathrm{i}, \mathrm{r}, \mathrm{t}}= & \ln (\mathrm{k} 0)_{\mathrm{i}, \mathrm{r}}+\mathrm{k}_{\mathrm{i}, \mathrm{r}} * \mathrm{LNSPENDOFF}_{\mathrm{i}, \mathrm{t}}+\rho_{\mathrm{i}, \mathrm{r}} * \mathrm{LRSPENDOFF}_{\mathrm{i}, \mathrm{r}, \mathrm{l}}, \\
& -\rho *\left(\mathrm{LN}(\mathrm{K} 0)_{\mathrm{i}, \mathrm{r}}+\mathrm{k} 1_{\mathrm{i}, \mathrm{r}} * \mathrm{LNSPENDOFF}_{\mathrm{i}, \mathrm{t}-\mathrm{1}}\right), \\
& \text { for } \mathrm{i}=2, \mathrm{r}=.10
\end{aligned}
$$

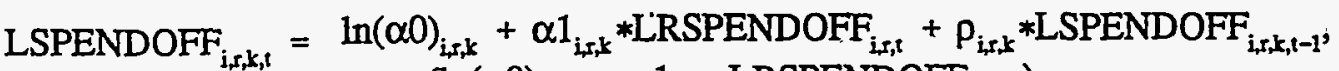

$$
\begin{aligned}
& -\rho_{\mathrm{i}, \mathrm{r}, \mathrm{k}} *\left(\ln (\alpha 0)_{\mathrm{i}, \mathrm{r}, \mathrm{k}}+\alpha 1_{\mathrm{i}, \mathrm{r}, \mathrm{L}} * \mathrm{LRSPNDOFF}_{\mathrm{i}, \mathrm{i}, \mathrm{i}-1}\right) \text {, } \\
& \text { for } i=2, r=10, k=1
\end{aligned}
$$

where,

$$
\begin{aligned}
\text { LRSPENDOFF } & =\begin{array}{l}
\text { natural logarithm of regional lower } 48 \text { offshore development drilling } \\
\text { expenditures }
\end{array} \\
\text { LNSPENDOFF } & =\text { natural logarithm of national offshore development drilling expenditures } \\
\text { LSPENDOFF } & =\text { natural logarithm of lower } 48 \text { offshore exploration drilling expenditures by } \\
\ln (k 0), k 1 & =\text { estimat type } \\
\ln (\alpha 0), \alpha 1 & =\text { estimated parameters } \\
\rho & =\text { autocorrelation parameter } \\
\mathbf{i} & =\text { well type, } 2 \text { for development } \\
r & =\text { OGSM region } 10 \text { for lower } 48 \text { offshore } \\
\mathbf{k} & =\text { fuel type, } 1 \text { for oil. } \\
t & =\text { year. }
\end{aligned}
$$

Results

\begin{tabular}{||l|l|}
\hline Parameter & $\begin{array}{l}\text { Region 10 } \\
\text { CGOM }\end{array}$ \\
\hline $\ln (\mathrm{k} 0)$ & $\begin{array}{l}-0.103715 \\
(-0.049704)\end{array}$ \\
\hline $\mathrm{k} 1$ & $\begin{array}{l}0.988356 \\
(10.1020)\end{array}$ \\
\hline$\rho$ & $\begin{array}{l}0.546690 \\
(2.48363)\end{array}$ \\
\hline
\end{tabular}




\begin{tabular}{||l|l|}
\hline Parameter & Oil \\
\hline $\ln (\alpha 0)$ & $\begin{array}{l}-2.28826 \\
(-0.569286)\end{array}$ \\
\hline$\alpha I$ & $\begin{array}{l}1.06808 \\
(5.58077)\end{array}$ \\
\hline$\rho$ & $\begin{array}{l}0.602485 \\
(2.55872)\end{array}$ \\
\hline
\end{tabular}

Standard Errors computed from quadratic form of analytic first derivatives (Gauss)

NUMBER OF OBSERVATIONS $=14$

Dependent variable: LRSPENDOFF $_{\mathrm{i}, \mathrm{x}}(\mathrm{i}=2$ development, $\mathrm{I}=10$ )

Mean of dependent variable $=20.9800$

Std. dev. of dependent var. $=.326342$

Sum of squared residuals $=.086414$

Variance of residuals $=.617241 \mathrm{E}-02$

Std.error of regression ${ }^{\circ}=.078565$

R-squared $\quad=.937959$

Durbin-Watson statistic . $\quad=: 1: 85576$,

Dependent variable: LSPENDOFF $_{i, \mathrm{k}}(\mathrm{i}=2$ development, $\mathrm{r}=10, \mathrm{k}=1$ )

Mean of dependent variable $=20.1798$

Std. dev. of dependent var, $=.430307$

Sum of squared residuals $\quad=\quad .350060$

Variance of residuals $=.025004$

Std. error of regression $\quad=\quad .158127$

R-squared $\quad=.866879$

Durbin-Watson statistic $\quad=\quad 1.23126$

\section{Offshore Development (Region 11)}

$$
\begin{aligned}
& \text { LRSPENDOFF }_{\mathrm{i}, \mathrm{s}, \mathrm{t}}=\ln (\mathrm{k} 0)_{\mathrm{i}, \mathrm{r}}+\mathrm{k}_{\mathrm{i}, \mathrm{r}} * \mathrm{LNSPENDOFF}_{\mathrm{i}, \mathrm{t}}+\mathrm{k} 2_{\mathrm{i}, \mathrm{r}} * \mathrm{LRSPENDOFF}_{1, \mathrm{~s}, \mathrm{l}-1} \text {, } \\
& +\mathrm{k} 3_{\mathrm{i}, \mathrm{r}} * \mathrm{DUM} 86_{\mathrm{i}} \text {, for } \mathrm{i}=2, \mathrm{r}=11 \text {. }
\end{aligned}
$$

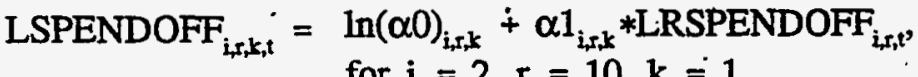

$$
\begin{aligned}
& \text { for } \mathrm{i}=2, \mathrm{r}=10, \mathrm{k}=1
\end{aligned}
$$

where,

$$
\begin{aligned}
& \text { LRSPENDOFF } \begin{array}{l}
\text { natural logarithm of regional lower } 48 \text { offshore development drilling } \\
\text { expenditures }
\end{array} \\
& \text { LNSPENDOFF }= \text { natural logarithm of national offshore development drilling expenditures } \\
& \text { LSPENDOFF }= \text { natural logarithm of lower } 48 \text { offshore exploration drilling expenditures by } \\
& \text { fuel type }
\end{aligned}
$$


$\ln (\mathrm{k} 0), \mathrm{k} 1, \mathrm{k} 2, \mathrm{k} 3 \quad=\quad$ estimated parameters

$\ln (\alpha 0), \alpha 1=$ estimated parameters

$\mathrm{i}=$ well type, 2 for development

$r=$ OGSM region 10 for lower 48 offshore

$\mathrm{k}=$ fuel type, 1 for oil

$\mathrm{t}=$ year.

Results

\begin{tabular}{||l|l|}
\hline Parameter & $\begin{array}{l}\text { Region 11 } \\
\text { DGOM }\end{array}$ \\
\hline $\ln (k 0)$ & $\begin{array}{l}-57.6517 \\
(-6.55986) . .\end{array}$ \\
\hline$k 1$ & $\begin{array}{l}2.72413 \\
(7.33808)\end{array}$ \\
\hline$k 2$ & $\begin{array}{l}0.774502 \\
(2.52189)\end{array}$ \\
\hline$k 3$ & $\begin{array}{l}0.899920 \\
(6.02508)\end{array}$ \\
\hline
\end{tabular}

\begin{tabular}{|l|l|}
\hline Parameter & Oil \\
\hline $\ln (\alpha 0)$ & $\begin{array}{l}1.33227 \\
(0.828947)\end{array}$ \\
\hline$\alpha 1$ & $\begin{array}{l}0.908824 \\
(10.3470)\end{array}$ \\
\hline
\end{tabular}

Standard Errors computed from quadratic form of analytic first derivatives (Gauss)

\section{NUMBER OF OBSERVATIONS $=11$}

Dependent variable: LRSPENDOFF ir, $(\mathrm{i}=2$ development, $\mathrm{r}=11$ )

Mean of dependent variable $=18.2887$

Std. dev. of dependent var. $=.606302$

Sum of squared residuals $=.405837$

Variance of residuals $\quad=\quad 036894$

Std. enror of regression . $\quad .=\quad .192079$

R-squared $\quad=\quad 889601$

Durbin-Watson statistic $\cdots=2.32591$

Dependent variable: LSPENDOFF $_{\mathrm{i}, \mathrm{r}, \mathrm{k}}$ ( $\mathrm{i}=2$ development, $\mathrm{r}=11, \mathrm{k}=1$ )

Mean of dependent variable $=17.9535$

Std. dev. of dependent var. $=.588164$

Sum of squared residuals $=.313955$

Variance of residuals $\quad=\quad .028541$

Std. error of regression $\quad=\quad .168942$

R-squared $\quad=.909529$

Durbin-Watson statistic . . . = 1.73902 


\section{Onshore Drilling Cost Equations}

Drilling costs were hypothesized to be a function of drilling, depth, and a time trend that proxies for the cumulative effect of technological advances on costs. The form of the equation was assumed to be loglinear. The equations were estimated in log-linear form using Zellner's Seemingly Unrelated Regression (SURE) technique available in TSP. Where necessary, equations were estimated in generalized difference form to correct for first order serial correlation. The forms of the equations are:

$$
\begin{aligned}
& \text { LDRILLCOST }_{r, k, t}=\ln (\delta 0)_{1, k}+\sum_{r=2}^{5} \ln (\delta 0)_{r, k} * \text { DUM }_{r}+\delta 1_{k} * \text { LWELLSON }_{t-1} \\
& +\delta 2_{k} * \operatorname{DEPTH}_{t, k, t}+\delta 3_{k} * \operatorname{TIME}_{\mathrm{t}}+\rho_{\mathrm{k}} * \operatorname{LDRILLCOST}_{t, k, t-1} \\
& -\rho_{\mathrm{k}} *\left[\ln (\delta 0)_{1, k}+\sum_{\mathrm{r}=2}^{5} \ln (\delta 0)_{\mathrm{r}, \mathrm{k}} * \mathrm{DUM}_{\mathrm{r}}+\delta 1_{\mathrm{k}} \text { LWELLSON }_{\mathrm{t}-2}\right. \\
& \left.+\delta 2_{\mathrm{k}} * \mathrm{DEPTH}_{\mathrm{r}, \mathrm{k}, \mathrm{t-1}}+\delta 3_{\mathrm{k}} * \mathrm{TIME}_{\mathrm{t}-1}\right] \\
& \text { for } r=1 \text { thru } 6, k=1,2 \\
& \text { for } r=2 \text { thru } 5, k=3 \\
& \operatorname{LDRYCOST}_{\mathrm{r}, \mathrm{t}}=\ln (\delta 0)_{1, \mathrm{Dry}}+\sum_{\mathrm{r}=2}^{6} \ln (\delta 0)_{\mathrm{r}, \mathrm{Dry}} * \mathrm{DUM}_{\mathrm{r}}+\delta 1_{\mathrm{Dry}} * \operatorname{LWELLSON}_{\mathrm{t}-1} \\
& +\delta 2_{D_{\text {ryy }}} * \mathrm{DEPTH}_{\mathrm{x}, \mathrm{Dry}, \mathrm{t}}+\delta 3_{\mathrm{Dry}} * \mathrm{TIME}_{\mathrm{t}}+\rho_{\mathrm{Dry}_{\mathrm{y}}} * \mathrm{LDRYCOST}_{\mathrm{t}, \mathrm{t}-1} \\
& -\rho_{D x y} *\left[\ln (\delta 0)_{s, d x y}+\sum_{r=2}^{6} \ln (\delta 0)_{s, D x y} * D_{1} M_{r}+\delta 1_{d y y} * L_{W W L L S O N}\right. \\
& \left.+\delta 2_{\text {dry }} * \mathrm{DEPTH}_{\mathrm{r}, \mathrm{Dry}, \mathrm{t}-1}+\delta 3_{\mathrm{Dry}} * \mathrm{TIME}_{\mathrm{t}-1}\right] \\
& \text { for } I=1 \text { thru } 6
\end{aligned}
$$

where,

$$
\begin{aligned}
\text { LDRILLCOST } & =\text { natural logarithm of oil and gas well drilling costs } \\
\text { LDRYCOST } & =\text { natural logarithm of dry well drilling costs } \\
\text { LWELLSON } & =\text { natural logarithm of total lower } 48 \text { onshore wells drilled } \\
\text { DEPTH } & =\text { average well depth } \\
\text { DUM } & =\text { regional dummy variable } \\
\text { TIME } & =\text { time trend - proxy for technology } \\
\ln (\delta 0), \delta 1, \delta 2, \delta 3 & =\text { estimated parameters } \\
\rho & =\text { autocorrelation parameter } \\
\mathbf{T} & =\text { OGSM region } \\
\mathbf{k} & =\text { fuel type, 1=0il, 2=gas, } 3=\text { deep gas } \\
\mathrm{t} & =\text { year. }
\end{aligned}
$$




\section{Regions 2 through 5}

\section{Results}

\begin{tabular}{|c|c|c|c|c|}
\hline Parameter & Oil & Gas & $\begin{array}{l}\text { Deep } \\
\text { Gas }\end{array}$ & Dry \\
\hline $\ln (80)_{2}$ & $\begin{array}{l}8.68679 \\
(10.9521)\end{array}$ & $\begin{array}{l}8.66416 \\
(9.78440)\end{array}$ & $\begin{array}{l}9.83554 \\
(10.4316)\end{array}$ & $\begin{array}{l}5.83519 \\
(5.40268)\end{array}$ \\
\hline $\ln (80)_{3}$ & $\begin{array}{l}8.41953 \\
(10.6543)\end{array}$ & $\begin{array}{l}8.17122 \\
(9.27303)\end{array}$ & $\begin{array}{l}9.65428 \\
(10.2901)\end{array}$ & $\begin{array}{l}5.51985 \\
(5.37236)\end{array}$ \\
\hline $\ln (\delta 0)_{4}$ & $\begin{array}{l}8.39672 \\
(10.5851)\end{array}$ & $\begin{array}{l}7.99693 \\
(9.08909)\end{array}$ & $\begin{array}{l}9.58517 \\
(10.2248)\end{array}$ & $\begin{array}{l}5.48152 \\
(5.37333)\end{array}$ \\
\hline $\ln (\delta 0)_{s}$ & $\begin{array}{l}8.68178 \\
(10.8492)\end{array}$ & $\begin{array}{l}8.16807 \\
(9.23808)\end{array}$ & $\begin{array}{l}9.92199 \\
(10.6966)\end{array}$ & $\begin{array}{l}5.68240 \\
(5.38710)\end{array}$ \\
\hline$\delta 1$ & $\begin{array}{l}0.307521 \\
(4.76784)\end{array}$ & $\begin{array}{l}0.467873 \\
(6.16185)\end{array}$ & 0 & $\begin{array}{l}0.548316 \\
(6.40852)\end{array}$ \\
\hline$\delta 2$ & $\begin{array}{l}0.257331 \mathrm{E}-03 \\
(11.9177)\end{array}$ & $\begin{array}{l}0.386004 \mathrm{E}-04 \\
(2.36007)\end{array}$ & $\begin{array}{l}0.611056 \mathrm{E}-04 \\
(3.06293)\end{array}$ & $\begin{array}{l}0.285033 \mathrm{E}-03 \\
(4.93455)\end{array}$ \\
\hline 83 & $\begin{array}{l}-0.030660 \\
(-3.84332)\end{array}$ & $\begin{array}{l}-0.030660 \\
(-3.84332)\end{array}$ & $\begin{array}{l}-.032378 \\
(-2.31056)\end{array}$ & $\begin{array}{l}-0.036720 \\
(-3.94497)\end{array}$ \\
\hline$\rho$ & $\begin{array}{l}0.680679 \\
(10.5608)\end{array}$ & $\begin{array}{l}.712572 \\
(11.0474)\end{array}$ & $\begin{array}{l}0.587481 \\
5.16675\end{array}$ & $\begin{array}{l}0.640095 \\
(9.32456)\end{array}$ \\
\hline
\end{tabular}

\section{NUMBER OF OBSERVATIONS $=72$.}

Standard Errors computed from quadratic form of analytic first derivatives (Gauss)

Dependent variable: LDRHLCOST $_{x, k, t}$ ( $r=2$ through $5, k=1$ - oil)

$\begin{array}{lll}\text { Mean of dependent variable } & = & 12.6901 \\ \text { Std. dev. of dependent var. } & = & .451964 \\ \text { Sum of squared residuals } & = & .583890 \\ \text { Variance of residuals } & = & .810959 \mathrm{E}-02 \\ \text { Std. error of regression } & = & .090053 \\ \text { R-squared } & = & .959743 \\ \text { Durbin-Watson statistic } & = & 1.23623\end{array}$.

Dependent variable: LDRILLCOST $_{r, k, t}(r=2$, through $5, k=2-. g a s)$

Mean of dependent variable $=13.0000$

Std. dev. of dependent var. $=.403131$

Sum of squared residuals $=1.21201$

Variance of residuals $=.016833$

Std. error of regression $=.129744$

R-squared $\quad=\quad .898564$

Durbin-Watson statistic $\quad=1.49166^{\circ}$ 
Dependent variable: LDRILLCOST $_{r, k, t}(r=2$ through $5, k=3$ - deep gas)

$\begin{array}{lll}\text { Mean of dependent variable } & = & 15.4090 \\ \text { Std. dev. of dependent var. } & = & .428683 \\ \text { Sum of squared residuals } & = & 3.97551 \\ \text { Variance of residuals } & = & .055215 \\ \text { Std. error of regression } & = & .234980 \\ \text { R-squared } & = & .699751 \\ \text { Durbin-Watson statistic } & = & 1.87112\end{array}$

Dependent variable: LDRYCOST $_{\mathrm{r}, \mathrm{t}}(\mathrm{r}=2$ through 5)

$\begin{array}{lll}\text { Mean of dependent variable } & =12.5533 \\ \text { Std. dev. of dependent var. } & = & .575427 \\ \text { Sum of squared residuals } & = & 1.37289 \\ \text { Variance of residuals ... } & = & .019068 \\ \text { Std. error of regression } & .138087 \\ \text { R-squared } & =.941804 \\ \text { Durbin-Watson statistic } & =1.34434\end{array}$

\section{Regions 1 and 6}

\section{Results}

\begin{tabular}{||l|l|l|l|}
\hline \hline Parameter & Oil & Gas & Dry \\
\hline $\ln (\delta 0)_{1}$ & $\begin{array}{l}8.55780 \\
(6.89273)\end{array}$ & $\begin{array}{l}8.65729 . \\
(8.56781)\end{array}$ & $9.10485(8.26450)$ \\
\hline $\ln (\delta 0)_{6}$ & $\begin{array}{l}9.36099 \\
(7.62783)\end{array}$ & $\begin{array}{l}9.30829 \\
(9.37214)\end{array}$ & $9.65563(8.61662)$ \\
\hline$\delta 1$ & $\begin{array}{l}0.204054 \\
(1.87674)\end{array}$ & $\begin{array}{l}0.269163 \\
(2.85968)\end{array}$ & $\begin{array}{l}0.170904 \\
(1.72650)\end{array}$ \\
\hline$\delta 2$ & $\begin{array}{l}0.416463 \mathrm{E}-03 \\
(6.30041)\end{array}$ & $\begin{array}{l}0.180328 \mathrm{E}-03 \\
(3.76057)\end{array}$ & $\begin{array}{l}0.302324 \mathrm{E}-03 \\
(7.07144)\end{array}$ \\
\hline$\delta 3$ & $\begin{array}{l}-0.014124 \\
(-1.8577)\end{array}$ & $\begin{array}{l}-0.014124 \\
(-1.85776)\end{array}$ & $\begin{array}{l}-0.014124 \\
(-1.85776\end{array}$ \\
\hline$\rho$ & $\begin{array}{l}0.750900 \\
(6.39681)\end{array}$ & $\begin{array}{l}0.648082 \\
(5.36698)\end{array}$ & $\begin{array}{l}0.546016 \\
(4.99897)\end{array}$ \\
\hline
\end{tabular}

NUMBER OF OBSERVATIONS $=72$

Standard Errors computed from quadratic form of analytic first derivatives (Gauss)

Dependent variable: LDRILLCOST $_{x, k, t}(r=1$ and $6, \dot{k}=1$ - oil)

Mean of dependent variable $=11.8600$

Std. dev. of dependent var. $=.436132$

Sum of squared residuals $=.390888$

Variance of residuals $=.010858$

Std. error of regression $=.104202$

R-squared $\quad=.941466$ 
Durbin-Watson statistic $=.911170$

\begin{tabular}{|c|c|c|c|}
\hline \multicolumn{4}{|c|}{ Dependent variable: $\operatorname{LDRILLCOST}_{r, \mathrm{k}_{\mathrm{t}}}(\mathrm{r}=1$ and $6, \mathrm{k}=2$ - gas $)$} \\
\hline & Mean of dependent variable & $=$ & 12.5682 \\
\hline & Std. dev. of dependent var. & & 639909 \\
\hline & Sum of squared residuals & & .396732 \\
\hline & Variance of residuals & $=$ & .011020 \\
\hline & Std. error of regression & $=$ & 104978 \\
\hline & R-squared & $=$ & .972335 \\
\hline & Durbin-Watson statistic & & 1.54885 \\
\hline
\end{tabular}

Dependent variable: $\operatorname{LDRYCOST}_{\mathrm{r}, \mathrm{t}}(\mathrm{r}=1$ and 6$)$

Mean of dependent variable $=12.2902$

Std. dev. of dependent.var. $=.822264$

Sum of squared residuals $=.570764$

Variance of residuals $=\quad .015855$

Std. error of regression $=.125915$

R-squared $=.975894$

Durbin-Watson statistic = $\quad 1.35244$

\section{Onshore Lease Equipment Cost Equations}

Lease equipment costs were hypothesized to be a function of total successful wells and a time trend that proxies for the cumulative effect of technological advances on costs. The form of the equation was assumed to be log-linear. The equations were estimated in log-linear form using Zellner's Seemingly Unrelated Regression (SURE) technique available in TSP. Where necessary, equations were estimated in generalized difference form to correct for first order serial correlation. The forms of the equations are:

$$
\begin{aligned}
& \text { LLEQC }_{x, k, t}=\ln (\varepsilon 0)_{2, \mathrm{k}}+\sum_{\mathrm{s}=3}^{5} \ln (\varepsilon 0)_{s, k} * \mathrm{DUM}_{\mathrm{r}}+\varepsilon 1_{\mathrm{x}} * \mathrm{LSUCWELL}_{\mathrm{t}} \\
& +\varepsilon 2_{k} * \operatorname{TIME}_{t}+\rho_{k} * \operatorname{LLEQC}_{\mathrm{s}, \mathrm{k}, \mathrm{t}-1 .}-\rho_{\mathrm{k}} * \ln (\varepsilon 0)_{2, \mathrm{k}} \\
& \left.+\sum_{r=3}^{5} \ln (\varepsilon 0)_{\mathrm{r}, \mathrm{k}} * \mathrm{DUM} \mathrm{M}_{\mathrm{r}}+\varepsilon 1_{\mathrm{l}} \mathrm{LSUCWELL}_{\mathrm{t}-1}+\varepsilon 2_{\mathrm{k}} * \mathrm{TIME}_{\mathrm{t}-1}\right]
\end{aligned}
$$

$$
\begin{aligned}
& \text { 'LLEQC }_{t, k, t}=\ln (\varepsilon 0)_{1, k}+\ln (\varepsilon 0)_{6, k} * D U M_{6}+\varepsilon 1_{k} * \text { LSUCWELL }_{t} \\
& +\varepsilon 2_{k} * T I M E_{t}+\rho_{k} * \operatorname{LLEQC}_{r, k, t-1}-\rho_{k} *\left[\ln (\varepsilon 0)_{1, k}\right. \\
& \left.+\ln (\varepsilon 0)_{6, \mathrm{k}} * \mathrm{DUM}_{6}+\varepsilon 1_{\mathrm{k}} \text { LSUCWELL }_{\mathrm{t}-1}+\varepsilon 2_{\mathrm{k}} * \mathrm{TIME}_{\mathrm{t}-1}\right] \\
& \text { for } \mathrm{r}=1,6, \mathrm{k}=1,2
\end{aligned}
$$

where,

$$
\begin{aligned}
\text { LLEQC } & =\text { natural logarithm of oil and gas well lease equipment costs } \\
\text { LSUCWELL } & =\text { natural logarithm of total lower } 48 \text { successful onshore wells } \\
\text { DUM } & =\text { regional dummy variable } \\
\text { TIME } & =\text { time trend }- \text { proxy for technology }
\end{aligned}
$$




$$
\begin{aligned}
\ln (\varepsilon 0), \varepsilon 1, \varepsilon 2 & =\text { estimated parameters } \\
\rho & =\text { autocorrelation parameter } \\
\cdot \mathrm{r} & =\text { OGSM region } \\
\mathrm{k} & =\text { fuel type, } 1=\text { oil, } 2=\text { gas } \\
\mathrm{t} & =\text { year. }
\end{aligned}
$$

\section{Regions 2 through 5}

\section{Results}

\begin{tabular}{|c|c|c|c|}
\hline Parameter & Oil & Gas & $\begin{array}{l}- \\
\text { Deep } \\
\text { Gas }\end{array}$ \\
\hline $\ln (\varepsilon 0)_{2}$ & $\begin{array}{l}10.6817 \\
(39.3042)\end{array}$ & $\begin{array}{l}10.1310 \\
(39.3623)\end{array}$ & $\begin{array}{l}10.8906 \\
(41.5025)\end{array}$ \\
\hline $\ln (\varepsilon 0)_{3}$ & 0 & $\begin{array}{l}-0.230158 \\
(-3.95464)\end{array}$ & 0 \\
\hline $\ln (\varepsilon 0)_{4}$ & $\begin{array}{l}0.295385 \\
(7.84719)\end{array}$ & $\begin{array}{l}-0.159171 \\
(-2.65776)\end{array}$ & 0 \\
\hline $\ln (\varepsilon 0)_{5}$ & $\begin{array}{l}0.454107 \\
(12.01420\end{array}$ & $\begin{array}{l}0.171094 \\
(2.83822)\end{array}$ & 0 \\
\hline$\varepsilon 1$ & $\begin{array}{l}0.089401 \\
(3.80082)\end{array}$ & $\begin{array}{l}0.089401 \\
(3.80082)\end{array}$ & $\begin{array}{l}0.089401 \\
(3.80082)\end{array}$ \\
\hline$\varepsilon 2$ & $\begin{array}{l}-0.023245 \\
(-5.90695)\end{array}$ & $\begin{array}{l}-0.023245 \\
(-5.90695)\end{array}$ & $\begin{array}{c}-0.023245 \\
(-5.90695)\end{array}$ \\
\hline$\rho$ & $\begin{array}{l}0.618953 \\
(7.70048)\end{array}$ & $\begin{array}{l}0.604100 \\
(7.61161)\end{array}$ & $\begin{array}{l}0.738635 \\
(11.2750)\end{array}$ \\
\hline
\end{tabular}

\section{NUMBER OF OBSERVATIONS $=64$}

Standard Errors computed from quadratic form of analytic first derivatives (Gauss)

Dependent variable: LLEQC $_{\mathrm{r}, \mathrm{k}, \mathrm{t}}(\mathrm{r}=2$ through $5, \mathrm{k}=1$ - oil)

Mean of dependent variable $=11.4256$

Std. dev. of dependent var. $=.234217$

Sum of squared residuals $=.154139$

Variance of residuals $\quad=\quad .240842 \mathrm{E}-02$

Std. error of regression $\quad=.049076$

R-squared $\quad=.955433$

Durbin-Watson statistic . = 1.73836

Dependent variable: $\mathrm{LLEQC}_{\mathrm{r}, \mathrm{k}, \mathrm{t}}(\mathrm{r}=2$ through $5, \mathrm{k}=2$ - gas)

Mean of dependent variable $=10.5904$

Std. dev. of dependent var. $=.243927$

Sum of squared residuals $=.377238$

Variance of residuals $=.589435 \mathrm{E}-02$

Std. error of regresșion $\quad=\quad .076775$

R-squared $\quad=.901703$ 
Durbin-Watson statistic $\quad=\quad 1.57186$

Dependent variable: LLEQC $_{r, k, t}(r=2$ through $5, k=3$ - deep gas)

Mean of dependent variable $=11.3619$

Std. dev. of dependent var. $=.090395$

Sum of squared residuals $\quad=\quad .188368$

Variance of residuals $\quad=.294325 \mathrm{E}-02$

Std. error of regression $=.054252$

R-squared

$=.682226$

Durbin-Watson statistic $\quad=\quad 1.64263$

\section{Regions 1 and 6}

Results

\begin{tabular}{||l|l|l||}
\hline Parameter & Oil & Gas \\
\hline $\ln (\varepsilon 0)_{1}$, & $\begin{array}{l}10.4789 \\
(32.2341)\end{array}$ & $\begin{array}{l}9.30470 \\
(30.8499)\end{array}$ \\
\hline $\ln (\varepsilon 0)_{6}$ & $\begin{array}{l}0.499867 \\
(8.27755)\end{array}$ & $\begin{array}{l}0.540403 \\
(18.6321)\end{array}$ \\
\hline$\varepsilon 1$ & $\begin{array}{l}0.089630 \\
(2.85431)\end{array}$ & $\begin{array}{l}0.089630 \\
(2.85431)\end{array}$ \\
\hline$E 2$, & $\begin{array}{l}-0.018611 \\
(-5.98760)\end{array}$ & $\begin{array}{l}-0.018611 \\
(-5.98760)\end{array}$ \\
\hline$P$ & $\begin{array}{l}0.655095 \\
(5.68798)\end{array}$ & 0 \\
\hline
\end{tabular}

NUMBER OF OBSERVATIONS $=32$

Standard Errors computed from quadratic form of analytic first derivatives (Gauss)

Dependent variable: $\operatorname{LLEQC}_{s, k, t}(r=1$ and $6, \mathrm{k}=1$ - oil)

Mean of dependent variable $=\cdot 11.3468$

Std. dev. of dependent var. ${ }^{\circ}=.263270$

Sum of squared residuals $=.100944$.

Variance of residuals $\quad=.315449 \mathrm{E}-02$

Std. error of regression $=.056165$

R-squared $\quad=.953475$

Durbin-Watson statistic $\quad=\quad 1.06397$

Dependent variable: $\operatorname{LLEQC}_{\mathrm{r}, \mathrm{k}, \mathrm{t}}(\mathrm{r}=1$ and $6, \mathrm{k}=2-\mathrm{gas})$.

Mean of dependent variable $=10.1626$

Std. dev. of dependent var. $=.306308$

Sum of squared residuals $=.229390$

Variance of residuals $\quad=\quad .716845 \mathrm{E}-02$

Std. error of regression $\quad=\quad .084667$

R-squared $\quad=.921289$ 
Durbin-Watson statistic $\quad=\quad .506073$

\section{Onshore Operating Cost Equations}

Lease equipment costs were hypothesized to be a function of total successful wells and a time trend that proxies for the cumulative effect of technological advances on costs. The form of the equation was assumed to be log-linear. Parameters were estimated with TSP using a maximum likelihood iterative technique developed by Beach and MacKinnon (1978) to correct for first order serial correlation. The technique retains the initial observation, appropriately transformed, and searches for the value of the autocorrelation parameter that maximizes the $\log$ of the likelihood function. The form of the equation is:

$$
\begin{aligned}
& \mathrm{LOPC}_{\mathrm{r}, \mathrm{k}, \mathrm{t}}=\ln (\phi 0)_{\mathrm{r}, \mathrm{k}}+\phi \mathrm{T}_{\mathrm{r}, \mathrm{k}} * \mathrm{LSUCWELL}_{\mathrm{t}}+\phi 2_{\mathrm{r}, \mathrm{k}} * \mathrm{TIME}_{\mathrm{t}}+\phi 3_{\mathrm{r}, \mathrm{k}} * \mathrm{DUM} 86_{\mathrm{t}} \\
& +\phi 4_{r, k} * \operatorname{DEPTH}_{\mathrm{r}, \mathrm{k}, \mathrm{t}}+\rho_{\mathrm{r}, \mathrm{k}} * \mathrm{LOPC}_{\mathrm{r}, \mathrm{k}, \mathrm{t}-1}-\rho_{\mathrm{r}, \mathrm{k}} *\left[\ln (\phi 0)_{\mathrm{r}, \mathrm{k}}+\phi 1_{\mathrm{r}, \mathrm{k}} * \mathrm{LSUCWELL}_{\mathrm{t}-1}\right. \\
& \left.+\phi 2_{\mathrm{r}, \mathrm{k}} * \mathrm{TIME}_{\mathrm{t}-1}+\phi 3_{\mathrm{r}, \mathrm{k}} * \mathrm{DUM} 86_{\mathrm{t}-1}+\phi 4_{\mathrm{r}, \mathrm{k}} * \mathrm{DEPTH}_{\mathrm{r}, \mathrm{k}, \mathrm{t}}\right] \text {. } \\
& \text { for } \mathrm{I}=1, \mathrm{k}=1,2 \text {, for } \mathrm{r}=2, \mathrm{k}=1,2,3
\end{aligned}
$$

where,

$$
\begin{aligned}
\text { LOPC } & =\text { natural logarithm of oil and gas well operating costs } \\
\text { LSUCWELL } & =\text { natural logarithm of total lower } 48 \text { successful onshore wells } \\
\text { DUM86 } & =\text { regional dummy variable } \\
\text { DEPTH } & =\text { average well depth } \\
\text { TIME } & =\text { time trend - proxy for technology } \\
\ln (\phi 0), \phi 1, \phi 2, \phi 3, \phi 4 & =\text { estimated parameters } \\
P & =\text { autocorrelation parameter } \\
\mathrm{r} & =\text { OGSM region } \\
\mathbf{k} & =\text { fuel type, } 1=\text { oil, } 2=\text { gas, } 3=\text { deep gas } \\
\mathrm{t} & =\text { year. }
\end{aligned}
$$

\section{Region 1}

\section{Results}

\begin{tabular}{||l|l|l|}
\hline Parameter & Oil & Gas \\
\hline $\ln (\phi 0)$ & $\begin{array}{l}8.58309 \\
(49.3163)\end{array}$ & $\begin{array}{l}8.39116 \\
(50.1298)\end{array}$ \\
\hline$\phi 1$ & $\begin{array}{l}0.097168 \\
(6.09800)\end{array}$ & $\begin{array}{l}0.097168 \\
(6.09800)\end{array}$ \\
\hline$\phi 2$ & $\begin{array}{l}-0.010697 \\
(-5.17972)\end{array}$ & $\begin{array}{l}-0.010597 \\
(-5.17972)\end{array}$ \\
\hline$\phi 3$ & 0 & 0 \\
\hline$\rho$ & 0 & 0.564432 \\
& 0 & $(3.10898)$ \\
\hline
\end{tabular}


Standard Errors computed from quadratic form of analytic first derivatives (Gauss)

Dependent variable: $\operatorname{LOPC}_{r, k, t}(r=1, k=1$ - oil $)$

Mean of dependent variable $=9.40143$

Std. dev. of dependent var. $=.079777$

Sum of squared residuals $\quad=\quad .818417 \mathrm{E}-02$

Variance of residuals $\quad=.629552 \mathrm{E}-03$

Std. error of regression $=.025091$

$\mathrm{R}$-squared

$=.893522$

Durbin-Watson statistic . $\quad=\quad 1.57560$

Dependent variable: $\operatorname{LOPC}_{\mathrm{r}, \mathrm{k}, \mathrm{i}}(\mathrm{r}=1, \mathrm{k}=2$ - gas $)$

Mean of dependent variable $=9.13786$

Std. dev. of dependent var. $=.057723$

Sum of squared residuals $=.022071$

Variance of residuals $\quad=.169778 \mathrm{E}-02$

Std. error of regression $\quad=\quad 041204$

R-squared $=.520118$

Durbin-Watson statistic $\quad=\quad 1.53151$

\section{Region 2}

\section{Results}

\begin{tabular}{||l|l|l|l||}
\hline Parameter & Oil & Gas & Deep Gas \\
\hline $\ln (\phi 0)$ & $\begin{array}{l}8.49952 \\
(23.5287)\end{array}$ & $\begin{array}{l}8.51676 \\
(25.3121)\end{array}$ & $\begin{array}{l}9.31324 \\
(27.7322)\end{array}$ \\
\hline$\phi 1$ & $\begin{array}{l}0.165451 \\
(5.16444)\end{array}$ & $\begin{array}{l}0.165451 \\
(5.16444)\end{array}$ & $\begin{array}{l}0.165451 \\
(5.1644)\end{array}$ \\
\hline$\phi 2$ & $\begin{array}{l}-0.015224 \\
(-4.47485)\end{array}$ & $\begin{array}{l}-0.015224 \\
(-4.47485)\end{array}$ & $\begin{array}{c}-0.015224 \\
(-4.47485)\end{array}$ \\
\hline$\phi 3$ & 0 & 0 & $\begin{array}{c}-0.115493 \\
(-6.64446)\end{array}$ \\
\hline$\rho$ & 0 & 0 & 0 \\
\hline
\end{tabular}

\section{NUMBER OF OBSERVATIONS $=13$}

Standard Errors computed from quadratic form of analytic first derivatives (Gauss)

Dependent variable: $\operatorname{LOPC}_{s, \mathrm{k}, \mathrm{l}}(\mathrm{r}=2, \mathrm{k}=1$ - oil)

Mean of dependent variable $=9.92573$

Std. dev. of dependent var. $=.115864$

Sum of squared residuals $\quad=\quad 019161$

Variance of residuals $\quad=\quad: 147392 \mathrm{E}-02$. 
Std. error of regression , $=\quad .038392$

R-squared $\quad=\quad .890134$

Durbin-Watson statistic $\quad=\quad .1 .22968$

Dependent variable: $\operatorname{LOPC}_{r, k, t}(r=2, k=2$ - gas)

Mean of dependent variable $=9.85114$

Std. dev. of dependent var. $=.118588$

Sum of squared residuals $=\quad .020018$

Variance of residuals $\quad=\quad .153982 \mathrm{E}-02$

Std. error of regression $=.039240$

R-squared $=.884614$

Durbin-Watson statistic $\quad=\quad 1.13415$

Dependent variable: $\operatorname{LOPC}_{r, k, t}(r=2, k=3$ - deep gas)

Mean of dependent variable $=10.6032$

Std. dev. of dependent var. = $\quad .174167$

Sum of squared residuals $=.031895$

Variance of residuals $=.245344 \mathrm{E}-02$

Std. error of regression. , = $\quad .049532$

R-squared $\quad .913666$

Durbin-Watson statistic $=\quad .915284$

\section{Region 3}

Results

\begin{tabular}{||l|l|l|l||}
\hline Parameter & Oil & Gas & Deep Gas \\
\hline $\ln (\phi 0)$ & $\begin{array}{l}9.30408 \\
(24.1452)\end{array}$ & $\begin{array}{l}9.53423 \\
(26.0402)\end{array}$ & $\begin{array}{l}10.2963 \\
(27.2202)\end{array}$ \\
\hline$\phi 1$ & $\begin{array}{l}0.056469 \\
(1.87390)\end{array}$ & $\begin{array}{l}0.056469 \\
(1.87390)\end{array}$ & $\begin{array}{l}0.056469 \\
(1.87390)\end{array}$ \\
\hline$\phi 2$ & $\begin{array}{l}-0.028802 \\
(-3.26672)\end{array}$ & $\begin{array}{l}-0.028802 \\
(-3.26672)\end{array}$ & $\begin{array}{l}-0.028802 \\
(-3.26672)\end{array}$ \\
\hline$\phi 3$ & 0 & 0 & 0 \\
\hline$\rho$ & 0.529570 & 0.481165 & $\begin{array}{l}0.754275 \\
(10.1876\end{array}$ \\
\hline
\end{tabular}

NUMBER OF OBSERVATIONS $=13$

Standard Errors computed from quadratic form of analytic first derivatives (Gauss)

Dependent variable: $\operatorname{LOPC}_{\mathrm{r}, \mathrm{k}, \mathrm{t}}(\mathrm{r}=3, \mathrm{k}=1$ - oil $)$

Mean of dependent variable $=9.42149$

Std. dev. of dependent var. $=.147092$

Sum of squared residuals $=.036529$.

Variance of residuals $\quad=.280991 \mathrm{E}-02$

Std. error of regression $=.053009$ 
$\begin{array}{lll}\text { R-squared } & = & .865127 \\ \text { Durbin-Watson statistic } & = & 1.14066\end{array}$

Dependent variable: $\mathrm{LOPC}_{\mathrm{r}, \mathrm{k}, \mathrm{t}}(\mathrm{r}=3, \mathrm{k}=2$ - gas)

Mean of dependent variable $=9.61350$

Std. dev. of dependent var. $=.130225$

Sum of squared residuals $=.047332$

Variance of residuals $\quad=\quad .364089 \mathrm{E}-02$

Std. error of regression $=\quad .060340$

R-squared $\quad=.767711$

Durbin-Watson statistic $=1.53223$

Dependent variable: $\mathrm{LOPC}_{\mathrm{r}, \mathrm{k}, \mathrm{t}}(\mathrm{r}=3, \mathrm{k}=3$ - deep gas)

Mean of dependent variable $=10.3351$

Std. dev. of dependent var. $=.100778$

Sum of squared residuals $=.011861$

Variance of residuals $\quad=\quad .912385 \mathrm{E}-03$

Std. error of regression $\quad \dot{=} .030206$

R-squared $\quad=.903115$

Durbin-Watson statistic $=.895752$

\section{Region 4}

Results

\begin{tabular}{||l|l|l|l|}
\hline Parameter & Oil & Gas & Deep Gas \\
\hline $\ln (\phi 0)$ & $\begin{array}{l}7.75200 \\
(32.5345)\end{array}$ & $\begin{array}{l}8.02520 \\
(35.7077)\end{array}$ & $\begin{array}{l}8.95918 \\
(39.8343)\end{array}$ \\
\hline$\dot{\phi} 1$ & $\begin{array}{l}0.194707 \\
(9.00196)\end{array}$ & $\begin{array}{l}0.194707 \\
(9.00196)\end{array}$ & $\begin{array}{l}0.194707 \\
(9.00196\end{array}$ \\
\hline$\phi 2$ & -0.011942 & -0.011942 & -0.011942 \\
$(-4.58656)$ & $(-4.58656)$ & $0.58656)$ \\
\hline$\phi 3$ & 0 & 0 & $\begin{array}{l}-0.146338 \\
(-9.62407)\end{array}$ \\
\hline$\rho$ & 0 & 0 & 0 \\
\hline
\end{tabular}

\section{NUMBER OF OBSERVATIONS $=13$}

Standard Errors computed from quadratic form of analytic first derivatives (Gauss)

Dependent variable: $\mathrm{LOPC}_{\mathrm{r}, \mathrm{k}, \mathrm{t}}(\mathrm{r}=4, \mathrm{k}=1$ - oil)

Mean of dependent variable $=9.53421$

Std. dev. of dependent var. $=.124210$

Sum of squared residuals $=.022217$

Variance of residuals $\quad=.170903 \mathrm{E}-02^{\circ}$

Std. error of regression $=.041340$

R-squared $\cdot .=.880423$ 
Durbin-Watson statistic $=\quad=\quad 1.40243$

Deperident variable: $\mathrm{LOPC}_{\mathrm{r}, \mathrm{k}, \mathrm{t}}(\mathrm{r}=4, \mathrm{k}=2$-.gas)

Mean of dependent variable $=9.68514$

Std. dev. of dependent var. $=.112625$

Sum of squared residuals $=.014511$

Variance of residuals $\quad=.111623 \mathrm{E}-02$

Std. error of regression $=.033410$

. R-squared $\quad=.906425$

Durbin-Watson statistic . $=1.24042$

Dependent variable: $\operatorname{LOPC}_{\mathrm{r}, \mathrm{k}, \mathrm{t}}(\mathrm{r}=4, \mathrm{k}=3$ - deep gas)

Mean of dependent variable . $=10.5628^{\circ}$

Std. dev. of dependent $\cdot$ var. $=.186446$

Sum of squared residuals $=.025357$

Variance of residuals $=.195054 \mathrm{E}-02$

Std. error of regression $=.044165$

R-squared . = $.941044^{\circ}$

. Durbin-Watson statistic $=1.02366$

\section{Region 5}

\section{Results}

\begin{tabular}{||l|l|l|l||}
\hline Parameter & Oil & Gas & Deep Gas \\
\hline $\ln (\phi 0)$ & $\begin{array}{l}9.46712 \\
(24.4031)\end{array}$ & $\begin{array}{l}9.66188 \\
(25.9468)\end{array}$ & $\begin{array}{l}9.87359 \\
(13.4176)\end{array}$ \\
\hline$\phi 1$ & $\begin{array}{l}0.072598 \\
(2.29584)\end{array}$ & $\begin{array}{l}0.072598 \\
(2.29584)\end{array}$ & $\begin{array}{l}0.072598 \\
(2.29584)\end{array}$ \\
\hline$\phi 2$ & $\begin{array}{c}-0.025459 \\
(-4.24453)\end{array}$ & $\begin{array}{l}-0.025459 \\
(-4.24453)\end{array}$ & $\begin{array}{c}-0.025459 \\
(-4.24453)\end{array}$ \\
\hline$\phi 3$ & 0 & 0 & $\begin{array}{c}-0.101192 \\
(-3.49463)\end{array}$ \\
\hline$\phi 4$ & 0 & 0 & $\begin{array}{l}0.048138 \\
(0.746649)\end{array}$ \\
\hline$\rho$ & 0.440347 & $\begin{array}{l}0.686961 \\
(5.92037)\end{array}$ & $\begin{array}{l}0.577666 \\
(4.41624)\end{array}$ \\
\hline
\end{tabular}

\section{NUMBER OF OBSERVATIONS $=13$}

Standard Errors computed from quadratic form of analytic first derivatives (Gauss)

Dependent variable: $\operatorname{LOPC}_{\mathrm{r}, \mathrm{k}, \mathrm{t}}(\mathrm{r}=5, \mathrm{k}=1$ - oil $)$

Mean of dependent variable $=9.80403$

Std. dev. of dependent var. $=\quad .121646$

Sum of squared residuals, $=\cdot .015092$

Variance of residuals $=\quad .116094 \mathrm{E}-02$ 


\begin{tabular}{|c|c|}
\hline Std. error of regression & $=$ \\
\hline R-squared & - \\
\hline Durbin-Watson statistic & $=$ \\
\hline
\end{tabular}

Dependent variable: $\operatorname{LOPC}_{r, k, t}(r=5, k=2$ - gas)

Mean of dependent variable $=9.93907$

Std. dev: of dependent var. $=.136212$

Sum of squared residuals: $=.027439$

Variance of residuals $\quad=\quad .211072 \mathrm{E}-02$

Std. error of regression $\cdot=.045943$

R-squared $\quad=\quad .895978$

Durbin-Watson statistic $\quad=\quad 1.06265$

Dependent variable: $\operatorname{LOPC}_{\mathrm{r}, \mathrm{k}, \mathrm{i}}(\mathrm{r}=5, \mathrm{k}=3$ - deep gas)

Mean of dependent variable $=10.5872$

Std. dev. of dependent var. $=.177296$

Sum of squared residuals $=.020524$

Variance of residuals $\quad=\quad .157873 \mathrm{E}-02$

Std. error of regression $=.039733$

$\begin{array}{ll}\mathrm{R} \text {-squared } & =.949061\end{array}$

Durbin-Watson statistic $\quad=\quad 1.37975$

\section{Region 6}

For Region 6, estimated operating cost equations yielded counterintuitive results. Consequently, real operating costs for Region 6 were kept constant at their 1990 values.

\section{Canadian Successful Oil and Gas Wells Equations}

A successful oil wells equation and a successful gas wells equation were estimated in generalized difference form using SURE. Successful oil (gas) wells were estimated as a function of the expected DCF for an oil (gas) well and a dummy variable to control for Canadian oil and gas policy changes in the early to mid 1980's.

$$
\begin{aligned}
\text { WELLS }_{k, t}= & \beta 0_{k}+\beta 1_{k} * D C F_{k, t}+\beta 2_{k} * D U M 83_{t}+\rho_{t} * \text { WELLS } \\
& -\rho_{k} *\left(\beta 0_{k}+\beta 1_{k} * D C F_{k, t-1}+\beta 2_{k} * D U M 83_{t-1}\right)
\end{aligned}
$$

where,

$$
\begin{aligned}
\text { WELLS } & =\text { successful Canadian well completions } \\
\text { DCF } & =\text { discounted cash flow for a well } \\
\text { DUM83 } & =1 \text { if } t>1982,0 \text { otherwise } \\
\beta 0, \beta 1, \beta 2 & =\text { econometrically estimated parameters } \\
\rho & =\text { autocorrelation parameter } \\
\mathbf{k} & =\text { fuel type } \\
t & =\text { year. }
\end{aligned}
$$


Results

\begin{tabular}{||l|l|l||}
\hline Parameter $^{\circ}$ & OIL & GAS \\
\hline$\beta 0$ & $\begin{array}{l}499.230 \\
(1.33979)\end{array}$ & $\begin{array}{l}1829.02 \\
(2.94956)\end{array}$ \\
\hline$\beta 1$ & $\begin{array}{l}0.170973 \mathrm{E}-02 \\
(4.18866)\end{array}$ & $\begin{array}{l}0.132393 \mathrm{E}-02 \\
(3.23435)\end{array}$ \\
\hline$\beta 2$ & $\begin{array}{l}949.572 \\
(2.05196)\end{array}$ & $\begin{array}{l}-1276.28 \\
(-3.06764)\end{array}$ \\
\hline$\rho$ & $\begin{array}{l}0.298608 \\
(1.41467)\end{array}$ & $\begin{array}{l}0.726749 \\
(4.50509)\end{array}$ \\
\hline
\end{tabular}

NUMBER OF OBSERVATIONS $=20$

Standard Errors computed from quadratic form of analytic first derivatives (Gauss)

Dependent variable: WELLS (oil)

Mean of dependent variable

Std. dev. of dependent var.

Sum of squared residuals

Variance of residuals

$$
\begin{array}{ll}
= & 2235.30 \\
= & 1467.19 \\
= & .976854 \mathrm{E}+07 \\
= & 488427 . \\
= & 698.876 \\
= & .764132
\end{array}
$$

Std. error of regression

R-squared

Durbin-Watson statistic . . . $=2.10944$

Dependent variable: WELLS (gas)

Mean of dependent variable =

Std. dev. of dependent var.

Sum of squared residuals

$=2353.75$

$=958.064$

Variance of residuals

$=.391239 \mathrm{E}+07$

Std. error of regression

$=195619$.

R-squared

$=\quad 442.289$

Durbin-Watson statistic

$=\quad .789470$

$=1.95590$

\section{Price Elasticities of Short Run Supply}

As noted in chapter 4, the PMM and NGTDM calculate production levels through the use of short-run supply functions that require estimates of the price elasticities of supply. One option is to employ the price elasticity estimates that are passed from the OGSM to the PMM and NGTDM. The section below documents the estimation of these elasticities.

\section{Onshore Lower 48 States}

Oil

Price elasticities were estimated using the AR1 technique in TSP which corrects for serial correlation using the maximum likelihood iterative technique of Beach and MacKinnon (1978). Equations for onshore 
regions 1 and 6 were estimated separately due to the regions' unique characteristics. The functional form is given by:

$$
\begin{aligned}
\text { LCRUDE }_{t}= & a 0+a 1 * \text { LOILRES }_{t}+a 2 * \text { LPOIL }_{t}+\rho * \operatorname{LCRUDE}_{t-1} \\
& -p *\left(a 0+a 1 * \text { LOILRES }_{t-1}+a 2 * \text { LPOIL }_{t-1}\right)
\end{aligned}
$$

where,

$$
\begin{aligned}
\text { LCRUDE } & =\text { natural } \log \text { of crude oil production } \\
\text { LOILRES } & =\text { natural } \log \text { of beginning of year oil reserves } \\
\text { LPOIL } & =\text { natural log of the regional wellhead price of oil in } 1987 \text { dollars } \\
\rho & =\text { autocorrelation parameter } \\
t & =\text { year. }
\end{aligned}
$$

\section{Region 1}

Reśults

\begin{tabular}{|l|l|l|l||}
\hline Variable & Estimated Coefficient & Standard Error & t-statistic \\
\hline $\mathrm{a} 0$ & -.977125 & .680644 & -1.43559 \\
\hline LOILRES & .814563 & .114311 & 7.12584 \\
\hline LPOIL & .08385 & .040682 & 2.06115 \\
\hline$\rho$ & .334416 & .297765 & 1.12309 \\
\hline
\end{tabular}

SAMPLE: 1978 to 1990

NUMBER OF OBSERVATIONS $=13$

Dependent variable: LCRUDE

(Statistics based on transformed data)

Mean of dependent variable $=3.03941$

Std. dev. of dependent var. $=.365187$

Sum of squared residuals $=.015765$

Variance of residuals $\quad=\quad .157651 \mathrm{E}-02$

Std. error of regression $\cdot=.039705$

R-squared $\quad \cdot=.990477$

Adjusted R-squared $\quad=.988573$

Durbin-Watson statistic $\quad=\quad 1.58775$

F-statistic (zero slopes) $\quad=502.556$

Log of likelihood function $=25.1414$

(Statistics based on original data)

Mean of dependent variable $=4.43559$

Std. dev. of dependent var. $=.142410$

Sum of squared residuals $=.015832$

Variance of residuals $\quad=\quad .158323 \mathrm{E}-02$

Std. error of regression $=.039790$

R-squared $\quad=\quad .936035$

Adjusted R-squared $\quad=\quad .923242$ 
Durbin-Watson statistic . $\quad=\quad 1.57879$

\section{'Region 6}

Results

\begin{tabular}{|l|l|l|l|}
\hline Variable & Estimated Coefficient $\cdot$ & Standard Error & t-statistic \\
\hline $\mathrm{a} 0$ & 6.69155 & 2.14661 & 3.11727 \\
\hline LOILRES & -.123763 & .255535 & -.484329 \\
\hline LPOIL & .031845 & .038040 & .837163 \\
\hline$p$ & .833915 & .135664 & 6.14691 \\
\hline
\end{tabular}

SAMPLE: 1978 to 1990

- NUMBER OF OBSERVATIONS = 13

Dependent variable: LCRUDE

(Statistics based on transformed data)

Mean of dependent variable $=$

Std. dev. of dependent var. =

Sum of squared residuals

Variance of residuals

Std. error of regression =

R-squared $=$

Adjusted R-squared : $\quad=.996676$

Durbin-Watson statistic $\quad=.896816$

F-statistic (zero slopes) $\quad=\quad 1657.10$

Log of likelihood function $\cdot=$ ' 25.7519

(Statistics based on original data)

Mean of dependent variable

Std. dev. of dependent var.

Sum of squared residuals

Variance of residuals

Std. error of regression

R-squared .

1.13005

.605103

.013218

$.132176 \mathrm{E}-02$

$=.036356$

Adjusted R-squared

Durbin-Watson statistic .

$\begin{array}{ll}= & 5.78242 \\ = & .061666 \\ = & .014455 \\ = & .144552 \mathrm{E}-02 \\ = & .038020 \\ = & .707387 \\ = & .648864 \\ = & .892422\end{array}$

For onshore regions 2 through 5, the data were pooled and regional dummy variables were used to allow the estimated production elasticity to vary across the regions. Region 2 is taken as the base region. The form of the equation is given by:

$$
\begin{aligned}
\text { LCRUDE }_{t}= & a 0+a 1 * \text { LOILRES }_{t}+a 2 * \text { LPOIL }_{t}+a 3 * \text { LPDUM }_{t}+a 4 * \text { LPDUM }_{t}+\cdots \\
& \text { a5 } * \text { LPDUM5 }_{t}+\rho * \text { LCRUDE }_{t-1}-\rho *\left(a 0+a 1 * \text { LOILRES }_{t-1}+.\right. \\
& \text { a2 } \left.* \text { LPOIL }_{t-1}+a 3 * \text { LPDUM }_{t-1}+a * \text { LPDUM }_{t-1}+a 5 * \text { LPDUM }_{t-1}\right)
\end{aligned}
$$

where, 


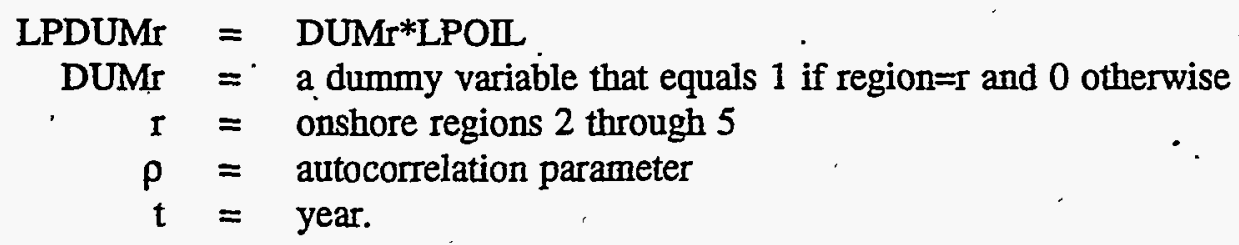

Regions 2 through 5

Results

\begin{tabular}{|l|l|l|l|}
\hline Variable & Estimated Coefficient & Standard Error & t-statistic \\
\hline a0 & 1.38487 & .646290 & 2.14279 \\
\hline LOILRES & .549313 & .077877 & 7.05360 \\
\hline LPOIL & .105051 & .032631 & 3.21932 \\
\hline LPDUM3 & -.077217 & .034067 & -2.26660 \\
\hline LPDUM4 & -.028657 & .034318 & -.835047 \\
\hline LPDUM5 & -.089397 & .032700 & -2.73387 \\
\hline$\rho$ & .867072 & .080470 & 10.7751 \\
\hline
\end{tabular}

SAMPLE: 1978 to 1990

NUMBER OF OBSERVATIONS $=52$

Dependent variable: LCRUDE

(Statistics based on transformed data)

Mean of dependent variable =

Std. dev. of dependent var. $=$

Sum of squared residuals $=.109259$

Variance of residuals $\quad=.237519 \mathrm{E}-02$

Std. error of regression $=.048736$

R-squared $\quad=.994731$

Adjusted R-squared $\quad$. $\quad=\quad .994159$

Durbin-Watson statistic $\quad=\quad 1.42150$

F-statistic (zero slopes) $\quad=1602.00$

Log of likelihood function $=83.7253$

(Statistics based on original data)

Mean of dependent variable $=5.93153$.

Std. dev. of dependent var. $=.428916$

Sum of squared residuals $=.110274$

Variance of residuals $\quad=.239725 \mathrm{E}-02$

Std. error of regression $\quad=\quad .048962$

R-squared $=.988524$

Adjusted R-squared $\quad=\quad .987277$

Durbin-Watson statistic $\quad=1.40740^{\circ}$ 
The estimated coefficient on LPOIL is the price elasticity of crude oil production for region 2 . The elasticity for region $r(r=3,4,5)$ is obtained by adding the coefficient on LPDUMr to the coefficient on * LPOIL.

\section{Dry Non-Associated Natural Gas}

The data for onshore regions 1 through 6 were pooled and a single regression equation estimated with dummy variables used to allow the slope coefficients to vary across regions. Region 1 was taken as the base region. The equation was estimated using the non-linear two stage least squares procedure in TSP.

The form of the equation is given by:

$$
\begin{aligned}
\mathrm{LPROD}= & \mathrm{AO}+\left(\mathrm{A} 1+\sum_{\mathrm{r}} \mathrm{Ar} * \mathrm{DUMr}\right) * \mathrm{LGATSES}+\left(\mathrm{B} 1+\sum_{\mathrm{r}} \mathrm{Br} * \mathrm{DUMr}\right) * \\
& \mathrm{LPGAS}+\mathrm{C} * \mathrm{DEDSHR}
\end{aligned}
$$

where,

$$
\begin{aligned}
\text { LPROD } & =\text { natural } \log \text { of natural gas production } \\
\text { LGASRES } & =\text { natural } \log \text { of beginning of year natural gas reserves } \\
\text { LPGAS } & =\text { natural } \log \text { of the regional wellhead price of natural gas in } 1987 \text { dollars } \\
\text { DEDSHR } & =\text { natural } \log \text { of the share of natural gas production that is accounted for by } \\
\text { DUMr } & =\text { pipeline sales(included to capture the effect of open access on production) } \\
r & =\text { onshym variable that equals } 1 \text { if region }=r \text { and } 0 \text { otherwise }
\end{aligned}
$$

Results

\begin{tabular}{|l|l|l|l||}
\hline Variable & Estimated Coefficient & Standard Error & t-statistic \\
\hline A0 & -3.02039 & 3.46358 & -.872044 \\
\hline A1 & .962078 & .206360 & 4.66213 \\
\hline A2 & .067699 & .016754 & 4.04076 \\
\hline A3 & .049399 & .017549 & 2.81494 \\
\hline A4 & .062093. & .018170 & 3.41733 \\
\hline A5 & $.450603 E-02$ & .016987 & .265262 \\
\hline A6 & .047330 & .054670 & .865738 \\
\hline B1 & .852276 & .326959 & 2.60668 \\
\hline B2 & -.589608 & .331977 & -1.77605 \\
\hline B3 & -.645398 & .306376 & -2.10623 \\
\hline B4 & -.730398 & .341712 & -2.13747 \\
\hline B5 &. .733917 & .265693 & -2.76228 \\
\hline B6 & -.388545 & .471104 & -.822833 \\
\hline C & -.305243 & .082627 & -3.69421 \\
\hline
\end{tabular}

SAMPLE: 1985 to 1990

E-56 Energy Information Administration/Oll and Gas Supply Module Documentation 
NUMBER OF OBSERVATIONS $=36$

Dependent variable: LPROD

$\begin{array}{lll}\text { Mean of dependent variable } & = & 13.7972 \\ \text { Std. dev. of dependent var. } & = & 1.08967 \\ \text { Sum of squared residuals } & = & .089311 \\ \text { Variance of residuals } & = & .405960 \mathrm{E}-02 \\ \text { Std. error of regression } & = & .063715 \\ \text { R-squared } & = & .997851 \\ \text { Adjusted R-squared } & = & .996581 \\ \text { Durbin-Watson statistic } & = & 2.42140\end{array}$

The price elasticity of natural gas production for onshore region 1 is given by the estimated parameter B1. The price elasticity for any other onshore region $r(r=2$ through 6$)$ is derived by adding the estimate for $\mathrm{Br}$ to the value of $\mathrm{B} 1$.

\section{Offshore Gulf of Mexico}

\section{Oil}

Price elasticities were estimated using OLS. The functional form is given by:

$$
\begin{aligned}
\text { LCRUDE } & =a 0+a 1 * \text { LOILRES }+a 2 * \text { LPOIL + } a 3 * \text { LCRUDE }(-1)+ \\
& a 4 * \text { DUM }
\end{aligned}
$$

where,

$$
\begin{aligned}
\text { LCRUDE } & =\text { natural } \log \text { of crude oil production } \\
\text { LOILRES } & =\text { natural } \log \text { of beginning of year oil reserves } \\
\text { LPOIL } & =\text { natural log of the regional wellhead price of oil in } 1987 \text { dollars } \\
\text { LCRUDE(-1) } & =\text { natural log of crude oil production in the previous year } \\
\text { DUM } & =\text { a dummy variable that equals } 1 \text { for years after } 1986 \text { and } 0 \text { otherwise. }
\end{aligned}
$$

Results

\begin{tabular}{|l|l|l|l|}
\hline Variable & Estimated Coefficient & Standard Error & t-statistic \\
\hline $\mathrm{a} 0$ & -6.48638 & 2.65947 & -2.43897 \\
\hline LOILRES & .821851 & .313405 & 2.62233 \\
\hline LPOIL & .115556 & .051365 & 2.24969 \\
\hline LCRUDE(-1) & .974244 & .137890 & 7.06538 \\
\hline DUM & .079112 & .045683 & 1.73175 \\
\hline
\end{tabular}

SAMPLE: 1978 to 1991

NUMBER OF OBSERVATIONS $=14$. 
Dependent variable: LCRUDE

Mean of dependent variable $=\dot{5} .65758$

Std. dev. of dependent var. $=.106897$

Sum of squared residuals $=.021640$

Variance of residuals $\quad=\cdot .240446 \mathrm{E}-02$

Std. error of regression $=.049035$

R-squared $\quad=.854325$

Adjusted R-squared $\quad=\quad .789581$

Durbin-Watson statistic $\quad=\quad 1.47269$

Durbin's h $\quad=1.04017$

Durbin's h alternative $\cdot \quad=\quad .725714$

F-statistic (zero slopes) . $\quad=\quad 13.1954$

Schwarz Bayes. Info. Crit. = -5.52974

Log of likelihood function $=25.4407$

\section{Pacific Offshore}

Oil

Price elasticities were estimated using the AR1 procedure in TSP which corrects for first order serial correlation using a maximum likelihood iterative technique. The regression equation is given by:

$$
\begin{aligned}
\text { LCRUDE }_{\mathrm{t}}= & \mathrm{a} 0+\mathrm{a} 1 * \mathrm{LOILRES}_{\mathrm{t}}+\mathrm{a} 2 * \mathrm{LPOIL}_{\mathrm{t}}+\rho * \mathrm{LCRUDE}_{\mathrm{t}-1}- \\
& \rho *\left(\mathrm{a} 0+\mathrm{a} 1 * \operatorname{LOIRES}_{\mathrm{t}-1}+\mathrm{a} 2 * \mathrm{LPOI}_{\mathrm{t}-1}\right)
\end{aligned}
$$

where,

$$
\begin{aligned}
\text { LCRUDE } & =\text { natural } \log \text { of crude oil production } \\
\text { LOILRES } & =\text { natural } \log \text { of beginning of year crude oil reserves } \\
\text { LPOIL } & =\text { natural } \log \text { of the regional wellhead price of crude oil in } 1987 \text { dollars } \\
p & =\text { autocorrelation parameter } \\
t & =\text { year. }
\end{aligned}
$$

Results

\begin{tabular}{|l|l|l|l|}
\hline Variable & Estimated Coefficient & Standard Eror & t-statistic \\
\hline $\mathrm{a} 0^{-}$ & 1.34325 & .443323 & 3.02995 \\
\hline LOILRES & .310216 & .067090 & 4.62390 \\
\hline LPOIL & .181190 & .067391 & 2.68865 \\
\hline$\rho$ & -.355962 & .320266 & -1.11146 \\
\hline
\end{tabular}

SAMPLE: 1977 to 1.991

NUMBER OF OBSERVATIONS $=15$

Dependent variable: LCRUDE

(Statistics based on transformed data)

Mean of dependent variable $=.5 .31728$ 
Std. dev. of dependent var. $=.646106^{\circ}$

Sum of squared residuals $=.209786$

Variance of residuals $=.017482$

Std. error of regression $=\quad .132220$

R-squared $\quad=.971382$

Ädjusted R-squared $\quad \doteq .966613$

Durbin-Watson statistic $\quad=\quad 1.61085$

F-statistic (zero slopes) $\quad=161.152$

Log of likelihood function . . $\quad 10.6711$

(Statistics based on original data)

Mean of dependent variable $=4.001171$

Std. dev. of dependent var. $=.231415$

Sum of squared residuals $=.220359$

Variance of residuals $\quad=\quad .018363$

Std. error of regression $\quad=\quad .135511$

R-squared $\quad=\quad .711359$

Adjusted R-squared $\quad=.663252$

Durbin-Watson statistic $\quad=\quad 1.61258$ 
